ESCOLA POLITÉCNICA DA UNIVERSIDADE DE SÃO PAULO

DANILO COSTA DE FRANÇA

PROVAS DE CARGA ESTÁTICAS INSTRUMENTADAS EM PROFUNDIDADE EM ESTACAS ESCAVADAS DE GRANDE DIÂMETRO (ESTACÕES) 
DANILO COSTA DE FRANÇA

\section{PROVAS DE CARGAS ESTÁTICAS INSTRUMENTADAS EM PROFUNDIDADE EM ESTACAS ESCAVADAS DE GRANDE DIÂMETRO (ESTACÕES)}

Dissertação apresentada à Escola Politécnica da Universidade de São Paulo para a obtenção do título de Mestre em Engenharia

Área de Concentração:

Engenharia Geotécnica

Orientador: Profo Livre Docente

Faiçal Massad 
DANILO COSTA DE FRANÇA

\section{PROVAS DE CARGAS ESTÁTICAS INSTRUMENTADAS EM PROFUNDIDADE EM ESTACAS ESCAVADAS DE GRANDE DIÂMETRO (ESTACÕES)}

Dissertação apresentada à Escola Politécnica da Universidade de São Paulo para a obtenção do título de Mestre em Engenharia 


\section{FICHA CATALOGRÁFICA}

França, Danilo Costa de

Provas de cargas instrumentadas em profundidade em estacas escavadas de grande diâmetro (Estações) / D.C. de França. - São Paulo, 2011.

$$
162 \mathrm{p} \text {. }
$$

Dissertação (Mestrado) - Escola Politécnica da Universidade de São Paulo. Departamento de Engenharia de Estruturas e Geotécnica.

1. Estacas (Instrumentação) 2. Fundações profundas 3. Prova de carga estática I. Universidade de São Paulo. Escola Politécnica. Departamento de Engenharia de Estruturas e Geotécnica II. t. 


\section{DEDICATÓRIA}

Ao meu Senhor e Salvador Jesus Cristo.

À Michele, minha esposa e amiga.

Aos meus queridos pais.

À Daniela, minha irmã. 


\section{AGRADECIMENTOS}

Primeiramente, o agradecimento deve ser dado ao meu Senhor e Salvador Jesus Cristo, que me resgatou da punição eterna e proporcionou-me o ingresso na INTERACT Assessoria Técnica em Engenharia e a possibilidade de tratar desse assunto interessante. Pelas Suas misericórdias, pude concluir essa dissertação.

À minha esposa Michele, a qual constantemente incentivou-me para a realização desse trabalho e pela cuidadosa revisão ortográfica elaborada para que essa dissertação pudesse estar bem redigida.

Aos meus pais, Célia e Murilo, que me deram uma educação excelente, pelo caráter que ajudaram a formar e pelo esforço que fizeram para que eu pudesse graduar-me na melhor escola de engenharia do país, a Escola Politécnica da USP.

Ao professor e orientador Faiçal Massad pelo estímulo constante durante a elaboração da dissertação e pelas palavras de fundamental importância quando eu estava passando por dificuldades em conciliar a vida profissional e estudantil.

Aos meus grandes amigos Adalberto e Wilson, os quais fizeram o curso comigo e passaram pelas mesmas dificuldades, pelas infinitas ajudas para que eu pudesse entender as disciplinas.

Aos amigos do mestrado, Nelson, Alexandre, Guilherme, Estela, que proporcionaram momentos divertidos e de aprendizado; e pelas horas extras que ficamos para conseguirmos a aprovação na disciplina de Resistência e Deformabilidade dos Solos.

À INTERACT Assessoria Técnica em Engenharia, que me possibilitou trabalhar nesse projeto de fundações e ao Eugenio, pela solicitação das provas de cargas e pelo trabalho conjunto na interpretação dos dados para o projeto. Agradeço-o, também, pela luta para que eu pudesse tratar das provas de carga na minha dissertação do mestrado, junto ao cliente. 
Ao ex-companheiro de INTERACT, Alexandre, pelos constantes esclarecimentos referentes à execução das provas de cargas e pelas fotos fornecidas durante 0 andamento dos ensaios nas estacas.

À amiga de INTERACT, Marina Lemos, pela ajuda prestimosa no ensino sobre a formatação do trabalho.

Ao professor Paulo Albuquerque, que realizou a instrumentação em profundidade das estacas, pela ajuda no fornecimento das deformações específicas e pela conversa proveitosa que tivemos ao telefone.

Ao ex-companheiro de INTERACT, Tiago, pela ajuda memorável para conseguir os dados, junto ao professor Paulo Albuquerque, de deformações específicas, durante o período do seu mestrado na Unicamp, e pelas trocas de idéias na interpretação dos dados.

Ao amigo de INTERACT, Nilson Cassiano, pelas informações e fotos sobre a amostragem realizada em obra.

E, por fim, ao amigo Victor León, pela ajuda fundamental na redação do resumo na língua estrangeira. 


\section{RESUMO}

Objetivou-se estudar o comportamento de estacas escavadas de grande diâmetro em uma obra de um Shopping Center na cidade de São Paulo. As estacas foram submetidas a carregamentos axiais de compressão, sendo que as estacas foram instrumentadas em profundidade. Utilizou-se de teorias amplamente conhecidas no meio técnico com o propósito de interpretar as curvas carga vs recalque, obtendo-se resultados como os diagramas de transferência de carga ao longo do fuste e atrito lateral unitário, gráficos do produto ES das estacas ensaiadas, gráficos de rigidez das estacas e as duas relações modificadas de Cambefort. O presente trabalho visa conseguir parâmetros que pudessem proporcionar uma redução no comprimento das estacas em obra e apresentar resultados que auxiliem os projetistas no dimensionamento de fundações usando-se estacas escavadas de grande diâmetro, sempre tendo cuidado e critério na extrapolação dos resultados em solos diferentes dos apresentados aqui.

Palavras Chave: Estacão. Estacas Escavadas de Grande Diâmetro. Prova de Carga Estática. Instrumentação em Profundidade. NBR 12131. 


\begin{abstract}
The objective of this Msc Thesis is to study the behavior of large diameter drilled pile in the construction of a shopping mall in Sao Paulo. The piles were subjected to axial compression loads and instrumented in depth. Widely known theories were used to interpret load vs settlement curves, obtaining such results as transfer loads diagrams along the shaft and lateral friction unit, ES product and stiffness grafics of tested piles and two modified Cambefort Laws. This paper aims to achieve parameters that will allow a reduction in pile lengths and to present results that will aid designers in the design of large diameter drilled pile, provided that the needed care is taken when extrapolating results to soils of different geological origins from those presented here.
\end{abstract}

Key Words: Large Diameter Drilled Pile. Static Load Test. Instrumentation in Depth. Brazilian Standard 12131. 


\section{LISTA DE FIGURAS}

Figura 2.1 - Equipamentos necessários para a execução dos estacões.................10

Figura 2.2 - Colocação da Armadura do estacão. ...............................................11

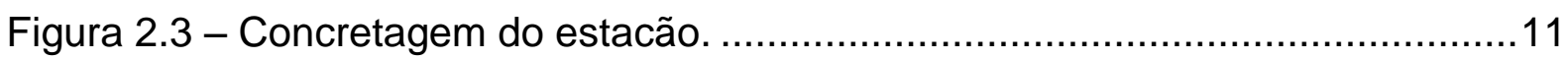

Figura 2.4 - Cravação da camisa metálica e escavação do estacão (Manual de Especificações de Produtos e Procedimentos ABEF/2004) ..................................12

Figura 2.5 - Desarenação ou troca de lama bentonítica (Manual de Especificações de Produtos e Procedimentos ABEF/2004) ...................................................... 13

Figura 2.6 - Equilíbrio de Forças num elemento de estaca (Massad, 1991). ...........14

Figura 2.7 - Ponte de Wheatstone (Portela e Silva, 1996)...................................16

Figura 2.8 - Esquemas da Ponte de Wheatstone (Portela e Silva, 1996).................16

Figura 2.9 - Disposição dos Extensômetros e Tipos de Circuitos possíveis para a Ponte de Wheatstone para Estruturas submetidas à Compressão. (UFSC, 2004)...17

Figura 2.10 - Hastes Medidoras_Tell Tales (Nacano, 2001). .................................19

Figura 2.11 - Célula de Osterberg (Penteado e Brito, 2009). ................................21

Figura 2.12 - Detalhe do dispositivo acoplado à base da célula Expancell (Alonso e

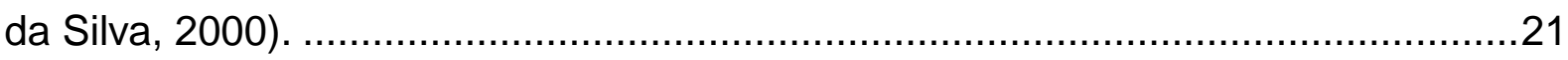

Figura 2.13 - Transferência de Carga e Curva Equivalente (Alonso e da Silva, 2000).

Figura 2.14 - Relação entre a Carga Admissível Calculada e Carga Admissível da Prova pelo Método de Décourt\&Quaresma (Décourt e Quaresma, 1978).

Figura 2.15 - Esquema de forças e tensões atuantes na estaca (Aoki e Velloso, 1975). .28

Figura 2.16 - Rupturas Convencional e Física numa estaca pré-moldada (Décourt, 2008).

Figura 2.17. Gráfico de Rigidez para Fundação Direta (sapata) (Décourt, 2008). ....32 Figura 2.18. Método da Rigidez_Limites Inferior (lower bound) e Superior (upper bound) (Décourt, 2008).

Figura 2.19. Método de Extrapolação proposto por Chin-Kondner (Fellenius, 2006).

Figura 2.20. Método de Extrapolação proposto por Chin-Kondner (Fellenius, 2006). 
Figura 2.22 - 2ª Relação de Cambefort (Cambefort, 1964).

Figura 2.23 - Curva Carga vs Recalque Típica para Estacas Curtas (Massad e Lazo, 1998) 39

Figura 2.24 - Construção Gráfica do Método das 2 Retas (Massad e Lazo, 1998). . 41 Figura 2.25 - Método Gráfico da NBR 6122 (NBR 6122/1996)............................42

Figura 2.26 - Método de Brinch-Hansen 80\% (apud Fellenius, 2006).....................43

Figura 2.27 - Método de De Beer (apud Fellenius, 2006).....................................44

Figura 2.28 - Método Gráfico de Van der Veen modificado por Aoki (FAG, 2008)...46

Figura 2.29 - Método Gráfico de Mazurkiewicz (FAG, 2008)..................................47

Figura 2.30 - Método Gráfico de Butler \& Roy (Aviz, 2006) ................................47

Figura 2.31 - Deformações Específicas nos níveis 1 ao 7. (Fellenius, 2006)...........49

Figura 3.1 - Vista aérea do terreno de implantação do Shopping União de Osasco (Google Earth, acessado em 13.05.2009) ..............................................................

Figura 3.2 - Sistema de Reação da Prova de Carga ...........................................55

Figura 3.3 - Perfuratriz para Execução dos Tirantes. ..........................................55

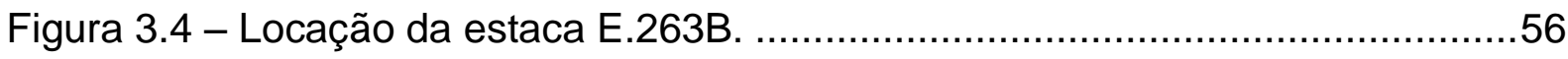

Figura 3.5 - Posicionamento da Instrumentação ao longo do fuste da estaca E,263B. .59

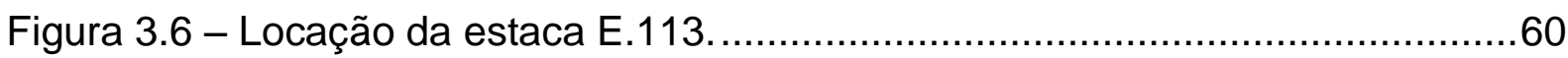

Figura 3.7 - Tubos para passagem das Barras Instrumentadas.............................61

Figura 3.8 - Posicionamento da Instrumentação ao longo do fuste da estaca E.113.

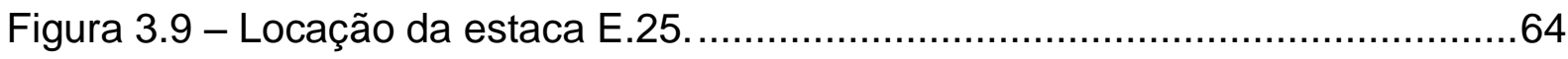

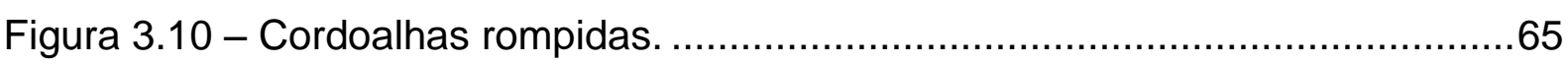

Figura 3.11 - Posicionamento da Instrumentação ao longo do fuste da estaca E.25.

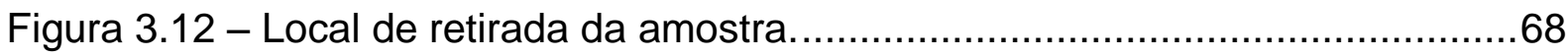

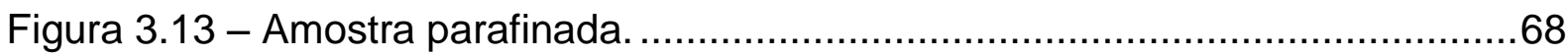

Figura 3.14 - Curva Granulométrica da amostra AM-01 ....................................70

Figura 3.15 - Curva Granulométrica da amostra AM-02 …….............................70

Figura 3.16 - Curva Granulométrica da amostra AM-03.......................................

Figura 3.17 - Ensaio Triaxial para a amostra AM-04 ........................................ 72

Figura 3.18 - Ensaio Triaxial para a amostra AM-05 ........................................73

Figura 3.19 - Tensão vs Deformação da estaca E.263b. .....................................76 
Figura 3.20 - Tensão vs Deformação da estaca E.113.

Figura 4.1 - Ampliação do Trecho Instrumentado para o Cálculo do Encurtamento.96

Figura 4.2. Resultados do Método de Randolph-Wroth para a PC.01 ( $\mathrm{N}_{\mathrm{SPT}}$ médio)

Figura 4.3. Resultados do Método de Randolph-Wroth para a PC.02 ( $\mathrm{N}_{\mathrm{SPT}}$ médio)

Figura 4.4. Resultados do Método de Randolph-Wroth para a PC.03 ( $\mathrm{N}_{\mathrm{SPT}}$ médio)

Figura 4.5. Capacidade de Carga utilizando a SP.31 pelo Método de Décourt-

Quaresma (PC.01)

Figura 4.6. Capacidade de Carga utilizando a SP.30 pelo Método de Décourt-

Quaresma (PC.02)

Figura 4.7. Capacidade de Carga utilizando a SP.33 pelo Método de Décourt-

Quaresma (PC.03)

Figura 4.8. Capacidade de Carga utilizando a SP.31 pelo Método de Aoki-Velloso (PC.01)

Figura 4.9. Capacidade de Carga utilizando a SP.30 pelo Método de Aoki-Velloso (PC.02) 132

Figura 4.10. Capacidade de Carga utilizando a SP.33 pelo Método de Aoki-Velloso (PC.03) 133

Figura 4.11. Capacidade de Carga para a SP. 31, Após os Resultados das Provas de Cargas Estáticas.

Figura 4.12. Capacidade de Carga para a SP. 30, Após os Resultados das Provas de Cargas Estáticas.

Figura 4.13. Capacidade de Carga para a SP. 33, Após os Resultados das Provas de Cargas Estáticas. 


\section{LISTA DE GRÁFICOS}

Gráfico 4.1. Carga vs Recalque no Topo (PC 01) ..........................................

Gráfico 4.2. Diagrama Módulo Tangente da Prova de Carga 01.............................83

Gráfico 4.3. Diagrama Módulo Tangente da Prova de Carga 02...............................85

Gráfico 4.4. Diagrama Módulo Tangente da Prova de Carga 03.............................86

Gráfico 4.5. Transferência de Carga ao longo do fuste da estaca E.263b. ...............88

Gráfico 4.6. Transferência de Carga ao longo do fuste da estaca E.113..................89

Gráfico 4.7. Transferência de Carga ao longo do fuste da estaca E.25...................90

Gráfico 4.8. Diagrama Atrito Lateral Unitário_PC01 - N = 660kN a 2640kN.............91

Gráfico 4.9. Diagrama Atrito Lateral Unitário_PC01 $-\mathrm{N}=3300 \mathrm{kN}$ a $5280 \mathrm{kN}$...........92

Gráfico 4.10. Diagrama Atrito Lateral Unitário_PC01 $-\mathrm{N}=5940 \mathrm{kN}$ a $7920 \mathrm{kN}$.........92

Gráfico 4.11. Diagrama Atrito Lateral Unitário_PC01 $-\mathrm{N}=8580 \mathrm{kN}$ e $8880 \mathrm{kN}$.........92

Gráfico 4.12. Diagrama Atrito Lateral Unitário_PC02 $-\mathrm{N}=1000 \mathrm{kN}$ a $4000 \mathrm{kN} \ldots \ldots \ldots . .93$

Gráfico 4.13. Diagrama Atrito Lateral Unitário_PC02 $-\mathrm{N}=5000 \mathrm{kN}$ a $8000 \mathrm{kN} \ldots \ldots \ldots . .93$

Gráfico 4.14. Diagrama Atrito Lateral Unitário_PC02 $-\mathrm{N}=9000 \mathrm{kN}$ a $11000 \mathrm{kN}$.......94

Gráfico 4.15. Diagrama Atrito Lateral Unitário_PC03 $-\mathrm{N}=1200 \mathrm{kN}$ a $4800 \mathrm{kN}$.........94

Gráfico 4.16. Diagrama Atrito Lateral Unitário_PC03 $-\mathrm{N}=6000 \mathrm{kN}$ a $9600 \mathrm{kN}$.........95

Gráfico 4.17. Diagrama Atrito Lateral Unitário_PC03 $-\mathrm{N}=10800 \mathrm{kN}$ e $11140 \mathrm{kN}$.....95

Gráfico 4.18. 1르 Relação de Cambefort_PC01 (E.263b).......................................99

Gráfico 4.19. 2ª Relação de Cambefort_PC01 (E.263b).........................................99

Gráfico 4.20.1 $1^{\text {a }}$ Relação de Cambefort_PC02 (E.113).......................................101

Gráfico 4.21. 2ª Relação de Cambefort_PC02 (E.113) .......................................102

Gráfico 4.22. 1르 Relação de Cambefort_PC03 (E.25)........................................104

Gráfico 4.23. 2를 Relação de Cambefort_PC03 (E.25) .........................................104

Gráfico 4.24. Método da Rigidez para a PC02 (E.113) ….................................106

Gráfico 4.25. Método da Rigidez para a PC03 (E.25) ….....................................107

Gráfico 4.26. Método de Chin-Kondner para os 3 ensaios...................................108

Gráfico 4.27. Método de Davisson para os 3 ensaios.........................................110

Gráfico 4.28. Método das 2 Retas aplicado à PC.01 ..........................................111

Gráfico 4.29. Método das 2 Retas aplicado à PC.02 ..........................................112

Gráfico 4.30. Método das 2 Retas aplicado à PC.03..........................................113

Gráfico 4.31. Método de Extrapolação da NBR 6122.......................................114

Gráfico 4.32. Método de Brinch-Hansen 80\% para os 3 ensaios..........................115 
Gráfico 4.33. Método de De Beer para os 3 ensaios........................................116

Gráfico 4.34. Método de Van der Veen para a PC.01 (E263) ...............................117

Gráfico 4.35. Método de Van der Veen para a PC.02 (E113) .................................118

Gráfico 4.36. Método de Van der Veen para a PC.03 (E25) .................................118

Gráfico 4.37. Método de Mazurkiewicz para os 3 ensaios. ...................................119

Gráfico 4.38. Método de Butler\&Roy para os 3 ensaios.......................................120

Gráfico 4.39. Método de Randolph-Wroth para a PC.01 (E.263b) .........................122

Gráfico 4.40. Método de Randolph-Wroth Ajustado para a PC.01 ........................123

Gráfico 4.41. Método de Randolph-Wroth para a PC.02 (E.113) ..........................124

Gráfico 4.42. Método de Randolph-Wroth Ajustado para a PC.02 .......................125

Gráfico 4.43. Método de Randolph-Wroth para a PC.03 (E.25) ...........................126

Gráfico 4.44. Método de Randolph-Wroth Ajustado para a PC.03 ......................127

Gráfico 4.45. Cota de Ponta das Estacas Pertencentes às Provas de Cargas .......134

Gráfico 4.46. Atrito Lateral Total para as 3 Provas de Cargas Estáticas.................135

Gráfico 4.47. Comparativo entre os Valores de Atrito Lateral dos Métodos Semi-

Empíricos e das Provas de Carga

Gráfico 4.48. Comparação do Atrito Lateral Unitário Máximo obtido pelas Provas de

Cargas Estáticas e o Método Décourt-Quaresma.

Gráfico 4.49. Comparativo entre os Valores de Ponta dos Métodos Semi-Empíricos

e das Provas de Carga.

Gráfico 4.50. Comparação da Reação de Ponta obtida pelas Provas de Cargas

Estáticas e os Métodos Semi-Empíricos

Gráfico 4.51. Cotas de Ponta das Estacas Após os Resultados das Provas de

Cargas Estáticas. 


\section{LISTA DE TABELAS}

Tabela 2.1 - Especificação da Bentonita (NBR 6122/1996). ....................................

Tabela 2.2 - Especificação da Lama Bentonítica (Manual de Especificações de

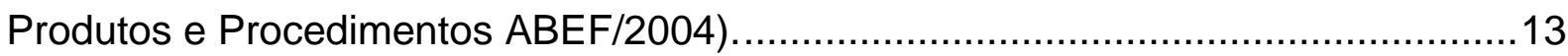

Tabela 2.3 - Casos de Estacões Instrumentados divulgados na literatura técnica...23

Tabela 2.4 - Valores do Coeficiente K em função do tipo de solo (Décourt, 1998). .25

Tabela 2.5 - Valores do Coeficiente $\alpha$ em função do tipo de solo (Décourt, 1998)...26

Tabela 2.6 - Valores do Coeficiente $\beta$ em função do tipo de solo (Décourt, 1998)...26

Tabela 2.7 - Valores dos parâmetros $\mathrm{K}$ e a em função do tipo de solo (Aoki e

Velloso, 1975). 30

Tabela 2.8 - Valores dos parâmetros F1 e F2 em função do tipo da estaca (Aoki e Velloso, 1975). .30

Tabela 2.9 - Parâmetros do Método de Randolph - Wroth. .....................................50

Tabela 3.1 - Carregamentos de alguns Pilares no Shopping União de Osasco. ......52

Tabela 3.2 - Cargas Axiais calculadas em função do Diâmetro dos Estacões no

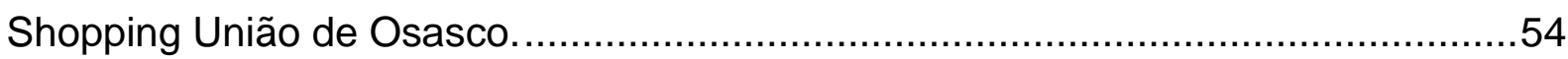

Tabela 3.3 - Cargas Atuantes no Pilar 11R no Shopping União de Osasco..............56

Tabela 3.4 - Posição da Instrumentação na estaca E.263B. ...................................60

Tabela 3.5 - Cargas Atuantes no Pilar 11H no Shopping União de Osasco..............60

Tabela 3.6 - Posição da Instrumentação na estaca E.113. …………………..........64

Tabela 3.7 - Cargas Atuantes no Pilar 13B no Shopping União de Osasco..............64

Tabela 3.8 - Posição da Instrumentação na estaca E.25 ......................................66

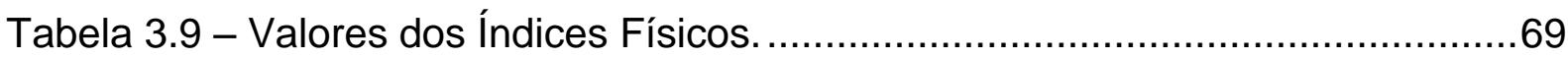

Tabela 3.10 - Resultados do ensaio de Granulometria. ........................................69

Tabela 3.11 - Resultados dos ensaios triaxiais das cinco amostras........................74

Tabela 3.12 - Resistência à compressão da E.263b..........................................75

Tabela 3.13 - Deformação Específica e Módulo de Deformação Secante em função

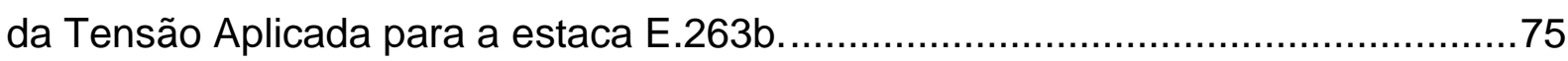

Tabela 3.14 - Módulo de Deformação Secante da E.263b.....................................76

Tabela 3.15 - Resistência à compressão da E.113 ............................................77

Tabela 3.16 - Deformação Específica e Módulo de Deformação Secante em função

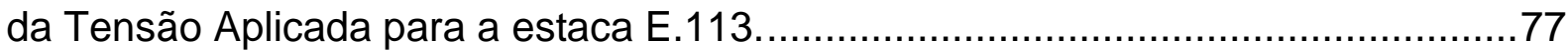

Tabela 3.17 - Módulo de Deformação Secante da E.113.......................................78 
Tabela 4.1 - Fases de Cargas da Primeira Prova de Carga (E.263b). ...................80

Tabela 4.2 - Fases de Cargas da Segunda Prova de Carga (E.113). ....................81

Tabela 4.3 - Fases de Cargas da Terceira Prova de Carga (E.25). ......................82

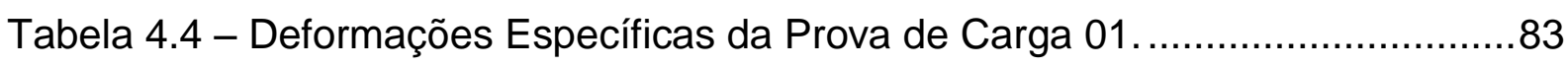

Tabela 4.5 - Valores do Produto ES Obtidos da Prova de Carga 01 .......................84

Tabela 4.6 - Deformações Específicas da Prova de Carga 02............................84

Tabela 4.7 - Valores do Produto ES Obtidos da Prova de Carga 02 ......................85

Tabela 4.8 - Deformações Específicas da Prova de Carga 03 ...............................86

Tabela 4.9 - Valores do Produto ES Obtidos da Prova de Carga 03.......................86

Tabela 4.10 - Cargas Axiais ao longo do fuste da estaca E.263b. .........................88

Tabela 4.11 - Cargas Axiais ao longo do fuste da estaca E.113 ..........................89

Tabela 4.12 - Cargas Axiais ao longo do fuste da estaca E.25. ..........................90

Tabela 4.13 - Encurtamentos ao longo do fuste da estaca E.263b. .......................98

Tabela 4.14 - Deslocamentos ao longo do fuste da estaca E.263b.......................98

Tabela 4.15 - Encurtamentos ao longo do fuste da estaca E.113. ......................100

Tabela 4.16 - Deslocamentos ao longo do fuste da estaca E.113.......................101

Tabela 4.17 - Encurtamentos ao longo do fuste da estaca E.25........................103

Tabela 4.18 - Deslocamentos ao longo do fuste da estaca E.25........................103

Tabela 4.19. Valores da Carga de Ruptura pelo Método de Chin-Kondner...........109

Tabela 4.20. Valores das Cargas de Ruptura pelo Método de Davisson. ...............110

Tabela 4.21. Valores da Carga de Ruptura pelo Método de De Beer. ...................116

Tabela 4.22. Valores das Cargas de Ruptura pelo Método de Mazurkiewicz. ........120

Tabela 4.23. Valores das Cargas de Ruptura para o Método de Butler \& Roy. ......120

Tabela 4.24. Cotas de Ponta para os Estacões das Provas de Cargas Estáticas. .134 Tabela 4.25. Cargas no Topo, Ponta e Atrito Lateral Obtidos das Provas de Cargas

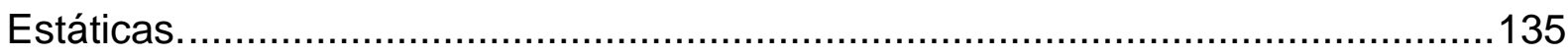

Tabela 4.26. Atrito Lateral Total para a PC.01 (E.263) .....................................136

Tabela 4.27. Atrito Lateral Total para a PC.02 (E.113) .....................................137

Tabela 4.28. Atrito Lateral Total para a PC.03 (E.25) ......................................138

Tabela 4.29. Cotas de Ponta das Estacas Após os Resultados das Provas de Cargas Estáticas.

Tabela 5.1. Carga no Topo e Deslocamento Atingidos nas Provas de Cargas

Estáticas............................................................................................. 149

Tabela 5.2. Valores do Produto ES das Estacas Ensaiadas. ................................149 
Tabela 5.3. Cargas no Topo, Ponta e Atrito Lateral Obtidos das Provas de Cargas

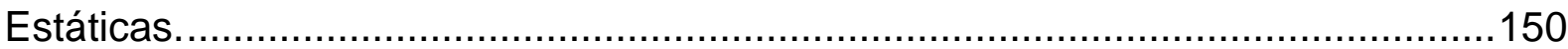

Tabela 5.4. Resumo dos Métodos de Extrapolação da Curva Carga vs Recalque. 151 Tabela 5.5. Comparativo dos Valores de Atrito Lateral: Método das 2 Retas e PCE's 152

Tabela 5.6. Comparativo entre os Métodos Semi-Empíricos e as Provas de Cargas Estáticas. 152 


\section{LISTA DE ABREVIATURAS E SIGLAS}

ABEF

ABNT

CIU

CP

CPT

CP 190RB

MIT

NBR

$\mathbf{R}$

SPT

Associação Brasileira de Empresas de Engenharia de

Fundações e Geotecnia

Associação Brasileira de Normas Técnicas

Ensaio Triaxial Confined Isotropic Undrained

Cota de Ponta do Estacão ou Corpo de Prova

Cone Penetration Test

Aço para Concreto Protendido, de Relaxação Baixa, com tensão

de ruptura igual a $190 \mathrm{kgf} / \mathrm{mm}^{2}$

Massachussetts Institute of Technology

Norma Brasileira emitida pela ABNT

Ensaio Triaxial do tipo Rápido Pré-Adensado

Standard Penetration Test 


\section{LISTA DE SÍMBOLOS}

$\boldsymbol{\alpha}, \boldsymbol{\beta} \quad$ Coeficientes função do tipo de solo e do tipo da estaca para a ponta e o atrito, respectivamente

A Coeficiente Angular da reta do Módulo secante

B Coeficiente Linear da reta do Módulo secante

b Diâmetro da Estaca

C Coesão

$\mathbf{C}_{1} \quad$ Inclinação da Linha Reta

$\mathbf{C}_{2} \quad$ Intersecção com o eixo $\mathrm{Y}$

do Incremento de Tensão

de Incremento de Deformação

$\Delta \mathbf{R} \quad$ Variação de Resistência por Deformação

$\varepsilon \quad$ Deformação Específica

$\varepsilon_{\mathrm{r}} \quad$ Deformação Específica na Ruptura

$\mathbf{E}_{\text {sec }} \quad$ Módulo de Elasticidade Secante da Estaca

$\mathbf{E}_{\mathrm{tg}} \quad$ Módulo de Elasticidade Tangente da Estaca

F $\quad$ Fator de segurança global

$\mathbf{F}_{\mathbf{p}} \quad$ Fator de segurança relativo aos parâmetros do solo

$\mathbf{F}_{\mathbf{f}} \quad$ Fator de segurança relativo à formulação adotada

$\mathbf{F}_{\mathrm{d}} \quad$ Fator de segurança para evitar recalques excessivos

$\mathbf{F}_{\mathbf{w}} \quad$ Fator de segurança relativo à carga de trabalho da estaca

$\mathbf{F}_{1}, \mathbf{F}_{2} \quad$ Fatores definidos para relacionar a estaca padrão aos outros tipos de estaca para a ponta e o atrito, respectivamente.

$\mathbf{F}_{\mathbf{z}} \quad$ Força Axial paralela ao eixo $\mathbf{Z}$

f $\quad$ Resistência Característica do Concreto à Compressão

$\mathbf{H}_{\mathbf{x}} \quad$ Força Horizontal paralela ao eixo $\mathrm{X}$

$\mathbf{H}_{\mathbf{y}} \quad$ Força Horizontal paralela ao eixo $\mathrm{Y}$ 

$\mathbf{h}_{\text {bloco }}$
Altura do Bloco de Fundação
K
Coeficiente função do tipo de solo no qual a ponta está assentada
k
Fator do Extensômetro
I
Medida da seção no momento da medição
$I_{0}$
Medida original (inicial) da seção
LL Limite de Liquidez
LP Limite de Plasticidade
$\mathrm{M}_{\mathbf{x}}$
Momento Fletor em torno do eixo $\mathrm{X}$
$\mathrm{M}_{\mathrm{y}}$
Momento Fletor em torno do eixo $Y$
$\mathbf{N}_{\text {SPT }}$
Número de golpes obtidos no ensaio SPT
$\mathbf{N}_{\text {eq }}$
$\mathrm{N}$ equivalente
$\mathbf{N}_{\text {estaca }}$
Carga Axial em cada estaca do binário
OS
Offset em relação à origem
$\mathbf{P}_{\mathbf{R}}$
Carga de Ruptura da Estaca
$P_{L}$
Carga Lateral da Estaca
$\mathbf{P}_{\mathbf{P}}$
Carga de Ponta da Estaca
$\mathbf{P}_{\text {bloco }}$
Peso do Bloco de Fundação
$\mathbf{Q}_{\mathrm{u}}$
Carga de Ruptura da Estaca
Q
$\mathbf{Q}_{\mathrm{adm}}$
Carga Aplicada
$q_{p}$
Carga Admissível da Estaca
$\mathrm{q}_{\mathrm{L}}$
Resistência de Ponta da Estaca
$\mathbf{R}_{\mathrm{p}}$
Resistência Lateral ou Atrito Lateral Unitário
$\mathbf{R}^{\prime}$
Resistência de Ponta da Estaca
$\mathbf{R}_{0}$
Resistência Lateral ou Atrito Lateral Unitário
$S_{p}$
Resistência Inicial do Extensômetro
$S_{L}$
Área de Ponta da Estaca
U
Área Lateral da Estaca
Perímetro da Estaca 


$\begin{array}{ll}\mathbf{u}_{\mathbf{R}} & \text { Pressão Neutra na Ruptura } \\ \mathbf{w} & \text { Teor de Umidade } \\ \delta & \text { Recalque correspondente à carga aplicada } \\ \rho_{\mathbf{n}} & \text { Densidade Natural } \\ \rho_{\mathbf{s}} & \text { Densidade dos Grãos } \\ \rho_{\mathbf{d}} & \text { Densidade Seca } \\ \boldsymbol{\varphi} & \text { Ângulo de Atrito Interno do Solo } \\ \sigma_{3} & \text { Pressão Confinante } \\ \sigma_{\mathbf{R}} & \text { Tensão na Ruptura }\end{array}$




\section{SUMÁRIO}

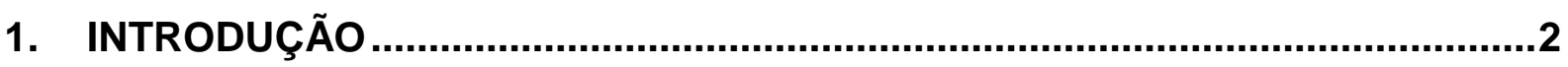

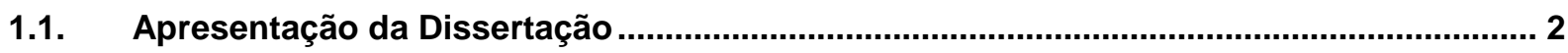

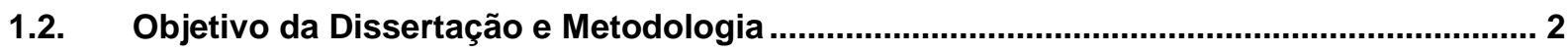

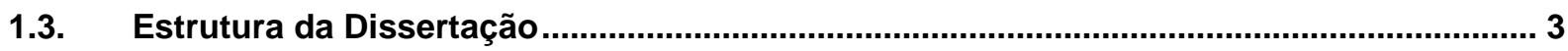

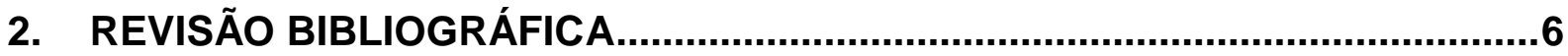

2.1. Conceituação de Estacas de Deslocamento e Estacas sem Deslocamento ..................... 6

2.2. Conceituação de Estaca Escavada de Grande Diâmetro no sentido mais Amplo............ 8

2.2.1. Características dos Equipamentos........................................................................ 9

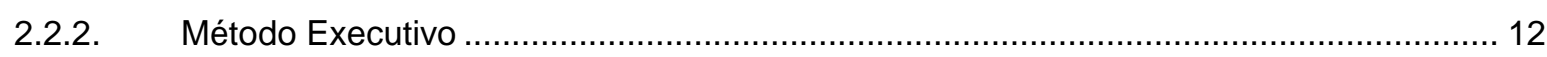

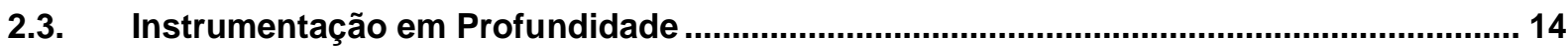

2.3.1. Tipos de Instrumentação ............................................................................... 15

2.3.1.1. Strain-Gages (Extensômetros Elétricos de Resistência) …...................................... 15

2.3.1.2. Tell-Tales (Hastes Medidoras de Deslocamentos) ................................................. 18

2.3.1.3. Célula de Carga (Transdutor de Força) ............................................................ 19

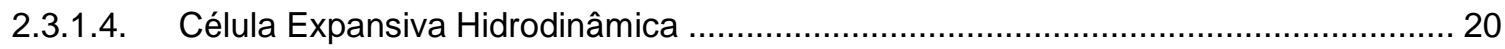

2.3.1.5. Micrômetro Deslizante (Torpedo Kovary) .............................................................. 22

2.3.2. Casos de Estacões Instrumentados Divulgados na Literatura Técnica ........................... 23

2.4. Métodos Semi-Empíricos de Capacidade de Carga ..................................................... 24

2.4.1. Método Décourt\&Quaresma (1978) e Décourt (1998) .................................................... 24

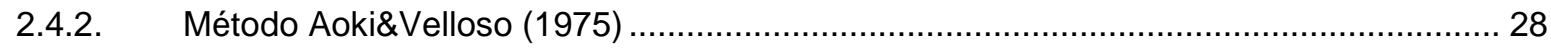

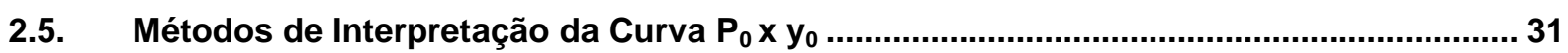

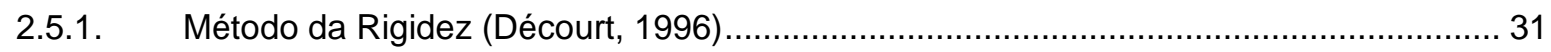

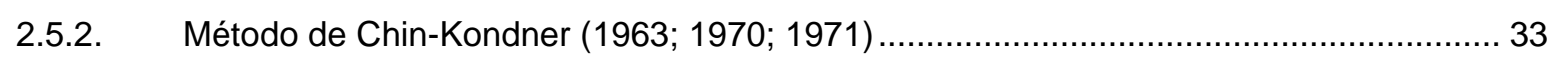

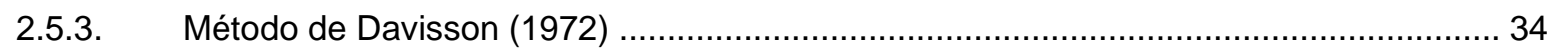

2.5.4. Método Baseado nas Relações de Cambefort Modificadas ............................................ 36

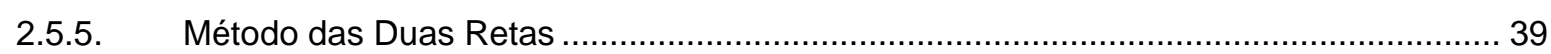

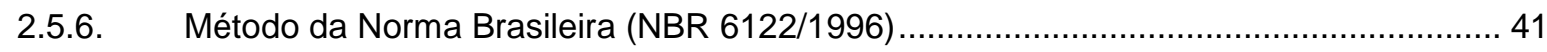

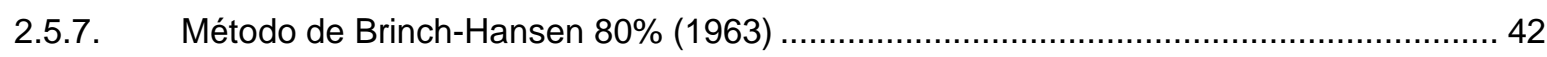

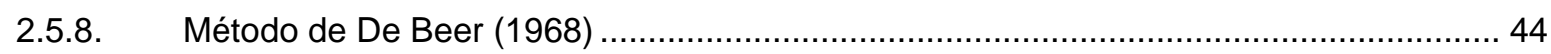

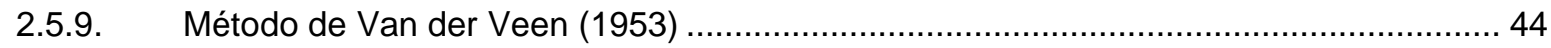




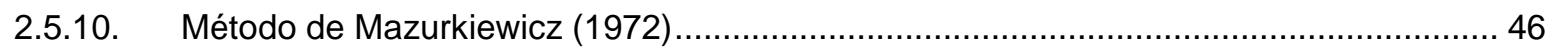

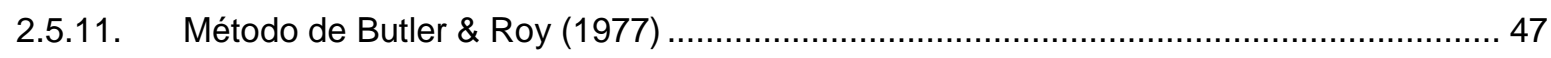

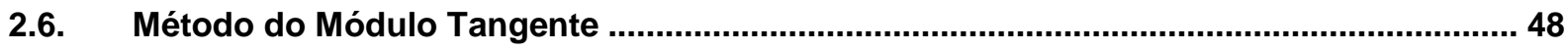

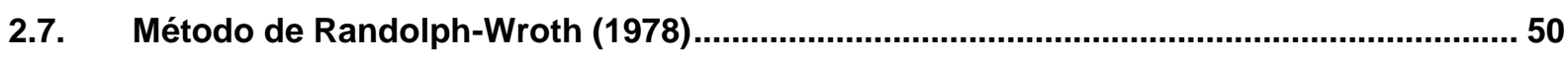

3. DESCRIÇÃO DA OBRA DO SHOPPING UNIÃO DE OSASCO.....................51

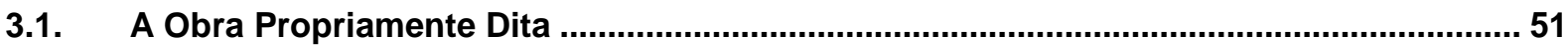

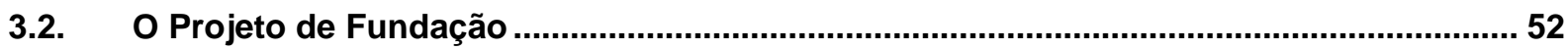

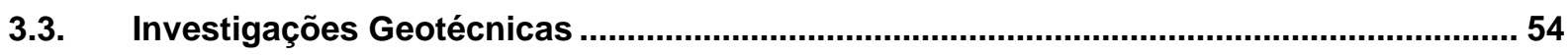

3.3.1. As Provas de Cargas Estáticas (projeto)..................................................................... 54

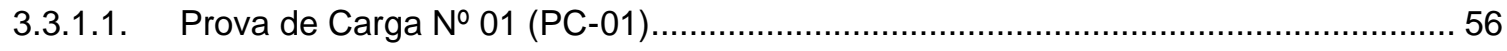

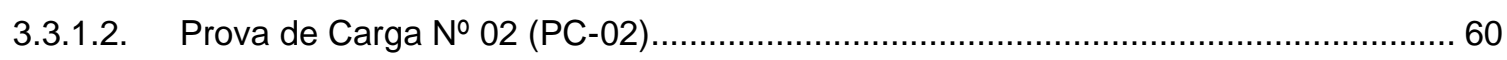

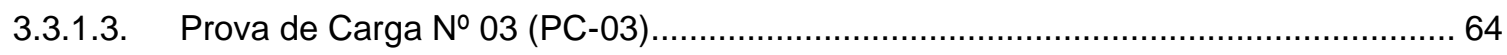

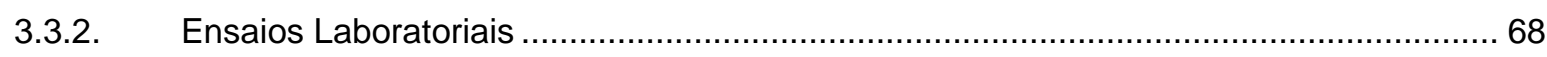

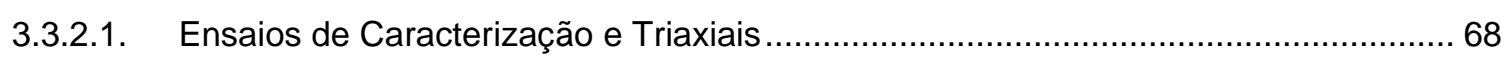

3.3.2.2. Ensaios de Obtenção do Módulo de Young do Concreto .......................................... 74

4. ANÁLISE DOS RESULTADOS …..............................................................

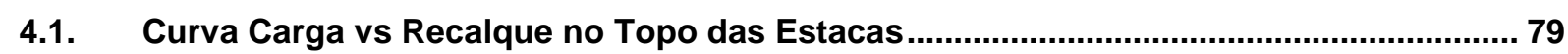

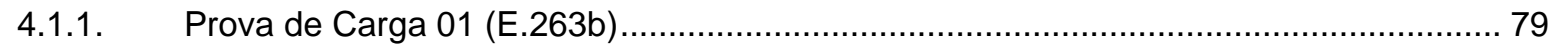

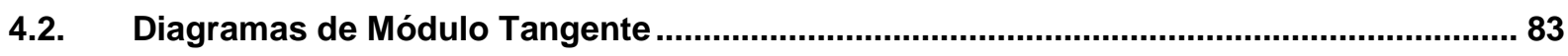

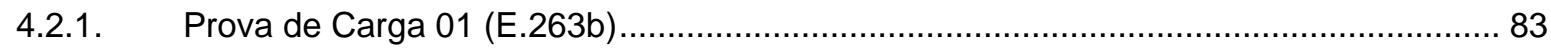

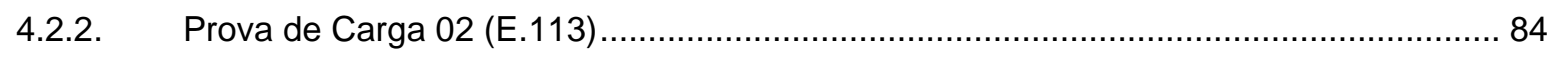

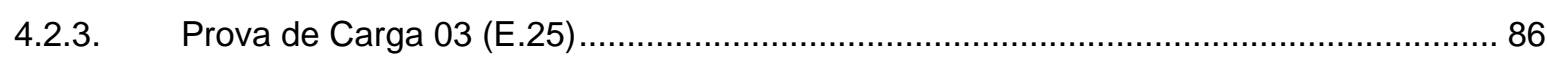

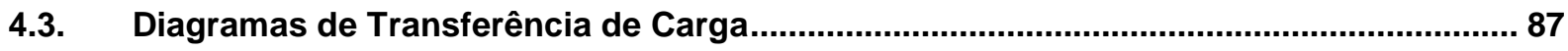

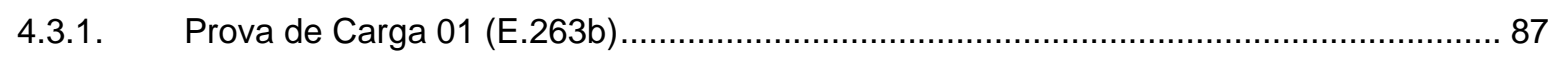

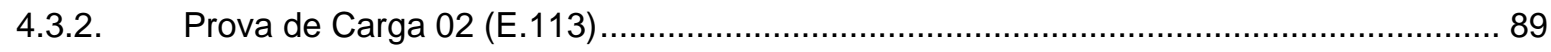

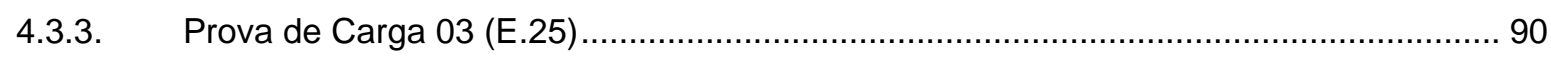

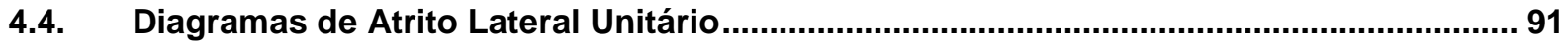

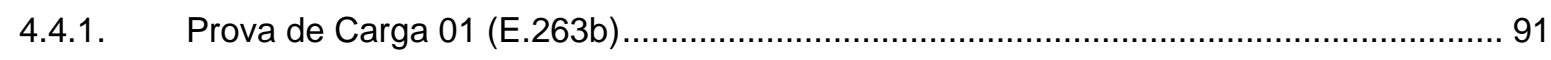

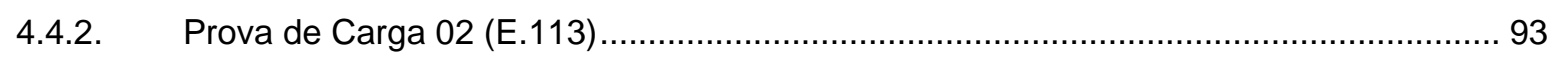

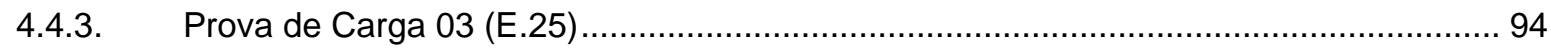

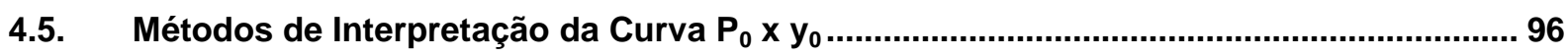


4.5.1. Funções de Transferência de Carga (Relações de Cambefort) …..................................96

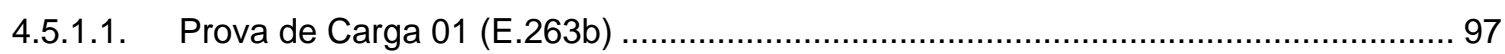

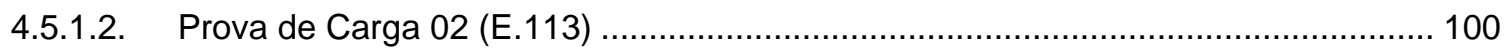

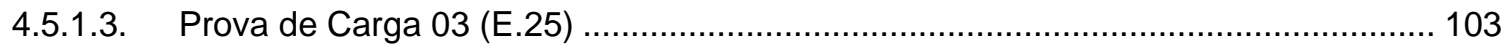

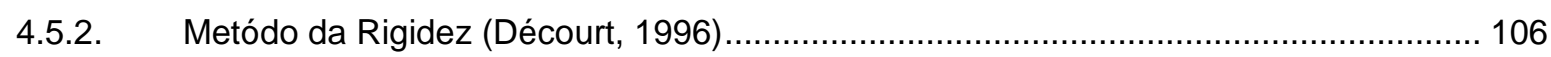

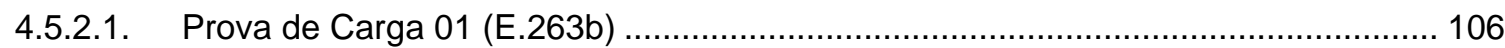

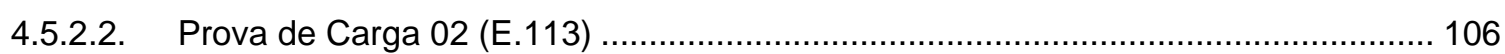

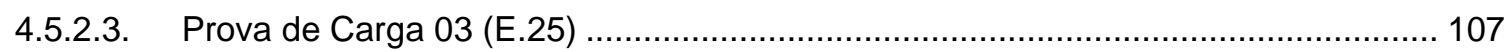

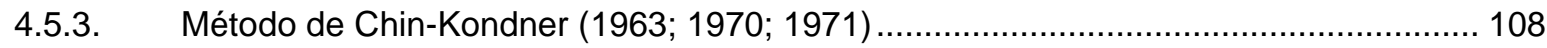

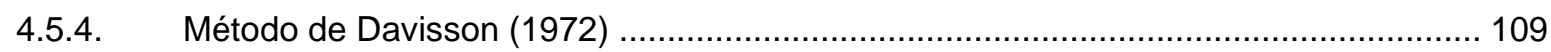

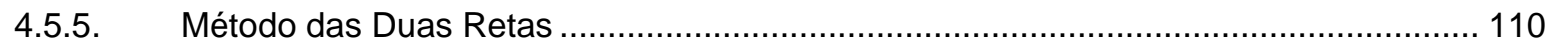

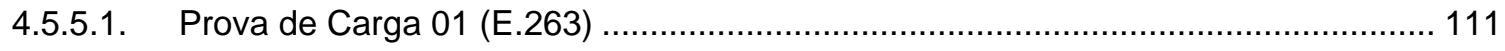

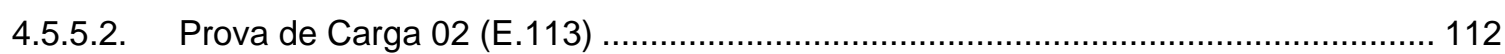

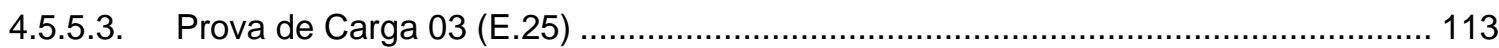

4.5.6. Método da Norma Brasileira (NBR 6122/1996) ...................................................... 113

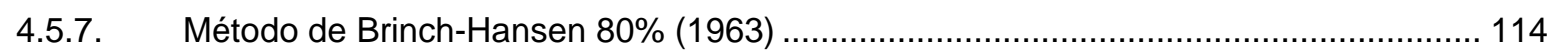

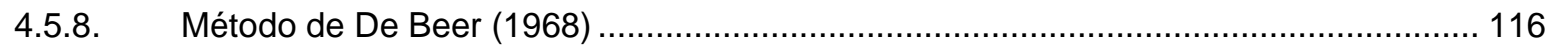

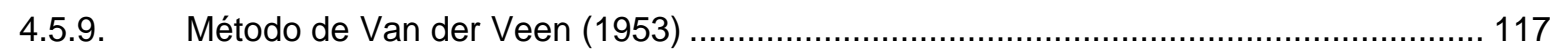

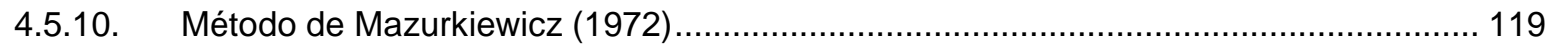

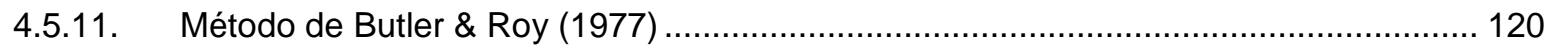

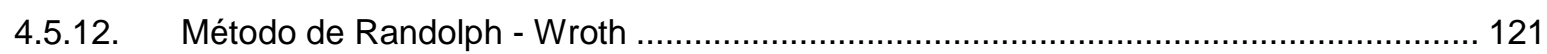

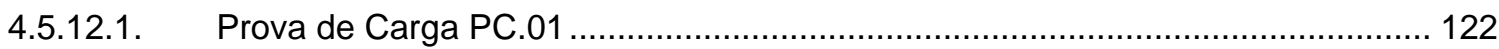

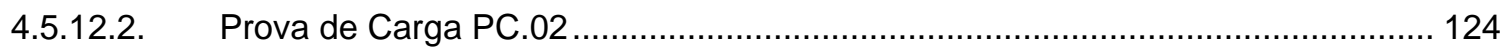

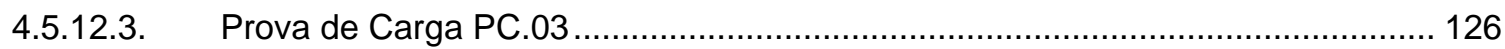

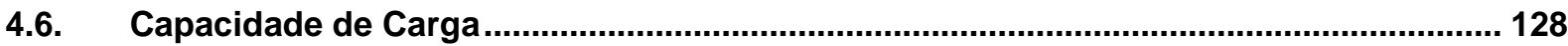

4.7. Comparações entre as Provas de Cargas Estáticas e os Métodos Semi-Empíricos.... 134

4.7.1. Estudo para a Tentativa de Redução do Comprimento das Estacas .......................... 142

5. CONCLUSÕES E SUGESTÕES PARA PESQUISAS FUTURAS ...................147

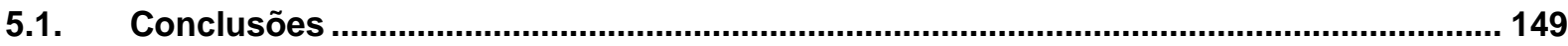

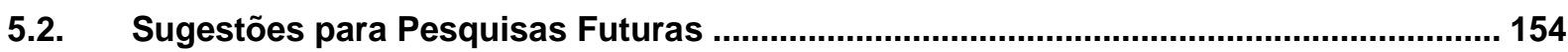

6. REFERÊNCIAS BIBLIOGRÁFICAS ........................................................155 


\section{Introdução}

\subsection{Apresentação da Dissertação}

Atualmente, no Brasil, vive-se um período em que os ensaios necessários para a melhor compreensão dos eventuais problemas nas obras de construção civil são inexistentes, sendo vistos como custos para o projeto, e não como investimentos necessários para um dimensionamento mais seguro e correto. As obras são contratadas por preço global (turn key), ou seja, a empresa contratada é obrigada a entregar a obra completa em condições de pleno funcionamento pelo preço cobrado; e a inclusão do valor dos ensaios pode levar a empresa a não conseguir ganhar a obra. A ausência de ensaios obriga os projetistas a recorrerem aos dados bibliográficos, que muitas vezes não são válidos para o local da obra, e à utilização de cálculos conservadores, para suprir as incertezas decorrentes de se tratar com um elemento natural, ao invés de um elemento formado pelas mãos humanas.

Porém, na obra do shopping União de Osasco, foi possível dispor de dois tipos de investigações geotécnicas: as provas de cargas estáticas e os ensaios laboratoriais.

A execução das provas de cargas estáticas instrumentadas em profundidade é justificada para compreender melhor o mecanismo de transferência de carga em fundações profundas, bem como a distribuição do atrito lateral. Também é possível a obtenção da curva carga vs recalque e a consequente carga de ruptura, por ser uma técnica efetivamente confiável. Além desses fatores, Milititsky (1991) cita também "A natural dificuldade de conhecimento das propriedades do solo[...] alteração das 
condições iniciais provocada pela execução das estacas e o comportamento complexo do conjunto estaca-solo[...]" como justificativas para a utilização das provas de carga visando o real comportamento da estaca.

\subsection{Objetivo da Dissertação e Metodologia}

O presente trabalho tratará do estudo das três provas de cargas estáticas, instrumentadas em profundidade, realizadas em três estacões de 1,20m de diâmetro, escavados na obra do Shopping União de Osasco.

O objetivo do estudo é a interpretação dos resultados obtidos pela instrumentação em profundidade, bem como a elaboração dos diagramas de transferência de carga, atritos laterais unitários, método do módulo tangente (Fellenius, 1989) e os gráficos representativos das $1^{\underline{a}}$ e $2^{a}$ relações modificadas de Cambefort (Cambefort, 1964).

Também serão estudadas as teorias de interpretação da curva $\mathrm{P}_{0} \times \mathrm{y}_{0}$, definidas por Décourt (1996), Chin-Kondner (modificações propostas por Chin (1970, 1971) ao trabalho de Kondner (1963) e Davisson (1972), com o intuito de estimar a carga de ruptura das provas de carga, sendo que será possível saber, para a primeira prova de carga, o quão próximos chegam essas estimativas do valor real obtido em obra.

Outros métodos de extrapolação da carga de ruptura também serão mostrados nesse trabalho, com o intuito de verificar a aplicabilidade dos mesmos nesse tipo de estaca.

Outro ponto importante é a tentativa em diminuir os comprimentos, definidos por métodos consagrados de previsão de capacidade de carga, tais como Décourt\&Quaresma (1978) e Aoki\&Velloso (1975), dos estacões restantes em obra, para que essa economia justificasse a execução das provas de carga. 
Por fim, serão disponibilizados os ensaios laboratoriais, tais como ensaios de caracterização e triaxiais do tipo CIU (Confined Isotropic Undrained) ou UU (Rápido Pré-Adensado - R), que foram realizados em amostras cúbicas próximos aos pontos onde foram realizadas as provas de carga, com a finalidade de uma possível sugestão em fazer a comparação dos resultados obtidos pelas provas de carga e uma simulação numérica, utilizando-se um software geotécnico de tensãodeformação, com a teoria de elementos finitos, tal como o Plaxis.

\subsection{Estrutura da Dissertação}

O desenvolvimento da pesquisa terá as etapas que se descrevem a seguir:

\section{Capítulo 2. Revisão Bibliográfica}

Nesse capítulo serão tratadas as teorias necessárias para 0 correto desenvolvimento e compreensão do trabalho.

Primeiramente, será tratado o conceito de estacas de e sem deslocamento, dando ênfase às estacas escavadas de grande diâmetro, mais conhecidos no meio técnico como estacões, definindo-as de acordo com a norma técnica de fundações vigente em 2007, data dos ensaios estáticos, a NBR 6122/1996, e o Manual de Especificações de Produtos e Procedimentos ABEF (2004), esclarecendo, quando necessário, com fotos dos equipamentos de obra e ou figuras retiradas das referências listadas.

A seguir, serão mencionados alguns dos tipos de instrumentação em profundidade que estão disponíveis atualmente, dando maior ênfase para o que foi utilizado na obra do Novo Shopping União de Osasco. Em seguida, serão apresentados alguns casos de obra com estacões instrumentados divulgados na literatura técnica. 
Também serão mostradas as formulações dos métodos semi-empíricos, DécourtQuaresma e Aoki\&Velloso, utilizados no projeto de fundação, para a determinação da profundidade necessária das estacas para as diversas cargas atuantes.

Os métodos de interpretação da curva carga vs recalque no topo serão tratados aqui com a finalidade da obtenção da carga última das três estacas analisadas. Para a primeira prova de carga, na qual houve a caracterização da ruptura, será feita a comparação entre os valores obtidos por esses métodos e o valor real medido, fornecido pelo ensaio estático. Para as outras duas provas de carga, apenas serão estimados os valores de carga limite.

Utilizando o método do "Módulo Tangente" proposto por Fellenius, serão encontrados os valores do produto ES (produto entre o módulo de elasticidade e a área da seção transversal da estaca) do concreto constituinte das estacas. Em seguida, será possível confrontar os módulos obtidos em ensaios laboratoriais com os módulos obtidos pelo método proposto.

\section{Capítulo 3. Descrição da obra do Shopping União de Osasco}

Nesse capítulo serão abordados aspectos referentes à obra propriamente dita, ou seja, explicações para que haja entendimento geral sobre a mesma. Será enfatizada a concepção do projeto de fundações, bem como o projeto das provas de carga. Serão expostos, também, os resultados obtidos pelos ensaios de caracterização e triaxiais CIU ou R, realizados em amostras cúbicas, conforme escrito no capítulo 1.

\section{$>$ Capítulo 4. Análise dos Resultados}

Nesse capítulo serão aplicadas as teorias explicadas no decorrer do capítulo 2 aos dados proporcionados pelas provas de cargas estáticas, mostrando os cálculos referentes aos diagramas de transferência de carga e atritos laterais unitários, extrapolação da carga de ruptura. Com a utilização das sondagens à percussão realizadas próximas às estacas que foram submetidas aos carregamentos estáticos, 
será possível o cálculo da capacidade de carga, por meio dos métodos Décourt\&Quaresma e Aoki\&Velloso, os quais possibilitarão o conhecimento das profundidades necessárias para as diferentes cargas atuantes.

Além desses, também serão mostradas as curvas carga vs recalque no topo e as funções de transferência de carga, dadas pelas relações baseadas nas leis de Cambefort, bem como o método das duas retas, proposto por Massad e Lazo (1998). Alguns outros métodos de interpretação também serão mostrados nesse capítulo, com o objetivo de analisar a aplicabilidade dos mesmos para os casos estudados.

$>$ Capítulo 5. Conclusões e Sugestões para Pesquisas Futuras

Nesse capítulo serão expostas as conclusões referentes aos cálculos apresentados no transcorrer do capítulo 4 , mostrando se os objetivos foram ou não atingidos, bem como sugestões para que possam ser realizadas pesquisas futuras baseadas nos assuntos tratados nesse trabalho. 


\section{Revisão Bibliográfica}

\subsection{Conceituação de Estacas de Deslocamento e Estacas sem Deslocamento}

Os tipos de fundações profundas, mais especificamente as estacas, podem ser divididos em duas categorias: as estacas de deslocamento e as estacas sem deslocamento. Na primeira categoria englobam-se as estacas pré-moldadas de concreto, metálicas, Franki e ômega; já na segunda, as estacas Strauss, barretes, estacões (estacas de grande diâmetro) e a hélice contínua.

As estacas pré-moldadas de concreto são constituídas de concreto armado ou protendido e, devido à dificuldade de transporte, possuem limitação de comprimento. São armadas para resistir aos esforços decorrentes do transporte e do içamento. As estacas metálicas são constituídas de perfis laminados ou soldados, simples ou compostos, tubulares e trilhos soldados.

Esses dois tipos de estacas são cravadas no terreno com o auxílio de martelo em queda livre, fazendo-se com que a relação peso do martelo e peso da estaca seja a maior possível. No caso das pré-moldadas, o martelo não pode ter peso inferior a $15 \mathrm{kN}$; já para as metálicas, $10 \mathrm{kN}$.

As estacas tipo Franki são moldadas in loco e seu processo construtivo consiste na cravação de um tubo de ponta fechada por uma bucha composta de material granular (areia e brita). Ao se atingir a profundidade estimada em projeto, o concreto 
seco vai sendo colocado sob os golpes do pilão e a bucha vai sendo expulsa do tubo para a execução da base alargada. Deve-se inserir os últimos $0,15 \mathrm{~m}^{3}$ de concreto com uma energia mínima de 2,5MN.m, para estacas com diâmetros até $450 \mathrm{~mm}$, e 5MN.m para estacas maiores que $450 \mathrm{~mm}$.

As estacas tipo ômega também são moldadas in loco, sem vibração durante a sua execução, por meio de uma máquina semelhante à da hélice contínua. No entanto, não há o deslocamento de solo até a superfície, o que contribui para a compactação do solo ao redor da estaca.

As estacas Strauss são constituídas de concreto simples ou armado e são moldadas in loco, executadas com revestimento metálico recuperável. São executadas por meio da colocação de tubos metálicos dentados na extremidade inferior e o solo é retirado à medida do avanço dos tubos até alcançar a profundidade de projeto. É fundamental, depois de atingida a cota de ponta, que seja feita a limpeza do fundo antes da concretagem da estaca.

Os estacões, que serão melhor detalhados ao longo da dissertação, são constituídos de concreto armado e são executados com o auxílio de lama bentonítica ou polimérica. As estacas barretes possuem o mesmo método executivo, porém é necessária a utilização de outro equipamento, denominado Clam-shell.

As estacas do tipo hélice contínua são moldadas in loco com a inserção de um trado contínuo helicoidal no terreno. Após atingir a cota de ponta, a concretagem é iniciada de baixo para cima e o solo escavado vai sendo levado até a superfície. Por fim, a armadura da estaca é posicionada conforme projeto.

Finalizando, os métodos construtivos desses dois tipos de categoria de estacas influenciam na capacidade de carga das mesmas. Nas estacas de deslocamento, após a cravação das estacas, ocorre uma compactação do solo ao redor da estaca e tensões superficiais de atrito surgem no perímetro das mesmas, fazendo com que haja uma mobilização próxima ao estado passivo. Por sua vez, nas estacas sem deslocamento, após a escavação do fuste, ocorre um alívio de tensões que proporciona uma mobilização próxima ao estado ativo. Em geral, as estacas de 
deslocamento possuem resistências laterais e de ponta superiores às estacas sem deslocamento. Nessas, o atrito lateral é um pouco prejudicado e a resistência de ponta é limitada por norma em apenas $20 \%$ da carga atuante na mesma.

\subsection{Conceituação de Estaca Escavada de Grande Diâmetro no sentido mais Amplo}

As estacas escavadas de grande diâmetro são conhecidas no meio técnico como estacões. Elas podem ser definidas como estacas escavadas por rotação, com o auxílio de camisa-guia e lama bentonítica ou polimérica, com diâmetros que variam de $0,60 \mathrm{~m}$ a 2,50m. A carga admissível desse tipo de estaca depende do atrito lateral ao longo do fuste, sendo que, para a mobilização da resistência de ponta, são necessários deslocamentos elevados, conforme prescrito na NBR 6122/1996. Lembra-se que a norma de fundações foi atualizada em 2010 e a nova versão passou a ser obrigatória desde 20 de outubro de 2010; no entanto, os conceitos escritos e adotados em projeto não se alteraram.

A lama bentonítica é a mistura de água e bentonita, composta, fundamentalmente, pelo argilo mineral montmorilonita sódica, e possui as seguintes características:

> Estabilidade produzida pelo fato da suspensão de bentonita manter-se por longo período;

> Capacidade de formar nos vazios do solo e, especialmente junto à superfície lateral da escavação, uma película impermeável, denominada cake.

- Tixotropia, ou seja, propriedade capaz de proporcionar fluidez quando agitada e a formação de "gel", quando em repouso.

As especificações da bentonita estão contidas na Tabela 2.1. 
Tabela 2.1 - Especificação da Bentonita (NBR 6122/1996).

\begin{tabular}{lc}
\hline \multicolumn{1}{c}{ Requisito } & Valor \\
\hline Resíduos na peneira \#200 & $\leq 1 \%$ \\
Teor de Umidade & $\leq 1 \%$ \\
Limite de Liquidez & $\geq 440$ \\
Viscosidade Marsh 1500/1000 da suspensão a 60 em água destilada & $\geq 40$ \\
Decantação da Suspensão a 6\% em 24h & $\leq 2 \%$ \\
Água separada por pressofiltração de 450 $\mathrm{cm}^{3}$ da suspensão a 6\% nos & $\leq 18 \mathrm{~cm}^{3}$ \\
primeiros 30min, à pressão de 0,7MPa & 7 a 9 \\
PH da água filtrada & $\leq 2,5 \mathrm{~mm}$ \\
Espessura do cake no filtro prensa &
\end{tabular}

\subsubsection{Características dos Equipamentos}

De acordo com o Manual de Especificações e Procedimentos ABEF (2004), as características dos equipamentos necessários para a execução dos estacões são descritos a seguir:

a.) Equipamento de Perfuração. Constituído de uma mesa rotativa que aciona uma haste telescópica (tipo Kelly);

b.) Guindaste Auxiliar. Guindaste sobre esteiras com lança treliçada com a capacidade de erguer a armação;

c.) Caçamba. Ferramenta acoplada à ponta da haste telescópica, para retirada do material escavado;

d.) Misturador de Lama Bentonítica. Recipiente e bomba de alta turbulência;

e.) Silos de Acumulação de Lama Bentonítica;

f.) Desarenador. Ferramenta utilizada para retirar a areia em suspensão da lama bentonítica;

g.) Bombas de sucção ou submersas. Equipamentos utilizados para a troca ou desarenação da lama durante a concretagem; 
h.) Tubo tremonha, funil de concretagem e acessórios. Ferramentas utilizadas para realizar a concretagem da estaca;

i.) Air Lift. Sistema de ar comprimido para a substituição de lama e/ou limpeza do fundo da escavação, embora não seja comum em obra.

Na Figura 2.1 é possível visualizar alguns dos equipamentos descritos acima.

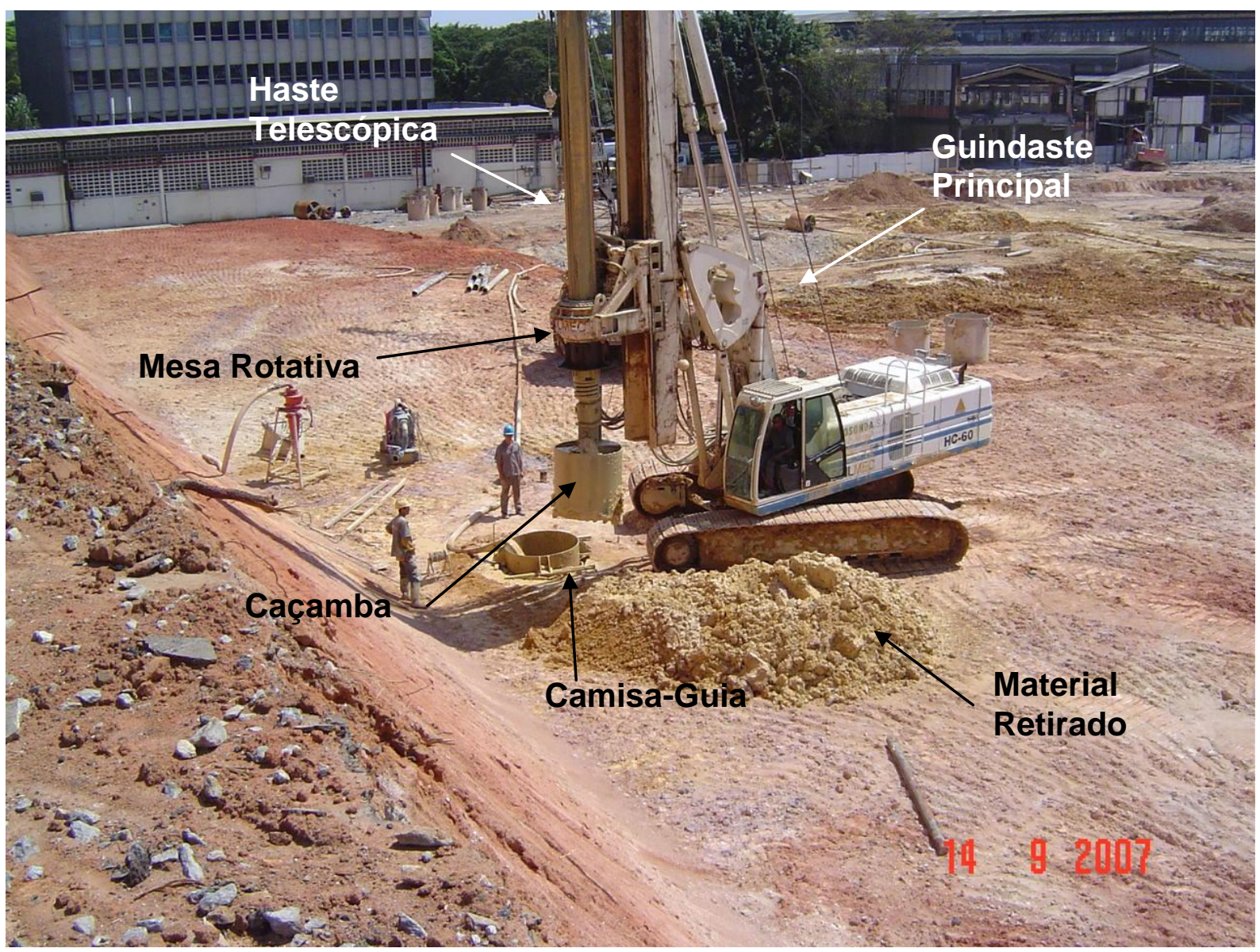

Figura 2.1 - Equipamentos necessários para a execução dos estacões.

Já nas Figuras 2.2 e 2.3, é mostrado o momento da colocação da armação na estaca com o guindaste auxiliar e a concretagem de um estacão, respectivamente. 


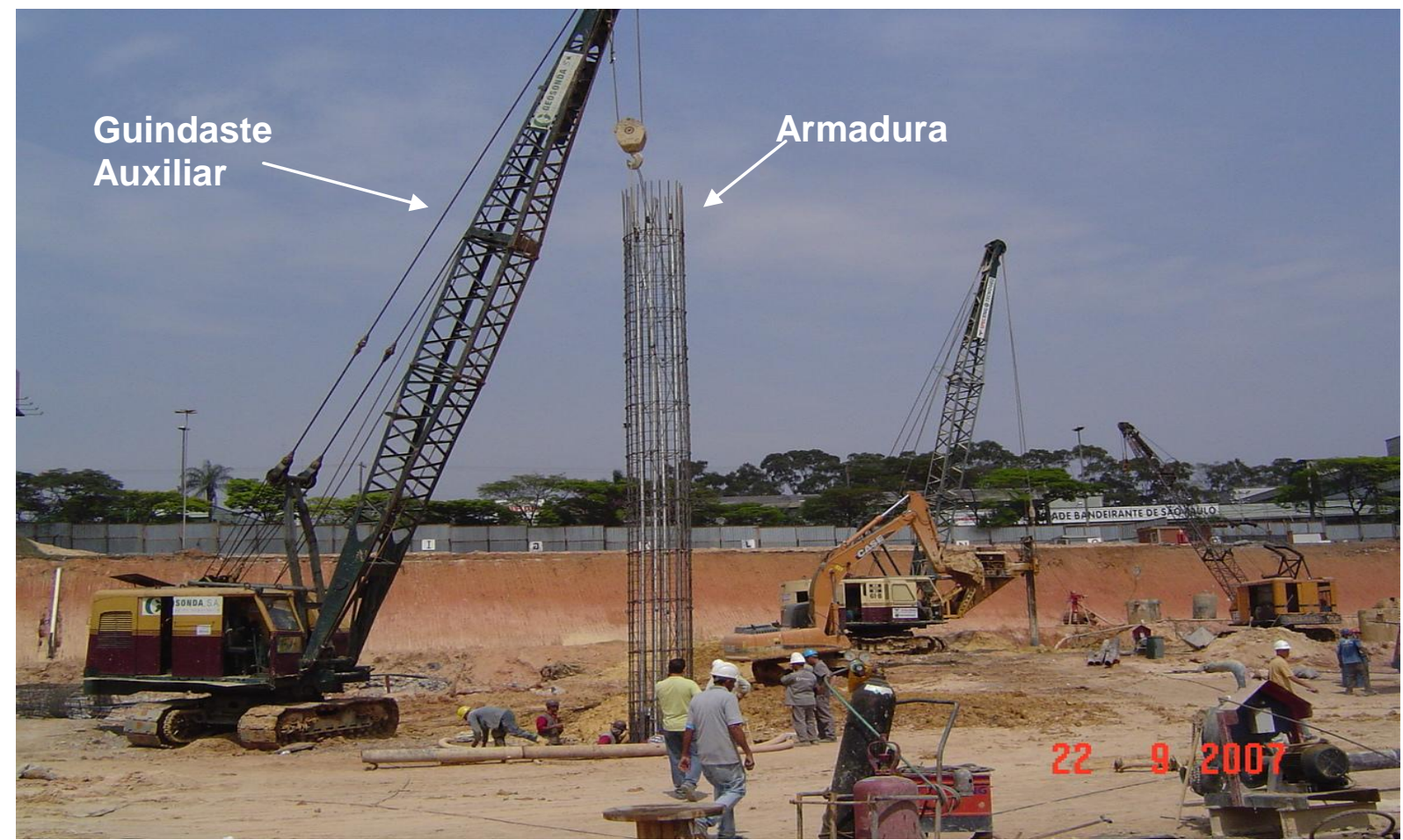

Figura 2.2 - Colocação da Armadura do estacão.

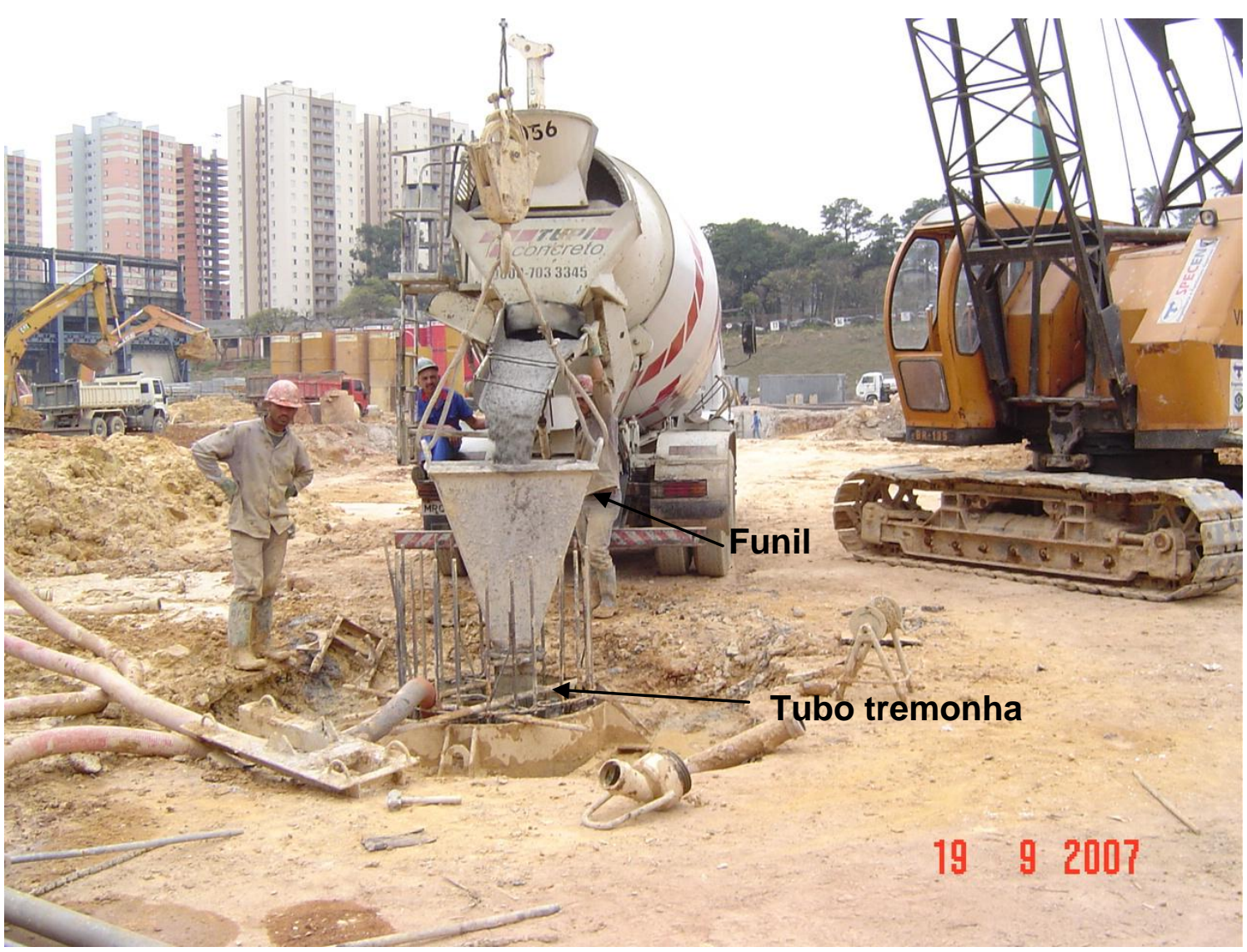

Figura 2.3 - Concretagem do estacão. 


\subsubsection{Método Executivo}

A sequência executiva dos estacões compreende as seguintes fases:

a.) Cravar no terreno a camisa metálica até $1,50 \mathrm{~m}$ a 2,00m de comprimento, aproximadamente, com diâmetro $10 \mathrm{~cm}$ maior do que o da estaca, garantindo o contato íntimo com o solo e, simultaneamente, proteger o topo da escavação. Essa fase pode ser visualizada por meio da Figura 2.4 ;

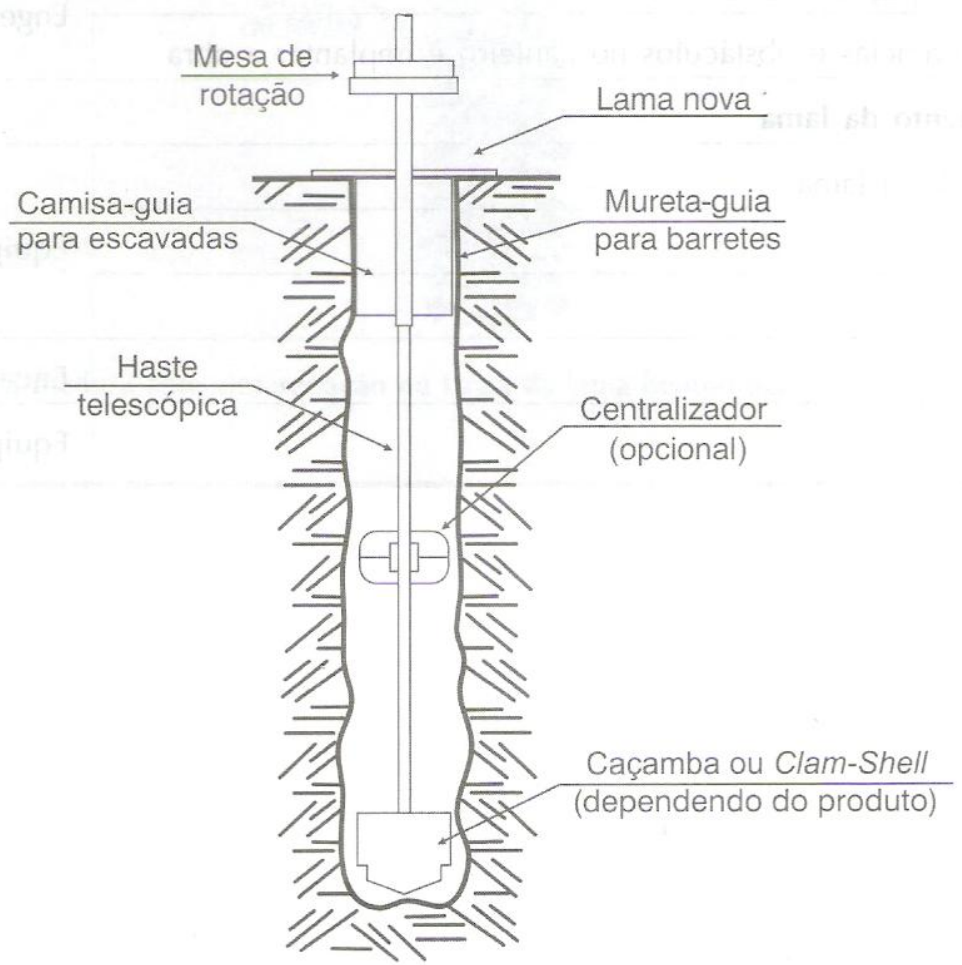

Figura 2.4 - Cravação da camisa metálica e escavação do estacão (Manual de Especificações de Produtos e Procedimentos ABEF/2004)

b.) Iniciar a escavação ou perfuração da estaca e, simultaneamente, iniciar o enchimento com lama bentonítica previamente preparada;

c.) À medida que se prossegue a escavação, deve-se tomar o cuidado com a manutenção do prumo, bem como do nível de lama bentonítica dentro da escavação; 
d.) Após a escavação, realizar a desarenação no furo, como mostrado na Figura 2.5, respeitando-se o limite do teor de areia, conforme Tabela 2.2;

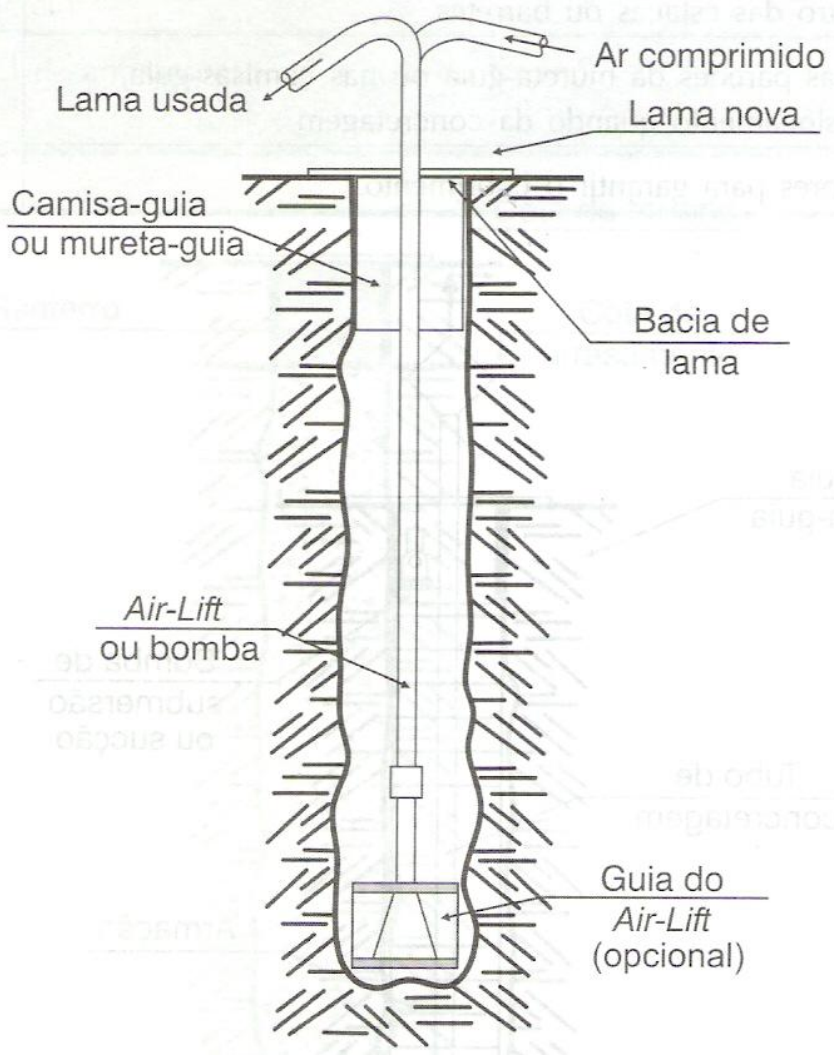

Figura 2.5 - Desarenação ou troca de lama bentonítica (Manual de Especificações de Produtos e Procedimentos ABEF/2004)

Tabela 2.2 - Especificação da Lama Bentonítica (Manual de Especificações de Produtos e Procedimentos ABEF/2004).

\begin{tabular}{lcl}
\hline \multicolumn{1}{c}{ Parâmetro } & Valores & \multicolumn{1}{c}{ Equipamento para Ensaio } \\
\hline Massa Específica & $10,25 \mathrm{kN} / \mathrm{m}^{3}$ a $11 \mathrm{kN} / \mathrm{m}^{3}$ & Densímetro \\
Viscosidade & $30 \mathrm{~s} \mathrm{a} 90 \mathrm{~s}$ & Funil MARSH \\
$\mathrm{PH}$ & 7 a 11 & Papel de tormasol \\
Teor de Areia & $\leq 3 \%$ & "Baroid Sand Content ou Similar" \\
\hline
\end{tabular}

e.) Colocar a armadura, colocando-se roletes para garantir o cobrimento especificado em projeto, conforme Figura 2.2;

f.) Proceder a concretagem utilizando-se o funil ou a bomba de concreto, do fundo para a superfície, mantendo-se sempre o tubo dentro do concreto; 


\subsection{Instrumentação em Profundidade}

A instrumentação em profundidade das estacas foi elaborada pela equipe do Prof $^{\circ}$ Dro Paulo Albuquerque, da Unicamp, entre os dias 13 de dezembro de 2007 e 18 de janeiro de 2008.

Na Figura 2.6 são mostradas as forças atuantes em um elemento de estaca, com as quais é possível fazer o equilíbrio de forças do sistema:

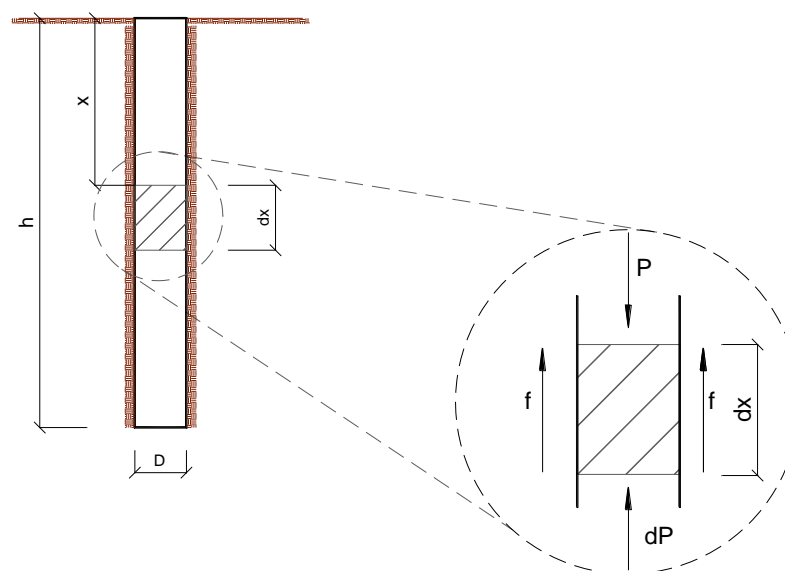

Figura 2.6 - Equilíbrio de Forças num elemento de estaca (Massad, 1991).

$$
\begin{gathered}
P=P+d P+\pi . D . f \\
\frac{d P}{d x}=-\pi . D . f
\end{gathered}
$$

E pela Lei de Hooke, pode-se escrever:

$$
\varepsilon=\frac{d y}{d x}=\frac{P}{E . S}
$$

onde:

$$
\begin{aligned}
& \mathrm{P}=\text { Carga Aplicada }[\mathrm{F}] \\
& \mathrm{dP}=\text { Incremento de carga }[\mathrm{F}]
\end{aligned}
$$


$\mathrm{D}=$ Diâmetro da estaca $[\mathrm{L}]$;

$\mathrm{f}=$ Atrito Lateral Unitário $\left[\mathrm{FL}^{-2}\right]$;

$\varepsilon=$ Deformação específica $\left[\mathrm{F}^{0} \mathrm{~L}^{0} \mathrm{~T}^{0}\right]$;

$\mathrm{S}=$ Área da Seção Transversal da Estaca $\left[\mathrm{L}^{-2}\right]$

$\mathrm{E}=$ Módulo de Elasticidade da Estaca $\left[\mathrm{FL}^{-2}\right]$;

\subsubsection{Tipos de Instrumentação}

Neste item serão abordados os tipos mais utilizados para realizar instrumentação em profundidade em estacas, dando-se maior ênfase à instrumentação utilizada na obra do shopping União de Osasco, que são os strain-gages. Sabe-se que a definição de deformação específica $(\varepsilon)$ é a relação entre a diferença entre a medida da seção no momento da medição e o medida da seção inicial, conforme equação (2.4).

$$
\varepsilon=\frac{l-l_{0}}{l_{0}}
$$

\subsubsection{Strain-Gages (Extensômetros Elétricos de Resistência)}

Os extensômetros elétricos de resistência baseiam-se na variação da resistência elétrica de um circuito quando submetido a uma deformação. O físico Sir Charles Wheatstone descobriu uma ponte para medição de pequenas variações de resistências, fato que ocorre nos extensômetros. A Figura 2.7 mostra a ponte de Wheatstone. 


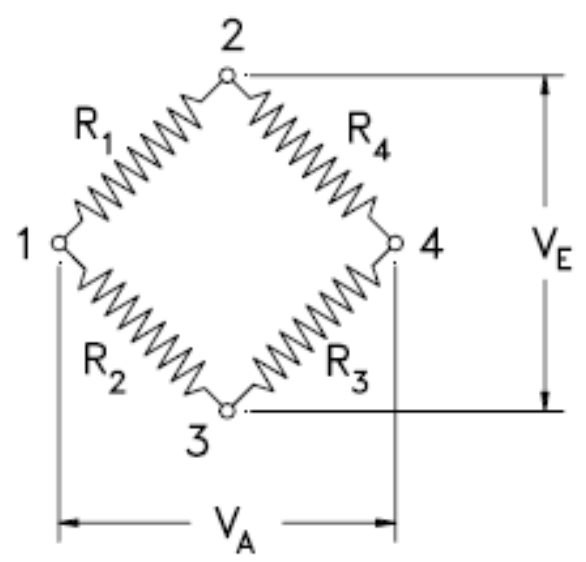

Figura 2.7 - Ponte de Wheatstone (Portela e Silva, 1996).

onde:

$$
\begin{aligned}
& \mathrm{V}_{\mathrm{E}}=\text { Tensão de Entrada }[\mathrm{mV}] \\
& \mathrm{V}_{\mathrm{A}}=\text { Tensão de Saída }[\mathrm{mV}] \\
& \mathrm{R}_{\mathrm{i}}=\text { Resistência de cada ramo da ponte }[\Omega]
\end{aligned}
$$

Na Figura 2.8 são mostrados os diversos esquemas possíveis de pontes de Wheatstone.
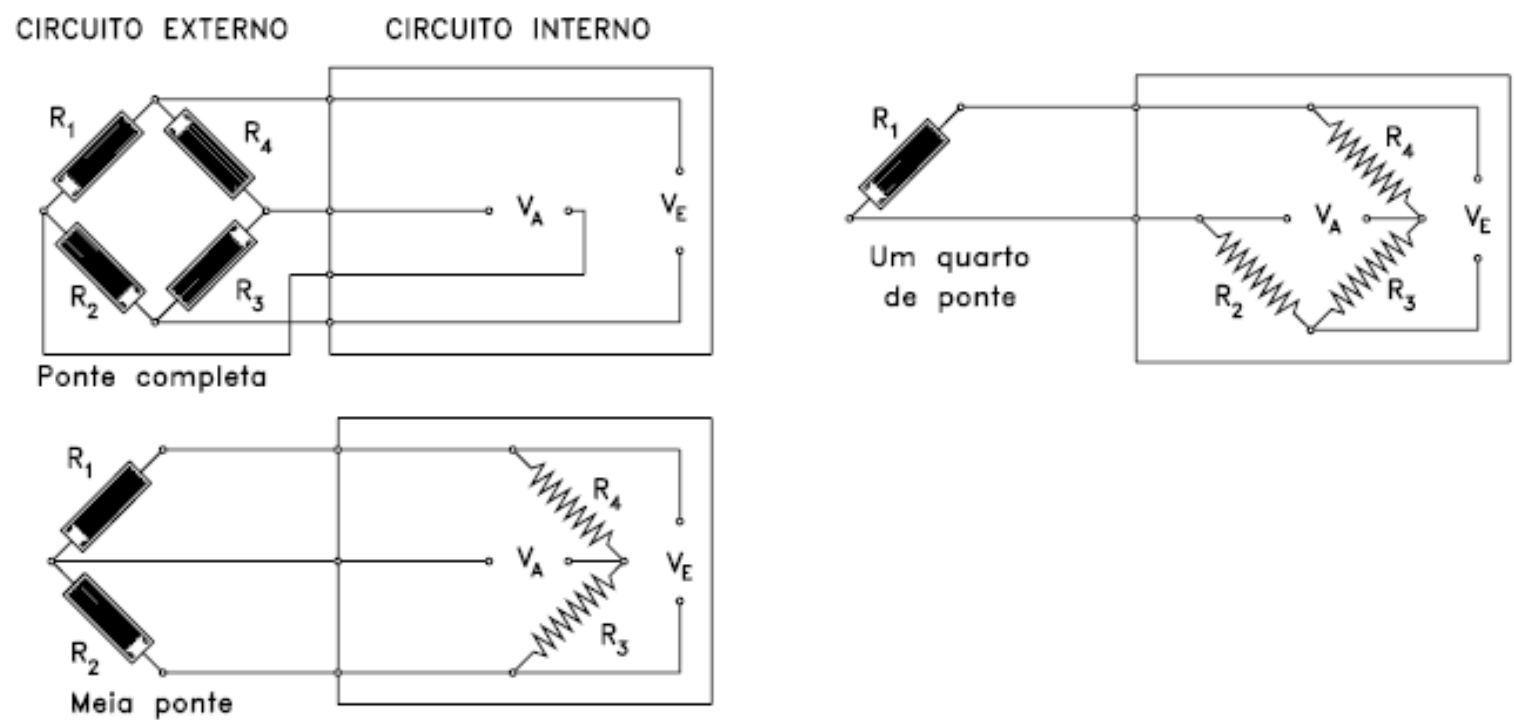

Figura 2.8 - Esquemas da Ponte de Wheatstone (Portela e Silva, 1996).

Já na Figura 2.9, pode-se ver um exemplo de aplicação em uma barra submetida a carga de compressão e os possíveis circuitos para a mesma. 


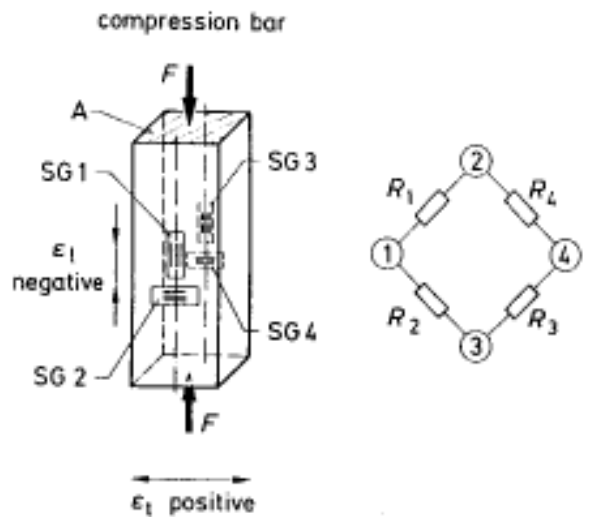

\begin{tabular}{|c|c|c|c|c|c|c|}
\hline Braço & R1 & R2 & R3 & R4 & Resultado & Observação \\
\hline Equação da ponte & \multicolumn{5}{|c|}{$\varepsilon_{1}-\varepsilon_{2}+\varepsilon_{3}-\varepsilon_{4}=\varepsilon_{i}$} & $\begin{array}{l}\text { Atenção aos sinais da fórmula e das } \\
\text { deformações }\end{array}$ \\
\hline $\begin{array}{l}\text { Um Quarto de } \\
\text { ponte }\end{array}$ & $\begin{array}{c}\text { SG } \\
1\end{array}$ & Rc & $\mathrm{Rc}$ & $\mathrm{Rc}$ & $\varepsilon_{i}=\varepsilon_{l}$ & $\sigma_{l}=\sigma_{b}+\sigma_{n}=\varepsilon_{i} \cdot E$ \\
\hline $\begin{array}{l}\text { Um Quarto de } \\
\text { ponte com SG de } \\
\text { comp. }\end{array}$ & $\begin{array}{c}\text { SG } \\
1\end{array}$ & $\mathrm{~K}$ & $\mathrm{Rc}$ & Rc & $\varepsilon_{i}=\varepsilon_{l}$ & $\begin{array}{l}\text { Compensação da tensão térmica usando } \\
\text { extensômetro de compensação }\end{array}$ \\
\hline Meia ponte & $\begin{array}{c}\mathrm{SG} \\
1\end{array}$ & $\begin{array}{c}\text { SG } \\
2\end{array}$ & $\mathrm{Rc}$ & $\mathrm{Rc}$ & $\begin{array}{l}\varepsilon_{i}=\varepsilon_{l}+\varepsilon_{t} \\
=(1+v) \cdot \varepsilon_{l}\end{array}$ & $\sigma_{l}=\sigma_{n}+\sigma_{b}=\varepsilon_{i} . E /(1+v)$ \\
\hline \multirow[t]{2}{*}{ Ponte em diagonal } & $\begin{array}{c}\mathrm{SG} \\
1\end{array}$ & Rc & $\begin{array}{c}S G \\
3\end{array}$ & Rc & $\varepsilon_{i}=2 \varepsilon_{b u}$ & \multirow{2}{*}{$\begin{array}{l}\text { Superposição da flexão é } \\
\text { compensada } \\
\sigma_{n}=1 / 2 \varepsilon_{i} . E\end{array}$} \\
\hline & $\begin{array}{c}\mathrm{SG} \\
2\end{array}$ & Rc & $\begin{array}{c}\mathrm{SG} \\
4\end{array}$ & $\mathrm{Rc}$ & $\varepsilon_{i}=2 \varepsilon_{b i b}$ & \\
\hline \multirow[t]{2}{*}{$\begin{array}{l}\text { Ponte em diagonal } \\
\text { com } 2 \text { SG de comp. }\end{array}$} & $\begin{array}{c}\text { SG } \\
1\end{array}$ & $\mathrm{~K}$ & $\begin{array}{c}\mathrm{SG} \\
3\end{array}$ & $\mathrm{Rc}$ & $\varepsilon_{i}=2 \varepsilon_{b u}$ & \multirow[t]{2}{*}{$\begin{array}{l}\text { Compensação da tensão térmica usando } \\
\text { extensômetro de compensação }\end{array}$} \\
\hline & $\begin{array}{c}\mathrm{SG} \\
2\end{array}$ & $\mathrm{~K}$ & $\begin{array}{c}\mathrm{SG} \\
3\end{array}$ & $\mathrm{Rc}$ & $\varepsilon_{i}=2 \varepsilon_{b i b}$ & \\
\hline Ponte completa & $\begin{array}{c}\text { SG } \\
1\end{array}$ & $\begin{array}{c}\text { SG } \\
2\end{array}$ & $\begin{array}{c}\mathrm{SG} \\
3\end{array}$ & $\begin{array}{c}\text { SG } \\
4\end{array}$ & $\begin{array}{l}\varepsilon_{i}=2\left(\varepsilon_{l}+\varepsilon_{t}\right) \\
=2 \varepsilon_{l}(1+v)\end{array}$ & $\begin{array}{l}\sigma_{n}=\varepsilon_{i} \cdot E /(2 \cdot(1+v)) \\
F=A \cdot \varepsilon_{i} \cdot E /(2 \cdot(1+v))\end{array}$ \\
\hline
\end{tabular}

Figura 2.9 - Disposição dos Extensômetros e Tipos de Circuitos possíveis para a Ponte de Wheatstone para Estruturas submetidas à Compressão. (UFSC, 2004).

As barras comprimidas, que são o caso em questão, estão submetidas a esforços advindos do carregamento axial, de flexão e de temperatura. Como o objetivo principal é descobrir as deformações específicas provenientes da força vertical, necessita-se anular os efeitos gerados pela flexão e temperatura. Para isso, utilizaram-se os strain-gages em ponte completa.

Com a disposição mostrada na Figura 2.9, as variações das quatro resistências gerarão quatro deformações segundo as equações abaixo:

sendo:

$\varepsilon_{n}=$ Deformação Específica Gerada pela Variação de Resistência; 
$\varepsilon_{N}=$ Deformação Específica devido ao Esforço Axial;

$\varepsilon_{\mathrm{f}}=$ Deformação Específica devido ao Esforço de Flexão;

$\varepsilon_{\top}=$ Deformação Específica devido ao Esforço de Temperatura;

$\varepsilon_{\mathrm{i}}=$ Deformação Específica Total (fornecida pelo aparelho de medição);

$$
\begin{gathered}
\varepsilon_{l}=\varepsilon_{N}+\varepsilon_{f}+\varepsilon_{T} \\
\varepsilon_{2}=-v \cdot \varepsilon_{1}=-v\left(\varepsilon_{N}+\varepsilon_{f}\right)+\varepsilon_{T} \\
\varepsilon_{3}=\varepsilon_{N}-\varepsilon_{f}+\varepsilon_{T} \\
\varepsilon_{4}=-v \cdot \varepsilon_{3}=-\nu\left(\varepsilon_{N}-\varepsilon_{f}\right)+\varepsilon_{T}
\end{gathered}
$$

Com isso, aplicando-se a equação da ponte de Wheatstone, definida por:

$$
\varepsilon_{i}=\varepsilon_{1}-\varepsilon_{2}+\varepsilon_{3}-\varepsilon_{4}
$$

Chega-se à equação final, para cada par de strain-gage:

$$
\varepsilon_{N}=\frac{\varepsilon_{i}}{2 .(1+v)} \cong \frac{\varepsilon_{i}}{2,6}
$$

As vantagens do uso dos strain-gages estão no fato de proporcionar diretamente os valores das deformações específicas em cada nível instrumentado, além da precisão dos resultados, que é de $10^{-6} \mathrm{~mm}$. Como desvantagem pode-se citar que a montagem dos mesmos deve ser muito rigorosa, para que não haja erros no pareamento dos fios entre os strain-gages, o que poderia proporcionar resultados não adequados com a finalidade requerida; além do custo da aparelhagem necessária.

\subsubsection{Tell-Tales (Hastes Medidoras de Deslocamentos)}

De acordo com Perez (1997), os tell-tales possuem o objetivo de medir o encurtamento elástico do tubo onde foi instalado. O sistema consiste em tubos de 
PVC ou metálicos, com extremidades providas de rosca, interligadas por luvas, nos quais são colocadas as hastes e estas são engastadas apenas nos pontos onde se deseja conhecer os deslocamentos, (é prudente a colocação de hastes sempre que houver mudança nas camadas atravessadas pela estaca), os quais são registrados por meio de deflectômetros instalados no topo das hastes. Na Figura 2.10 pode-se ver a instrumentação.

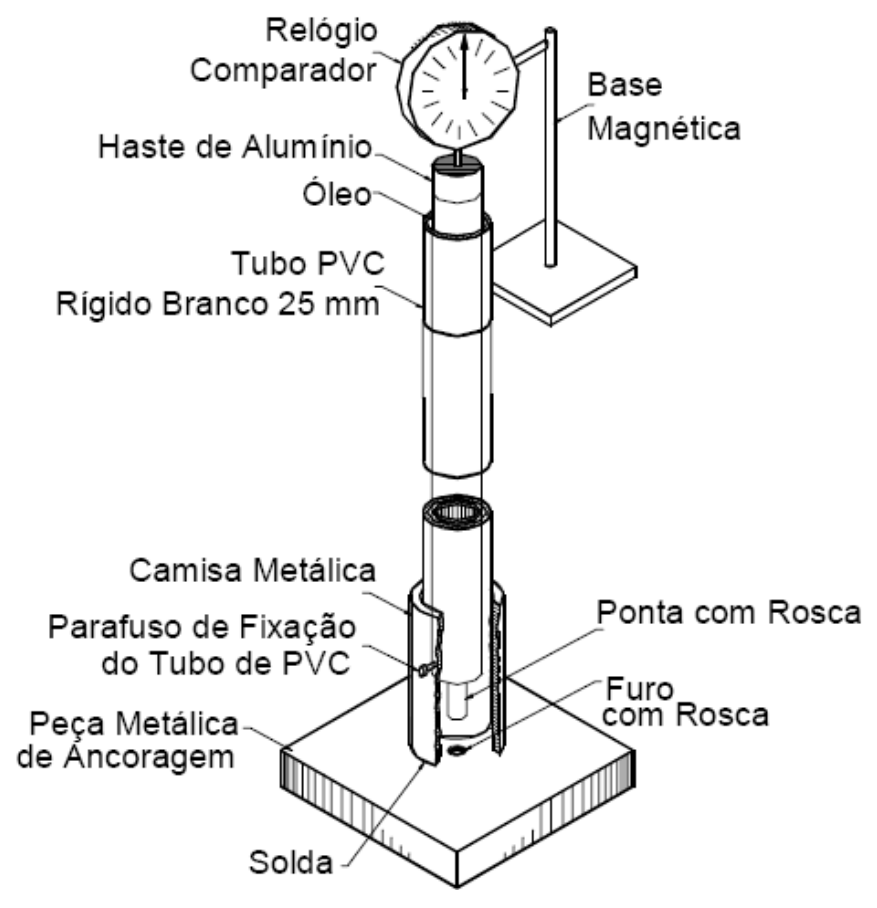

Figura 2.10 - Hastes Medidoras_Tell Tales (Nacano, 2001).

Embora os tell-tales forneçam uma medida mais direta, a qual pode ser lida diretamente dos relógios comparadores, o sistema possui precisão de $10^{-2} \mathrm{~mm}$ e não permite que pequenas deformações sejam medidas.

\subsubsection{Célula de Carga (Transdutor de Força)}

As células de carga são estruturas mecânicas, planejadas a receber esforços e deformar-se dentro do regime elástico a que foram dimensionadas.

São utilizadas para tração ou compressão, medindo esforços em prensas, cabos, dinamômetros, provas de cargas e etc. 
O princípio de funcionamento das células de carga baseia-se na variação da resistência ôhmica de um sensor, denominado extensômetro ou strain-gage, quando submetido a uma deformação. Comumente, utiliza-se a ponte de Wheatstone e o desbalanceamento da mesma, em virtude da deformação dos extensômetros, é proporcional à força que a provoca. Por meio desse desbalanceamento é que se obtém a força aplicada.

A força atua sobre o corpo da célula de carga e a sua deformação é transmitida aos extensômetros, que por sua vez medirão sua intensidade.

\subsubsection{Célula Expansiva Hidrodinâmica}

A célula expansiva, nomeada como Expancell, foi idealizada pelo engํㅜ civil Pedro Elísio C.A.F da Silva, mas passou a ser conhecida mundialmente como célula de Osterberg (O-cell).

Segundo da Silva (1986), a criação da nova técnica deveu-se à necessidade de quantificar as resistências do solo e das fundações, proporcionando um controle de qualidade para o projeto de fundações.

Alonso e da Silva (2000) relataram algumas vantagens na utilização da expancell, as quais estão listadas abaixo:

a.) Economia: a prova de carga com a célula é mais econômica que uma prova de carga à compressão tradicional;

b.) Carga de Ponta: sendo instalada nas proximidades da ponta da estaca, pode-se verificar a real capacidade dessa ponta;

c.) Carga de Atrito Lateral: pode-se determinar a adesão média do solo onde a estaca foi executada;

Esse sistema envolve a colocação de uma ou mais células perdidas, na base da estaca ou ao longo do fuste. Na Figura 2.11 é mostrado o sistema. 

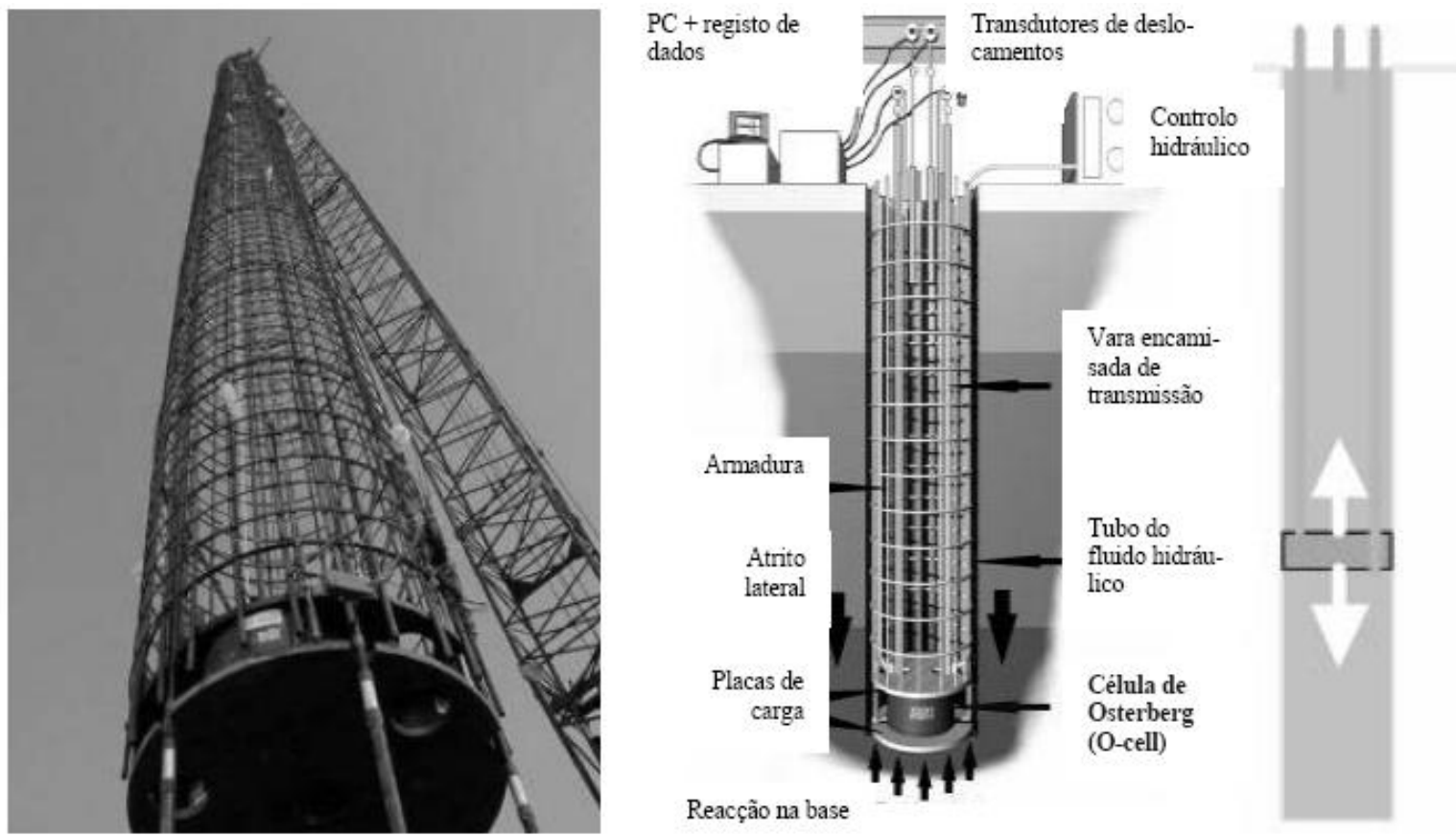

Figura 2.11 - Célula de Osterberg (Penteado e Brito, 2009).

No desenvolvimento do ensaio, especificamente para esse tipo, a célula expande-se hidraulicamente fazendo com que a parte superior da estaca reaja contra a parte inferior. Quando a célula é colocada na base da estaca, a reação é dada pelo solo sob a ponta da estaca. A carga é quantificada pela medição da pressão hidráulica exercida na estaca. Na Figura 2.12 é possível visualizar um detalhe da célula expansiva.

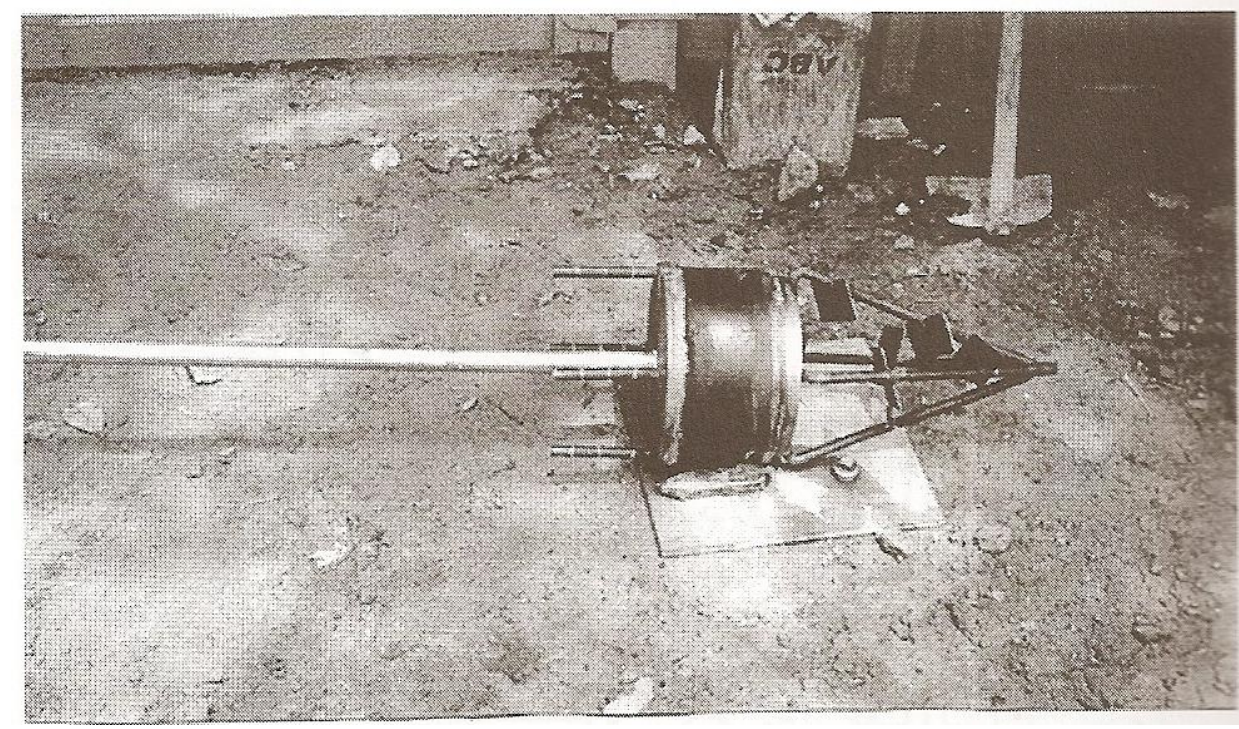

Figura 2.12 - Detalhe do dispositivo acoplado à base da célula Expancell (Alonso e da Silva, 2000). 
Já na Figura 2.13, é mostrado o esquema da transferência de carga por meio da célula expansiva e a curva carga vs recalque no topo sugerida.
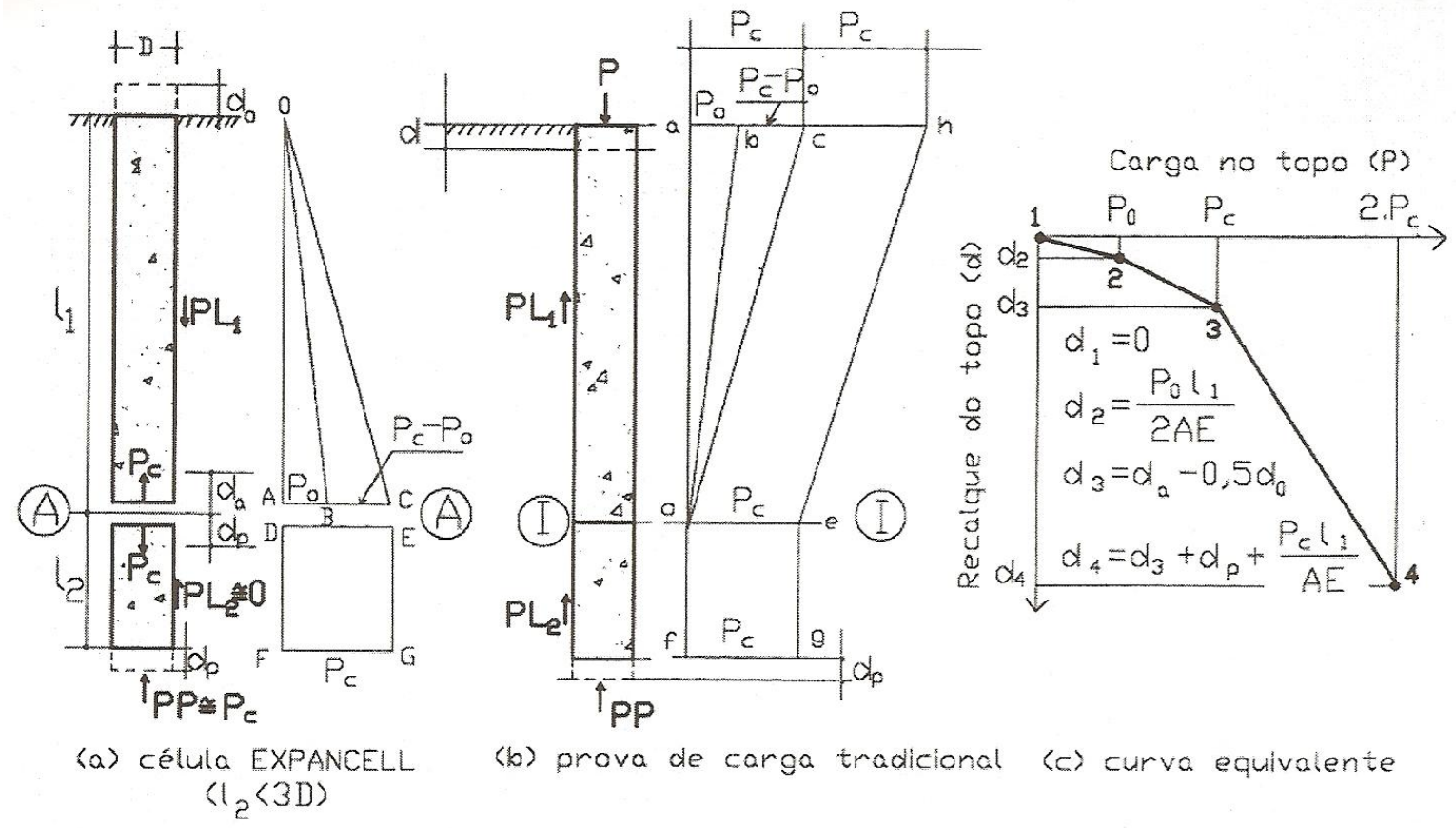

Figura 2.13 - Transferência de Carga e Curva Equivalente (Alonso e da Silva, 2000).

\subsubsection{Micrômetro Deslizante (Torpedo Kovary)}

O micrômetro deslizante, desenvolvido pela Seção de Obras em Rochas do ISETH, da Escola Politécnica de Zurich (Rottman, 1985), permite a determinação segura de componentes axiais de deslocamentos ao longo de eixos retilíneos no interior de concreto, rocha ou solo.

Em um furo de $10 \mathrm{~cm}$ de diâmetro são fixadas fortemente, por meio de injeções, marcas de referência a cada metro, ligadas entre si por um tubo protetor.

A sonda, associada a hastes metálicas (até $50 \mathrm{~m}$ de comprimento), é introduzida no tubo e levada, passo a passo, às marcas de referência. Mediante uma rotação de $45^{\circ}$ e tração do conjunto haste-sonda consegue-se posicionar os cabeçotes de medição entre duas marcas de referência consecutivas. Então, um transdutor indutivo, instalado na sonda, fornece os valores de medição transmitidos por cabo ao aparelho digital de leitura. 


\subsubsection{Casos de Estacões Instrumentados Divulgados na Literatura Técnica}

A seguir, na Tabela 2.3, são listados alguns casos recentes de instrumentações no topo e fuste em estacas escavadas de grande diâmetro. A lista somente abrange casos de estacões instrumentados em profundidade, conforme escopo do trabalho.

Tabela 2.3 - Casos de Estacões Instrumentados divulgados na literatura técnica.

\begin{tabular}{|c|c|c|c|c|c|c|}
\hline \multirow{2}{*}{ Nome } & \multirow{2}{*}{ Local } & \multirow{2}{*}{ Diâmetro } & \multirow{2}{*}{ Ano } & \multicolumn{2}{|c|}{ Tipo de Instrumentação } & \multirow{2}{*}{ Referência } \\
\hline & & & & Topo & Fuste & \\
\hline E9 & $\begin{array}{c}\text { Campo Experimental } \\
\text { da FEUP (ISC'2), } \\
\text { Porto }\end{array}$ & $60 \mathrm{~cm}$ & & $\begin{array}{l}\text { Deflectômetros e } \\
\text { Célula de Carga } \\
\text { Elétrica }\end{array}$ & $\begin{array}{l}5 \text { niveis com } \\
\text { extensômetros } \\
\text { removiveis }\end{array}$ & $\begin{array}{l}\text { Costa Esteves, } 2005 \\
\text { apud VIANA DA } \\
\text { FONSECA, } 2007\end{array}$ \\
\hline $\begin{array}{l}\text { Estaca } \\
\text { Protótipo }\end{array}$ & $\begin{array}{c}\text { Oceanário da Expo' } \\
\text { 98, Lisboa }\end{array}$ & & & & $\begin{array}{l}\text { Extensômetros de } \\
\text { resistência e Transdutor } \\
\text { de força na ponta }\end{array}$ & $\begin{array}{l}\text { Proença et al., } 1997 \\
\text { apud VIANA DA } \\
\text { FONSECA, } 2007\end{array}$ \\
\hline \multirow[t]{5}{*}{$\begin{array}{l}\text { P8 - P31 - } \\
\text { P79 - P311 }\end{array}$} & $\begin{array}{l}\text { Ponte Vasco da } \\
\text { Gama, Lisboa }\end{array}$ & & & & & $\begin{array}{c}\text { Seco e Pinto e } \\
\text { Oliveira, } 1998 \text { apud } \\
\text { VIANA DA } \\
\text { FONSECA, } 2007\end{array}$ \\
\hline & $\begin{array}{c}\text { Pavilhão de Portugal, } \\
\text { Lisboa }\end{array}$ & & & & $\begin{array}{l}\text { Sensores fixos e } \\
\text { removiveis }\end{array}$ & $\begin{array}{l}\text { Souza Coutinho et } \\
\text { al., } 2000 \text { apud VIANA } \\
\text { DA FONSECA, } 2007\end{array}$ \\
\hline & $\begin{array}{c}\text { Ponte Salgueiro Maia, } \\
\text { Santarém }\end{array}$ & $80 \mathrm{~cm}$ & & Deflectômetros & $\begin{array}{l}\text { Extensômetros } \\
\text { removiveis }\end{array}$ & $\begin{array}{l}\text { AGISCO - LCPC, } \\
1995 \text { apud VIANA DA } \\
\text { FONSECA, } 2007\end{array}$ \\
\hline & $\begin{array}{l}\text { Casa da Música, } \\
\text { Porto }\end{array}$ & $\begin{array}{l}80 \mathrm{~cm} \mathrm{e} \\
130 \mathrm{~cm}\end{array}$ & 2000 & Deflectômetros & & $\begin{array}{l}\text { Gaba et al., } 2004 \\
\text { apud VIANA DA } \\
\text { FONSECA, } 2007\end{array}$ \\
\hline & $\begin{array}{c}\text { IP6 Viadutos na } \\
\text { Ligação Peniche - A8, } \\
\text { Portugal }\end{array}$ & $80 \mathrm{~cm}$ & 2005 & Deflectômetros & $\begin{array}{l}\text { Barras extensiométricas } \\
\quad \text { (Strain-Gages) }\end{array}$ & $\begin{array}{c}\text { VIANA DA } \\
\text { FONSECA, } 2007\end{array}$ \\
\hline \multirow[t]{4}{*}{ E5 } & $\begin{array}{l}\text { Campo Experimental } \\
\text { Santo Estevão, } \\
\text { Pegões }\end{array}$ & $60 \mathrm{~cm}$ & & Deflectômetros & $\begin{array}{l}\text { Extensômetros de } \\
\text { resistência e Transdutor } \\
\text { de força na ponta }\end{array}$ & $\begin{array}{c}\text { Gouveia Pereira, } \\
2003 \text { apud VIANA DA } \\
\text { FONSECA, } 2007\end{array}$ \\
\hline & $\begin{array}{l}\text { Viaduto de Santana } \\
\text { Cartaxo, Santarém }\end{array}$ & $80 \mathrm{~cm}$ & 2003 & & $\begin{array}{c}\text { Extensômetros de corda } \\
\text { vibrante }\end{array}$ & $\begin{array}{c}\text { VIANA DA } \\
\text { FONSECA, } 2007\end{array}$ \\
\hline & $\begin{array}{c}\text { Travessia do Rio Tejo, } \\
\text { Carregado }\end{array}$ & $\begin{array}{l}80 \mathrm{~cm} \mathrm{e} \\
150 \mathrm{~cm}\end{array}$ & & & & $\begin{array}{l}\text { Santos et al., } 2006 \\
\text { apud VIANA DA } \\
\text { FONSECA, } 2007\end{array}$ \\
\hline & Porto do Rio Grande & $60 \mathrm{~cm}$ & 1979 & & $\begin{array}{c}\text { Strain-Gages e Tell- } \\
\text { Tales }\end{array}$ & $\begin{array}{l}\text { Rin, P.D; Barros, } \\
\text { L.A. e Mello, } \\
\text { L.G.F.S., } 1983\end{array}$ \\
\hline PC4 & Vitória - ES & $120 \mathrm{~cm}$ & 1982 & & Tell-Tales & Souza, R.N., 1996 \\
\hline PC7 & Ouro Branco - MG & $100 \mathrm{~cm}$ & 1982 & & Tell-Tales & Souza, R.N., 1996 \\
\hline \multirow[t]{5}{*}{$\mathrm{PC} 12$} & $\begin{array}{c}\text { Campo Experimental } \\
\text { da USP }\end{array}$ & $70 \mathrm{~cm}$ & 1989 & & Tell-Tales & Souza, R.N., 1996 \\
\hline & $\begin{array}{c}\text { Ponte sobre o Rio } \\
\text { Tagus, Carregado, } \\
\text { Portugal }\end{array}$ & $80 \mathrm{~cm}$ & 2006 & Deflectômetros & $\begin{array}{l}\text { Extensômetros } \\
\text { removiveis }\end{array}$ & Caputo, A., 2008 \\
\hline & $\begin{array}{c}\text { Ponte Carlos Perez } \\
\text { Perasso, Guayaquil, } \\
\text { Equador }\end{array}$ & $250 \mathrm{~cm}$ & & & Célula de Osterberg & $\begin{array}{l}\text { Mello, L.G., Robbe, } \\
\text { G. e Bilfinger, W., } \\
2008\end{array}$ \\
\hline & $\begin{array}{c}\text { Tunel HST, Antwerp - } \\
\text { Bélgica }\end{array}$ & $150 \mathrm{~cm}$ & & & & $\begin{array}{l}\text { Maertens, J., Theys, } \\
\text { F. e Maekelberg, W., } \\
2003\end{array}$ \\
\hline & Malásia & $120 \mathrm{~cm}$ & & & & $\begin{array}{l}\text { Jamaludin, A., } \\
\text { Hussein, A.N., } 1998\end{array}$ \\
\hline PC1 - PC2 & Distrito Federal, Brasil & $60 \mathrm{~cm}$ & & & Deflectômetros elétricos & Carvalho et al., 2002 \\
\hline
\end{tabular}


De acordo com a Tabela 2.3 pode-se perceber que os tipos de instrumentação mais utilizados internacionalmente têm sido os extensômetros elétricos de resistência "strain gages", aliados às células de carga na ponta; e os tell-tales, utilizados mais no âmbito nacional.

Note que os ensaios internacionais citados são razoavelmente recentes, daí a utilização mais difundida do strain gage e o fato de proporcionar, como resultado final, as próprias deformações específicas, que serão utilizadas como input para todos os cálculos desejados.

Por seu lado, os ensaios nacionais possuem datas mais antigas, período no qual os strain-gages não eram tão utilizados e muito provavelmente, ainda muito caros para serem adquiridos. Por isso, as hastes medidoras de deslocamentos (tell-tales) foram muito utilizadas.

\subsection{Métodos Semi-Empíricos de Capacidade de Carga}

Para a estimativa dos comprimentos dos estacões utilizou-se dois dos métodos mais difundidos na literatura e que possuem ampla aceitação no meio técnico: o Método de Décourt\&Quaresma (1978) e Décourt (1998) e Aoki-Velloso (1975).

\subsubsection{Método Décourt\&Quaresma (1978) e Décourt (1998)}

O método proposto por Décourt e Quaresma (1978) baseia-se nos resultados obtidos pelo ensaio de penetração dinâmica SPT (Standard Penetration Test), os quais proporcionam as resistências de ponta e de atrito, para fornecer a capacidade de carga para a estaca padrão, ou seja, estacas de deslocamento. Mais recentemente, Décourt (1998), com a implementação dos coeficientes $\alpha$ e $\beta$, proporcionou a extensão do método para outros tipos de estacas e com o conceito de $\mathrm{N}$ equivalente ( $\mathrm{N}_{\mathrm{eq}}$ ) (2002), que é o torque medido em kgf.m dividido por 1,2, a 
aplicação do método tem mostrado resultados muito mais precisos (informação verbal) ${ }^{1}$. A formulação do método segue abaixo:

$$
Q_{u}=\alpha \cdot q_{P} \cdot S_{P}+\beta \cdot q_{L} \cdot S_{L}
$$

onde:

$$
\begin{aligned}
& Q_{u}=\text { Carga de Ruptura da Estaca }[F] ; \\
& q_{P}=\text { Resistência de Ponta da Estaca }\left[\mathrm{FL}^{-2}\right] ; \\
& q_{L}=\text { Resistência Lateral ou Atrito Lateral Unitário }\left[\mathrm{FL}^{-2}\right] ; \\
& S_{P}=\text { Área de Ponta da Estaca }\left[\mathrm{L}^{2}\right] ; \\
& S_{L}=\text { Área Lateral da Estaca }\left[\mathrm{L}^{2}\right] ; \\
& \alpha, \beta=\text { Coeficientes função do tipo de solo e do tipo da estaca para a } \\
& \text { ponta e o atrito, respectivamente; }
\end{aligned}
$$

E a resistência de ponta e o atrito lateral unitário podem ser escritos da seguinte forma:

$$
\begin{gathered}
q_{P}=K \cdot N \\
q_{L}=10 \cdot\left(\frac{N}{3}+1\right) \quad \mathrm{kPa}
\end{gathered}
$$

onde:

$\mathrm{K}$ = Coeficiente função do tipo de solo no qual a ponta está assentada;

$\mathrm{N}=$ Número de golpes obtidos no ensaio SPT;

Tabela 2.4 - Valores do Coeficiente K em função do tipo de solo (Décourt, 1998).

\begin{tabular}{lc}
\hline \multicolumn{1}{c}{ Tipo de Solo } & K [kPa] \\
\hline Argila & 120 \\
Silte argiloso (solo residual) & 200 \\
Silte arenoso (solo residual) & 250 \\
Areia & 400 \\
\hline
\end{tabular}

\footnotetext{
${ }^{1}$ Informação fornecida pelo engo Luciano Décourt, na EPUSP, durante o curso de PEF 5821 Estacas Verticais Submetidas a Esforços Axiais, ministrado pelo prof ${ }^{\mathrm{a}}$ Dro $^{\circ}$ Faiçal Massad, em 2006
} 
Tabela 2.5 - Valores do Coeficiente a em função do tipo de solo (Décourt, 1998).

\begin{tabular}{lccccc}
\hline \multirow{2}{*}{ Tipo de Solo } & $\begin{array}{c}\text { Escavada } \\
\text { em geral }\end{array}$ & $\begin{array}{c}\text { Escavada com } \\
\text { bentonita }\end{array}$ & $\begin{array}{c}\text { Hélice } \\
\text { Contínua }\end{array}$ & Raiz & $\begin{array}{c}\text { Injetadas sob } \\
\text { altas pressões }\end{array}$ \\
\hline Argila & 0,85 & 0,85 & $0,30^{*}$ & $0,85^{*}$ & $1,00^{*}$ \\
Solos Intermediários & 0,60 & 0,60 & $0,30^{*}$ & $0,60^{*}$ & $1,00^{*}$ \\
Areias & 0,50 & 0,50 & $0,30^{*}$ & $0,50^{*}$ & $1,00^{*}$ \\
* Valores apenas orientativos diante do reduzido número de dados disponíveis & \\
\hline
\end{tabular}

Tabela 2.6 - Valores do Coeficiente $\beta$ em função do tipo de solo (Décourt, 1998).

\begin{tabular}{lccccc}
\hline \multirow{2}{*}{ Tipo de Solo } & \multicolumn{4}{c}{ Tipos de Estacas } \\
\cline { 2 - 6 } & $\begin{array}{c}\text { Escavada } \\
\text { em geral }\end{array}$ & $\begin{array}{c}\text { Escavada com } \\
\text { bentonita }\end{array}$ & $\begin{array}{c}\text { Hélice } \\
\text { Contínua }\end{array}$ & Raiz & $\begin{array}{c}\text { Injetadas sob } \\
\text { altas pressões }\end{array}$ \\
\hline Argila & 0,80 & $0,90^{*}$ & $1,00^{*}$ & $1,50^{*}$ & $3,00^{*}$ \\
Solos Intermediários & 0,65 & $0,75^{*}$ & $1,00^{*}$ & $1,50^{*}$ & $3,00^{*}$ \\
Areias & 0,50 & $0,60^{*}$ & $1,00^{*}$ & $1,50^{*}$ & $3,00^{*}$ \\
* Valores apenas orientativos diante do reduzido número de dados disponíveis \\
\hline
\end{tabular}

Para a determinação da carga admissível a ser adotada nos projetos de engenharia, Décourt\&Quaresma (1978) propuseram o seguinte fator de segurança global, composto das seguintes parcelas:

$$
F=F_{p} \cdot F_{f} \cdot F_{d} \cdot F_{w}
$$

onde:

$$
\begin{aligned}
& \mathrm{F}=\text { Fator de segurança global; } \\
& F_{p}=\text { Fator de segurança relativo aos parâmetros do solo } \\
& F_{p}=1,10 \text { para } 0 \text { atrito lateral; } \\
& F_{p}=1,35 \text { para a resistência de ponta; } \\
& F_{f}=\text { Fator de segurança relativo à formulação adotada }\left(F_{f}=1,00\right) \text {; } \\
& F_{d}=\text { Fator de segurança para evitar recalques excessivos; }
\end{aligned}
$$


$F_{d}=1,00$ para o atrito lateral;

$F_{d}=2,50$ para a resistência de ponta;

$F_{\mathrm{w}}=$ Fator de segurança relativo à carga de trabalho da estaca $(1,20)$;

Como os fatores parciais estão definidos, podem-se obter os fatores de segurança para o atrito e para a ponta, respectivamente:

$$
\begin{gathered}
F_{L}=1,10 \cdot 1,00 \cdot 1,00 \cdot 1,20=1,32 \cong 1,30 \\
F_{P}=1,35 \cdot 1,00 \cdot 2,50 \cdot 1,20=4,05 \cong 4,00
\end{gathered}
$$

Com isso, a carga admissível a ser adotada segue a formulação abaixo:

$$
Q_{a d m}=\frac{\alpha \cdot q_{P} \cdot S_{P}}{4,0}+\frac{\beta \cdot q_{L} \cdot S_{L}}{1,3}
$$

No entanto, a NBR 6122/1996 preconiza que a carga admissível é a metade da soma das parcelas de atrito lateral e ponta, conforme Equação (2.18).

$$
Q_{a d m}=\frac{\alpha \cdot q_{P} \cdot S_{P}+\beta \cdot q_{L} \cdot S_{L}}{2}
$$

Para finalizar, os autores mostram um gráfico relacionando as cargas admissíveis calculadas e medidas para estacas pré-moldadas de concreto, apoiadas em solos argilosos, arenosos, silto argilosos e silto arenoso. Também são mostradas estacas escavadas com ponta em material argiloso. 


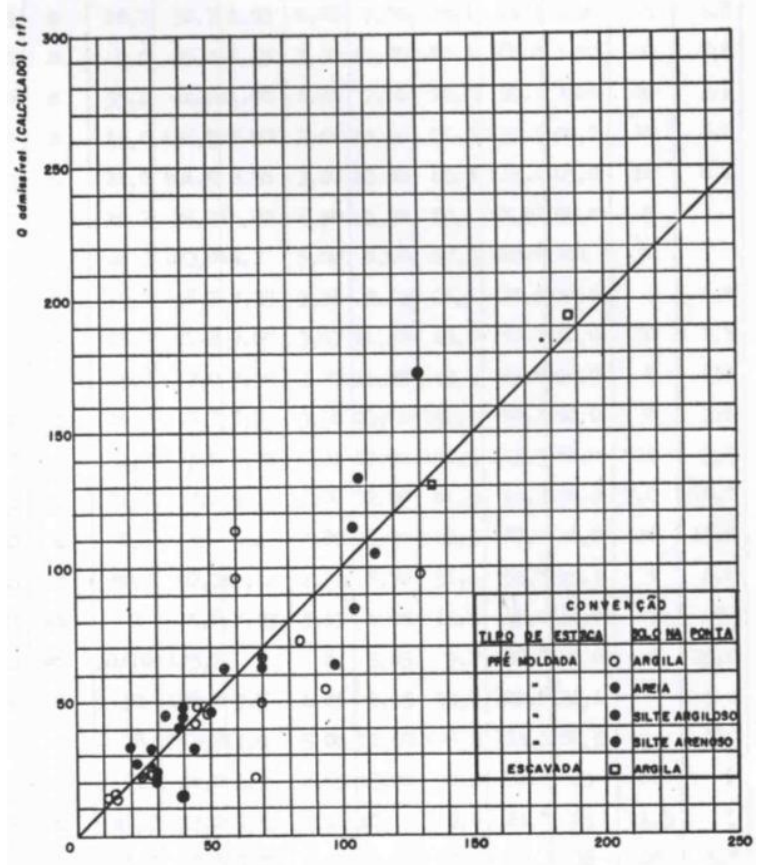

- oeminiver (mova) (in)

Figura 2.14 - Relação entre a Carga Admissível Calculada e Carga Admissível da Prova pelo Método de Décourt\&Quaresma (Décourt e Quaresma, 1978).

\subsubsection{Método Aoki\&Velloso (1975)}

O método proposto por Aoki e Velloso (1975) baseia-se nos resultados obtidos pelo ensaio de penetração estática do cone, CPT e nas correlações existentes entre esse ensaio e o ensaio de penetração dinâmico, SPT. A Figura 2.15 mostra o esquema explicativo para a formulação do método:

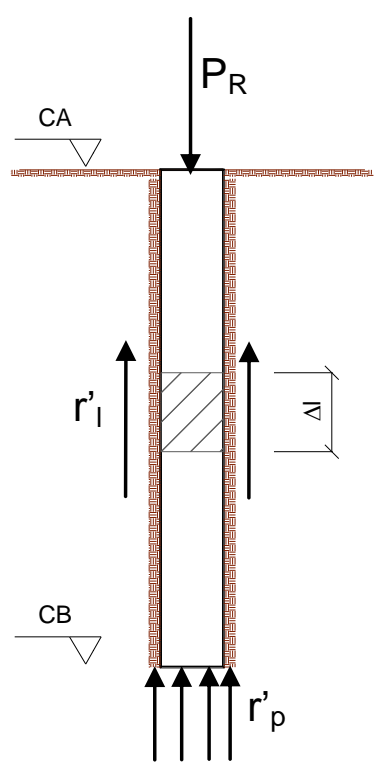

Figura 2.15 - Esquema de forças e tensões atuantes na estaca (Aoki e Velloso, 1975). 
onde:

$$
\begin{aligned}
& \mathrm{P}_{\mathrm{R}}=\text { Carga de Ruptura da Estaca }[\mathrm{F}] \\
& \mathrm{P}_{\mathrm{L}}=\text { Carga Lateral da Estaca }[\mathrm{F}] \\
& \mathrm{P}_{\mathrm{P}}=\text { Carga de Ponta da Estaca }[\mathrm{F}] \\
& \mathrm{r}_{\mathrm{P}}^{\prime}=\text { Resistência de Ponta da Estaca }\left[\mathrm{FL}^{-2}\right] ; \\
& \mathrm{r}_{\mathrm{L}}^{\prime}=\text { Resistência Lateral ou Atrito Lateral Unitário }\left[\mathrm{FL}^{-2}\right] ; \\
& \mathrm{S}_{\mathrm{P}}=\text { Área de Ponta da Estaca }\left[\mathrm{L}^{2}\right] ; \\
& \mathrm{U}=\text { Perímetro da Estaca }[\mathrm{L}]
\end{aligned}
$$

Com a definição dada acima, é possível escrever a equação (2.19):

$$
P_{R}=S_{P} \cdot r_{P}^{\prime}+\sum_{C A}^{C B} U \cdot \Delta l \cdot r_{L}^{\prime}
$$

Como na prática da engenharia brasileira não é comum a adoção de ensaios de cone, faz-se necessária a utilização de correlações que permitam a utilização dos dados obtidos no SPT. Então, foram definidas as seguintes equações.

$$
\begin{gathered}
r_{P}=K . N_{S P T} \\
r_{L}=\alpha \cdot r_{P}
\end{gathered}
$$

Os valores dos parâmetros $\mathrm{K}$ e a estão expressos na Tabela 2.7 em função do tipo de solo. 
Tabela 2.7 - Valores dos parâmetros K e a em função do tipo de solo (Aoki e Velloso, 1975).

\begin{tabular}{lccc}
\hline \multicolumn{1}{c}{ Solo } & Simbologia & $\mathbf{K}(\mathbf{k P a})$ & $\alpha(\%)$ \\
\hline Areia & 100 & 1000,0 & 1,4 \\
Areia Siltosa & 120 & 800,0 & 2,0 \\
Areia Silto Argilosa & 123 & 700,0 & 2,4 \\
Areia Argilosa & 130 & 600,0 & 3,0 \\
Areia Argilo Siltosa & 132 & 500,0 & 2,8 \\
Silte & 200 & 400,0 & 3,0 \\
Silte Arenoso & 210 & 550,0 & 2,2 \\
Silte Areno Argiloso & 213 & 450,0 & 2,8 \\
Silte Argiloso & 230 & 230,0 & 3,4 \\
Silte Argilo Arenoso & 231 & 250,0 & 3,0 \\
Argila & 300 & 200,0 & 6,0 \\
Argila Arenosa & 310 & 350,0 & 2,4 \\
Argila Areno Siltosa & 312 & 300,0 & 2,8 \\
Argila Siltosa & 320 & 220,0 & 4,0 \\
Argila Silto Arenosa & 321 & 330,0 & 3,0 \\
\hline
\end{tabular}

Com o intuito de considerar as diferenças existentes no comportamento a estaca padrão e os outros tipos foram definidos os fatores $F_{1}$ e $F_{2}$.

$$
\begin{gathered}
r_{P}^{\prime}=\frac{r_{P}}{F_{1}}=\frac{K \cdot N_{S P T}}{F_{1}} \\
r_{L}^{\prime}=\frac{r_{L}}{F_{2}}=\frac{\alpha \cdot r_{P}}{F_{2}}=\frac{\alpha \cdot K \cdot N_{S P T}}{F_{2}}
\end{gathered}
$$

Os valores dos parâmetros $F_{1}$ e $F_{2}$ estão expressos na Tabela 2.8.

Tabela 2.8 - Valores dos parâmetros F1 e F2 em função do tipo da estaca (Aoki e Velloso, 1975).

\begin{tabular}{lcc}
\hline \multicolumn{1}{c}{ Tipo da Estaca } & F1 & F2 \\
\hline Pré-Moldada de Concreto & 1,75 & 3,50 \\
Metálica & 1,75 & 3,50 \\
Franki & 2,50 & 5,00 \\
Escavada & 3,00 & 6,00 \\
\hline
\end{tabular}

Enfim, como todas as parcelas estão definidas, pode-se escrever a formulação do método como se segue. 


$$
P_{R}=S_{P} \cdot \frac{K \cdot N_{S P T}}{F_{1}}+\sum_{C A}^{C B} U \cdot \Delta l \cdot \frac{\alpha \cdot K \cdot N_{S P T}}{F_{2}}
$$

\subsection{Métodos de Interpretação da Curva $P_{0} \times y_{0}$}

Os métodos que serão abordados nesse trabalho são os cinco métodos indicados em Fellenius (2001), os quais são: Davisson (1972), De Beer (1968), Brinch-Hansen 80\% (1963), Chin-Kondner (1970; 1971 - modificação proposta no trabalho de Kondner (1963)) e Décourt (1996). Também serão mostrados os métodos de Van der Veen (1953), Mazurkiewcz (1972), Butler\&Roy (1977) e o da norma brasileira de fundações (1996). Além desses métodos, serão estudadas as relações modificadas de Cambefort (1964) e o Método das Duas Retas, segundo Massad e Lazo (1998).

\subsubsection{Método da Rigidez (Décourt, 1996)}

O método proposto por Décourt (1996), denominado como Método da Rigidez, utiliza-se do conceito de rigidez, que é a relação entre a carga aplicada no topo da estaca e o respectivo recalque. Com isso, pode-se elaborar um gráfico, no qual a abscissa representa a carga aplicada e a ordenada, a rigidez, já explicada anteriormente.

Do gráfico construído é possível obter dois tipos de ruptura:

a.) Ruptura Física. É a ruptura caracterizada quando a estaca apresentar rigidez nula, que seria uma deformação infinita para uma dada carga aplicada, o que, na prática da engenharia, é impossível;

b.) Ruptura Convencional. É a ruptura definida para um recalque do topo da estaca de $10 \%$ do diâmetro da mesma.

A Figura 2.16 mostra um caso de uma prova de carga numa estaca pré-moldada de concreto (estaca de deslocamento), com a rigidez decrescendo com o aumento da carga aplicada. 


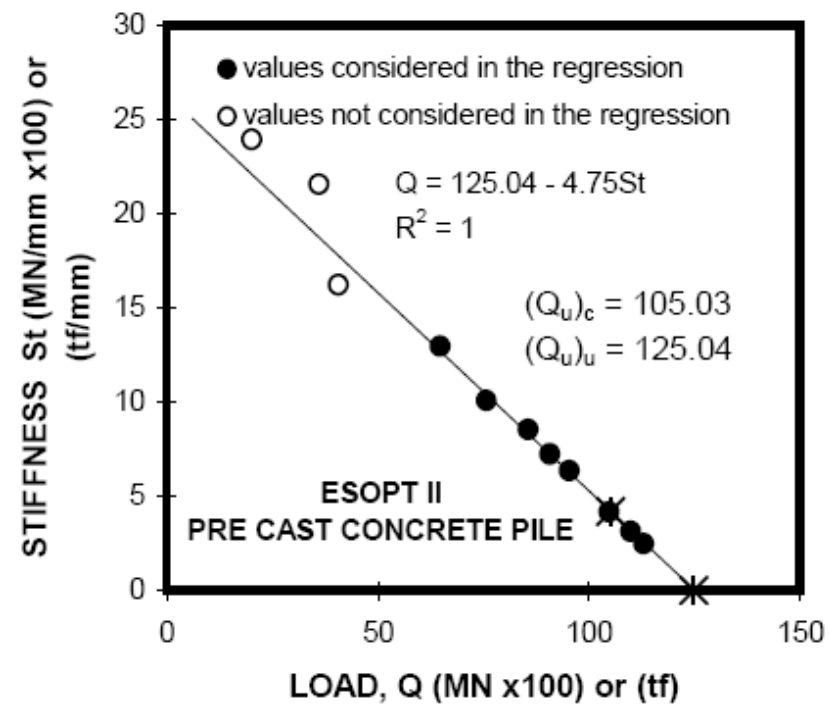

Figura 2.16 - Rupturas Convencional e Física numa estaca pré-moldada (Décourt, 2008).

É bastante usual as estacas de deslocamento alcançarem a ruptura física, ou pelo menos chegar muito próximo da mesma. Por outro lado, para as sapatas e estacas escavadas em geral, percebe-se outro comportamento, ou seja, nesses dois grupos não é possível notar a ruptura física, pois o gráfico tende a uma assíntota horizontal e não assume rigidez nula. Isto posto pode ser visto na Figura 2.17.

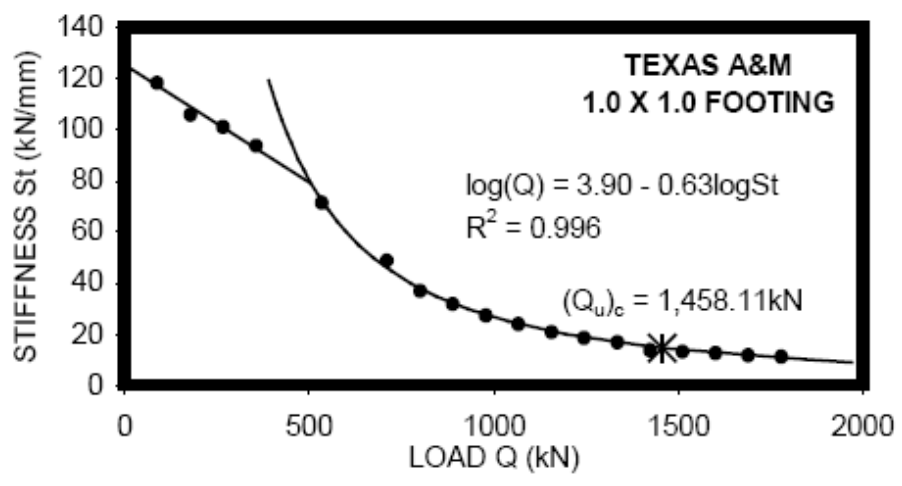

Figura 2.17. Gráfico de Rigidez para Fundação Direta (sapata) (Décourt, 2008).

Segundo Décourt (1996) "o gráfico de rigidez permite visualizar claramente a que distância se está da ruptura física, que por sua vez é definida de forma clara e precisa, por extrapolação linear ou logarítmica, como sendo o ponto de carga da curva $\mathrm{R}$ vs $\mathrm{Q}$ correspondente à rigidez nula". 
Em uma das atualizações do seu método, Décourt (2008) apresentou uma proposta de separar as parcelas com predominância da ponta e do atrito. Segundo Décourt, em uma prova de carga, na qual os carregamentos foram conduzidos até grandes deformações, os dois domínios serão facilmente identificados: no trecho onde a transferência por ponta é predominante (upper bound), a relação entre a carga e a rigidez é uma curva, tornando-se linear em um gráfico log x log. Já no trecho onde ocorre a predominância do atrito lateral (lower bound), essa relação é linear.

Na Figura 2.18 podemos ver o método aplicado.

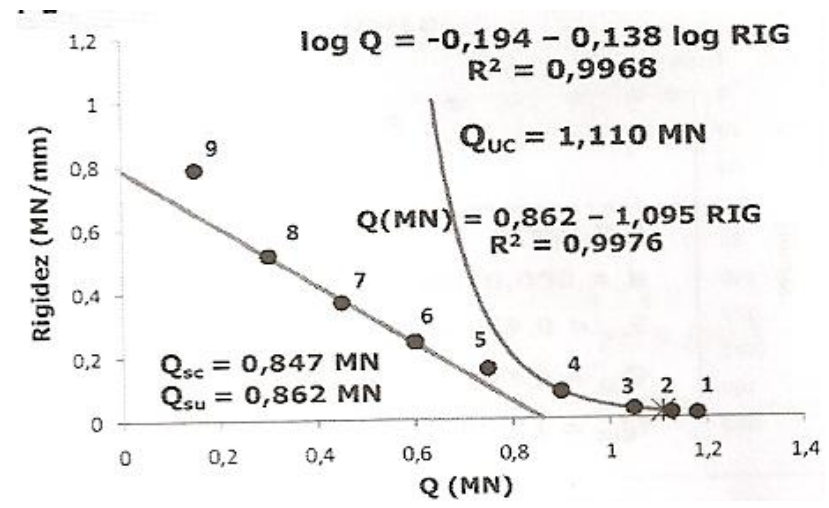

Figura 2.18. Método da Rigidez_Limites Inferior (lower bound) e Superior (upper bound) (Décourt, 2008).

\subsubsection{Método de Chin-Kondner (1963; 1970; 1971)}

O método proposto por Chin $(1970 ; 1971)$, em um estudo baseado no trabalho de Kondner (1963), possibilita a extrapolação da carga de ruptura em ambos os ensaios estáticos de prova de carga, ou seja, ensaios do tipo lento e rápido. O método consiste em dividir cada recalque pela respectiva carga aplicada e colocá-lo no eixo das ordenadas. Por sua vez, no eixo das abscissas, colocam-se os recalques obtidos durante a prova de carga estática. Na Figura 2.19 é mostrado um gráfico típico da aplicação do método. 


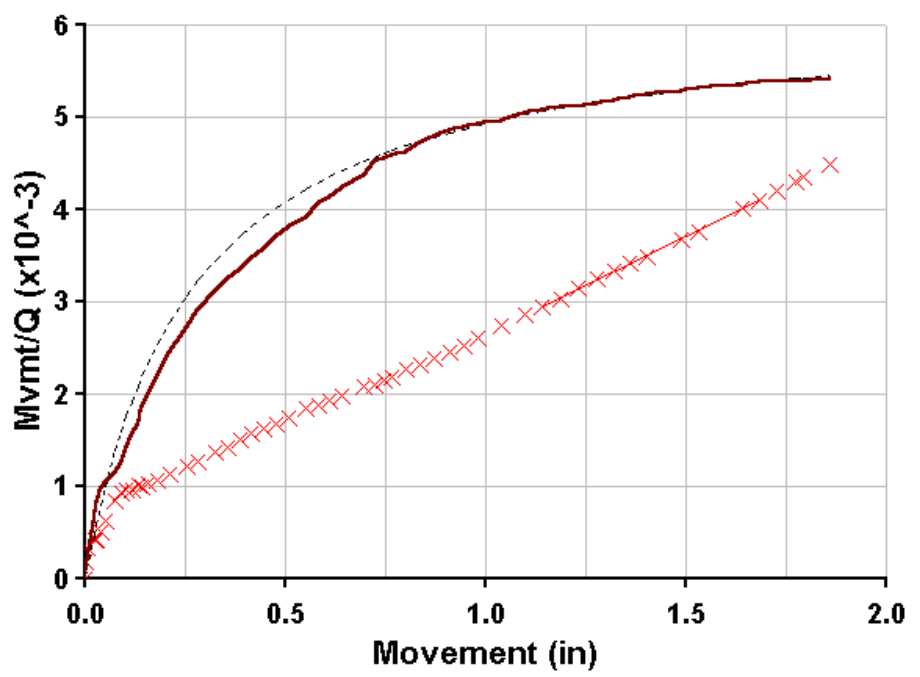

Figura 2.19. Método de Extrapolação proposto por Chin-Kondner (Fellenius, 2006).

A carga limite última é dada como o inverso da inclinação da linha formada pelos pontos plotados "cruzes vermelhas" no gráfico, de acordo com a equação (2.25).

$$
Q_{u}=\frac{1}{C_{1}}
$$

Já a curva ideal, representada também na Figura 2.19, possui a seguinte equação:

$$
Q=\frac{\delta}{C_{1} \cdot \delta+C_{2}}
$$

onde:

$Q=$ Carga Aplicada $[F]$;

$\mathrm{Q}_{\mathrm{u}}=$ Carga Limite Última $[\mathrm{F}]$;

$\mathrm{C}_{1}=$ Inclinação da Linha reta $\left[\mathrm{F}^{-1}\right]$;

$\mathrm{C}_{2}=$ Intersecção com o eixo $\mathrm{Y}\left[\mathrm{LF}^{-1}\right]$;

$\delta=$ Recalque correspondente à carga aplicada [L];

\subsubsection{Método de Davisson (1972)}

O método proposto por Davisson (1972), conhecido como Offset Limit, pressupõe que a carga limite é dada por uma equação dependente do diâmetro da estaca e 
que exceda a compressão elástica da estaca em $4 \mathrm{~mm}$. A formulação do método está indicada a seguir.

$$
\rho=\left(4+\frac{b}{120}\right)+\frac{Q . L}{E . S}
$$

onde:

$$
\begin{aligned}
& \rho=\text { Recalque para uma dada carga aplicada }[\mathrm{mm}] \\
& \mathrm{b}=\text { Diâmetro da estaca }[\mathrm{mm}] \\
& \mathrm{L}=\text { Comprimento da estaca }[\mathrm{mm}] \\
& \mathrm{Q}=\text { Carga Aplicada }[\mathrm{kN}] \\
& \mathrm{E}=\text { Módulo de Young da estaca }\left[\mathrm{kN} / \mathrm{m}^{2}\right] \\
& \mathrm{S}=\text { Área da Seção Transversal da estaca }\left[\mathrm{m}^{2}\right]
\end{aligned}
$$

Na Figura 2.20 é possível visualizar a curva carga vs recalque para uma estaca prémoldada de concreto de $12 "(30,5 \mathrm{~cm})$ de diâmetro, para a qual o OS foi de $0,25 "$ (6mm), o que correspondeu a uma carga de 375Kips (1668kN). 


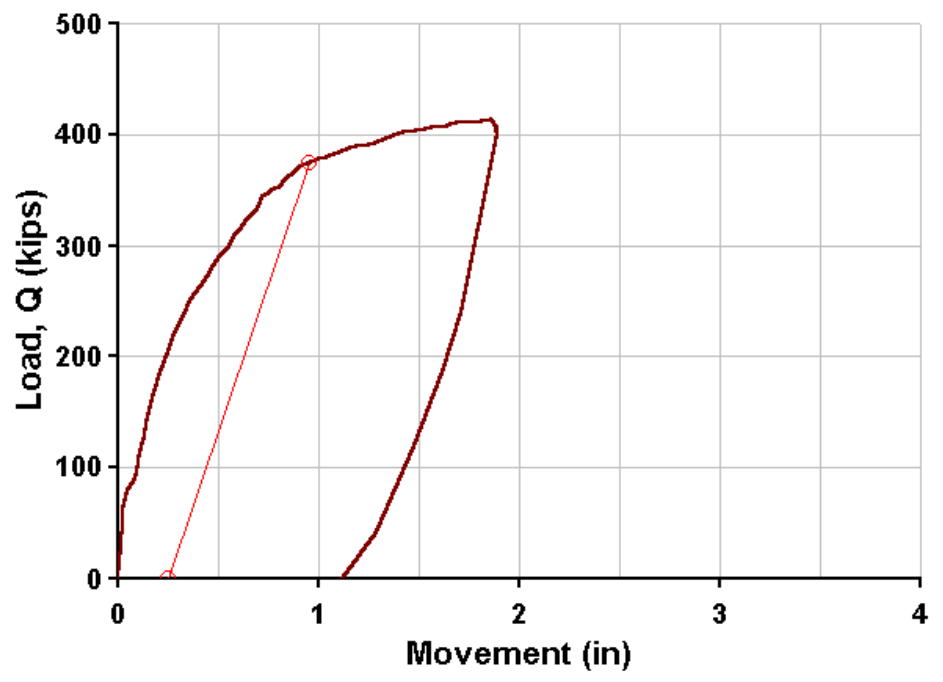

Figura 2.20. Método de Extrapolação proposto por Chin-Kondner (Fellenius, 2006).

\subsubsection{Método Baseado nas Relações de Cambefort Modificadas}

O estudo das estacas escavadas submetidas a esforços axiais pode ser realizado de acordo com o trabalho proposto por Baguelin e Venon (1971), o qual se baseia nas relações de Cambefort (1964), as quais mostram as funções existentes entre atrito lateral e reação de ponta com o recalque da estaca, conforme Figura 2.21 e Figura 2.22, respectivamente.

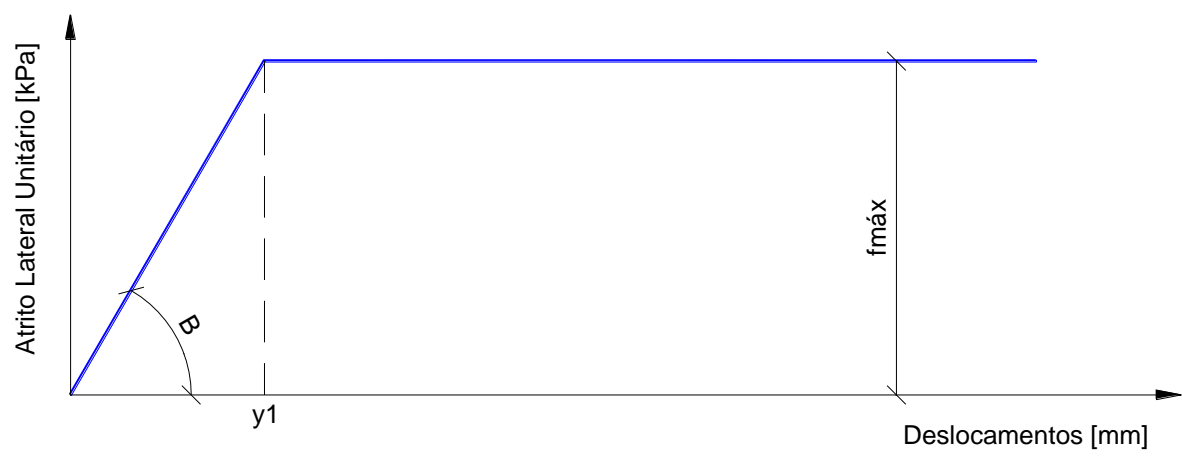

Figura 2.21 - 1를 Relação de Cambefort (Cambefort, 1964). 


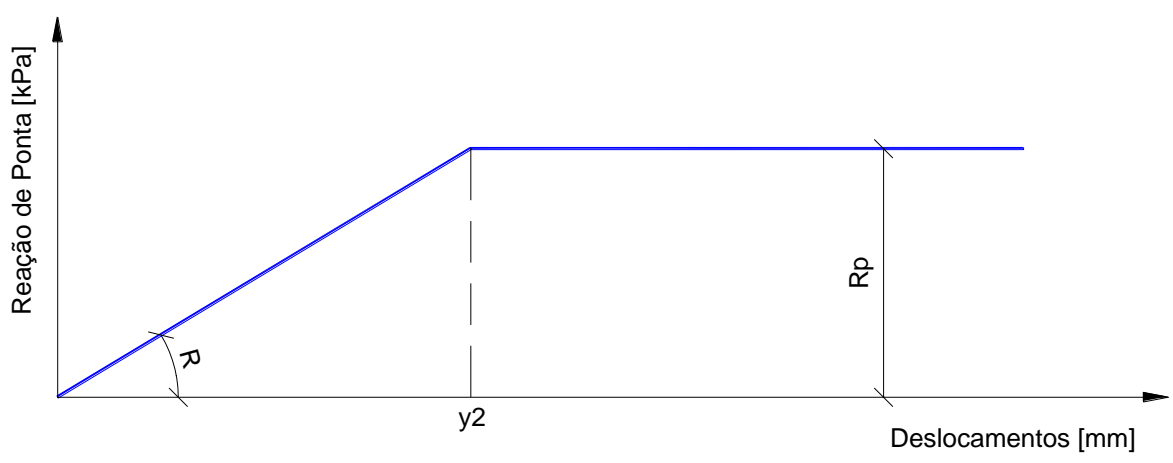

Figura $2.22-2^{\mathrm{a}}$ Relação de Cambefort (Cambefort, 1964).

As leis ou relações de Cambefort explicam o que já está consagrado no meio técnico: a Figura 2.21 mostra que são necessários poucos $\mathrm{mm}\left(\mathrm{y}_{1}\right)$ para que o atrito lateral seja totalmente esgotado; enquanto que para se atingir a ruptura da base é necessário atingir deslocamentos bem maiores $\left(\mathrm{y}_{2}\right)$, conforme Massad (1991), o que pode ser visto na Figura 2.22.

Analisando-se os gráficos das leis de Cambefort podem-se escrever as seguintes equações:

$$
\begin{aligned}
& f=\left\{\begin{array}{cc}
B \cdot y, & y<y_{1} \\
f_{\text {máx }}=B \cdot y_{1}, & y \geq y_{1}
\end{array}\right. \\
& q=\left\{\begin{array}{cc}
R \cdot y, & y<y_{2} \\
R_{p}=R \cdot y_{2}, & y \geq y_{2}
\end{array}\right.
\end{aligned}
$$

Utilizando-se as equações (2.2) e (2.3), pode-se chegar à equação (2.30):

$$
\frac{d^{2} y}{d x^{2}}=\frac{\pi \cdot D \cdot f}{E \cdot S}
$$

Porém, a equação (2.30) pode também ser escrita, segundo Massad (1991), da seguinte maneira, identificada na equação (2.31): 


$$
\frac{d^{2} y}{d x^{2}}= \begin{cases}\frac{k}{h^{2}} \cdot y, & y<y_{1} \\ \frac{k}{h^{2}} \cdot y_{1}, & y \geq y_{1}\end{cases}
$$

Baseado nas equações decorrentes das relações de Cambefort, que foram tratadas anteriormente, observa-se que a constante $\mathrm{k}$ pode ser definida como:

$$
k=\frac{Q_{L_{R U P}}}{K_{r} \cdot y_{1}}
$$

onde:

$\mathrm{k}=$ Rigidez Relativa Solo-Estaca $\left[\mathrm{FL}^{-1}\right]$;

$Q_{\text {Lrup }}=$ Atrito Lateral na ruptura [F], dado pela expressão (2.33):

$$
Q_{L_{R U P}}=\pi \cdot D \cdot f_{\text {máx }} \cdot h
$$

$\mathrm{f}_{\text {máx }}=$ Atrito Lateral Unitário na ruptura $\left[\mathrm{FL}^{-2}\right]$

$\mathrm{h}=$ Comprimento da Estaca [L]

$\mathrm{y}_{1}=$ Deslocamento necessário para o esgotamento do atrito lateral unitário [L];

$\mathrm{K}_{\mathrm{r}}=$ Rigidez da Estaca como Peça Estrutural [FL $\left.{ }^{-1}\right]$, dada por

$$
K_{r}=\frac{E \cdot S}{h}
$$

$\mathrm{S}=$ Área da Seção Transversal da Estaca $\left[\mathrm{L}^{2}\right]$

$\mathrm{E}=$ Módulo de Elasticidade da Estaca $\left[\mathrm{FL}^{-2}\right]$; 


\subsubsection{Método das Duas Retas}

O método das duas retas, proposto por Massad e Lazo (1998), aplica-se, especificamente, às estacas classificadas como rígidas ou curtas. Tal classificação é feita com base na equação (2.32), na qual $k \geq 8$ indica uma estaca compressível ou longa, que tem a necessidade de se deformar muito para que haja um esgotamento do atrito lateral. Por sua vez, se o resultado for $\mathrm{k} \leq 2$ há a situação de estaca rígida ou curta, para a qual o atrito lateral é praticamente esgotado instantaneamente.

O método propõe um ajuste da curva carga vs recalque no topo por duas retas, definidas para os trechos (0-3) e (4-5), conforme Figura 2.23

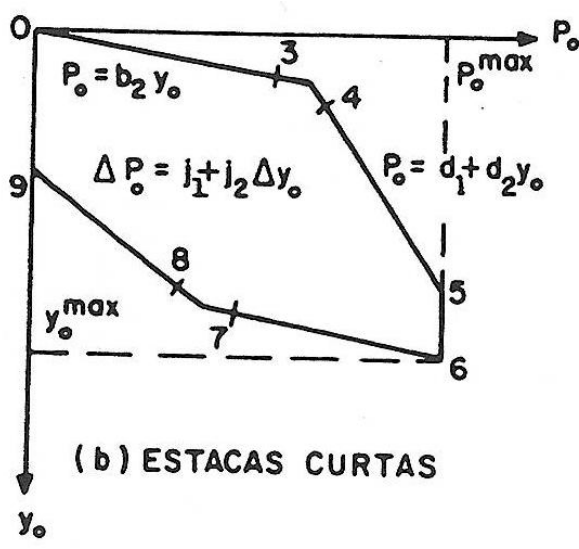

Figura 2.23 - Curva Carga vs Recalque Típica para Estacas Curtas (Massad e Lazo, 1998).

O trecho (0-3), conforme prescrito em Massad (1993), corresponde à fase pseudoelástica de mobilização do atrito lateral (1ª Relação Modificada de Cambefort). Já o trecho (4-5) corresponde à mobilização da resistência de ponta, de acordo com a $2^{\underline{a}}$ Relação Modificada de Cambefort.

A equação (2.35) representa a reta que passa pelos pontos 4 e 5 , enquanto que a reta do trecho (0-3) é representada pela equação (2.36).

$$
P_{0}=d_{1}+d_{2} \cdot y_{0}
$$




$$
P_{0}=b_{2} \cdot y_{0}
$$

Por sua vez, o atrito lateral na ruptura pode ser dado pela equação (2.37).

$$
\mu \cdot Q_{l_{r u p}}=\frac{d_{1}}{1-\frac{d_{2}}{2 \cdot K_{r}}}
$$

onde:

$$
\begin{aligned}
& \text { QLrup = Atrito Lateral na ruptura }[\mathrm{F}] ; \\
& \mu=\text { Fator majorador do Atrito Lateral }\left[\mathrm{F}^{0} \mathrm{~L}^{0} \mathrm{~T}^{0}\right] ; \\
& \mathrm{d}_{1}=\text { Coeficiente linear da reta do trecho }(4-5) ; \\
& \mathrm{d}_{2}=\text { Coeficiente angular da reta do trecho }(4-5) ; \\
& \mathrm{b}_{2}=\text { Coeficiente angular da reta do trecho }(0-3) ;
\end{aligned}
$$

Já no trecho de descarregamento, a equação (2.38) representa a reta do trecho (89), que pode também ser escrita, após algumas transformações e considerações, pela equação (2.39).

$$
\begin{aligned}
& \Delta P_{0}=j_{1}+j_{2} \cdot \Delta y_{0} \\
& 2 . Q_{l_{r u p}}=\frac{j_{1}}{1-\frac{j_{2}}{2 . K_{r}}}
\end{aligned}
$$

Por outro lado, o método das duas retas pode ser realizado por meio de uma construção gráfica, com o mesmo objetivo de determinar o atrito lateral na ruptura e a carga residual. Essa última, referindo-se às estacas cravadas ou um segundo carregamento em estacas escavadas. A Figura 2.24 mostra o que foi descrito acima. 


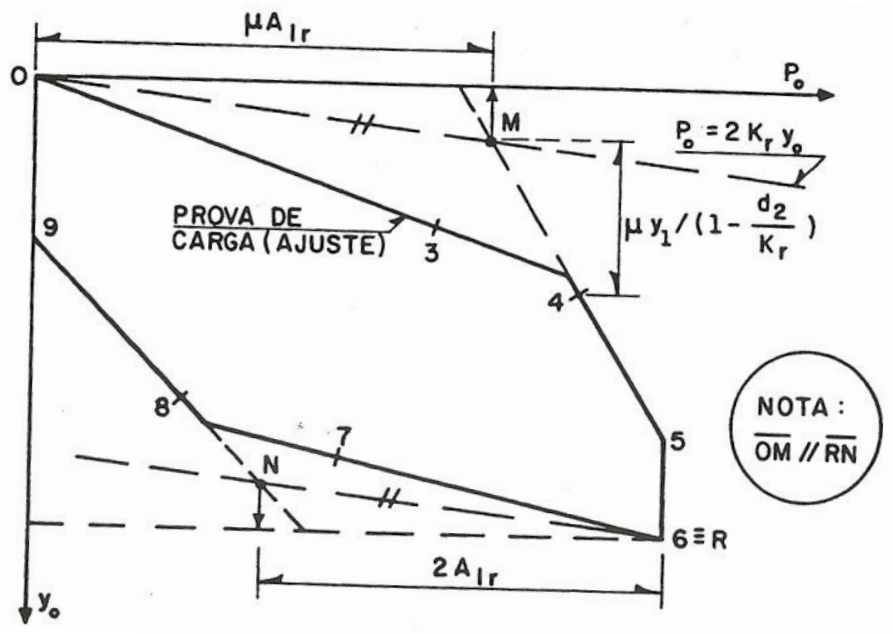

Figura 2.24 - Construção Gráfica do Método das 2 Retas (Massad e Lazo, 1998).

\subsubsection{Método da Norma Brasileira (NBR 6122/1996)}

O método da NBR 6122 baseia-se nos conceitos do método de Davisson (1972), mudando-se a parcela referente ao deslocamento plástico inicial. A formulação segue abaixo:

$$
\rho=\frac{D}{30}+\frac{Q . L}{E . S}
$$

onde:

$\rho=$ Recalque para uma dada carga aplicada [m];

$\mathrm{b}=$ Diâmetro da estaca $[\mathrm{m}]$;

$\mathrm{L}=$ Comprimento da estaca $[\mathrm{m}]$;

$\mathrm{Q}=$ Carga Aplicada $[\mathrm{kN}]$;

$\mathrm{E}=$ Módulo de Young da estaca $\left[\mathrm{kN} / \mathrm{m}^{2}\right]$;

$\mathrm{S}=$ Área da Seção Transversal da estaca [m²] 
Ressalta-se que na versão atual da norma, NBR 6122/2010, não houve qualquer modificação referente ao critério apresentado.

Na Figura 2.25 é possível visualizar o método proposto pela norma brasileira.

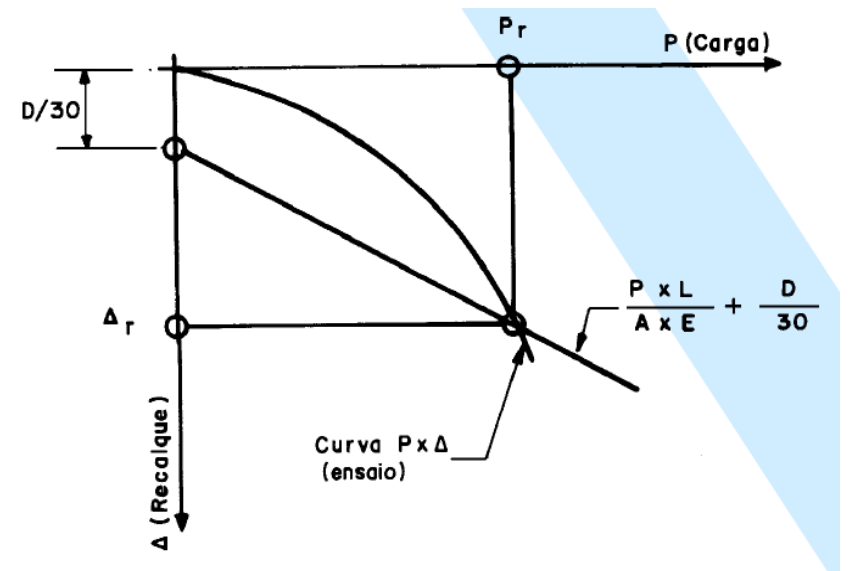

Figura 2.25 - Método Gráfico da NBR 6122 (NBR 6122/1996).

\subsubsection{Método de Brinch-Hansen $80 \%$ (1963)}

O método proposto por Hansen (apud Fellenius, 2006) pode ser obtido diretamente da curva carga vs recalque e a capacidade de carga foi definida como sendo a carga que proporciona um recalque no topo da estaca de quatro vezes, obtido para $80 \%$ dessa carga.

O método consiste em calcular as raízes quadradas dos recalques e dividi-las pelas respectivas cargas, colocando essa relação no eixo das ordenadas. Por sua vez, no eixo das abscissas, colocam-se os recalques obtidos durante a prova de carga estática. Na Figura 2.26 é mostrado um gráfico típico da aplicação do método. 


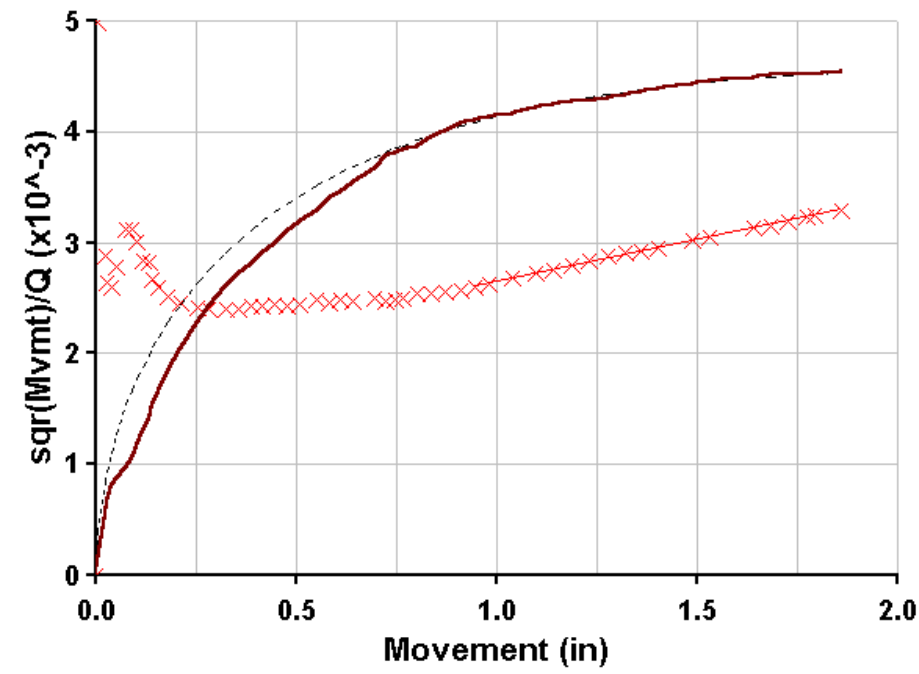

Figura 2.26 - Método de Brinch-Hansen 80\% (apud Fellenius, 2006).

A carga limite última é dada pela equação (2.41).

$$
Q_{u}=\frac{1}{2 \cdot \sqrt{C_{1} \cdot C_{2}}}
$$

Já o recalque para a carga última é dado pela relação entre os coeficientes angular e linear da regressão obtida dos pontos plotados (cruzes vermelhas). A equação (2.44) mostra o que foi explicado anteriormente:

$$
\delta_{u}=\frac{C_{1}}{C_{2}}
$$

onde:

$$
\begin{aligned}
& \mathrm{Q}_{\mathrm{u}}=\text { Carga Limite Última }[\mathrm{F}] \\
& \mathrm{C}_{1}=\text { Inclinação da Linha reta }, \\
& \mathrm{C}_{2}=\text { Intersecção com o eixo Y; } \\
& \delta_{\mathrm{u}}=\text { Recalque correspondente à carga última [L]; }
\end{aligned}
$$




\subsubsection{Método de De Beer (1968)}

O método proposto por De Beer (apud Fellenius), possibilita encontrar a carga de ruptura plotando-se um gráfico, no qual o logaritmo da carga é colocado no eixo das ordenadas, enquanto no eixo das abscissas, o logaritmo do recalque. O gráfico também pode ser construído em escala logarítmica.

Os pontos plotados no gráfico proporcionarão dois segmentos de reta com inclinações diferentes. A interceptação das duas retas resultará na carga de ruptura. A Figura 2.27 mostra o método acima.

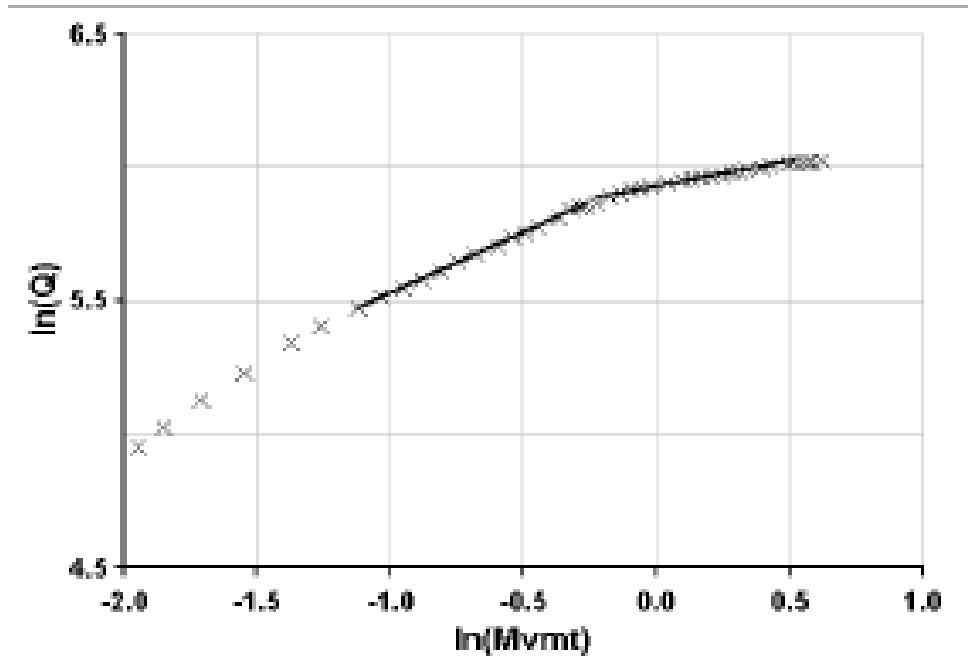

Figura 2.27 - Método de De Beer (apud Fellenius, 2006).

\subsubsection{Método de Van der Veen (1953)}

O método propõe que a relação entre a carga e o deslocamento no topo apresente um aspecto exponencial, dado pela equação (2.43).

$$
Q=Q_{u l t} \cdot\left(1-e^{-\alpha . r}\right)
$$

onde: 
$\mathrm{Q}=$ Carga Aplicada no Topo da Estaca [F];

$Q_{\text {ult }}=$ Carga de Ruptura $[F]$;

$\alpha=$ Coeficiente que define a Forma da Curva;

$\mathrm{r}=$ Recalque correspondente à Carga Aplicada [L];

Após algumas transformações e aplicando a propriedade dos logaritmos, tem-se:

$$
-\ln \left(1-\frac{Q}{Q_{u l t}}\right)=\alpha . r
$$

O professor Nelson Aoki sugeriu a alteração da fórmula acima, adicionando-se um coeficiente linear, resultando na equação (2.45).

$$
-\ln \left(1-\frac{Q}{Q_{u l t}}\right)=\alpha \cdot r+\beta
$$

Sendo assim, plota-se no eixo das abscissas a expressão $\ln \left(1-\frac{Q}{Q_{u l t}}\right)$, e no eixo das ordenadas, os recalques. A Figura 2.28 mostra o método gráfico.

A curva que apresentar o melhor coeficiente de correlação, $R^{2}$, proporcionará a carga de ruptura do ensaio. 


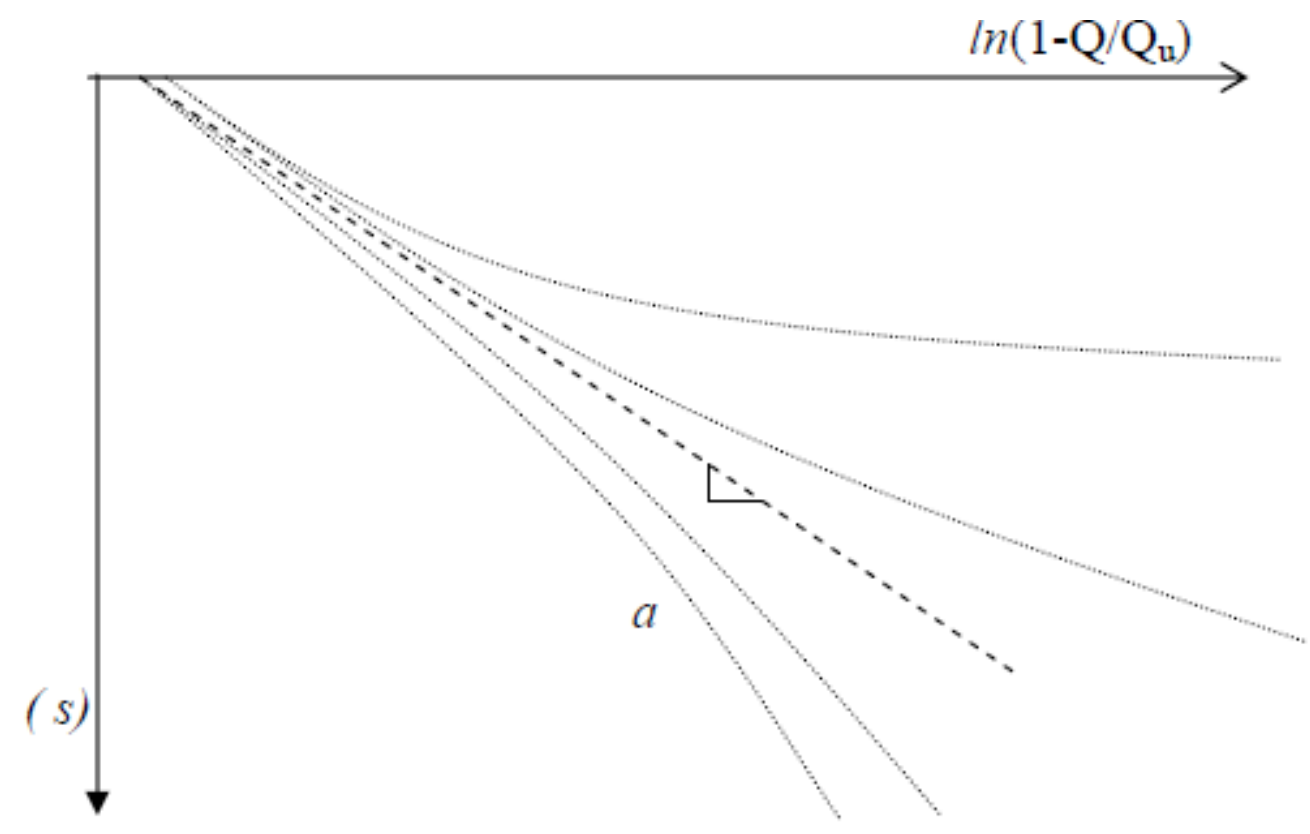

Figura 2.28 - Método Gráfico de Van der Veen modificado por Aoki (FAG, 2008).

\subsubsection{Método de Mazurkiewicz (1972)}

Mazurkiewicz (1972) sugeriu um método de extrapolação da curva carga vs recalque, supondo a mesma como uma parábola. Assim sendo, o método propõe linhas paralelas horizontais com distância $\mathrm{H}$ entre si, interceptando a curva; posteriormente, linhas verticais são traçadas, partindo de cada ponto de intersecção até o eixo das abscissas, correspondente às cargas no topo. Segmentos de reta a $45^{\circ}$ são traçados, cada um, com extremidades no ponto de intersecção do eixo das abscissas e na reta paralela vertical seguinte. Por fim, a linha que passa pelas intersecções dos segmentos com as verticais, ao cruzar o eixo horizontal, indicará a carga de ruptura. A Figura 2.29 mostra o que foi explicado. 


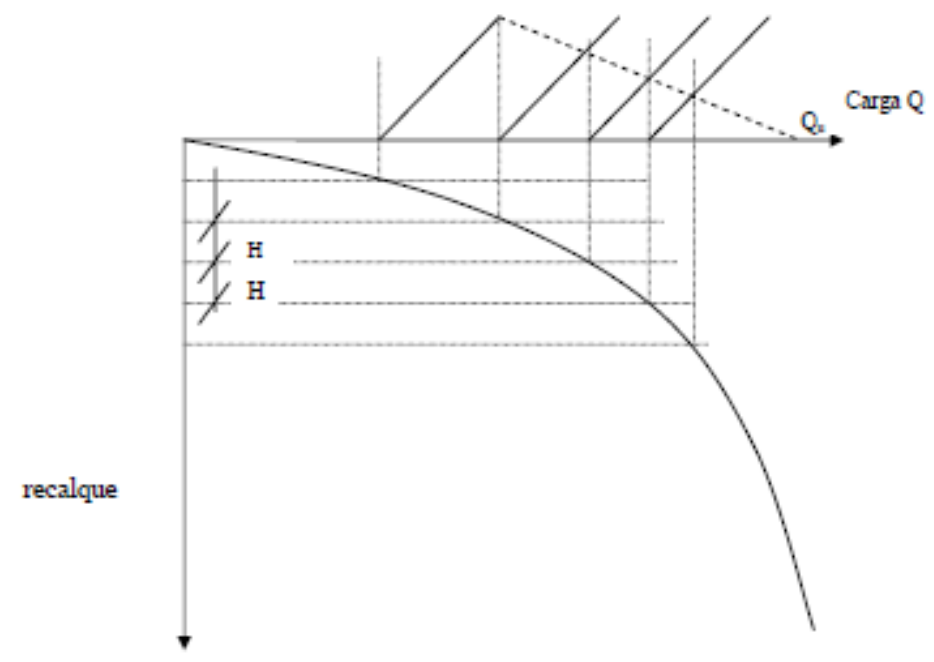

Figura 2.29 - Método Gráfico de Mazurkiewicz (FAG, 2008).

\subsubsection{Método de Butler \& Roy (1977)}

O método proposto por Butler \& Roy (1977) consiste nas seguintes etapas:

a.) Traçar um segmento de reta paralelo ao trecho inicial da curva carga vs recalque;

b.) No trecho final da curva, quando se está na iminência do esgotamento do atrito lateral, traçar uma reta com inclinação de $0,13 \mathrm{~mm} / \mathrm{kN}$;

c.) No cruzamento entre as duas retas, traçar uma vertical até o eixo das abscissas, referente às cargas no topo, para encontrar a carga de ruptura.

A Figura 2.30 mostra o gráfico em questão.

O (Tons)

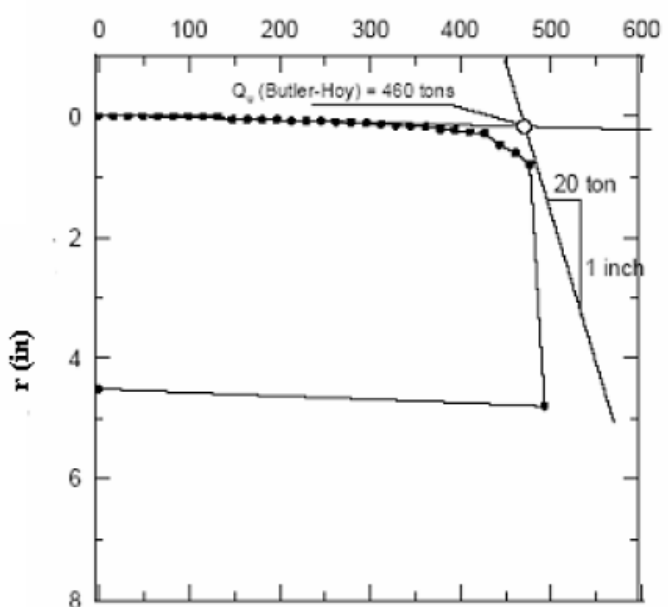

Figura 2.30 - Método Gráfico de Butler \& Roy (Aviz, 2006). 


\subsection{Método do Módulo Tangente}

De acordo com Fellenius (2001), o módulo de Young de uma estaca de concreto não é constante, ao contrário do módulo de uma estaca metálica, devido ao fato do módulo ser uma função da tensão a que está submetido em um determinado instante. Durante o andamento da prova de carga, quando submetida a altas tensões, pode haver diferenças significativas entre os módulos de elasticidade inicial e final da estaca. Isto se deve ao fato do diagrama carga $x$ recalque (ou tensãodeformação) não ser linear.

Com a finalidade de descobrir o módulo secante do concreto durante o ensaio estático na estaca, Fellenius (1989) propôs que a relação tensão-deformação poderia ser expressa com adequada significância, sem que ocorressem erros na obtenção das cargas a partir das leituras de deformação, por uma equação do segundo grau, conforme metodologia abaixo:

$$
\begin{gathered}
E_{t g}=\frac{d \sigma}{d \varepsilon}=A \cdot \varepsilon+B \\
\int \frac{d \sigma}{d \varepsilon}=\int A \cdot \varepsilon+B \\
\sigma=0,50 \cdot A \cdot \varepsilon^{2}+B \cdot \varepsilon
\end{gathered}
$$

E, pela Lei de Hooke tem-se:

$$
\sigma=E_{\mathrm{sec}} \cdot \varepsilon
$$

Então, substituindo a equação (2.48) na equação (2.49), obtém-se:

$$
E_{\mathrm{sec}}=0,50 \cdot A \cdot \varepsilon+B
$$


onde:

$E_{\mathrm{tg}}=$ Módulo de Elasticidade Tangente da Estaca $\left[\mathrm{FL}^{-2}\right]$;

$\mathrm{E}_{\mathrm{sec}}=$ Módulo de Elasticidade Secante da Estaca $\left[\mathrm{FL}^{-2}\right]$;

d $\sigma=$ Incremento de tensão $\left[\mathrm{FL}^{-2}\right]$;

$\mathrm{d} \varepsilon=$ Incremento de deformação $\left[\mathrm{FL}^{-2}\right]$;

$A=$ Coeficiente angular da reta do módulo secante $\left[\mathrm{FL}^{-2}\right]$;

$\varepsilon=$ Deformação específica $\left[\mathrm{F}^{0} \mathrm{~L}^{0} \mathrm{~T}^{0}\right]$;

$\mathrm{B}=$ Coeficiente linear da reta do módulo secante $\left[\mathrm{FL}^{-2}\right]$;

O autor também mostrou que é possível obter-se o produto ES da estaca ensaiada graficamente. Para tal, plota-se em um eixo cartesiano, com a ordenada representando as cargas axiais ao longo da profundidade e a abscissa, a deformação específica. O coeficiente angular da reta encontrada é o valor do produto ES que se procura, conforme Figura 2.31.

Também na Figura 2.31, os níveis 1 a 7 representam o posicionamento dos straingages do topo para a base. Note que nos níveis 1 a 3 houve um esgotamento (não há mais o desenvolvimento) do atrito lateral, representado pelo "paralelismo" entre as curvas representativas de cada um.

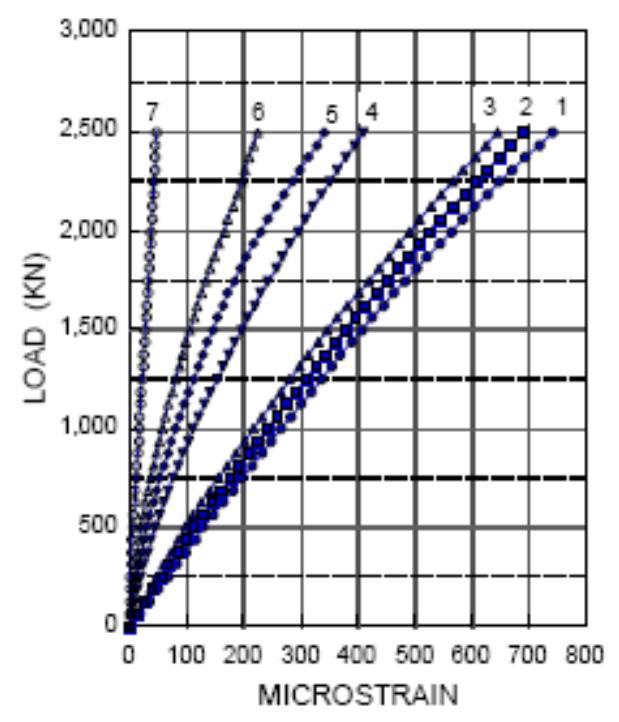

Figura 2.31 - Deformações Específicas nos níveis 1 ao 7. (Fellenius, 2006). 


\subsection{Método de Randolph-Wroth (1978)}

O método proposto por Randolph-Wroth (1978) sugere a construção da curva carga vs recalque com base nos parâmetros listados na Tabela 2.9, com uma boa previsão para as cargas de trabalho e não para as cargas últimas.

Tabela 2.9 - Parâmetros do Método de Randolph - Wroth.

\begin{tabular}{|c|c|}
\hline Parâmetro & Fórmulas \\
\hline$r_{0}=$ raio da estaca $[\mathrm{m}]$ & $r_{0}=\frac{D}{2}$ \\
\hline$\rho=$ fator de heterogeneidade & $\rho= \begin{cases}1,0, & \text { solo homogêneo } \\
0,5, & \text { solo tipo Gibson }\end{cases}$ \\
\hline $\mathrm{I}=$ comprimento da estaca $[\mathrm{m}]$ & \\
\hline$v=$ coeficiente de Poisson do solo & \\
\hline$r_{\mathrm{m}}=$ raio mágico $[\mathrm{m}]$ & $r_{m}=(1-v) \cdot 2,5 \cdot l \cdot \rho$ \\
\hline $\mathrm{E}=$ módulo de Young da estaca & \\
\hline $\mathrm{G}=$ módulo de cisalhamento do solo & $G=\frac{E_{s}}{2 .(1+v)}$ \\
\hline Índice de esbeltez & \\
\hline$\lambda=$ Índice de esbeltez & $\lambda=\frac{E}{G_{h}}$ \\
\hline $\begin{array}{l}\text { Fator que representa o logaritmo } \\
\text { neperiano da relação dos raios }\end{array}$ & $\varsigma=\ln \frac{r_{m}}{r_{0}}$ \\
\hline & $\mu \cdot l=\frac{l}{r_{0}} \cdot \sqrt{\frac{2}{\varsigma \cdot \lambda}}$ \\
\hline Carga no Topo & $P_{0}=G \cdot r_{0} \cdot w_{0} \cdot \frac{2 \cdot \pi}{\varsigma} \cdot \rho \cdot \frac{l}{r_{0}} \cdot \frac{\operatorname{tgh}(\mu l)}{\mu l}$ \\
\hline
\end{tabular}




\section{Descrição da obra do Shopping União de Osasco}

\subsection{A Obra Propriamente Dita}

O shopping União de Osasco localiza-se na confluência das Avenidas dos Autonomistas, Maria Campos, Domingos Odália Filho, Franz Voegeli e Hilário Pereira de Souza, no município de Osasco, na cidade de São Paulo, em um terreno com área de $156.000 \mathrm{~m}^{2}$ e $264.000 \mathrm{~m}^{2}$ de área construída. Na Figura 3.1 pode-se visualizar a região descrita.

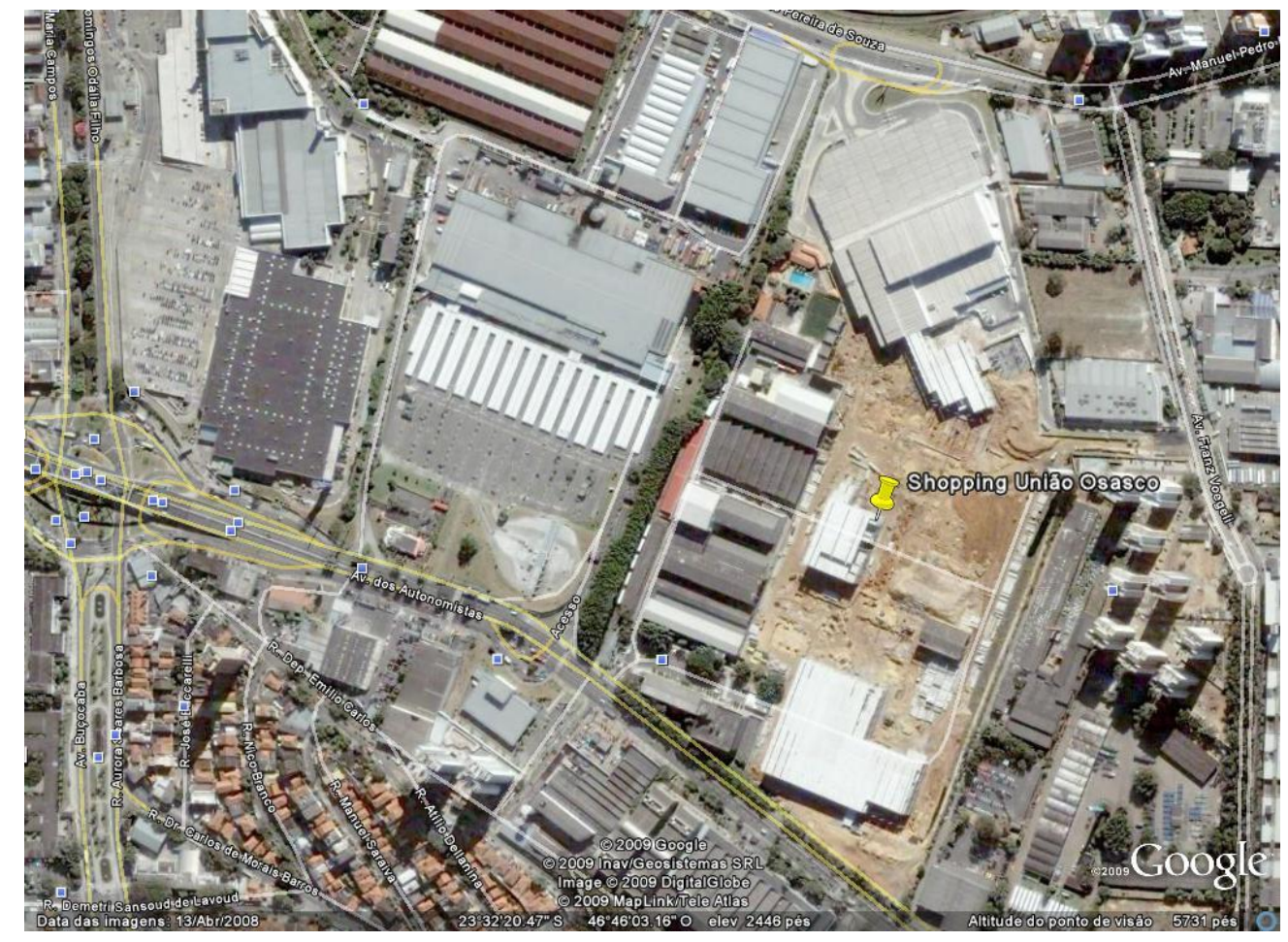

Figura 3.1 - Vista aérea do terreno de implantação do Shopping União de Osasco (Google Earth, acessado em 13.05.2009) 


\subsection{O Projeto de Fundação}

O shopping União de Osasco foi concebido em estrutura pré-moldada, com vãos de $8 \times 8 \mathrm{~m}$, constituída de lajes alveolares de $25 \mathrm{~cm}$, enchimento de $25 \mathrm{~cm}$ e acabamento de $7 \mathrm{~cm}$, sustentadas perifericamente por vigas com altura variando de $70 \mathrm{~cm}$ a $100 \mathrm{~cm}$. A sobrecarga livre utilizada na estrutura foi de $17 \mathrm{kPa}\left(1700 \mathrm{kgf} / \mathrm{m}^{2}\right)$. As cargas são então transferidas para a fundação por meio de pilares de dimensões $50 \times 50 \mathrm{~cm}$.

$\mathrm{Na}$ Tabela 3.1 são mostrados alguns carregamentos de pilares seguindo-se a concepção estrutural citada acima.

Tabela 3.1 - Carregamentos de alguns Pilares no Shopping União de Osasco.

\begin{tabular}{ccccccc}
\hline Nó da Estrutura & Condição & $\mathbf{H}_{\mathbf{x}}[\mathbf{k N}]$ & $\mathbf{H}_{\mathbf{y}}[\mathbf{k N}]$ & $\mathbf{F}_{\mathbf{z}}[\mathbf{k N}]$ & $\mathbf{M}_{\mathbf{x}}[\mathbf{k N} \cdot \mathbf{m}]$ & $\mathbf{M}_{\mathbf{y}}[\mathbf{k N} \cdot \mathbf{m}]$ \\
\hline \multirow{2}{*}{413 (Setor 3) } & Máximo & 26,45 & 11,17 & 2543,63 & 97,77 & 78,26 \\
& Mínimo & $-19,07$ & $-19,82$ & 1045,68 & $-36,18$ & $-51,91$ \\
\multirow{2}{*}{12 (Setor 2) } & Máximo & 192,92 & 43,44 & 3076,04 & 152,57 & 350,39 \\
& Mínimo & $-164,99$ & $-57,93$ & 1777,03 & $-114,43$ & $-349,68$ \\
\multirow{2}{*}{ 14B/M2 } & Máximo & 30,00 & 60,00 & 3890,00 & 250,00 & 100,00 \\
& Mínimo & 60,00 & 30,00 & 3890,00 & 100,00 & 250,00 \\
\multirow{2}{*}{29 (Setor 2) } & Máximo & 107,73 & 43,44 & 4738,98 & 152,57 & 218,91 \\
& Mínimo & $-157,07$ & $-57,93$ & 2288,39 & $-114,43$ & $-310,04$ \\
\multirow{2}{*}{23 (Setor 2) } & Máximo & 108,41 & 8,39 & 5644,41 & 16,46 & 219,59 \\
& Mínimo & $-159,12$ & $-6,29$ & 2207,57 & $-22,04$ & $-312,26$ \\
93 (Setor 2) & Máximo & 0,24 & 50,95 & 6674,83 & 101,47 & 0,33 \\
& Mínimo & 0,06 & $-38,20$ & 2815,22 & $-135,51$ & 0,09 \\
43 (Setor 3) & Máximo & 49,41 & $-2,36$ & 7724,47 & 63,43 & 137,46 \\
& Mínimo & $-65,34$ & $-10,94$ & 2381,98 & 28,18 & $-176,47$ \\
\multirow{2}{*}{43 (Setor 2) } & Máximo & 78,61 & 83,93 & 8743,89 & 167,15 & 159,36 \\
& Mínimo & $-103,80$ & $-62,93$ & 5151,98 & $-223,07$ & $-212,22$ \\
\hline
\end{tabular}

Na parte geotécnica, face ao tamanho do terreno, foram solicitadas 82 sondagens à percussão, elaboradas pela Ação Engenharia, totalizando 3500m de perfuração, aproximadamente. Depois dessa campanha de sondagens, foi realizada uma segunda campanha pela Engesolos Engenharia de Solos e Fundações Ltda., com 15 sondagens. Na Figura 3.5 é possível visualizar o perfil típico do subsolo local. 
Observando-se os resultados das sondagens à percussão apresentadas nas figuras citadas, pode-se notar que se trata de solos da Bacia Sedimentar de São Paulo. Olhando-se a estratigrafia, as estacas situam-se, provavelmente, em duas formações, sendo a parte superior contida na formação São Paulo, devido ao intemperismo e a laterização que melhoram as características geotécnicas dos sediimentos; e a inferior, na Resende, apresentando um entrelaçamento típico entre argila siltosa roxa e areia cinza e amarela, com consistência e compacidade, respectivamente, elevadas. As características fundamentais dos solos pertencentes a essa formação são a homogeneidade e o fato de serem pouco afetados pelo intemperismo e processos de laterização.

Baseado no relatório de sondagens à percussão e nos carregamentos apresentados na Tabela 3.1, a escolha técnica do tipo de fundação restringiu-se às estacas prémoldadas de concreto e às estacas escavadas de grande diâmetro.

Porém, uma escolha deve aliar técnica e economia. E a junção desses dois fatores resultou que a adoção de estacas escavadas de grande diâmetro seria mais econômica do que as estacas pré-moldadas para cargas axiais superiores a $2000 \mathrm{kN}$, pois essa última opção necessitaria de um alto número de estacas e o bloco de coroamento das mesmas seria de grandes dimensões, consumindo concreto, aço e fôrmas em alta escala.

Portanto, o tipo de fundação adotado foi a utilização de apenas um estacão por pilar; submetido a uma tensão no concreto de 5MPa, armado segundo as necessidades estruturais, a fim de combater esforços de momentos fletores advindo da análise estrutural, acrescidos dos momentos fletores gerados pelas forças horizontais e, por fim, pela excentricidade de obra, advinda das técnicas construtivas, adotada como $10 \%$ do diâmetro da estaca, conforme prescrito pela NBR 6122/1996. Vale ressaltar que não houve modificação quanto à excentricidade na NBR 6122/2010.

Assim sendo, é possível visualizar na Tabela 3.2 os diâmetros utilizados e as respectivas cargas axiais, calculadas para uma tensão no concreto de 5MPa, conforme escrito anteriormente. 
Tabela 3.2 - Cargas Axiais calculadas em função do Diâmetro dos Estacões no Shopping União de Osasco.

\begin{tabular}{cc}
\hline Diâmetro $[\mathbf{c m}]$ & $\mathbf{F}_{\mathbf{z}}[\mathbf{k N}]$ \\
\hline 80 & 2500 \\
90 & 3200 \\
100 & 3900 \\
110 & 4750 \\
120 & 5650 \\
130 & 6650 \\
140 & 7700 \\
150 & 8850 \\
\hline
\end{tabular}

\subsection{Investigações Geotécnicas}

As investigações geotécnicas realizadas na obra do Shopping União de Osasco que interessam podem ser divididas em dois grupos: os ensaios in-situ e os laboratoriais. No primeiro grupo, encontram-se as sondagens à percussão e as provas de cargas estáticas em três diferentes estacas. No segundo grupo, podem ser citados os ensaios de caracterização e triaxiais realizados em amostras cúbicas retiradas de locais próximos às estacas ensaiadas; como também os ensaios no concreto das estacas, para a obtenção do módulo de elasticidade do concreto das mesmas.

\subsubsection{As Provas de Cargas Estáticas (projeto)}

$\mathrm{Na}$ obra do shopping União de Osasco foram realizadas três provas de cargas estáticas em três estacões dimensionados para diferentes cargas atuantes, porém com a mesma seção transversal. A concepção de se realizar as provas de cargas estáticas em estacas de mesmo diâmetro deveu-se ao fato de existirem em maior número do que as demais.

O sistema de reação foi composto por uma carapaça metálica ancorada no terreno por 8 tirantes de 12 cordoalhas de aço CP 190 RB, com comprimento total de $30 \mathrm{~m}$, sendo $10 \mathrm{~m}$ ancorados, para carga máxima na prova de $1500 \mathrm{kN}$ em cada tirante. 


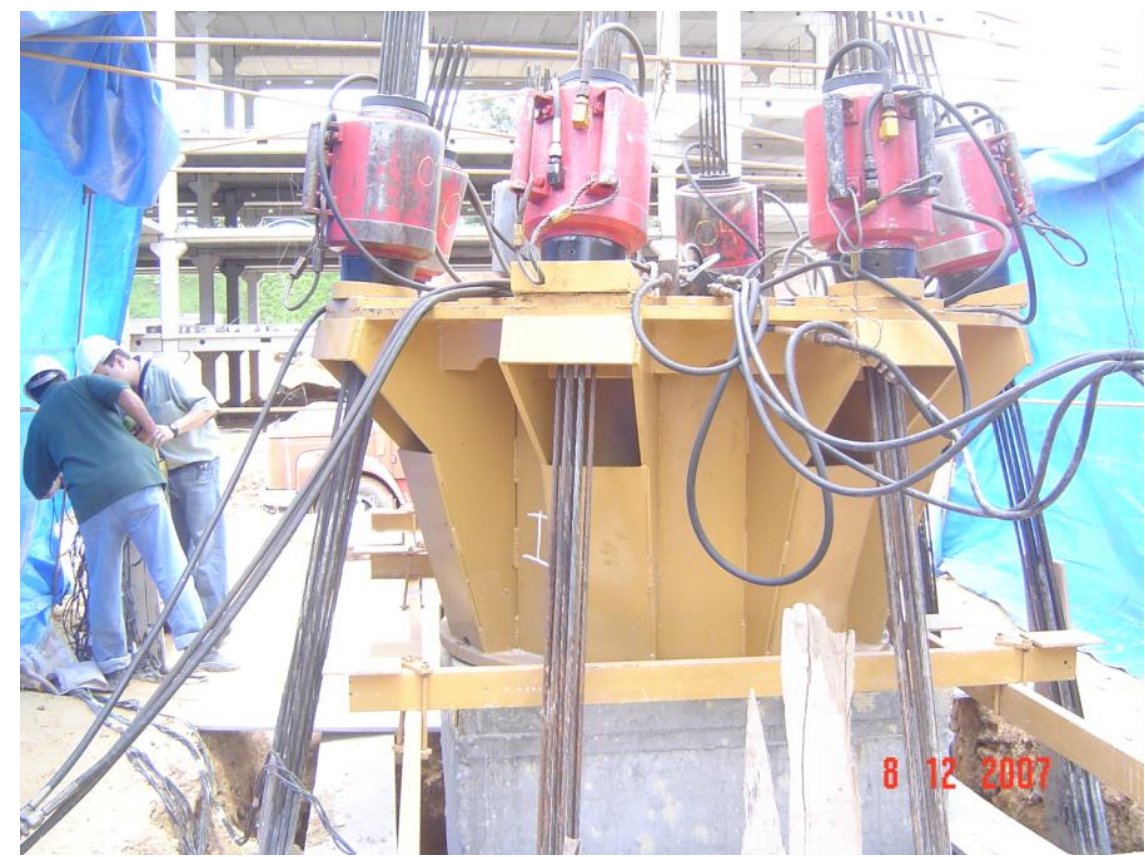

Figura 3.2 - Sistema de Reação da Prova de Carga.

Foram transmitidas cargas axiais à estaca por meio de 8 macacos hidráulicos, acionados por duas centrais de bombeamento, controlados por dois manômetros. Sendo assim, os deslocamentos verticais no topo da estaca foram medidos utilizando-se quatro deflectômetros posicionados dois a dois, diametralmente opostos, no bloco de coroamento da estaca. . A Figura 3.3 mostra a perfuratriz que executou os tirantes nas provas de cargas estáticas.

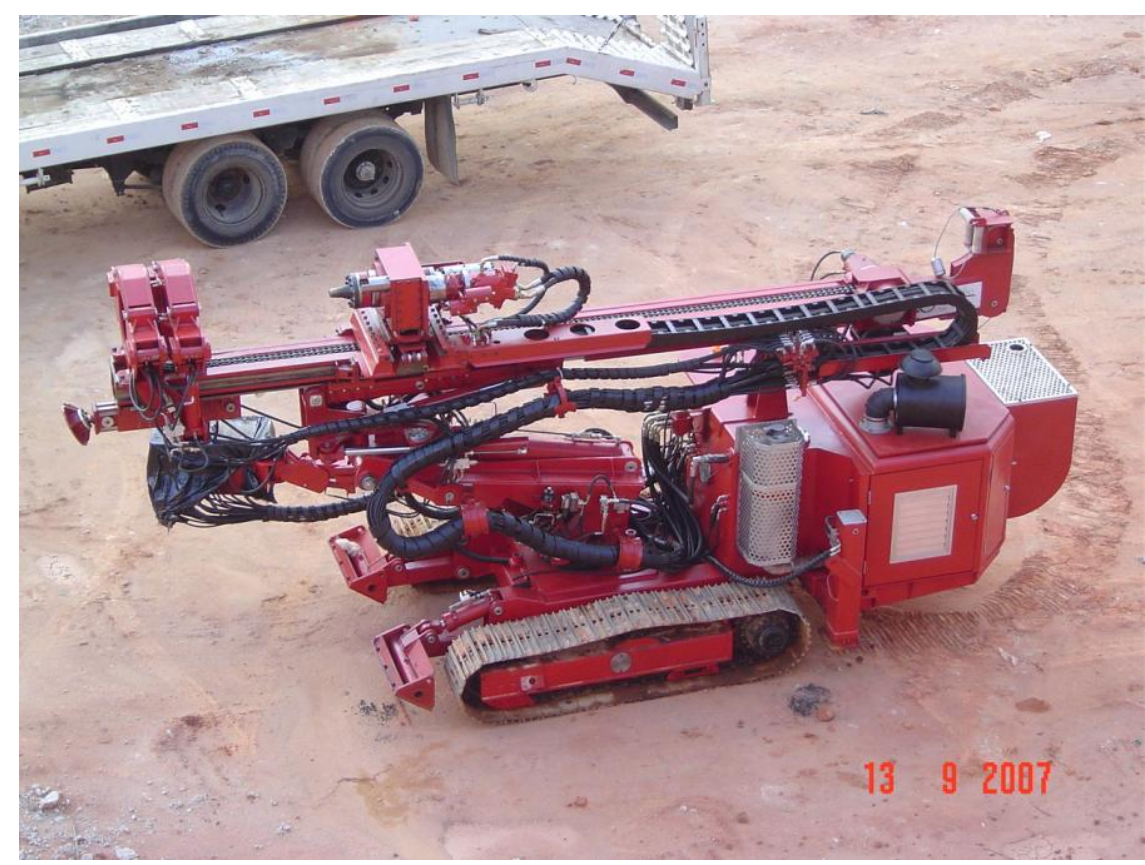

Figura 3.3 - Perfuratriz para Execução dos Tirantes. 
A seguir serão descritos os aspectos relevantes para cada ensaio realizado.

\subsubsection{Prova de Carga № 01 (PC-01)}

O primeiro ensaio foi realizado na estaca E.263B, que, juntamente com a estaca E.263A, formam as fundações para o pilar do eixo 11R, o qual possui o carregamento indicado na Tabela 3.3. Nesse caso, foi adotado um binário de estacas para que as mesmas fossem dimensionadas para uma carga baixa, possibilitando o fato de se atingir a ruptura no ensaio estático.

Tabela 3.3 - Cargas Atuantes no Pilar 11R no Shopping União de Osasco.

\begin{tabular}{ccccccc}
\hline Nó da Estrutura & Condição & $\mathbf{H}_{\mathbf{x}}[\mathbf{k N}]$ & $\mathbf{H}_{\mathbf{y}}[\mathbf{k N}]$ & $\mathbf{F}_{\mathbf{z}}[\mathbf{k N}]$ & $\mathbf{M}_{\mathbf{x}}[\mathbf{k N} \cdot \mathbf{m}]$ & $\mathbf{M}_{\mathbf{y}}[\mathbf{k N} \cdot \mathbf{m}]$ \\
\hline \multirow{2}{*}{408 (Pilar 11R) } & Máximo & 74,48 & 116,06 & 5182,58 & 213,33 & 106,12 \\
& Mínimo & $-81,80$ & $-89,69$ & 1869,37 & $-289,60$ & $-120,18$ \\
\hline
\end{tabular}

$\mathrm{Na}$ Figura 3.4 pode-se visualizar o posicionamento das estacas citadas anteriormente e, sabendo-se que o sentido horizontal representa o eixo x e o sentido vertical, o eixo y, é possível chegar à equação (3.1).

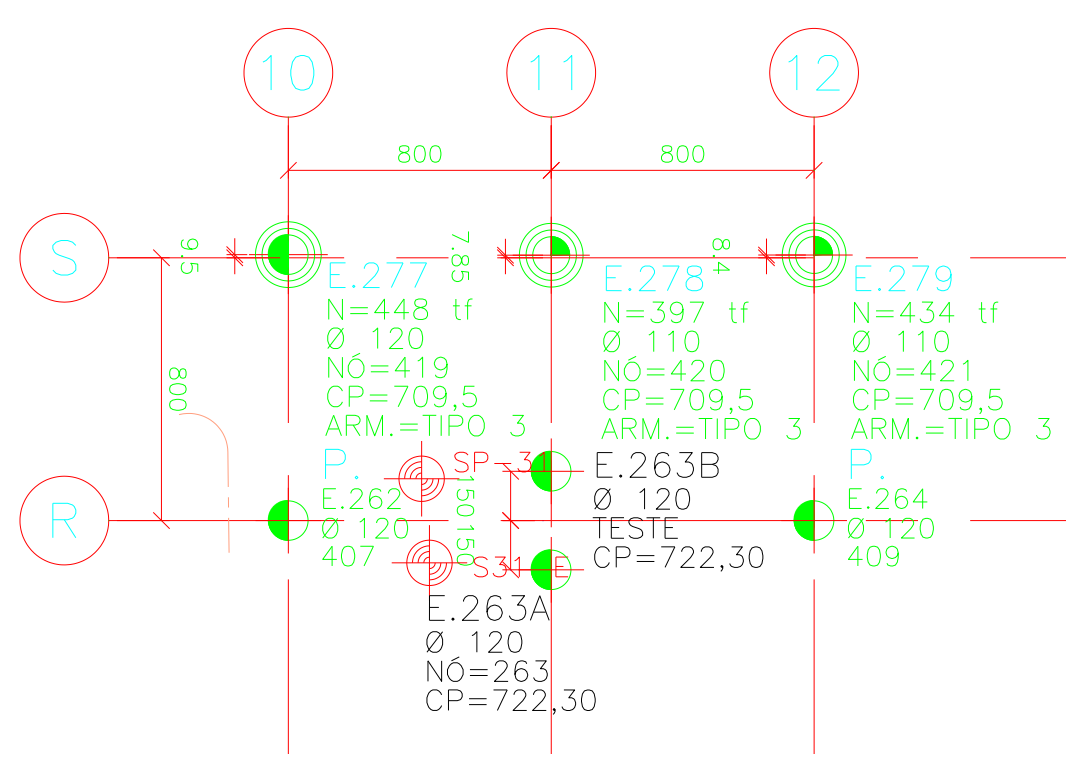

Figura 3.4 - Locação da estaca E.263B. 


$$
N_{E S T A C A}=\frac{F_{Z}}{2}+\frac{M_{X}+F_{Y} \cdot h_{B L O C O}}{e}+P_{B L O C O}
$$

onde:

$\mathrm{N}_{\mathrm{ESTACA}}=$ Carga Axial no Topo da Estaca [F];

$F_{Z}=$ Carga Axial no Pilar do Eixo 11R [F];

$\mathrm{M}_{\mathrm{X}}=$ Momento Fletor em torno do eixo alfabético [FL];

$F_{Y}=$ Carga Horizontal paralela ao eixo numérico $[F]$;

$\mathrm{h}_{\mathrm{BLOCO}}=$ Altura do bloco de coroamento das estacas [L];

$\mathrm{P}_{\mathrm{BLOCO}}=$ Peso do bloco de coroamento das estacas $[\mathrm{F}]$;

Substituindo os valores indicados na Tabela 3.3 na equação (3.1), tem-se:

$$
N_{E S T A C A}=\frac{5182,58}{2}+\frac{213,33+116,06 \cdot 1,60}{3}+25 \cdot(1,40 \cdot 1,40 \cdot 1,60)
$$

E, por fim, chega-se ao valor de $2800 \mathrm{kN}$, que é a carga atuante na estaca que será ensaiada.

A estaca E.263B possui diâmetro de 1,20m e cota de ponta (CP) 722,30m, representando $23 \mathrm{~m}$ de comprimento, aproximadamente. O comprimento da estaca foi obtido segundo os métodos de previsão de capacidade de carga descritos nesse trabalho, os quais são Décourt-Quaresma e Aoki-Velloso. Esta previsão será objeto de análise posterior.

Durante a montagem, verificou-se que, em dois tirantes, uma cordoalha ficou mais curta e não pode ser protendida junto com as demais pelo macaco hidráulico, limitando a carga desses tirantes ao equivalente a 11 cordoalhas.

A prova de carga foi realizada em 7 etapas distintas, descritas a seguir. Os carregamentos do tipo lento obedeceram a prescrição da norma NBR 12131/2006, que diz que a estabilização dos deslocamentos é admitida quando a diferença entre duas leituras consecutivas corresponder no máximo a $5 \%$ do deslocamento ocorrido no estágio e no mínimo 30 minutos. O critério de incremento de carga também foi 
obedecido, o qual diz que os mesmos não devem superar $20 \%$ da carga de trabalho da estaca.

a.) 1a Etapa: Carregamento do tipo lento, em 12 estágios de $660 \mathrm{kN}$. Ao atingir a carga de $7920 \mathrm{kN}$, o sistema hidráulico apresentou problemas que impediram a continuação da prova;

b.) 2a Etapa: Após o reparo do sistema, foram realizados três decréscimos de $1320 \mathrm{kN}$ e dois decréscimos de $1980 \mathrm{kN}$, com tempo de estabilização mínimo de 15 minutos;

c.) 3a Etapa: Carregamento do tipo rápido, com incrementos de carga de $330 \mathrm{kN}$, mantidos por 10 minutos, até atingir a carga de $7920 \mathrm{kN}$;

d.) 4ª Etapa: A partir desse ponto, foi realizado carregamento do tipo lento até a ruptura do conjunto solo-estaca;

e.) 5a Etapa: Descarregamento rápido, com decréscimos de $1980 \mathrm{kN}$;

f.) 6a Etapa: Carregamento rápido, com acréscimos de carga de $330 \mathrm{kN}$, até atingir 1,5 vezes a carga de trabalho da estaca ensaiada;

g.) 7ª Etapa: Descarregamento rápido, com decréscimos de $990 \mathrm{kN}$.

Na Figura 3.5 é possível visualizar o posicionamento da instrumentação ao longo da profundidade da estaca E.263B, os quais foram strain-gages (extensômetros elétricos de resistência), protegidos da umidade e choque mecânico. Maiores detalhes podem ser vistos no item 2.3.1.1 Para a garantia de que as barras instrumentadas seriam posicionadas nos níveis predefinidos, as mesmas foram conectadas às barras de ligação por meio de luvas rosqueadas, formando-se uma barra única. Colocado ao lado da sondagem SP.31, facilita a visualização das camadas atravessadas pela estaca. 
EIXO DE ANCORAGEM DOS TIRANTES

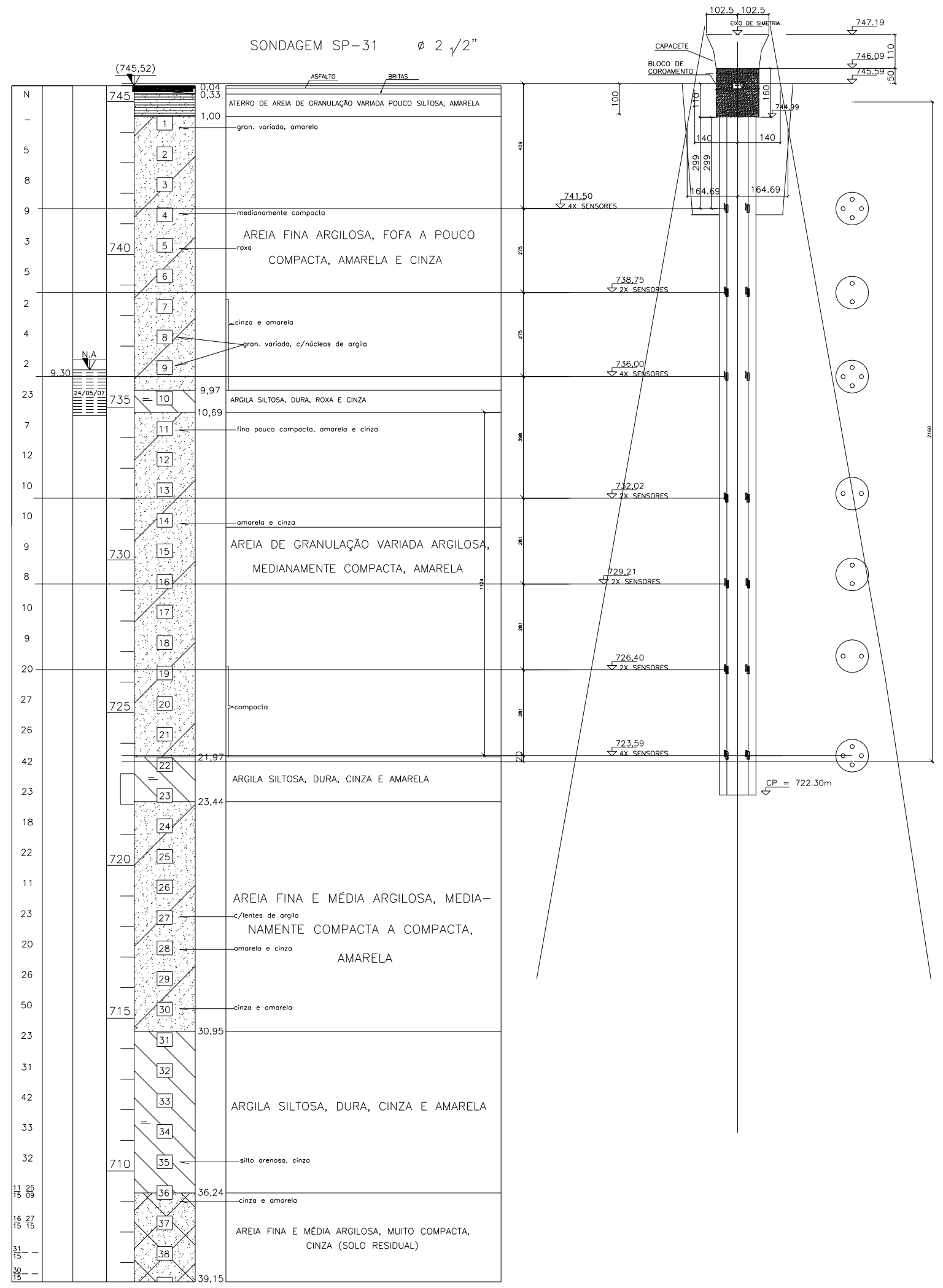

Figura 3.5 - Posicionamento da Instrumentação ao longo do fuste da estaca E,263B. 
Na Tabela 3.4 está mostrada a equivalência de níveis e cotas da instrumentação ao longo da profundidade da estaca E.263B.

Tabela 3.4 - Posição da Instrumentação na estaca E.263B.

\begin{tabular}{ccc}
\hline Nível [m] & Cota [m] & Número de Sensores \\
\hline Seção Referência $(0,0)$ & 741,50 & 4 \\
$-2,8$ & 738,75 & 2 \\
$-5,5$ & 736,00 & 4 \\
$-9,5$ & 732,02 & 2 \\
$-12,3$ & 729.21 & 2 \\
$-15,1$ & 726,40 & 2 \\
$-17,9$ & 723,53 & 4 \\
\hline
\end{tabular}

\subsubsection{Prova de Carga № 02 (PC-02)}

O segundo ensaio foi realizado na estaca E.113, a qual é a fundação para o pilar do eixo $11 \mathrm{H}$, o qual possui o carregamento indicado na Tabela 3.5. A Figura 3.6 mostra a alocação da estaca em obra.

Tabela 3.5 - Cargas Atuantes no Pilar 11H no Shopping União de Osasco.

\begin{tabular}{ccccccc}
\hline Nó da Estrutura & Condição & $\mathbf{H}_{\mathbf{x}}[\mathbf{k N}]$ & $\mathbf{H}_{\mathbf{y}}[\mathbf{k N}]$ & $\mathbf{F}_{\mathbf{z}}[\mathbf{k N}]$ & $\mathbf{M}_{\mathbf{x}}$ [kN.m] & $\mathbf{M}_{\mathbf{y}}$ [kN.m] \\
\hline \multirow{2}{*}{113 (Pilar 11H) } & Máximo & 44,10 & 32,68 & 4427,26 & 58,03 & 49,48 \\
& Mínimo & $-29,97$ & $-51,81$ & 853,13 & $-20,64$ & $-36,51$ \\
\hline
\end{tabular}

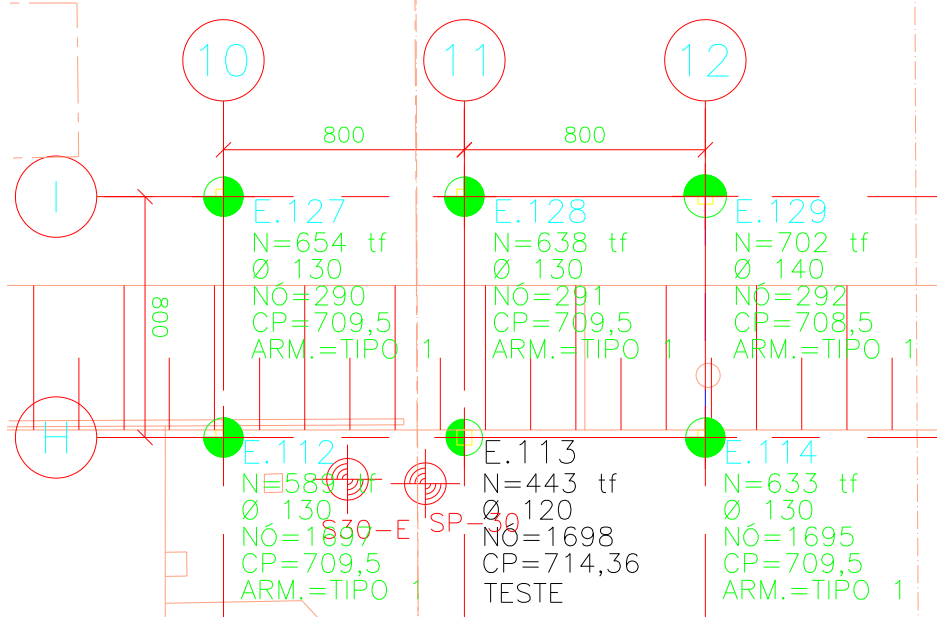

Figura 3.6 - Locação da estaca E.113. 
A estaca E.113 possui diâmetro de 1,20m e cota de ponta (CP) $714,36 \mathrm{~m}$, representando $29 \mathrm{~m}$ de comprimento, aproximadamente. O comprimento da estaca foi obtido segundo os métodos de previsão de capacidade de carga descritos nesse trabalho, os quais são Décourt-Quaresma e Aoki-Velloso. Esta previsão será objeto de análise posterior.

Na Figura 3.7 é possível ver a camisa guia e a armadura da estaca E.113, bem como os tubos que serviram para a passagem das barras instrumentadas.

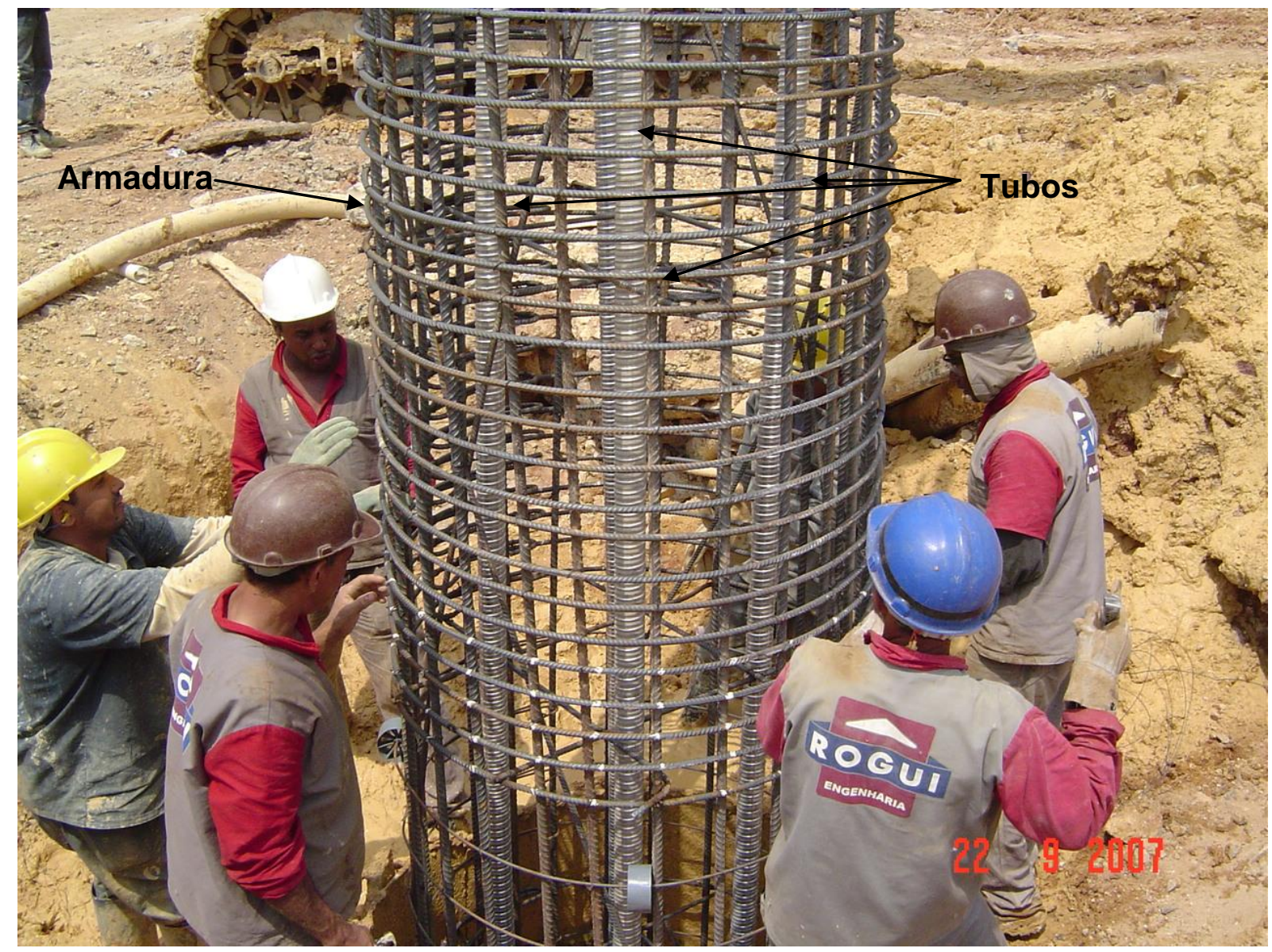

Figura 3.7 - Tubos para passagem das Barras Instrumentadas.

A prova de carga foi realizada em 2 etapas distintas, descritas a seguir. Os carregamentos do tipo lento obedeceram a prescrição da norma NBR 12131/2006, que diz que a estabilização dos deslocamentos é admitida quando a diferença entre duas leituras consecutivas corresponder no máximo a $5 \%$ do deslocamento ocorrido no estágio e no mínimo 30 minutos. O critério de incremento de carga também foi 
obedecido, o qual diz que os mesmos não devem superar $20 \%$ da carga de trabalho da estaca.

a.) 1a Etapa: Carregamento do tipo lento, em 11 estágios de $1000 \mathrm{kN}$;

b.) 2a Etapa: Foram realizados quatro decréscimos de $2000 \mathrm{kN}$ e um decréscimo de $3000 \mathrm{kN}$;

Na Figura 3.8 é possível visualizar o posicionamento da instrumentação ao longo da profundidade da estaca E.113. 
EIXO DE ANCORAGEM DOS TIRANTES

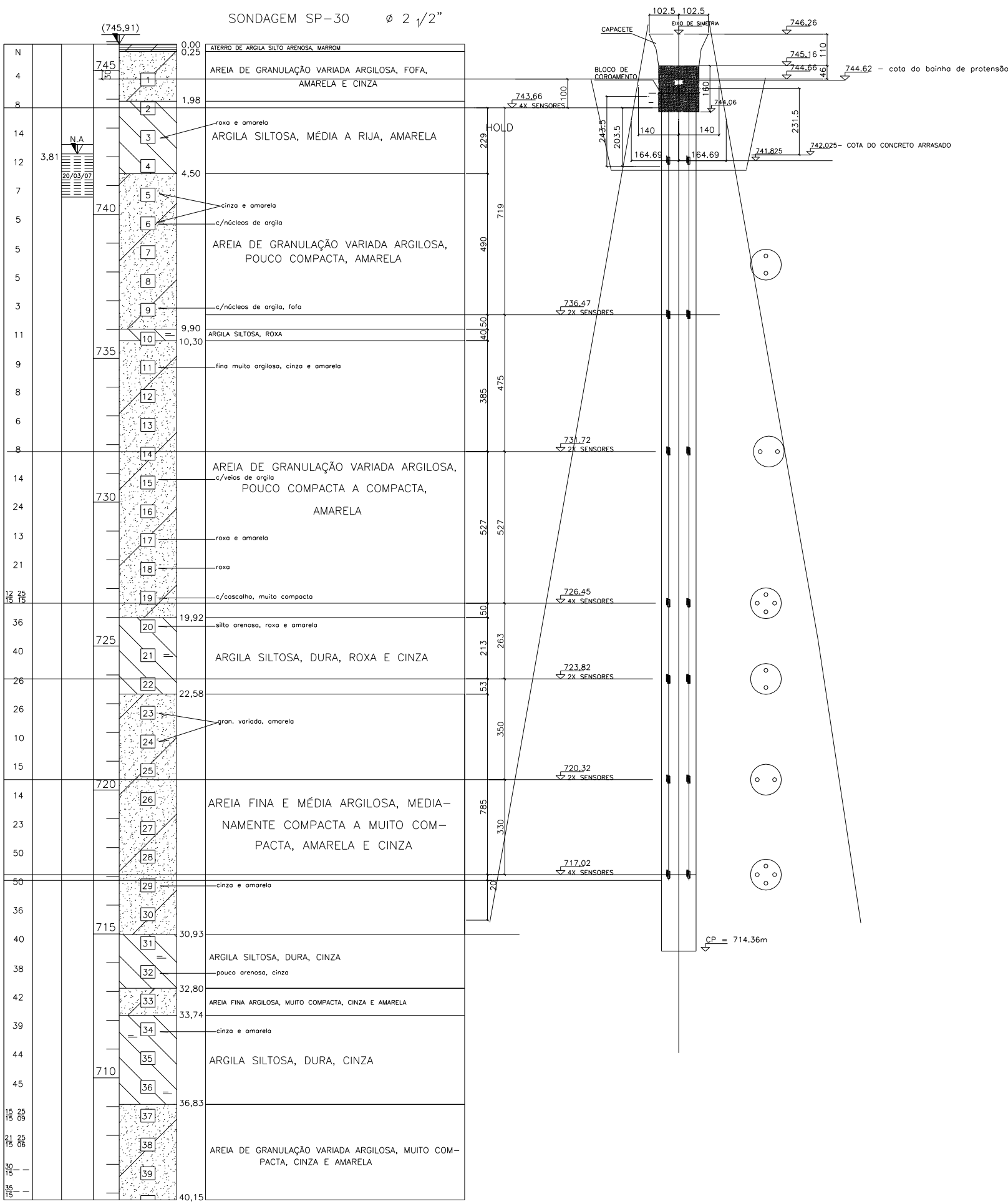

Figura 3.8 - Posicionamento da Instrumentação ao longo do fuste da estaca E.113. 
Na Tabela 3.6 está mostrada a equivalência de níveis e cotas da instrumentação ao longo da profundidade da estaca E.113.

Tabela 3.6 - Posição da Instrumentação na estaca E.113.

\begin{tabular}{ccc}
\hline Nível [m] & Cota [m] & Número de Sensores \\
\hline Seção Referência $(0,0)$ & 741,83 & 4 \\
$-5,35$ & 736,47 & 2 \\
$-10,1$ & 731,72 & 2 \\
$-15,4$ & 726,45 & 4 \\
$-18,0$ & 723,82 & 2 \\
$-21,5$ & 720,32 & 2 \\
$-21,8$ & 717,02 & 4 \\
\hline
\end{tabular}

\subsubsection{Prova de Carga № 03 (PC-03)}

O terceiro e último ensaio foi realizado na estaca E.25, a qual é a fundação para o pilar do eixo 13B, o qual possui o carregamento indicado na Tabela 3.7. A Figura 3.9 mostra a locação da estaca em obra.

Tabela 3.7 - Cargas Atuantes no Pilar 13B no Shopping União de Osasco.

\begin{tabular}{ccccccc}
\hline Nó da Estrutura & Condição & $\mathbf{H}_{\mathbf{x}}[\mathbf{k N}]$ & $\mathbf{H}_{\mathbf{y}}[\mathbf{k N}]$ & $\mathbf{F}_{\mathbf{z}}[\mathbf{k N}]$ & $\mathbf{M}_{\mathbf{x}}[\mathbf{k N} . \mathbf{m}]$ & $\mathbf{M}_{\mathbf{y}}[\mathbf{k N} . \mathbf{m}]$ \\
\hline \multirow{2}{*}{25 (Pilar 13B) } & Máximo & 32,14 & 170,87 & 4757,20 & 24,17 & 68,51 \\
& Mínimo & $-38,07$ & $-37,67$ & 1075,67 & $-129,97$ & $-64,38$ \\
\hline
\end{tabular}

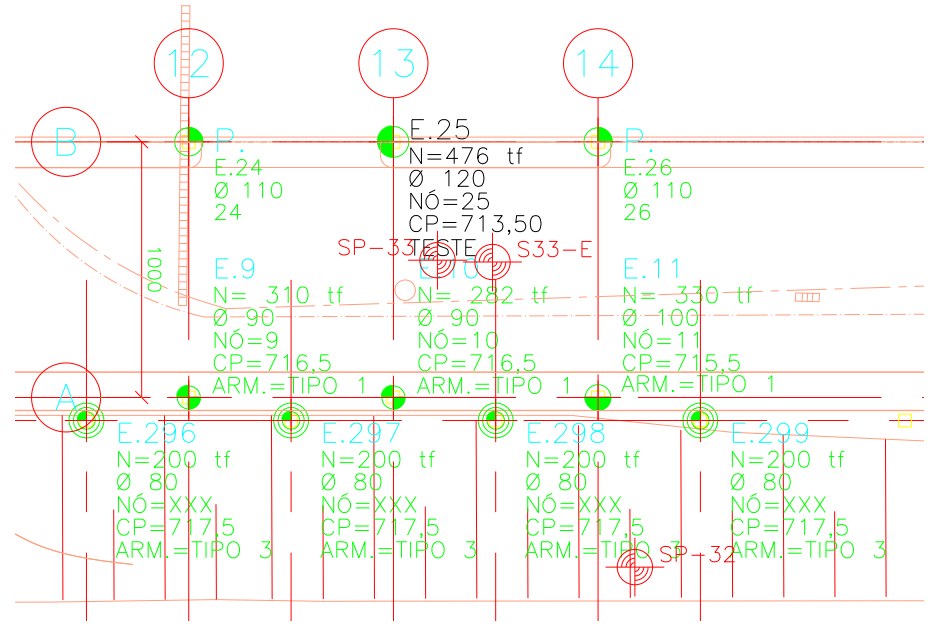

Figura 3.9 - Locação da estaca E.25. 
A estaca E.25 possui diâmetro de 1,20m e cota de ponta (CP) 713,86m, representando $31 \mathrm{~m}$ de comprimento, aproximadamente. O comprimento da estaca foi obtido segundo os métodos de previsão de capacidade de carga descritos nesse trabalho, os quais são Décourt-Quaresma e Aoki-Velloso. Esta previsão será objeto de análise posterior.

Durante a montagem, verificou-se que, em três tirantes distintos, uma cordoalha foi rompida, pela falta de cuidado na proteção dos mesmos em relação aos equipamentos de obra. Portanto, a carga da prova fica limitada ao equivalente a 11 cordoalhas. Na Figura 3.10 fica clara a observação citada anteriormente.

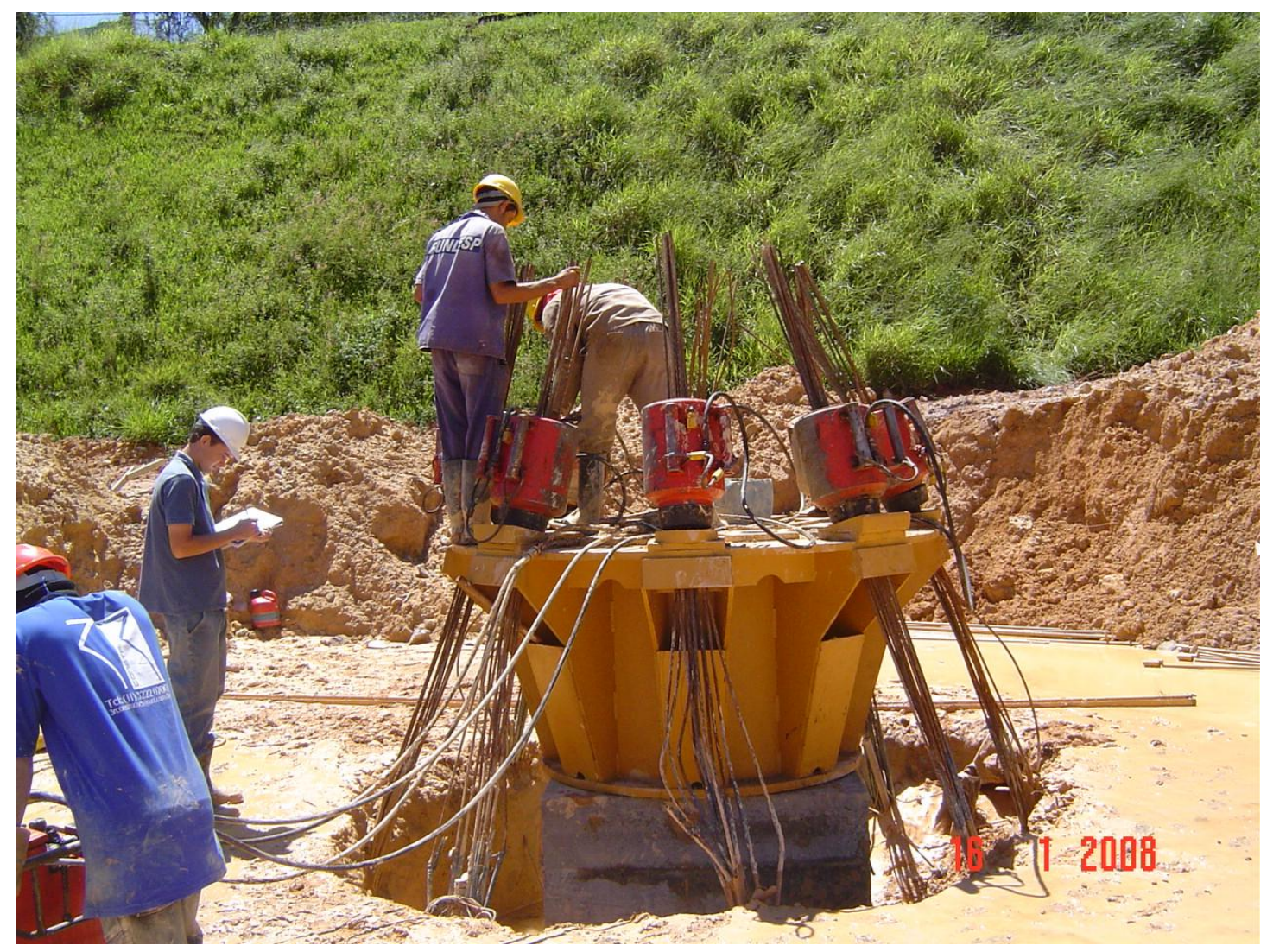

Figura 3.10 - Cordoalhas rompidas.

Foram transmitidas cargas axiais à estaca por meio de 8 macacos hidráulicos, acionados por duas centrais de bombeamento, controlados por dois manômetros. Sendo assim, os deslocamentos verticais no topo da estaca foram medidos utilizando-se quatro deflectômetros posicionados dois a dois, diametralmente opostos, no bloco de coroamento da estaca. 
Embora a carga do pilar 13B seja inferior à carga dimensionada para $5 \mathrm{MPa}$ na cabeça da estaca, optou-se por dimensioná-la para a carga total especificada em projeto, que é $5650 \mathrm{kN}$, de acordo com a Tabela 3.2.

A prova de carga foi realizada em 2 etapas distintas, descritas a seguir. Os carregamentos do tipo lento obedeceram a prescrição da norma NBR 12131/2006, que diz que a estabilização dos deslocamentos é admitida quando a diferença entre duas leituras consecutivas corresponder no máximo a $5 \%$ do deslocamento ocorrido no estágio e no mínimo 30 minutos. O critério de incremento de carga também foi obedecido, o qual diz que os mesmos não devem superar $20 \%$ da carga de trabalho da estaca.

a.) 1 Etapa: Carregamento do tipo lento, em 10 estágios de $1200 \mathrm{kN}$;

b.) 2a Etapa: Foram realizados seis decréscimos de $2400 \mathrm{kN}$;

c.) 3므 Etapa: Carregamento do tipo rápido, com incrementos de $600 \mathrm{kN}$ até atingir 1,6 vezes a carga de trabalho da estaca ensaiada;

d.) 4ª Etapa: Decréscimos de $1800 \mathrm{kN}$, do tipo rápido.

Na Tabela 3.8 está mostrada a equivalência de níveis e cotas da instrumentação ao longo da profundidade da estaca E.25.

Tabela 3.8 - Posição da Instrumentação na estaca E.25.

\begin{tabular}{ccc}
\hline Nível [m] & Cota [m] & Número de Sensores \\
\hline Seção Referência $(0,0)$ & 743,72 & 4 \\
$-5,45$ & 738,27 & 2 \\
$-10,8$ & 732,94 & 2 \\
$-14,0$ & 729,72 & 4 \\
$-20,4$ & 723,30 & 2 \\
$-25,5$ & 718,20 & 2 \\
$-28,7$ & 714,99 & 4
\end{tabular}

Na Figura 3.11 é possível visualizar o posicionamento da instrumentação ao longo da profundidade da estaca E.25. 


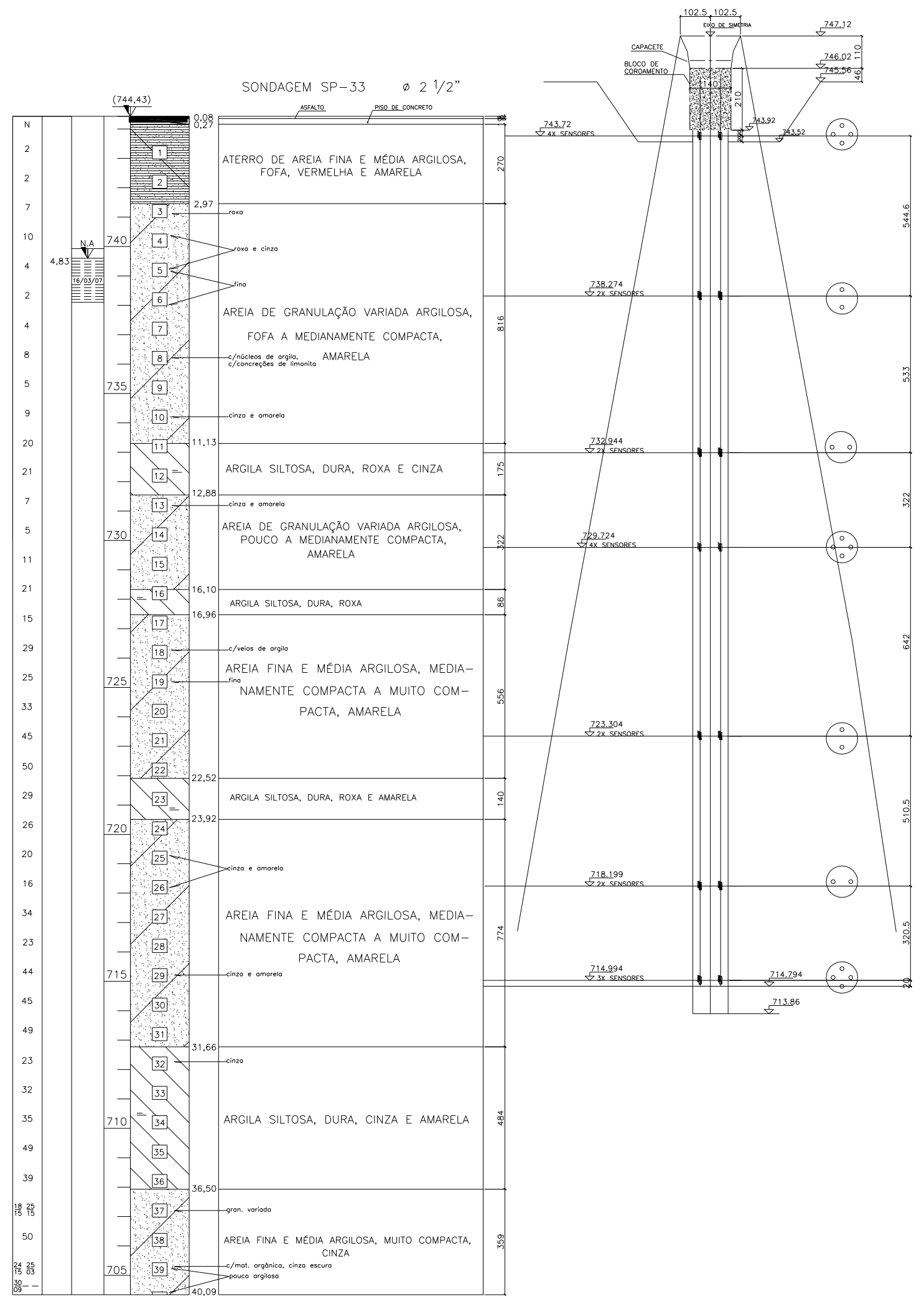

Figura 3.11 - Posicionamento da Instrumentação ao longo do fuste da estaca E.25. 


\subsubsection{Ensaios Laboratoriais}

\subsubsection{Ensaios de Caracterização e Triaxiais}

As amostras indeformadas foram retiradas dos taludes existentes em obra, no qual a Av. dos Autonomistas encontra-se na crista e a plataforma de implantação (nível $743,900)$ do shopping, no pé. O nível d'água do terreno encontrava-se na cota 740 , aproximadamente, conforme Figura 3.11. Também é possível, observando-se a mesma figura, perceber que as amostras representarão as propriedades do solo na parte superior da estaca.

Foram cinco amostras que tiveram dimensões de $30 \times 30 \times 30 \mathrm{~cm}^{3}$ e foram envoltas, para evitar a perda de umidade, com pano de algodão, fita crepe e, finalmente, com parafina, conforme mostra a Figura 3.13 .

Na Figura 3.12 pode-se ver o posicionamento da retirada de uma das amostras.

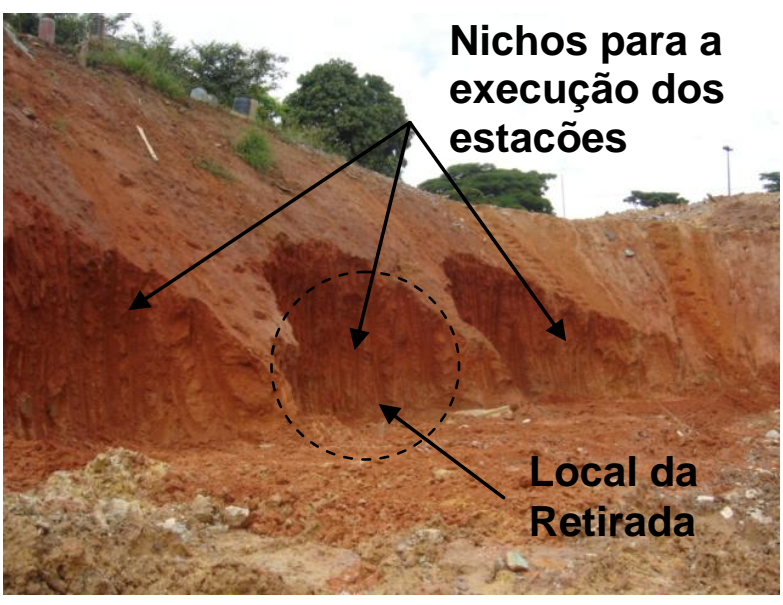

Figura 3.12 - Local de retirada da amostra.

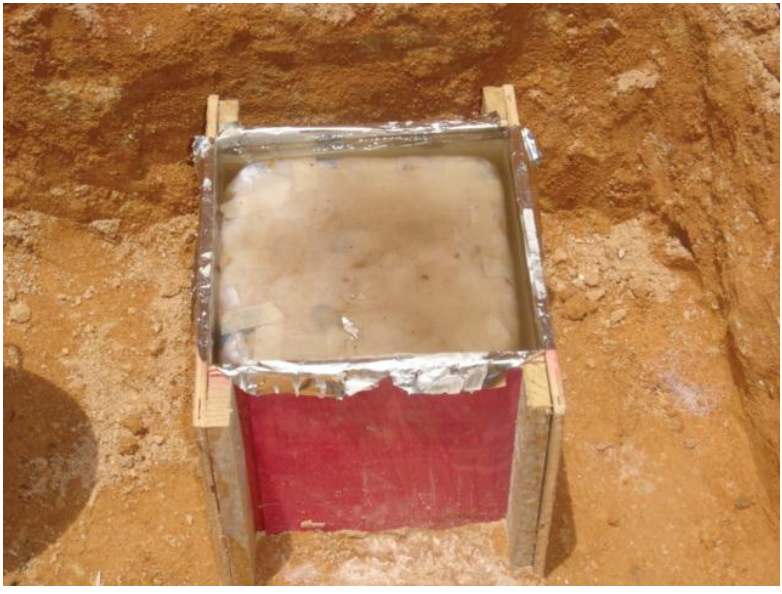

Figura 3.13 - Amostra parafinada.

$\mathrm{Na}$ Tabela 3.9 são mostrados os índices físicos determinados em laboratório, juntamente com os limites de Atterberg. Já nas Figuras 3.14 a 3.16, são apresentadas as curvas granulométricas das amostras AM-01, AM-02 e AM-03. Por 
meio de técnicas de análise tátil-visual, como toughness e resistência a seco, podem-se classificar as amostras como areia fina argilosa vermelha (130), para as três primeiras amostras e areia argilosa amarela (130) para as duas últimas. Os ensaios laboratoriais foram elaborados pela Dýnamis Engenharia Geotécnica.

Tabela 3.9 - Valores dos Índices Físicos.

\begin{tabular}{cccccc}
\hline Amostras & $\begin{array}{c}\text { Teor de Umidade } \\
(\mathbf{w})[\%]\end{array}$ & $\begin{array}{c}\text { Peso Específico }\left(\gamma_{\mathbf{n}}\right) \\
{\left[\mathbf{k N} / \mathbf{m}^{3}\right]}\end{array}$ & $\begin{array}{c}\text { Peso Específico dos } \\
\text { Grãos }\left(\gamma_{\mathbf{s}}\right)\left[\mathbf{k N} / \mathbf{m}^{3}\right]\end{array}$ & $\begin{array}{c}\text { Limite de } \\
\text { Liquidez [\%] }\end{array}$ & $\begin{array}{c}\text { Limite de } \\
\text { Plasticidade [\%] }\end{array}$ \\
\hline AM-01 & 11,87 & 17,490 & 27,620 & 45 & 20 \\
AM-02 & 12,56 & 18,490 & 27,130 & 68 & 27 \\
AM-03 & 19,90 & 19,270 & 27,470 & 66 & 26 \\
AM-04 & 14,53 & 17,630 & 27,010 & 26 & 20 \\
AM-05 & 17,47 & 18,720 & 26,490 & 49 & 37 \\
\hline
\end{tabular}

Os ensaios de granulometria, por peneiramento e sedimentação, revelaram os seguintes resultados, que podem ser vistos na Tabela 3.10.

Tabela 3.10 - Resultados do ensaio de Granulometria.

\section{GRANULOMETRIA}

\begin{tabular}{lllcccc}
\hline \multirow{2}{*}{ Amostras } & \multirow{2}{*}{ Argila } & Silte & \multicolumn{3}{c}{ Areia } & \multirow{2}{*}{ Pedregulho } \\
\cline { 4 - 6 } & & & Fina & Média & Grossa & \\
\hline AM-01 & 22,62 & 2,73 & 32,67 & 40,95 & 1,03 & - \\
AM-02 & 23,21 & 6,01 & 31,04 & 36,76 & 1,83 & 1,14 \\
AM-03 & 35,66 & 7,79 & 35,57 & 19,87 & 0,90 & 0,21 \\
AM-04 & 13,16 & 5,53 & 58,48 & 21,89 & 0,73 & 0,21 \\
AM-05 & 16,72 & 6,85 & 52,96 & 22,54 & 0,89 & 0,04 \\
\hline
\end{tabular}




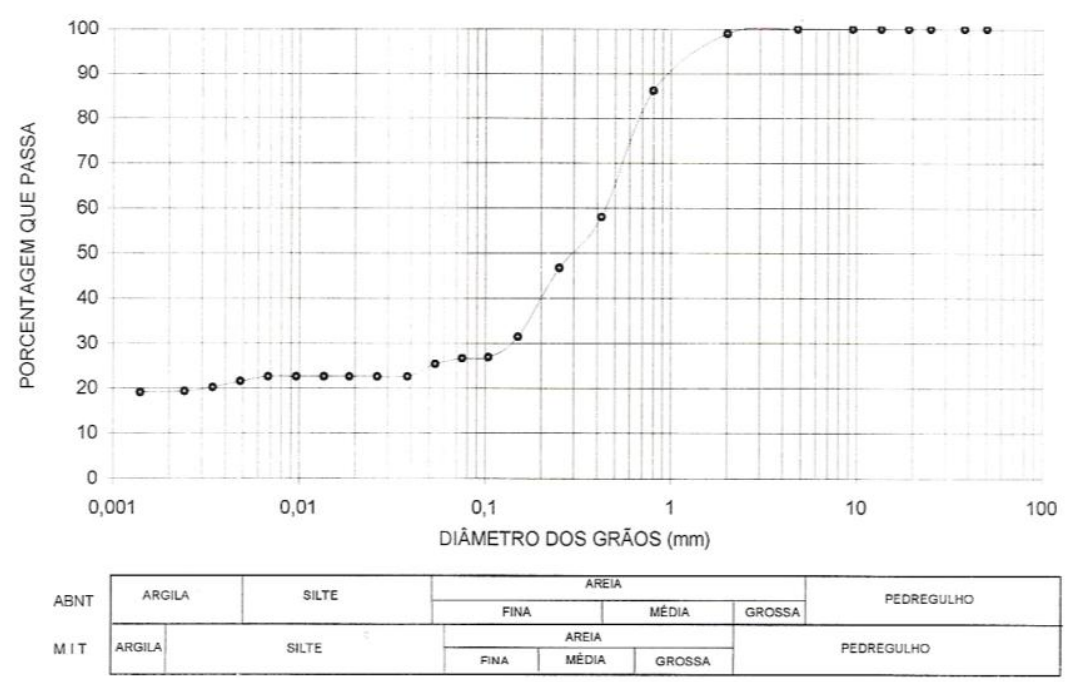

Figura 3.14 - Curva Granulométrica da amostra AM-01.

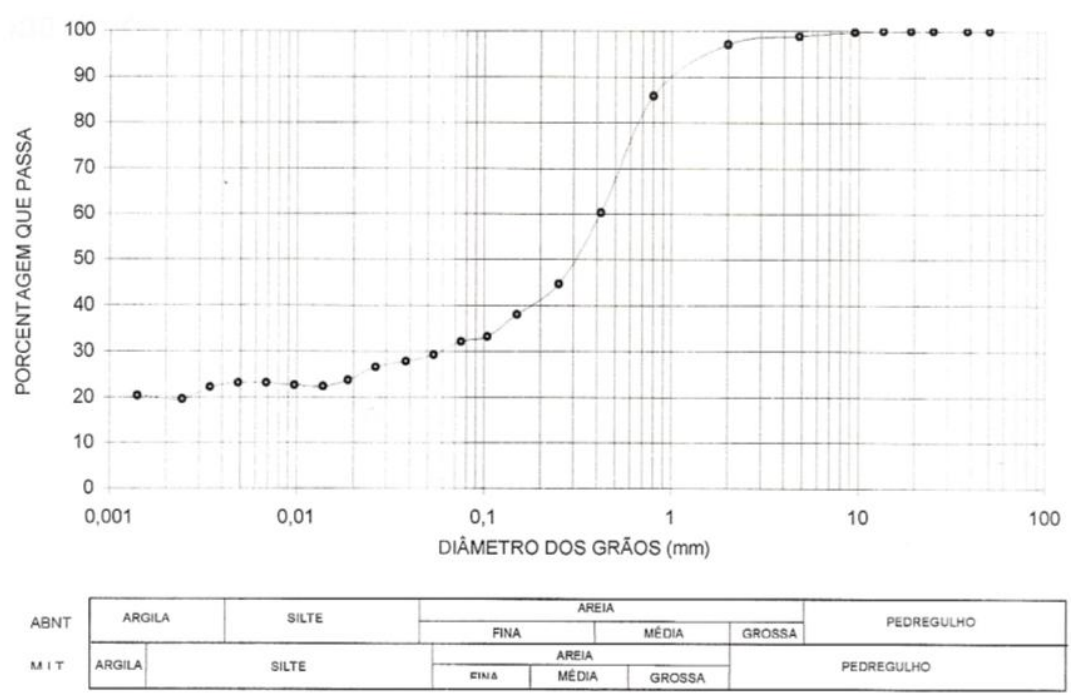

Figura 3.15 - Curva Granulométrica da amostra AM-02. 


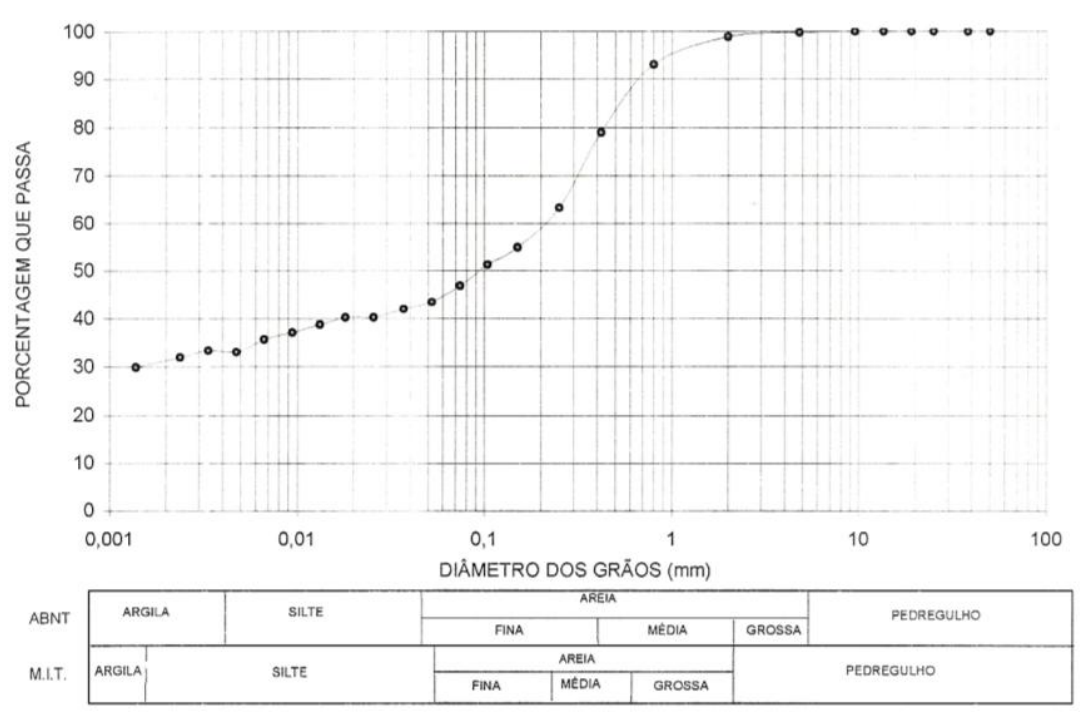

Figura 3.16 - Curva Granulométrica da amostra AM-03.

Além dos ensaios de caracterização mostrados anteriormente, foram realizados ensaios triaxiais CIU ou UU (R) em todas as cinco amostras. As amostras foram submetidas a pressões confinantes de $50 \mathrm{kPa}, 150 \mathrm{kPa}$ e $400 \mathrm{kPa}$. A seguir, nas Figuras 3.17 e 3.19, será possível ver os resultados obtidos para as amostras AM-04 e AM-05. 


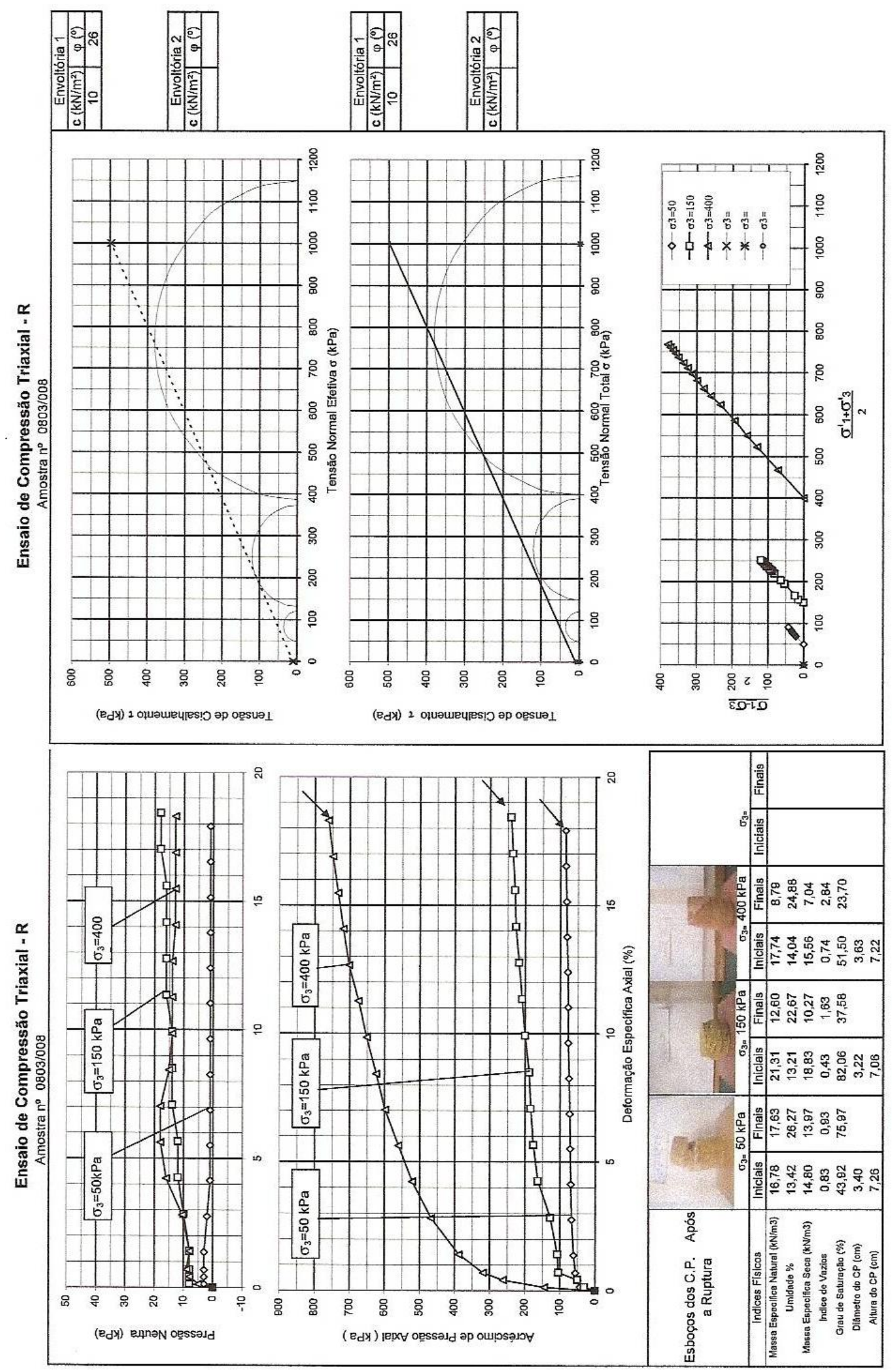

Figura 3.17 - Ensaio Triaxial para a amostra AM-04. 


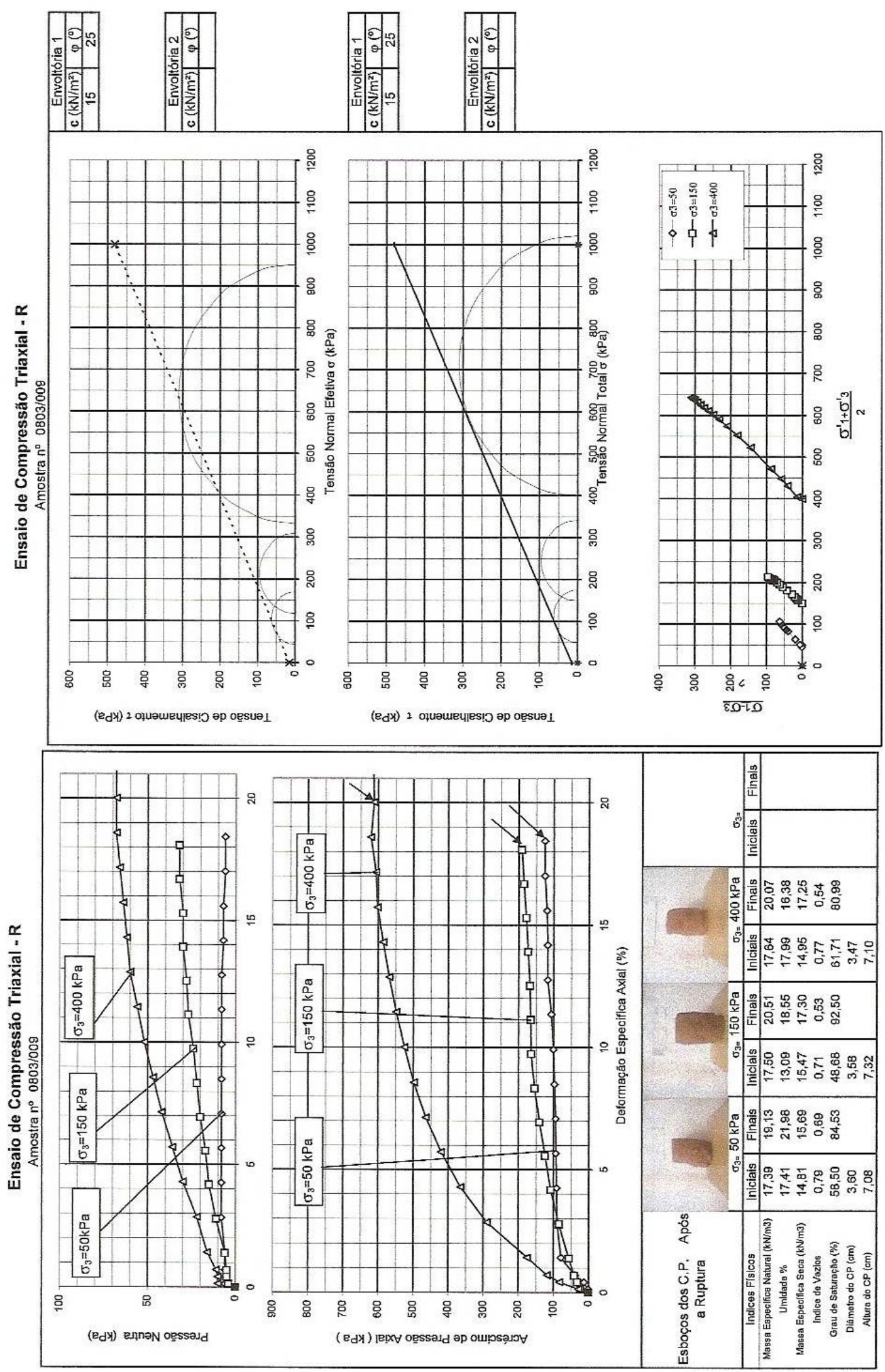

Figura 3.18 - Ensaio Triaxial para a amostra AM-05. 
Observando-se as Figuras 3.17 e 3.18, nota-se que os parâmetros de resistência, coesão e ângulo de atrito, assumiram valores iguais para as condições efetiva e total. Isso se deve ao fato do material ser predominantemente uma areia e, muito provavelmente, o índice de vazios do material estar próximo ao índice de vazios crítico.

Por fim, na Tabela 3.11, podem-se visualizar os resultados para as demais amostras, inclusive para as duas citadas anteriormente.

Tabela 3.11 - Resultados dos ensaios triaxiais das cinco amostras.

\begin{tabular}{|c|c|c|c|c|c|c|c|c|}
\hline \multirow[t]{2}{*}{ Amostras } & \multirow[t]{2}{*}{ CP } & \multicolumn{2}{|c|}{$\begin{array}{l}\text { Teor de Umidade } \\
\text { (w) [\%] }\end{array}$} & \multirow{2}{*}{$\begin{array}{c}\text { Densidade Seca } \\
\left(\rho_{\mathrm{s}}\right) \text { na ruptura } \\
{\left[\mathrm{g} / \mathrm{cm}^{3}\right]}\end{array}$} & \multirow{2}{*}{$\begin{array}{c}\text { Pressão } \\
\text { Confinante } \\
\left(\sigma_{3}\right)[\mathrm{kPa}]\end{array}$} & \multirow{2}{*}{$\begin{array}{c}\text { Deformação } \\
\text { Específica na } \\
\text { ruptura }\left(\varepsilon_{\mathrm{r}}\right)[\%]\end{array}$} & \multirow{2}{*}{$\begin{array}{c}\text { Tensão de } \\
\text { ruptura }\left(\sigma_{\mathrm{r}}\right) \\
{[\mathrm{kPa}]}\end{array}$} & \multirow{2}{*}{$\begin{array}{c}\text { Pressão Neutra } \\
\text { na ruptura }\left(u_{r}\right) \\
{[\mathrm{kPa}]}\end{array}$} \\
\hline & & Inicial & Final & & & & & \\
\hline \multirow{3}{*}{ AM -01} & 1 & 12,84 & 15,87 & 1,642 & 50 & 19,23 & 130,96 & 9,00 \\
\hline & 2 & 10,71 & 14,67 & 1,696 & 150 & 22,28 & 421,80 & 21,00 \\
\hline & 3 & 10,44 & 16,77 & 1,629 & 400 & 19,58 & 716,46 & 48,00 \\
\hline \multirow{3}{*}{ AM -02 } & 1 & 14,05 & 18,20 & 1,476 & 50 & 21,13 & 95,62 & 24,00 \\
\hline & 2 & 13,34 & 15,38 & 1,571 & 150 & 21,58 & 359,71 & 4,00 \\
\hline & 3 & 12,73 & 16,42 & 1,641 & 400 & 18,44 & 759,07 & 124,00 \\
\hline \multirow{3}{*}{ AM -03 } & 1 & 14,21 & 21,93 & 1,634 & 50 & 18,29 & 128,62 & 13,00 \\
\hline & 2 & 10,56 & 17,12 & 1,614 & 150 & 18,51 & 193,35 & 38,00 \\
\hline & 3 & 12,87 & 18,59 & 1,614 & 400 & 18,96 & 480,10 & 44,00 \\
\hline \multirow{3}{*}{ AM -04 } & 1 & 13,42 & 26,27 & 1,480 & 50 & 17,91 & 85,15 & 1,00 \\
\hline & 2 & 13,21 & 22,67 & 1,883 & 150 & 18,44 & 240,98 & 18,00 \\
\hline & 3 & 14,04 & 24,88 & 1,556 & 400 & 18,30 & 761,87 & 13,00 \\
\hline \multirow{3}{*}{ AM -05 } & 1 & 17,41 & 21,98 & 1,481 & 50 & 17,01 & 125,49 & 6,00 \\
\hline & 2 & 13,09 & 18,55 & 1,547 & 150 & 18,08 & 191,24 & 32,00 \\
\hline & 3 & 17,99 & 16,38 & 1,495 & 400 & 18,59 & 621,01 & 68,00 \\
\hline
\end{tabular}

\subsubsection{Ensaios de Obtenção do Módulo de Young do Concreto}

Para a obtenção dos módulos de Young das estacas que foram submetidas aos ensaios de carregamento estático, recorreu-se a ensaios laboratoriais conforme prescrição da NBR 8522/2003. Foram feitos ensaios somente nas estacas E.263b, referente à PC1 e a E.113, referente à PC2. Por motivos de organização e controle de obra, não foi realizado o ensaio na estaca E.25, que se refere à PC3.

Para cada uma das estacas ensaiadas, realizaram-se cinco séries de ensaios, constituídas por cinco corpos de prova cilíndricos, de dimensões 15×30cm. 
Em seguida, serão mostrados os dados obtidos para a resistência a compressão e módulo de deformação secante em uma determinada série de ensaio. Ao final, será mostrada a média dos valores dos módulos de elasticidade secante correspondentes a $40 \%$ da tensão de ruptura do ensaio, de acordo com a NBR 8522/2003. Tal média será comparada com a prescrição da NBR 6188/2003, e adotada como o valor final do módulo de elasticidade secante.

Na Tabela 3.12 é possível visualizar os valores da tensão de ruptura do concreto. Já na Tabela 3.13, são mostrados os valores de deformação específica e módulo de deformação secante para cada faixa de tensão aplicada.

Tabela 3.12 - Resistência à compressão da E.263b.

\begin{tabular}{cccc}
\hline Corpo de Prova & Diâmetro [mm] & Carga de Ruptura [N] & Resistência à Compressão [MPa] \\
\hline CP - 01 & 150 & 554884 & 31,4 \\
CP - 02 & 150 & 563720 & 31,9 \\
& & Média & 31,7 \\
\hline
\end{tabular}

Tabela 3.13 - Deformação Específica e Módulo de Deformação Secante em função da Tensão Aplicada para a estaca E.263b.

\begin{tabular}{|c|c|c|c|c|c|}
\hline \multicolumn{2}{|c|}{$\begin{array}{l}\text { Tensão Aplicada em } \\
\text { relação à Tensão } \\
\text { Prevista }\end{array}$} & \multicolumn{2}{|c|}{ CP - 03} & \multicolumn{2}{|c|}{ CP - 04} \\
\hline [\%] & [MPa] & $\begin{array}{l}\text { Deformação } \\
\text { Específica } \\
{\left[\mathrm{mm} / \mathrm{mm} \cdot 10^{-6}\right]}\end{array}$ & $\begin{array}{l}\text { Módulo de } \\
\text { Deformação } \\
\text { Secante } \\
\text { [GPa] }\end{array}$ & $\begin{array}{l}\text { Deformação } \\
\text { Específica } \\
{\left[\mathrm{mm} / \mathrm{mm} \cdot 10^{-6}\right]}\end{array}$ & $\begin{array}{c}\text { Módulo de } \\
\text { Deformação } \\
\text { Secante } \\
\text { [GPa] } \\
\end{array}$ \\
\hline Inicial & 0,5 & 102 & & 102 & \\
\hline 20 & 6,3 & 231 & 45,0 & 218 & 50,3 \\
\hline 30 & 9,5 & 435 & 27,0 & 442 & 26,4 \\
\hline 40 & 12,7 & 633 & 22,9 & 660 & 21,8 \\
\hline 50 & 15,8 & 871 & 19,9 & 857 & 20,3 \\
\hline 60 & 19,0 & 986 & 20,9 & 1034 & 19,8 \\
\hline 70 & 22,2 & 1211 & 19,5 & 1259 & 18,7 \\
\hline 80 & 25,3 & 1429 & 18,7 & 1497 & 17,8 \\
\hline
\end{tabular}

Após a determinação dos dados contidos na Tabela 3.13, para cada corpo-de-prova, foi elaborado um gráfico, no qual as deformações específicas foram colocadas na 
abscissa, enquanto as tensões aplicadas encontram-se nas ordenadas. Dele, foi feita uma regressão polinomial do segundo grau e, então, novos módulos foram calculados. Finamente, foi retirada uma média entre os valores de cada corpo de prova.

Na Tabela 3.14 podem-se ver os valores finais dos módulos de deformação secante em função da tensão axial aplicada. Por sua vez, a Figura 3.19 mostra o gráfico Tensão vs Deformação do ensaio.

Tabela 3.14 - Módulo de Deformação Secante da E.263b.

\begin{tabular}{ccc}
\hline $\begin{array}{c}\text { Tensão Aplicada em } \\
\text { relação à Tensão } \\
\text { Prevista }\end{array}$ & $\begin{array}{c}\text { Módulo de } \\
\text { Deformação } \\
\text { Secante [GPa] }\end{array}$ \\
\cline { 1 - 2 } [\%] & [MPa] & \\
\cline { 1 - 2 } Inicial & 0,5 & \\
20 & 6,3 & 27,5 \\
30 & 9,5 & 24,1 \\
$\mathbf{4 0}$ & $\mathbf{1 2 , 7}$ & $\mathbf{2 2 , 2}$ \\
50 & 15,8 & 20,8 \\
60 & 19,0 & 19,6 \\
70 & 22,2 & 18,4 \\
80 & 25,3 & 17,0 \\
\hline
\end{tabular}

\section{TENSÃO X DEFORMAÇÃO ESPECÍFICA}

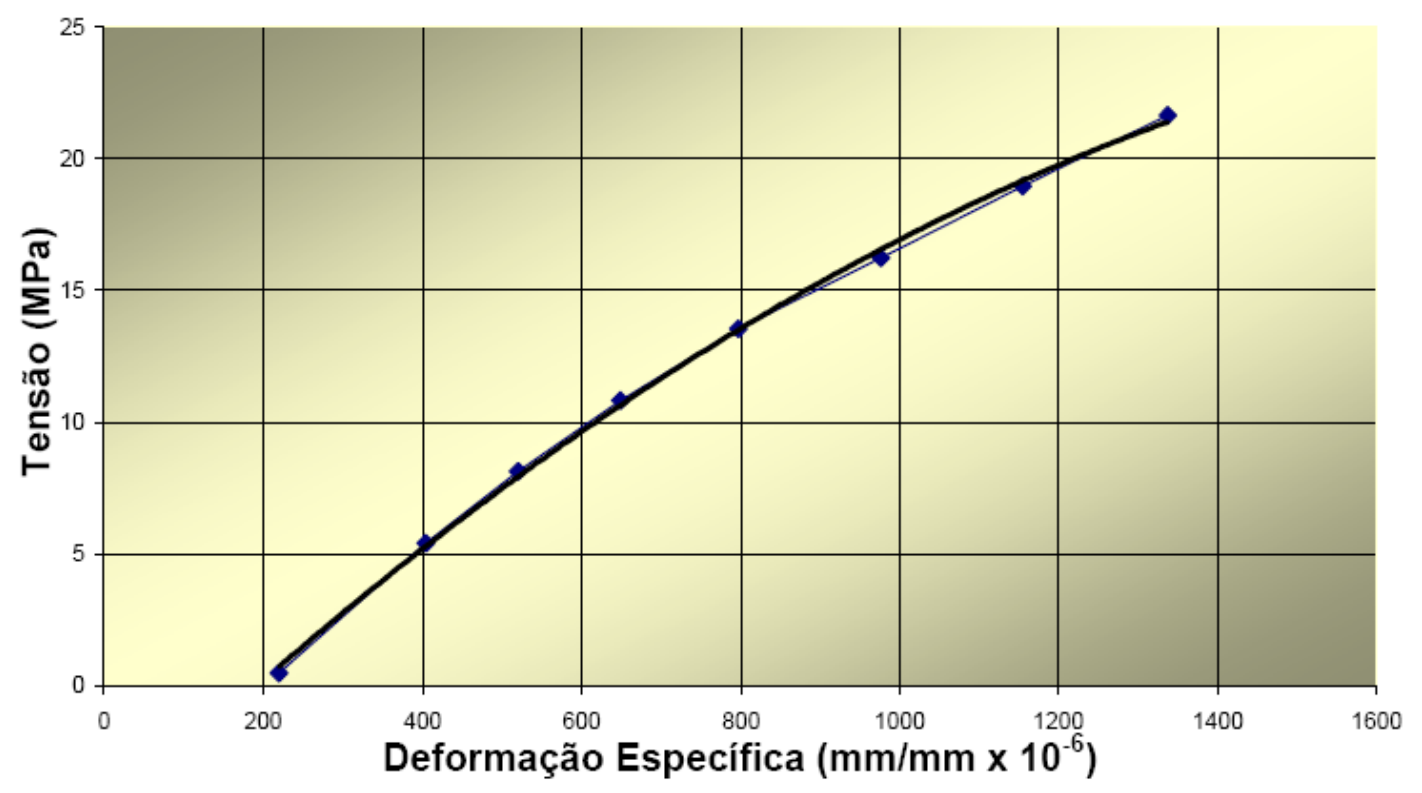

Figura 3.19 - Tensão vs Deformação da estaca E.263b. 
Comparando-se com o valor previsto indicado na NBR 6118/2003, considerando $31,70 \mathrm{MPa}$ como resistência característica do concreto, de acordo com a equação (3.3).

$$
E_{c_{s}}=0,85.5600 \cdot \sqrt{f_{c_{k}}}
$$

onde:

$$
\begin{aligned}
& \mathrm{f}_{\mathrm{ck}}=\text { Resistência característica do concreto à compressão [MPa]; } \\
& \mathrm{E}_{\mathrm{sec}}=\text { Módulo de Elasticidade Secante do Concreto [MPa]; }
\end{aligned}
$$

Chega-se ao valor de $26,8 \mathrm{GPa}$, que não se distancia muito do valor correspondente à $40 \%$ da tensão de ruptura do ensaio, conforme Tabela 3.14 .

Por sua vez, na Tabela 3.15 pode-se ver a tensão de ruptura para a estaca E.113 (PC2) e na Tabela 3.16 são mostrados os valores de deformação específica e módulo de deformação secante para cada faixa de tensão aplicada.

Tabela 3.15 - Resistência à compressão da E.113.

\begin{tabular}{cccc}
\hline Corpo de Prova & Diâmetro [mm] & Carga de Ruptura [N] & Resistência à Compressão [MPa] \\
\hline CP - 01 & 150 & 478897 & 27,1 \\
CP - 02 & 150 & 477129 & 27,0 \\
& & Média & 27,1 \\
\hline
\end{tabular}

\begin{tabular}{|c|c|c|c|c|c|c|c|}
\hline \multicolumn{2}{|c|}{$\begin{array}{l}\text { Tensão Aplicada em } \\
\text { relação à Tensão } \\
\text { Prevista }\end{array}$} & \multicolumn{2}{|c|}{$C P=03$} & \multicolumn{2}{|c|}{ CP - 04} & \multicolumn{2}{|c|}{ CP - 05} \\
\hline [\%] & [MPa] & $\begin{array}{l}\text { Deformação } \\
\text { Específica } \\
{\left[\mathrm{mm} / \mathrm{mm} \cdot 10^{-6}\right]}\end{array}$ & $\begin{array}{c}\text { Módulo de } \\
\text { Deformação } \\
\text { Secante } \\
\text { [GPa] }\end{array}$ & $\begin{array}{l}\text { Deformação } \\
\text { Específica } \\
{\left[\mathrm{mm} / \mathrm{mm} \cdot 10^{-6}\right]}\end{array}$ & $\begin{array}{l}\text { Módulo de } \\
\text { Deformação } \\
\text { Secante } \\
\text { [GPa] }\end{array}$ & $\begin{array}{l}\text { Deformação } \\
\text { Específica } \\
{\left[\mathrm{mm} / \mathrm{mm} \cdot 10^{-6}\right]}\end{array}$ & $\begin{array}{c}\text { Módulo de } \\
\text { Deformação } \\
\text { Secante } \\
\text { [GPa] }\end{array}$ \\
\hline Inicial & 0,5 & 204 & & 231 & & 224 & \\
\hline 20 & 5,4 & 395 & 25,8 & 423 & 25,6 & 395 & 28,9 \\
\hline 30 & 8,1 & 503 & 25,5 & 551 & 23,9 & 507 & 27,0 \\
\hline 40 & 10,8 & 621 & 24,8 & 690 & 22,5 & 637 & 25,0 \\
\hline 50 & 13,5 & 748 & 24,0 & 856 & 20,9 & 789 & 23,1 \\
\hline 60 & 16,2 & 897 & 22,7 & 1061 & 19,0 & 973 & 21,0 \\
\hline 70 & 18,9 & 1067 & 21,4 & 1252 & 18,1 & 1145 & 20,1 \\
\hline 80 & 21,6 & 1251 & 20,2 & 1458 & 17,3 & 1301 & 19,7 \\
\hline
\end{tabular}

Tabela 3.16 - Deformação Específica e Módulo de Deformação Secante em função da Tensão Aplicada para a estaca E.113. 
Seguindo-se o mesmo procedimento escrito anteriormente para a estaca E.263b, chega-se aos valores finais dos módulos de deformação secante em função da tensão axial aplicada, conforme Tabela 3.17. Por sua vez, a Figura 3.20 mostra o gráfico Tensão vs Deformação do ensaio.

Tabela 3.17 - Módulo de Deformação Secante da E.113.

\begin{tabular}{|c|c|c|}
\hline \multicolumn{2}{|c|}{$\begin{array}{l}\text { Tensão Aplicada em } \\
\text { relação à Tensão } \\
\text { Prevista }\end{array}$} & \multirow{2}{*}{$\begin{array}{c}\text { Módulo de } \\
\text { Deformação } \\
\text { Secante [GPa] }\end{array}$} \\
\hline [\%] & [MPa] & \\
\hline Inicial & 0,5 & \\
\hline 20 & 5,4 & 26,8 \\
\hline 30 & 8,1 & 25,4 \\
\hline 40 & 10,8 & 24,1 \\
\hline 50 & 13,5 & 22,6 \\
\hline 60 & 16,2 & 20,9 \\
\hline 70 & 18,9 & 19,8 \\
\hline 80 & 21,6 & 19,0 \\
\hline
\end{tabular}

\section{TENSÃO X DEFORMAÇÃO ESPECÍFICA}

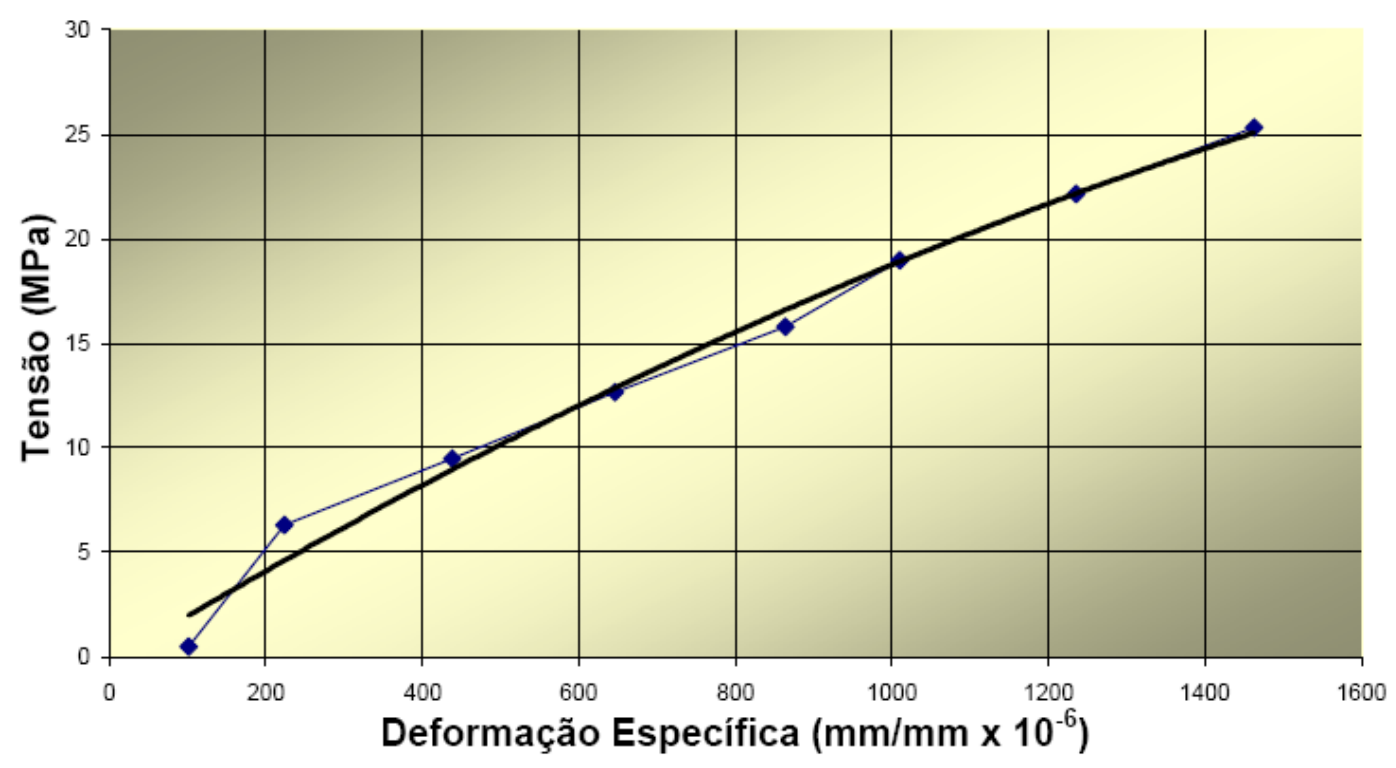

Figura 3.20 - Tensão vs Deformação da estaca E.113.

Portanto, de acordo com a Tabela 3.17, tem-se que o módulo de deformação secante é de $24,1 \mathrm{GPa}$, o qual é bem próximo do valor dado pela equação (3.3), cujo valor é 24,8GPa. 


\section{Análise dos Resultados}

\subsection{Curva Carga vs Recalque no Topo das Estacas}

De acordo com as explicações contidas nos itens 3.3.1.1, 3.3.1.2 e 3.3.1.3, pode-se registrar as cargas e os respectivos deslocamentos, com a finalidade de construir as curvas carga vs recalque para cada uma das provas de cargas estáticas.

\subsubsection{Prova de Carga 01 (E.263b)}

\section{Curva Carga vs Recalque no Topo}

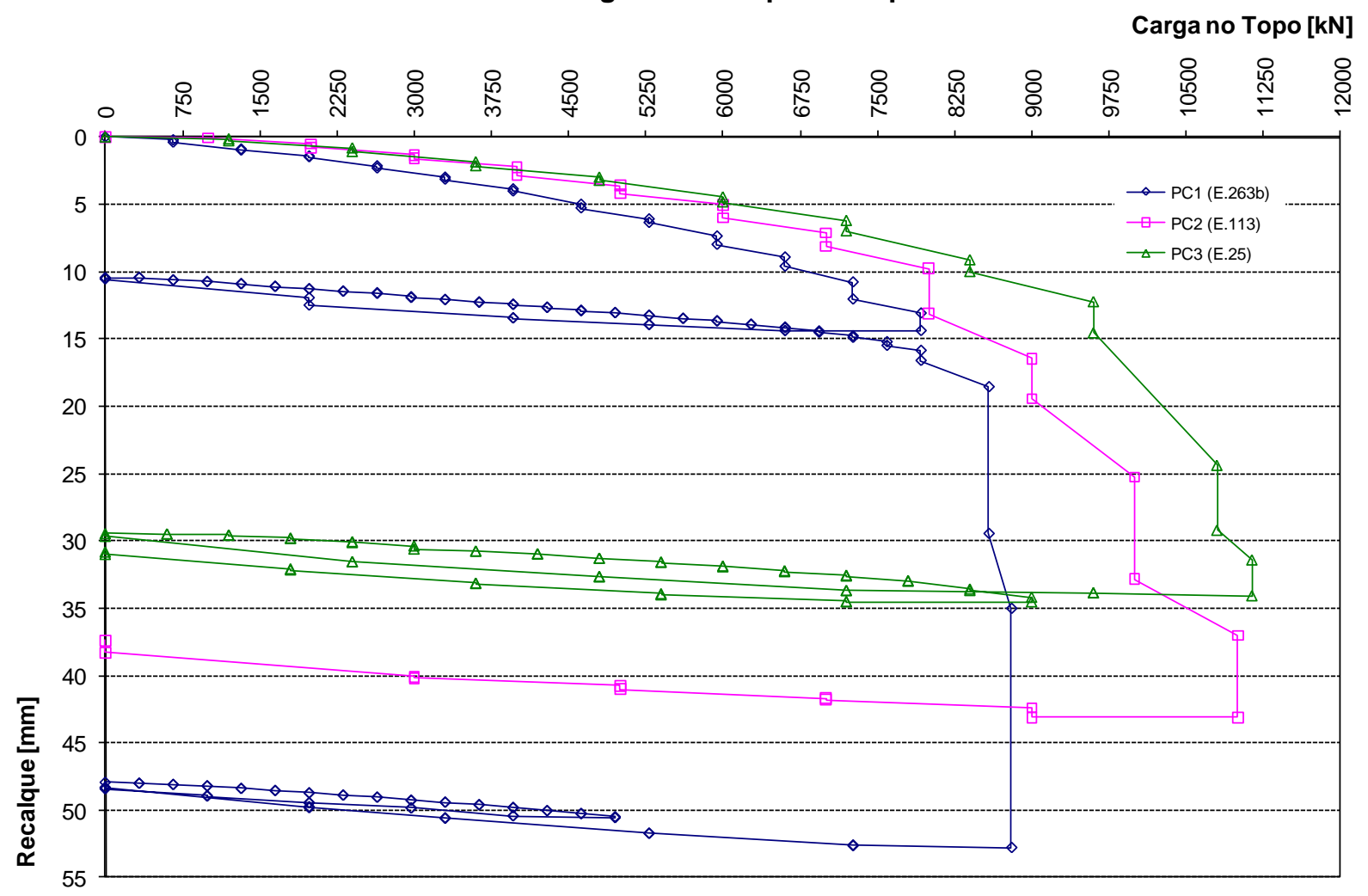

Gráfico 4.1. Carga vs Recalque no Topo (PC 01). 
A seguir, são mostradas as tabelas, as quais originaram o Gráfico 4.1, com os valores dos pares das cargas e dos recalques para cada prova de carga realizada.

Tabela 4.1 - Fases de Cargas da Primeira Prova de Carga (E.263b).

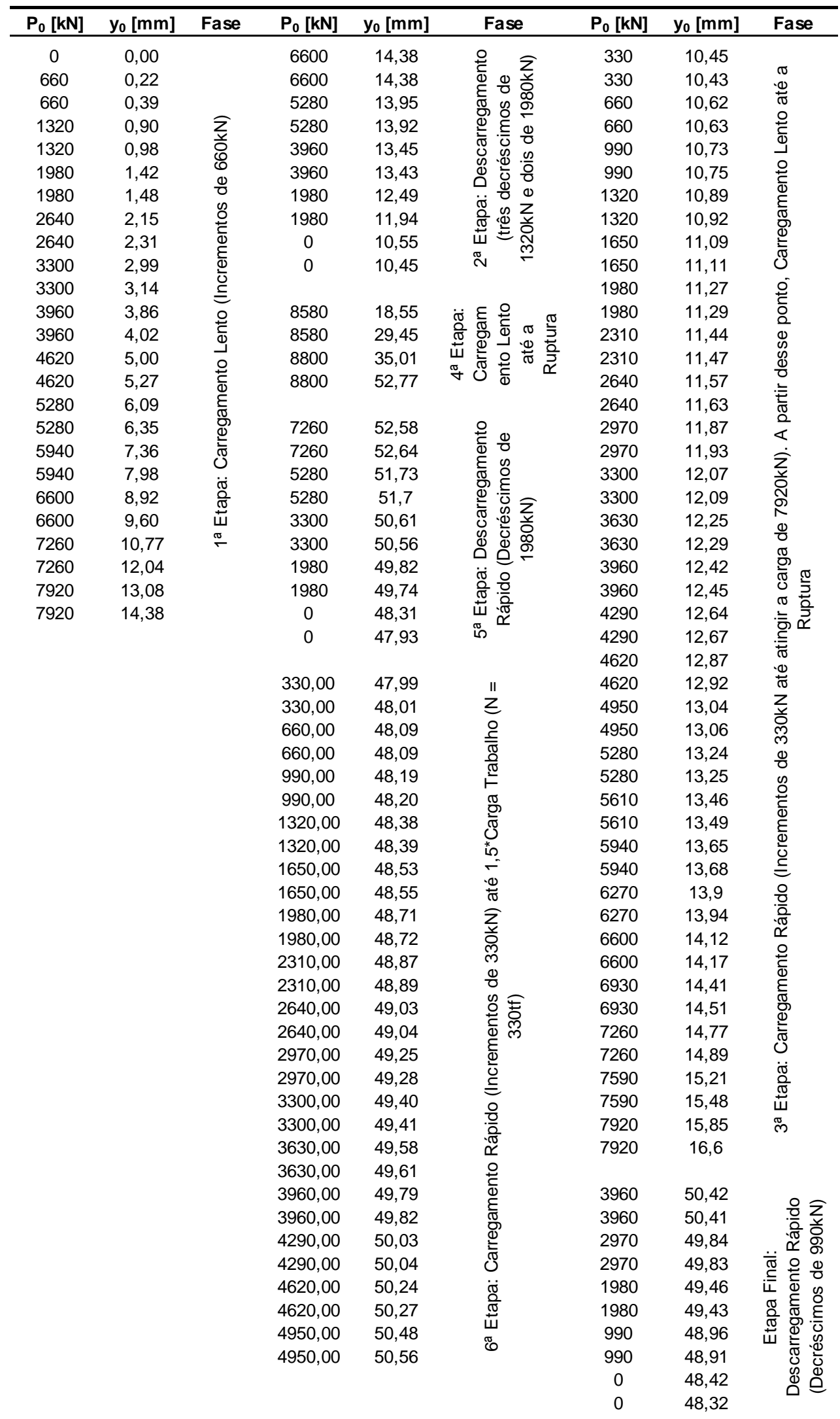


Tabela 4.2 - Fases de Cargas da Segunda Prova de Carga (E.113).

\begin{tabular}{|c|c|c|c|c|c|}
\hline$P_{0}[\mathrm{kN}]$ & $\mathrm{y}_{0}[\mathrm{~mm}]$ & Fase & $P_{0}[k N]$ & $\mathrm{y}_{0}[\mathrm{~mm}]$ & Fase \\
\hline 0 & 0,00 & \multirow{23}{*}{ 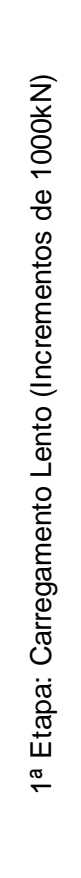 } & 9000 & 43,12 & \multirow{23}{*}{ 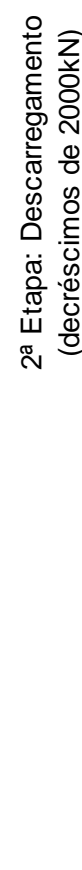 } \\
\hline 1000 & 0,04 & & 9000 & 42,40 & \\
\hline 1000 & 0,04 & & 7000 & 41,79 & \\
\hline 2000 & 0,52 & & 7000 & 41,70 & \\
\hline 2000 & 0,76 & & 5000 & 41,01 & \\
\hline 3000 & 1,31 & & 5000 & 40,77 & \\
\hline 3000 & 1,60 & & 3000 & 40,18 & \\
\hline 4000 & 2,24 & & 3000 & 40,10 & \\
\hline 4000 & 2,81 & & 0 & 38,28 & \\
\hline 5000 & 3,60 & & 0 & 37,38 & \\
\hline 5000 & 4,20 & & & & \\
\hline 6000 & 5,04 & & & & \\
\hline 6000 & 6,00 & & & & \\
\hline 7000 & 7,12 & & & & \\
\hline 7000 & 8,11 & & & & \\
\hline 8000 & 9,77 & & & & \\
\hline 8000 & 13,14 & & & & \\
\hline 9000 & 16,45 & & & & \\
\hline 9000 & 19,42 & & & & \\
\hline 10000 & 25,26 & & & & \\
\hline 10000 & 32,84 & & & & \\
\hline 11000 & 37,04 & & & & \\
\hline 11000 & 43,12 & & & & \\
\hline
\end{tabular}


Tabela 4.3 - Fases de Cargas da Terceira Prova de Carga (E.25).

\begin{tabular}{|c|c|c|c|c|c|c|c|c|}
\hline$P_{0}[k N]$ & $\mathrm{y}_{0}[\mathrm{~mm}]$ & Fase & $P_{0}[k N]$ & $\mathrm{y}_{0}[\mathrm{~mm}]$ & Fase & $P_{0}[k N]$ & $\mathrm{y}_{0}[\mathrm{~mm}]$ & Fase \\
\hline 0 & 0,00 & & 600 & 29,48 & $\|$ & 7200 & 34,51 & \multirow{32}{*}{ 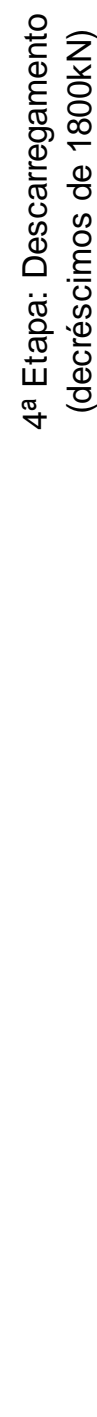 } \\
\hline 1200 & 0,14 & $\widehat{\underline{z}}$ & 600 & 29,48 & $z$ & 7200 & 34,50 & \\
\hline 1200 & 0,28 & 훙 & 1200 & 29,55 & 옫 & 5400 & 34,00 & \\
\hline 2400 & 0,81 & $\stackrel{\sim}{\sim}$ & 1200 & 29,58 & 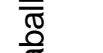 & 5400 & 33,92 & \\
\hline 2400 & 1,08 & $\frac{0}{0}$ & 1800 & 29,78 & $\stackrel{\text { तై }}{\models}$ & 3600 & 33,16 & \\
\hline 3600 & 1,85 & ஜ & 1800 & 29,82 & శ్ & 3600 & 33,13 & \\
\hline 3600 & 2,13 & $\frac{5}{0}$ & 2400 & 30,05 & స్ల & 1800 & 32,15 & \\
\hline 4800 & 2,98 & $\frac{E}{\mathcal{O}}$ & 2400 & 30,12 & * & 1800 & 32,07 & \\
\hline 4800 & 3,22 & $\overline{0}$ & 3000 & 30,37 & $=$ & 0 & 31,00 & \\
\hline 6000 & 4,45 & $\underbrace{=}_{0}$ & 3000 & 30,6 & $\stackrel{\oplus}{\oplus}$ & 0 & 30,82 & \\
\hline 6000 & 4,82 & $\frac{\underline{T}}{0}$ & 3600 & 30,75 & $\widehat{z}$ & & & \\
\hline 7200 & 6,20 & $\stackrel{\Xi}{0}$ & 3600 & 30,76 & 흥 & & & \\
\hline 7200 & 6,97 & $\stackrel{0}{\stackrel{0}{c}}$ & 4200 & 30,94 & 0 & & & \\
\hline 8400 & 9,12 & $\stackrel{\oplus}{E}$ & 4200 & 30,97 & $\frac{1}{0}$ & & & \\
\hline 8400 & 9,99 & ర్ర & 4800 & 31,28 & 응 & & & \\
\hline 9600 & 12,23 & 离 & 4800 & 31,28 & Ф & & & \\
\hline 9600 & 14,55 & 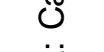 & 5400 & 31,56 & 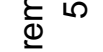 & & & \\
\hline 10800 & 24,39 & $\stackrel{\pi}{\pi}$ & 5400 & 31,59 & $\subseteq$ & & & \\
\hline 10800 & 29,21 & $\stackrel{w}{\omega}$ & 6000 & 31,86 & 0 & & & \\
\hline 11140 & 31,41 & $\stackrel{\sigma 1}{\Gamma}$ & 6000 & 31,92 & $\frac{0}{2}$ & & & \\
\hline \multirow[t]{2}{*}{11140} & 34,07 & & 6600 & 32,21 & 离 & & & \\
\hline & & & 6600 & 32,28 & $\stackrel{0}{\stackrel{2}{c}}$ & & & \\
\hline 9600 & 33,85 & 을 & 7200 & 32,54 & $\bar{\Phi}$ & & & \\
\hline 9600 & 33,85 & 我 & 7200 & 32,6 & స్ & & & \\
\hline 7200 & 33,68 & ㅌ్ ర్ & 7800 & 32,94 & $\stackrel{\infty}{\varrho}$ & & & \\
\hline 7200 & 33,68 & $\stackrel{0}{0}$ & 7800 & 32,99 & ర & & & \\
\hline 4800 & 32,67 & ర్ ర్ల & 8400 & 33,57 & $\ddot{\nabla}$ & & & \\
\hline 4800 & 32,63 & $\stackrel{\text { \& }}{\varepsilon}$ & 8400 & 33,68 & \pm & & & \\
\hline 2400 & 31,54 & 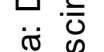 & 9000 & 34,18 & Ш & & & \\
\hline 2400 & 31,54 & 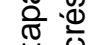 & 9000 & 34,52 & $m$ & & & \\
\hline 0 & 29,66 & Шे & & & & & & \\
\hline 0 & 29,46 & ñ & & & & & & \\
\hline
\end{tabular}




\subsection{Diagramas de Módulo Tangente}

De acordo com as equações contidas no item 2.6, e das tabelas de deformações específicas obtidas nos ensaios estáticos, foi possível a construção dos diagramas referentes ao método do módulo tangente para cada prova de carga realizada.

\subsubsection{Prova de Carga 01 (E.263b)}

Tabela 4.4 - Deformações Específicas da Prova de Carga 01.

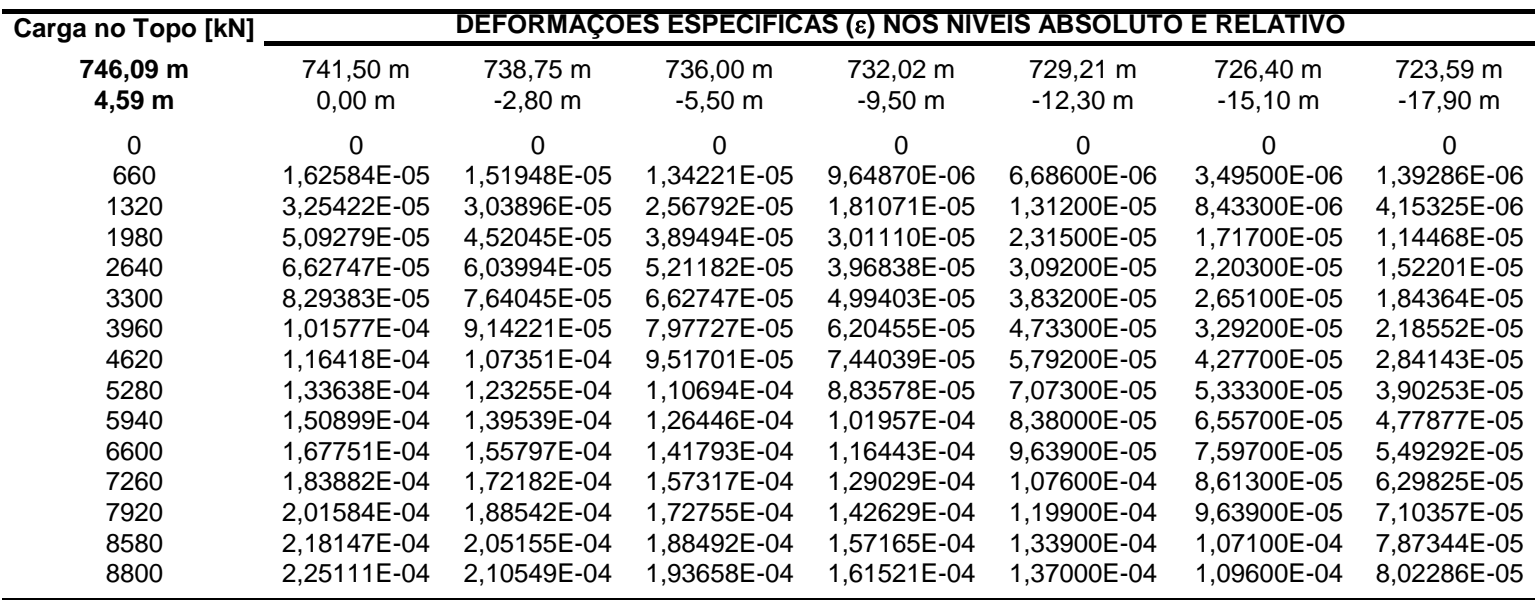

Método do Módulo Tangente - PC 1 (E263)

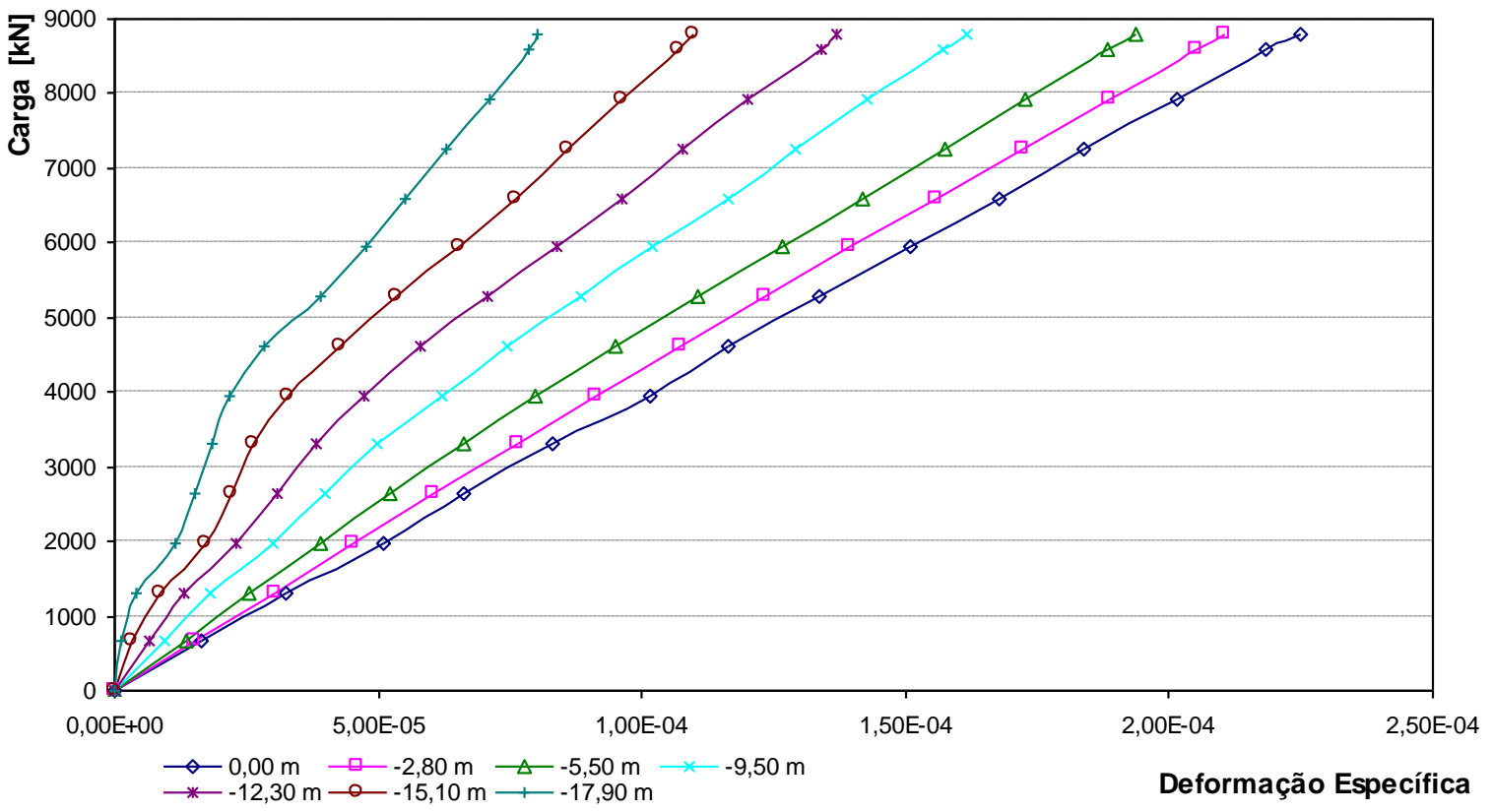

Gráfico 4.2. Diagrama Módulo Tangente da Prova de Carga 01. 
Tabela 4.5 - Valores do Produto ES Obtidos da Prova de Carga 01.

\begin{tabular}{ccc}
\hline Nível & Produto ES [kN] & Produto ES [GN] \\
\hline $0,00 \mathrm{~m}$ & 39100829,43 & 39,10 \\
$-2,80 \mathrm{~m}$ & 41130304,91 & 41,13 \\
$-5,50 \mathrm{~m}$ & 43163902,65 & 43,16 \\
$-9,50 \mathrm{~m}$ & 48858997,37 & 48,86 \\
$-12,30 \mathrm{~m}$ & 52904362,09 & 52,90 \\
$-15,10 \mathrm{~m}$ & 62247441,61 & 62,25 \\
$-17,90 \mathrm{~m}$ & 84823449,23 & 84,82 \\
\hline
\end{tabular}

Observe que a partir do quarto nível instrumentado, os valores começaram a se distoar em relação aos três primeiros. Uma possível explicação para isso pode ser a não uniformidade da seção escavada em profundidade.

\subsubsection{Prova de Carga 02 (E.113)}

Tabela 4.6 - Deformações Específicas da Prova de Carga 02.

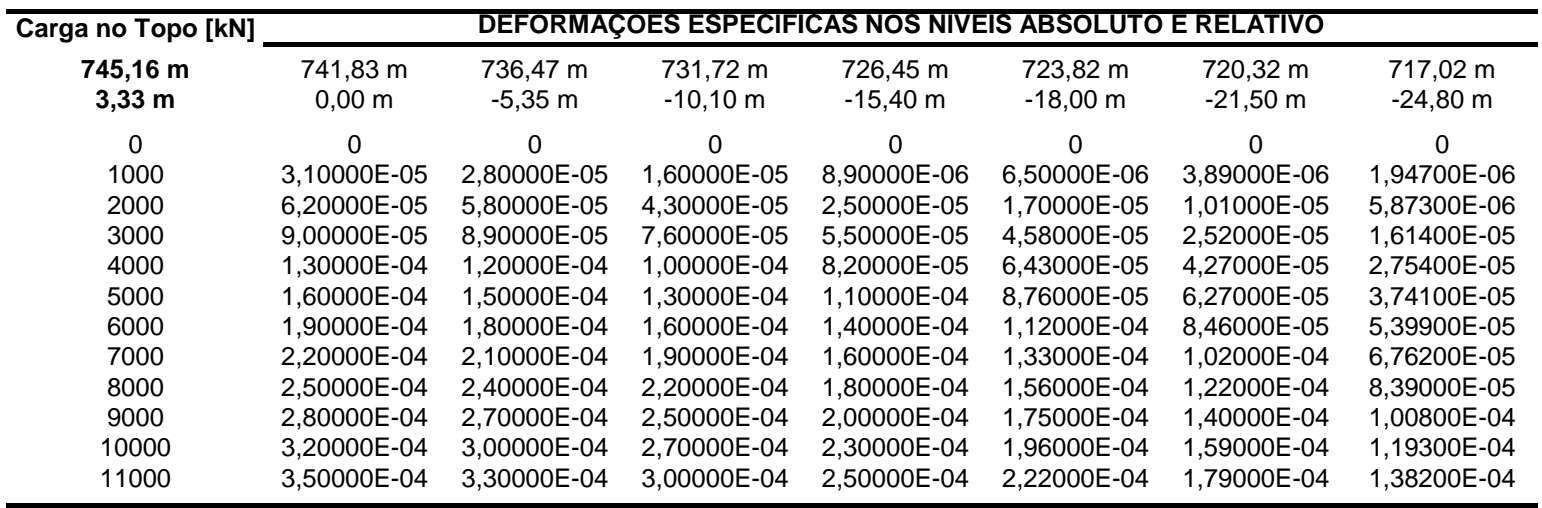


Método do Módulo Tangente - PC 2 (E113)

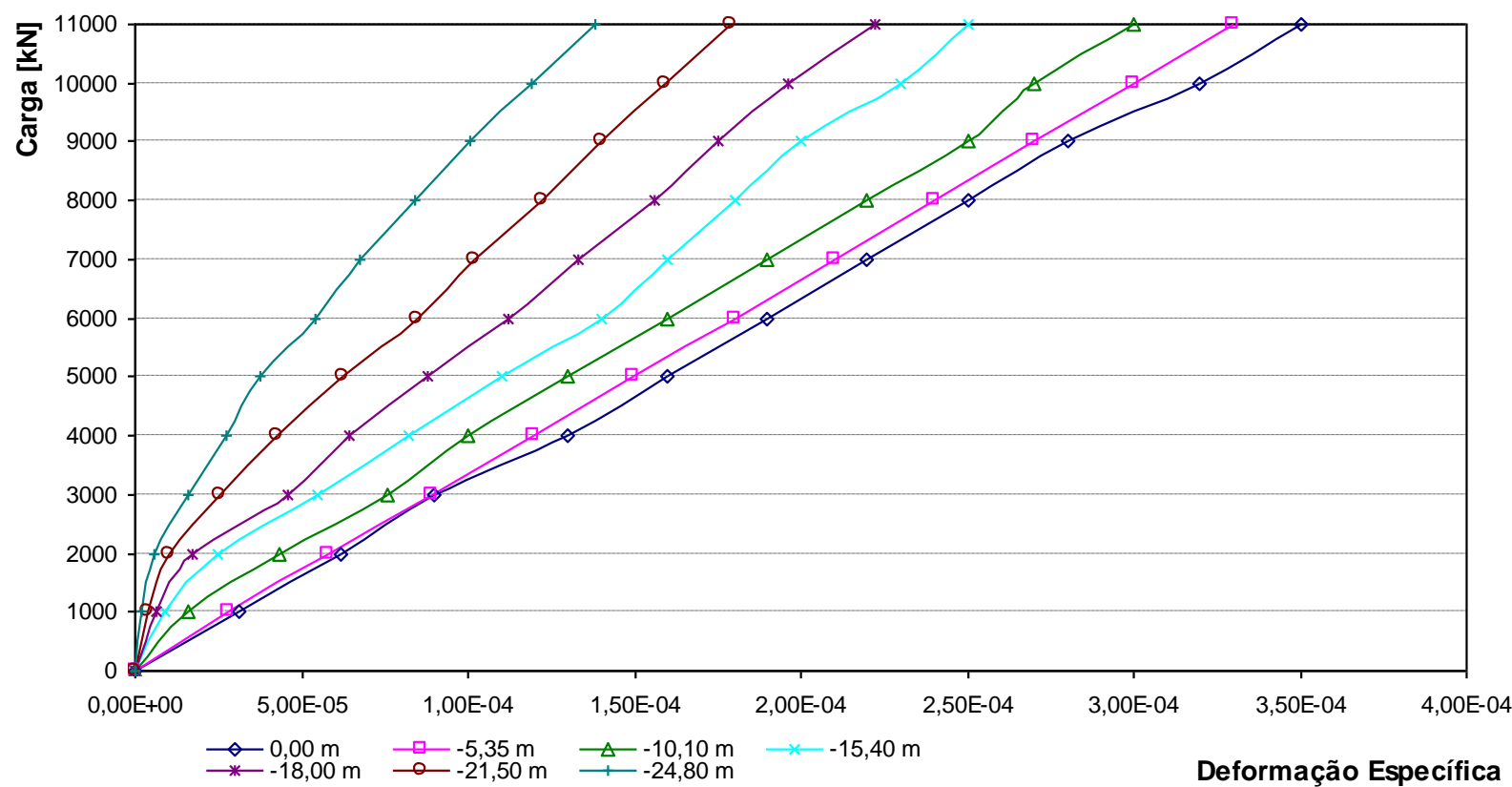

Gráfico 4.3. Diagrama Módulo Tangente da Prova de Carga 02.

Tabela 4.7 - Valores do Produto ES Obtidos da Prova de Carga 02.

\begin{tabular}{ccc}
\hline Nível & Produto ES [kN] & Produto ES [GN] \\
\hline $0,00 \mathrm{~m}$ & 31768953,07 & 31,77 \\
$-5,35 \mathrm{~m}$ & 33189048,94 & 33,19 \\
$-10,10 \mathrm{~m}$ & 34911976,86 & 34,91 \\
$-15,40 \mathrm{~m}$ & 41389589,54 & 41,39 \\
$-18,00 \mathrm{~m}$ & 45168335,56 & 45,17 \\
$-21,50 \mathrm{~m}$ & 51880484,96 & 51,88 \\
$-24,80 \mathrm{~m}$ & 59914820,74 & 59,91 \\
\hline
\end{tabular}

Neste ensaio também houve uma discrepância nos valores a partir do quarto nível instrumentado. Aqui também vale a explicação da não uniformidade da seção nominal de escavação. 


\subsubsection{Prova de Carga 03 (E.25)}

Tabela 4.8 - Deformações Específicas da Prova de Carga 03

\begin{tabular}{cccccccc}
\hline Carga no Topo [kN] & \multicolumn{7}{c}{ DEFORMAÇOES ESPECIFICAS NOS NIVEIS ABSOLUTOE RELATIVO } \\
\cline { 2 - 8 } $\mathbf{7 4 4 , 7 2 ~} \mathbf{m}$ & $743,72 \mathrm{~m}$ & $738,27 \mathrm{~m}$ & $732,94 \mathrm{~m}$ & $729,72 \mathrm{~m}$ & $723,30 \mathrm{~m}$ & $718,20 \mathrm{~m}$ & $714,99 \mathrm{~m}$ \\
$\mathbf{1 , 0 0} \mathbf{m}$ & $0,00 \mathrm{~m}$ & $-5,45 \mathrm{~m}$ & $-10,80 \mathrm{~m}$ & $-14,00 \mathrm{~m}$ & $-20,40 \mathrm{~m}$ & $-25,50 \mathrm{~m}$ & $-28,70 \mathrm{~m}$ \\
0 & 0 & 0 & 0 & 0 & 0 & 0 & 0 \\
1200 & $3,12300 \mathrm{E}-05$ & $3,07300 \mathrm{E}-05$ & $2,40000 \mathrm{E}-05$ & $1,98620 \mathrm{E}-05$ & $9,85100 \mathrm{E}-06$ & $5,61000 \mathrm{E}-06$ & $4,19000 \mathrm{E}-06$ \\
2400 & $6,26600 \mathrm{E}-05$ & $6,05500 \mathrm{E}-05$ & $5,36850 \mathrm{E}-05$ & $4,55430 \mathrm{E}-05$ & $2,67500 \mathrm{E}-05$ & $1,33000 \mathrm{E}-05$ & $9,77000 \mathrm{E}-06$ \\
3600 & $9,55200 \mathrm{E}-05$ & $8,86600 \mathrm{E}-05$ & $8,04880 \mathrm{E}-05$ & $7,17320 \mathrm{E}-05$ & $4,23700 \mathrm{E}-05$ & $2,36000 \mathrm{E}-05$ & $1,56000 \mathrm{E}-05$ \\
4800 & $1,25500 \mathrm{E}-04$ & $1,20700 \mathrm{E}-04$ & $1,04430 \mathrm{E}-04$ & $8,80700 \mathrm{E}-05$ & $5,46200 \mathrm{E}-05$ & $3,50000 \mathrm{E}-05$ & $2,41000 \mathrm{E}-05$ \\
6000 & $1,61700 \mathrm{E}-04$ & $1,52500 \mathrm{E}-04$ & $1,33590 \mathrm{E}-04$ & $1,17140 \mathrm{E}-04$ & $8,16100 \mathrm{E}-05$ & $5,30000 \mathrm{E}-05$ & $3,50000 \mathrm{E}-05$ \\
7200 & $1,94900 \mathrm{E}-04$ & $1,84200 \mathrm{E}-04$ & $1,65270 \mathrm{E}-04$ & $1,48800 \mathrm{E}-04$ & $1,07900 \mathrm{E}-04$ & $7,42000 \mathrm{E}-05$ & $5,31000 \mathrm{E}-05$ \\
8400 & $2,22800 \mathrm{E}-04$ & $2,13600 \mathrm{E}-04$ & $1,94720 \mathrm{E}-04$ & $1,77310 \mathrm{E}-04$ & $1,33300 \mathrm{E}-04$ & $9,38000 \mathrm{E}-05$ & $6,74000 \mathrm{E}-05$ \\
9600 & $2,53700 \mathrm{E}-04$ & $2,45600 \mathrm{E}-04$ & $2,26510 \mathrm{E}-04$ & $2,09000 \mathrm{E}-04$ & $1,62900 \mathrm{E}-04$ & $1,20000 \mathrm{E}-04$ & $9,03000 \mathrm{E}-05$ \\
10800 & $2,93300 \mathrm{E}-04$ & $2,77300 \mathrm{E}-04$ & $2,57430 \mathrm{E}-04$ & $2,39200 \mathrm{E}-04$ & $1,91800 \mathrm{E}-04$ & $1,42000 \mathrm{E}-04$ & $1,10000 \mathrm{E}-04$ \\
11140 & $3,06400 \mathrm{E}-04$ & $2,85500 \mathrm{E}-04$ & $2,64480 \mathrm{E}-04$ & $2,45520 \mathrm{E}-04$ & $1,97200 \mathrm{E}-04$ & $1,46000 \mathrm{E}-04$ & $1,13000 \mathrm{E}-04$ \\
\hline
\end{tabular}

Método do Módulo Tangente - PC 3 (E25)

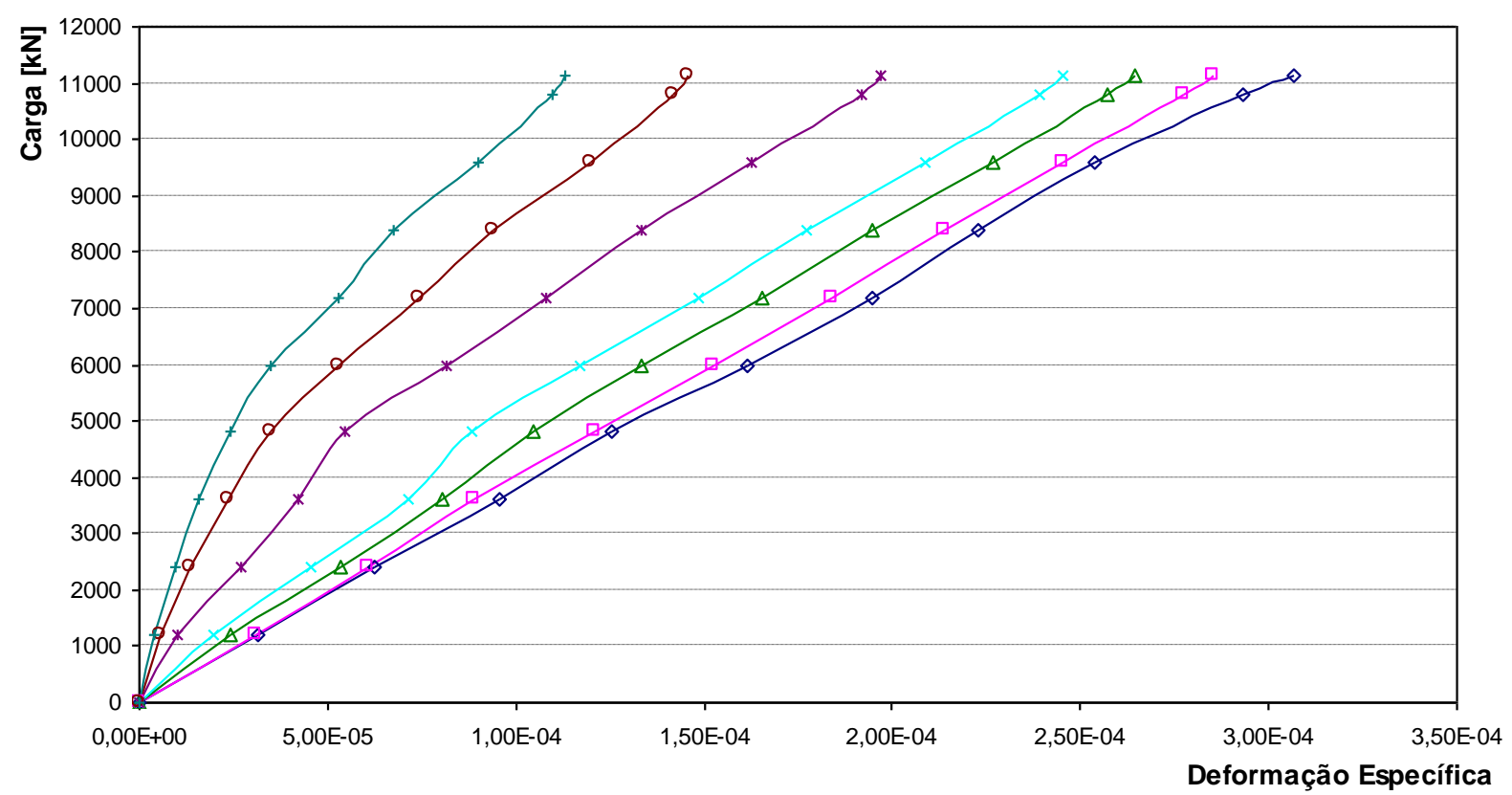

Gráfico 4.4. Diagrama Módulo Tangente da Prova de Carga 03.

Tabela 4.9 - Valores do Produto ES Obtidos da Prova de Carga 03.

\begin{tabular}{|c|c|c|}
\hline Nível & Produto ES [kN] & Produto ES [GN] \\
\hline $0,00 \mathrm{~m}$ & 36735680,85 & 36,74 \\
\hline$-5,45 m$ & 38904505,07 & 38,90 \\
\hline$-10,80 \mathrm{~m}$ & 39280119,39 & 39,28 \\
\hline$-14,00 \mathrm{~m}$ & 39808671,71 & 39,81 \\
\hline$-20,40 m$ & 44072248,12 & 44,07 \\
\hline$-25,50 m$ & 55566690,61 & 55,57 \\
\hline$-28,70 m$ & 64272054,37 & 64,27 \\
\hline
\end{tabular}




\subsection{Diagramas de Transferência de Carga}

De posse do produto ES obtido no item 4.2 e com os dados de deformação específicas mostrados no mesmo item, foi possível calcular as cargas ao longo do fuste das estacas instrumentadas, conforme equação (2.3), apresentada no item 2.3. A seguir, nas próximas tabelas e gráficos, é possível visualizar as cargas calculadas e os diagramas de transferência de carga para as estacas E.263b, E.113 e E.25.

\subsubsection{Prova de Carga 01 (E.263b)}

Conforme dito anteriormente, o cálculo das cargas ao longo do fuste depende do valor do produto ES e da deformação específica. Os valores do produto ES constam na Tabela 4.5, enquanto os valores da deformação específica, na Tabela 4.4.

Dos valores mostrados do produto ES foi adotado o valor de $39 \mathrm{GN}$ como o valor representativo para a PC01. No topo da estaca este valor corresponde a $E=$ 34,5GPa, que é superior ao valor máximo de 27,5GPa, mostrado na Tabela 3.14. Tomou-se este valor pelo fato da máxima tensão aplicada no topo da estaca ser da ordem de 7,8MPa. Sendo assim, as cargas em profundidade estão mostradas na Tabela 4.10 e o diagrama de transferência de carga, no Gráfico 4.5. 
Tabela 4.10 - Cargas Axiais ao longo do fuste da estaca E.263b.

\begin{tabular}{|c|c|c|c|c|c|c|c|c|}
\hline \multirow{2}{*}{$\begin{array}{c}\text { Carga no Topo [kN] } \\
746,09 \mathrm{~m} \\
4,59 \mathrm{~m} \\
\end{array}$} & \multicolumn{8}{|c|}{ CARGAS [kN] NOS NÍVEIS ABSOLUTO E RELATIVO } \\
\hline & $\begin{array}{c}741,50 \mathrm{~m} \\
0,00 \mathrm{~m} \\
\end{array}$ & $\begin{array}{c}738,75 \mathrm{~m} \\
-2,80 \mathrm{~m} \\
\end{array}$ & $\begin{array}{c}736,00 \mathrm{~m} \\
-5,50 \mathrm{~m} \\
\end{array}$ & $\begin{array}{c}732,02 \mathrm{~m} \\
-9,50 \mathrm{~m} \\
\end{array}$ & $\begin{array}{l}729,21 \mathrm{~m} \\
-12,30 \mathrm{~m} \\
\end{array}$ & $\begin{array}{l}726,40 \mathrm{~m} \\
-15,10 \mathrm{~m} \\
\end{array}$ & $\begin{array}{l}723,59 \mathrm{~m} \\
-17,90 \mathrm{~m} \\
\end{array}$ & $\begin{array}{l}722,30 m_{1}^{\prime} \\
-19,20 m_{1}^{\prime}\end{array}$ \\
\hline 660 & 660 & 593 & 523 & 376 & 261 & 136 & 54 & 16 \\
\hline 1320 & 1320 & 1185 & 1001 & 706 & 512 & 329 & 162 & 85 \\
\hline 1980 & 1980 & 1763 & 1519 & 1174 & 903 & 670 & 446 & 343 \\
\hline 3960 & 3960 & 3565 & 3111 & 2420 & 1846 & 1284 & 852 & 653 \\
\hline 4620 & 4620 & 4187 & 3712 & 2902 & 2259 & 1668 & 1108 & 850 \\
\hline 5280 & 5280 & 4807 & 4317 & 3446 & 2758 & 2080 & 1522 & 1265 \\
\hline 5940 & 5940 & 5442 & 4931 & 3976 & 3268 & 2557 & 1864 & 1545 \\
\hline 6600 & 6600 & 6076 & 5530 & 4541 & 3759 & 2963 & 2142 & 1764 \\
\hline 7260 & 7260 & 6715 & 6135 & 5032 & 4196 & 3359 & 2456 & 2040 \\
\hline 7920 & 7920 & 7353 & 6737 & 5563 & 4676 & 3759 & 2770 & 2314 \\
\hline
\end{tabular}

Valores Extrapolados

\section{Diagrama de Transferência de Carga PC 1 (E263)}

Carga $[k N]$

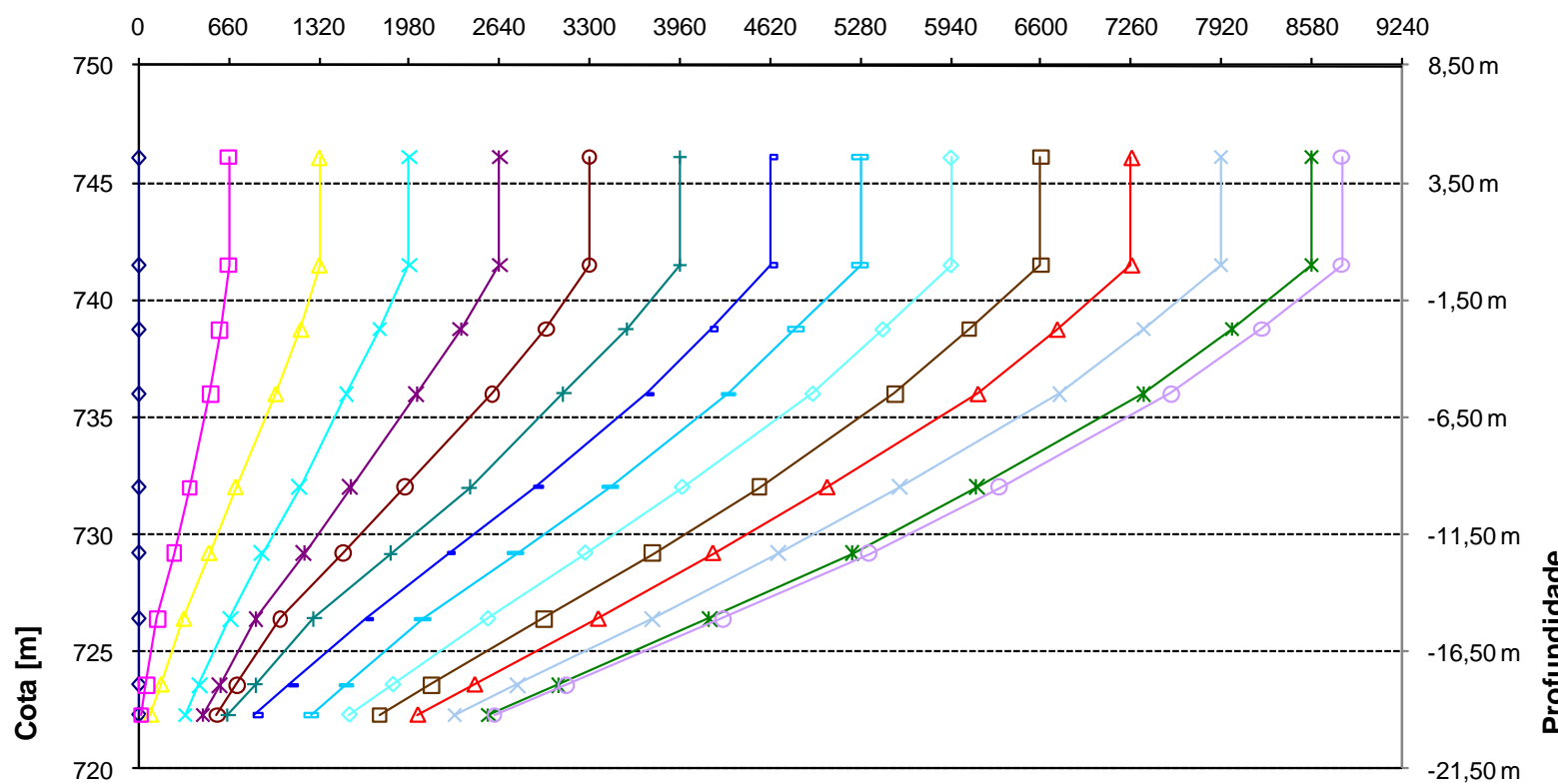

Gráfico 4.5. Transferência de Carga ao longo do fuste da estaca E.263b. 


\subsubsection{Prova de Carga 02 (E.113)}

Analogamente ao que foi descrito no item anterior, tem-se as cargas em profundidade, que estão mostradas na Tabela 4.11 e o diagrama de transferência de carga, no Gráfico 4.6. Os valores do produto ES constam na Tabela 4.7, enquanto os valores da deformação específica, na Tabela 4.6. Dos valores mostrados do produto ES foi adotado o valor de 32GN como o valor representativo para a PC02. No topo da estaca este valor corresponde a $E=28,3 \mathrm{GPa}$, que está próximo ao valor máximo de 26,8GPa, mostrado na Tabela 3.17. Tomou-se este valor pelo fato da máxima tensão aplicada no topo da estaca ser da ordem de 9,7MPa.

Tabela 4.11 - Cargas Axiais ao longo do fuste da estaca E.113.

\begin{tabular}{|c|c|c|c|c|c|c|c|c|}
\hline \multirow{2}{*}{$\begin{array}{c}\text { Carga no Topo [kN] } \\
745,16 \mathrm{~m} \\
3,33 \mathrm{~m} \\
\end{array}$} & \multicolumn{8}{|c|}{ CARGAS [kN] NOS NÍVEIS ABSOLUTO E RELATIVO } \\
\hline & $\begin{array}{c}741,83 \mathrm{~m} \\
0,00 \mathrm{~m} \\
\end{array}$ & $\begin{array}{c}736,47 m \\
-5,35 m \\
\end{array}$ & $\begin{array}{l}731,72 \mathrm{~m} \\
-10,10 \mathrm{~m}\end{array}$ & $\begin{array}{l}726,45 \mathrm{~m} \\
-15,40 \mathrm{~m} \\
\end{array}$ & $\begin{array}{l}723,82 \mathrm{~m} \\
-18,00 \mathrm{~m} \\
\end{array}$ & $\begin{array}{l}720,32 \mathrm{~m} \\
-21,50 \mathrm{~m} \\
\end{array}$ & $\begin{array}{l}717,02 \mathrm{~m} \\
-24,80 \mathrm{~m} \\
\end{array}$ & $\begin{array}{r}714,36 \mathrm{~m} \\
\quad-27,46 \mathrm{~m} \\
\end{array}$ \\
\hline 1000 & 1000 & 896 & 512 & 285 & 208 & 124 & 62 & 12 \\
\hline 2000 & 2000 & 1856 & 1376 & 800 & 544 & 323 & 188 & 79 \\
\hline 3000 & 3000 & 2848 & 2432 & 1760 & 1466 & 806 & 516 & 282 \\
\hline 4000 & 4000 & 3840 & 3200 & 2624 & 2058 & 1366 & 881 & 490 \\
\hline 7000 & 7000 & 6720 & 6080 & 5120 & 4256 & 3264 & 2164 & 1277 \\
\hline 8000 & 8000 & 7680 & 7040 & 5760 & 4992 & 3904 & 2685 & 1702 \\
\hline 9000 & 9000 & 8640 & 8000 & 6400 & 5600 & 4480 & 3226 & 2215 \\
\hline 10000 & 10000 & 9600 & 8640 & 7360 & 6272 & 5088 & 3818 & 2794 \\
\hline 11000 & 11000 & 10560 & 9600 & 8000 & 7104 & 5728 & 4422 & 3369 \\
\hline
\end{tabular}

Diagrama de Transferência de Carga PC 2 (E113)

Carga [kN]

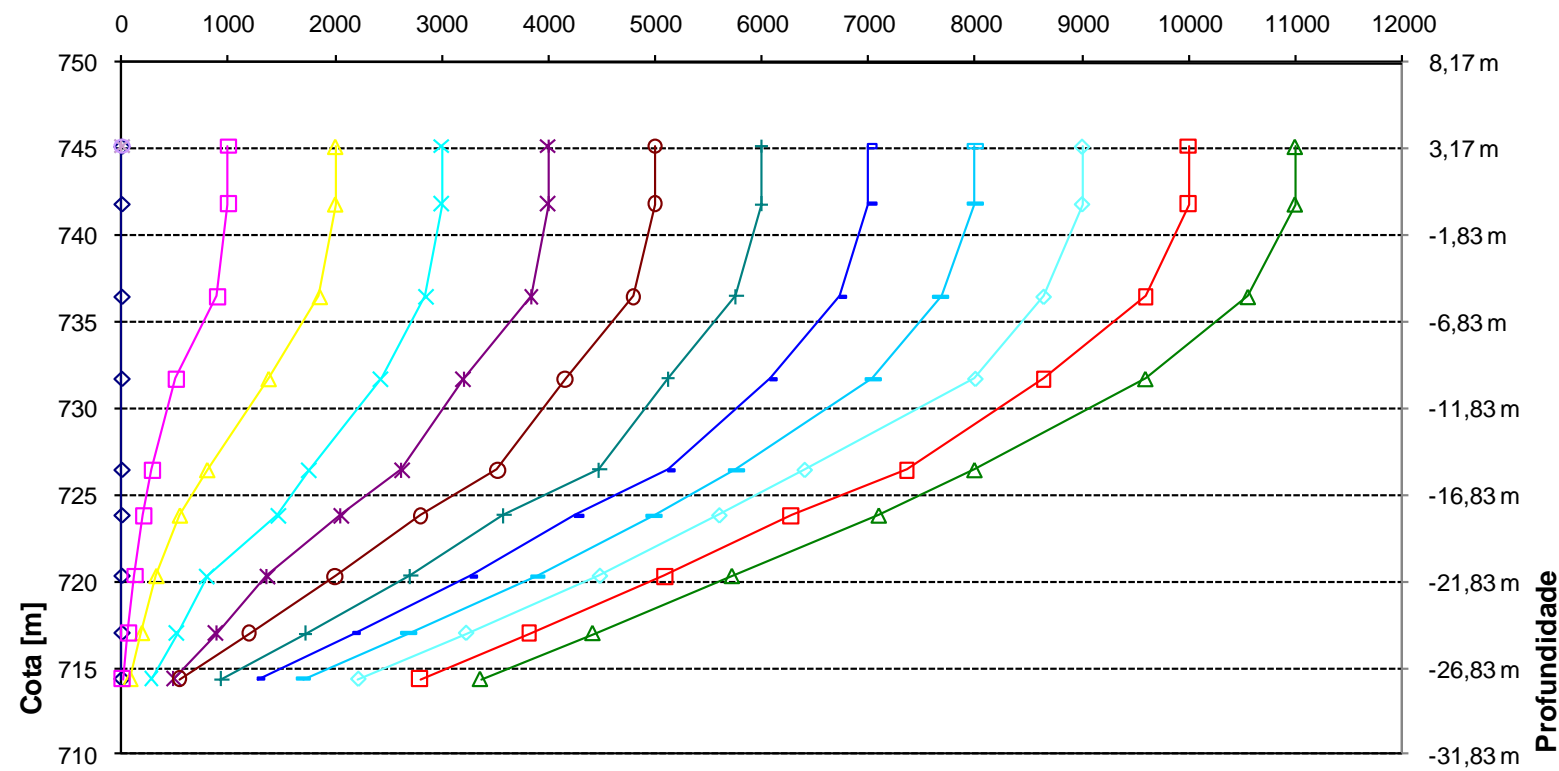

Gráfico 4.6. Transferência de Carga ao longo do fuste da estaca E.113. 


\subsubsection{Prova de Carga 03 (E.25)}

Analogamente ao que foi descrito no item 4.3.1, tem-se as cargas em profundidade, que estão mostradas na Tabela 4.12 e o diagrama de transferência de carga, no Gráfico 4.7. Os valores do produto ES constam na Tabela 4.9, enquanto os valores da deformação específica, na Tabela 4.8. Dos valores mostrados do produto ES foi adotado o valor de 37GN como o valor representativo para a PC03.

Tabela 4.12 - Cargas Axiais ao longo do fuste da estaca E.25.

\begin{tabular}{|c|c|c|c|c|c|c|c|c|}
\hline \multirow{2}{*}{$\begin{array}{c}\text { Carga no Topo [kN] } \\
746,02 \mathrm{~m} \\
2,30 \mathrm{~m} \\
\end{array}$} & \multicolumn{7}{|c|}{ CARGAS [kN] NOS NÍVEIS ABSOLUTO E RELATIVO } & $1-----1$ \\
\hline & $\begin{array}{c}743,72 \mathrm{~m} \\
0,00 \mathrm{~m} \\
\end{array}$ & $\begin{array}{c}738,27 \mathrm{~m} \\
-5,45 \mathrm{~m} \\
\end{array}$ & $\begin{array}{l}732,94 \mathrm{~m} \\
-10,80 \mathrm{~m} \\
\end{array}$ & $\begin{array}{l}729,72 \mathrm{~m} \\
-14,00 \mathrm{~m} \\
\end{array}$ & $\begin{array}{l}723,30 \mathrm{~m} \\
-20,40 \mathrm{~m} \\
\end{array}$ & $\begin{array}{l}718,20 \mathrm{~m} \\
-25,50 \mathrm{~m} \\
\end{array}$ & $\begin{array}{r}714,99 \mathrm{~m} \\
-28,70 \mathrm{~m} \\
\end{array}$ & $\begin{array}{r}713,86 \mathrm{~m} \\
-\quad-29,83 \mathrm{~m} \\
\end{array}$ \\
\hline 1200 & 1200 & 1137 & 888 & 735 & 364 & 208 & 155 & 136 \\
\hline 2400 & 2400 & 2240 & 1986 & 1685 & 990 & 492 & 361 & 315 \\
\hline 3600 & 3600 & 3280 & 2978 & 2654 & 1568 & 873 & 577 & 473 \\
\hline 4800 & 4800 & 4466 & 3864 & 3259 & 2021 & 1295 & 892 & 750 \\
\hline 8400 & 8400 & 7903 & 7205 & 6560 & 4932 & 3471 & 2494 & 2150 \\
\hline 9600 & 9600 & 9087 & 8381 & 7733 & 6027 & 4440 & 3341 & 2953 \\
\hline 10800 & 10800 & 10260 & 9525 & 8850 & 7097 & 5254 & 4070 & 3652 \\
\hline 11140 & 11140 & 10564 & 9786 & 9084 & 7296 & 5402 & 4181 & 3750 \\
\hline
\end{tabular}

Valores Extrapolados

Diagrama de Transferência de Carga PC 3 (E25)

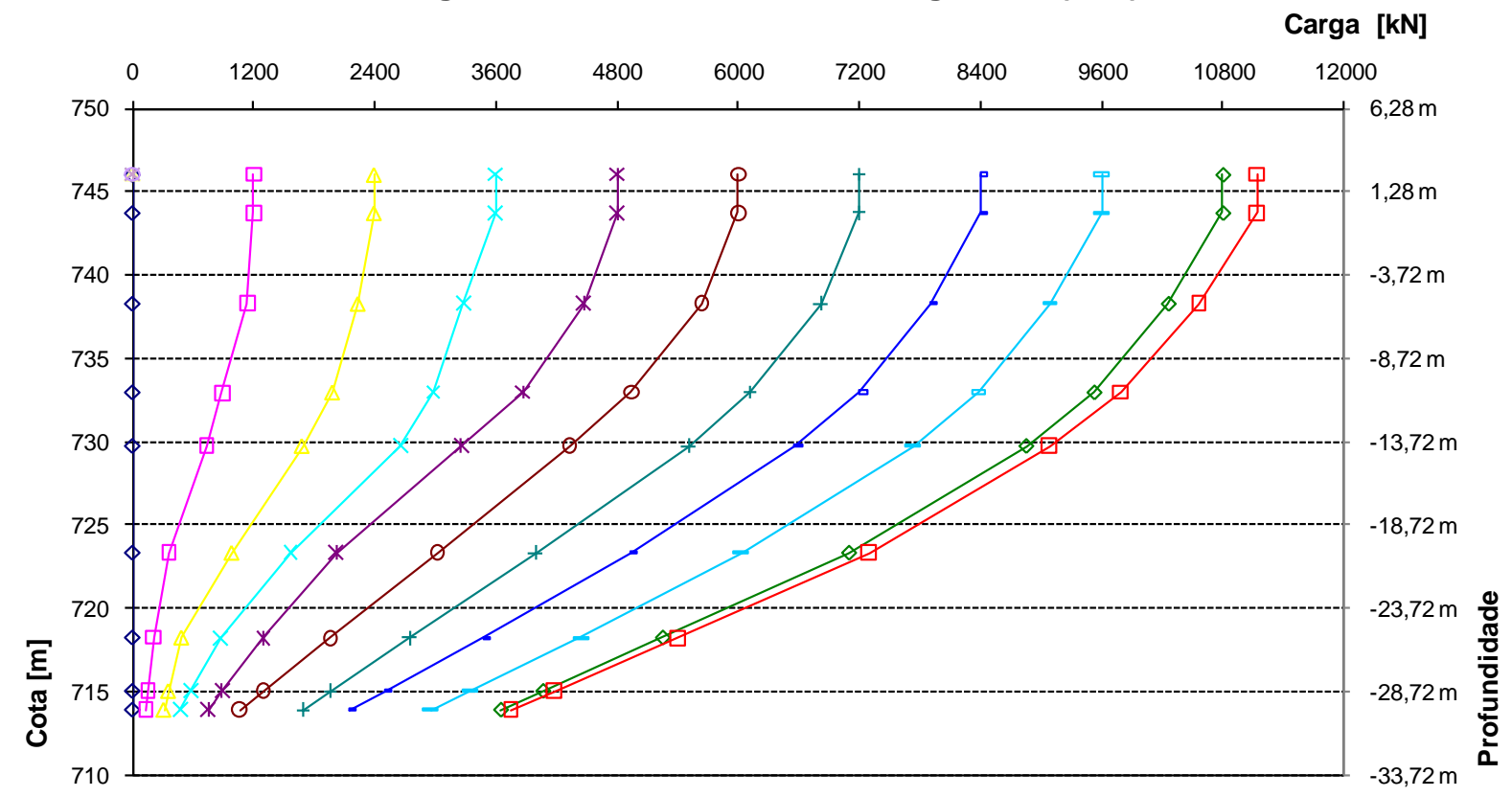

Gráfico 4.7. Transferência de Carga ao longo do fuste da estaca E.25. 


\subsection{Diagramas de Atrito Lateral Unitário}

Conforme equação (2.2), apresentada no item 2.3, pode-se construir os diagramas de atrito lateral unitário para as três provas de carga, referente aos patamares de carga de cada ensaio estático.

\subsubsection{Prova de Carga 01 (E.263b)}

Utilizando-se os dados da Tabela 4.10, que são as cargas axiais ao longo do fuste, pode-se construir os diagramas de atrito lateral unitário ao longo da profundidade em função de um determinado carregamento.

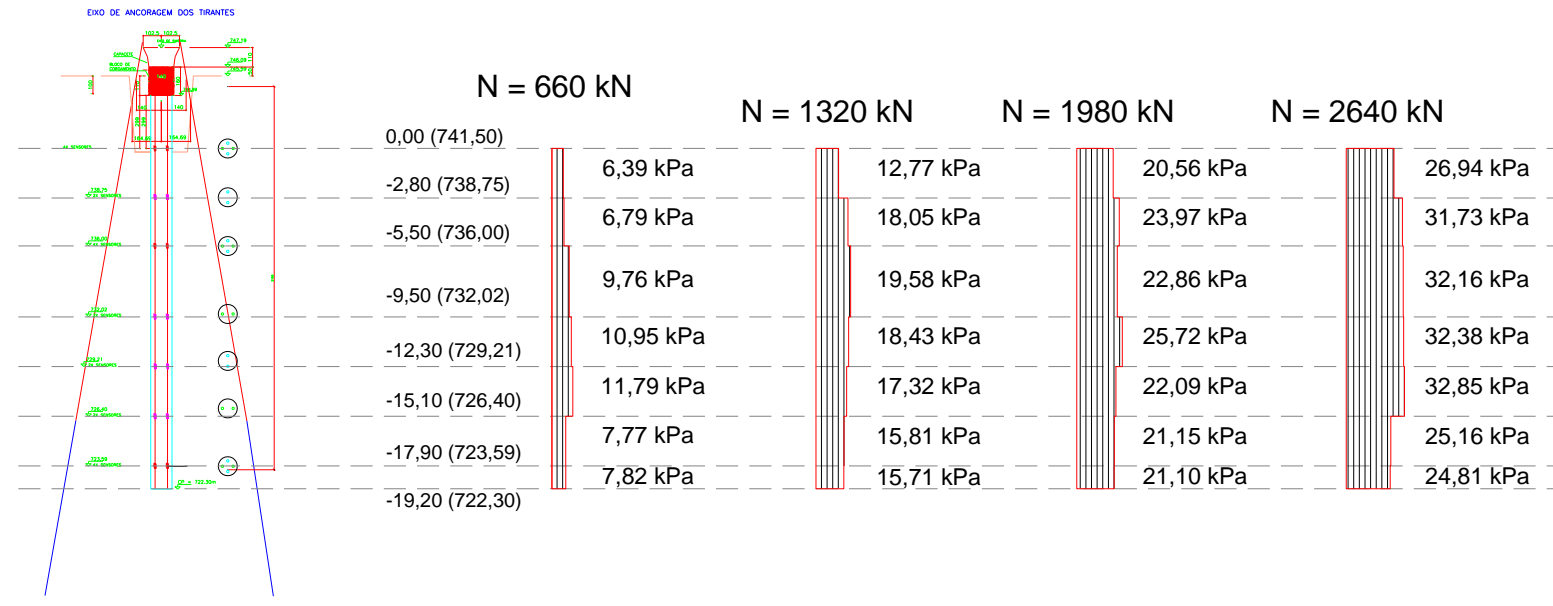

Gráfico 4.8. Diagrama Atrito Lateral Unitário_PC01 - N =660kN a 2640kN. 


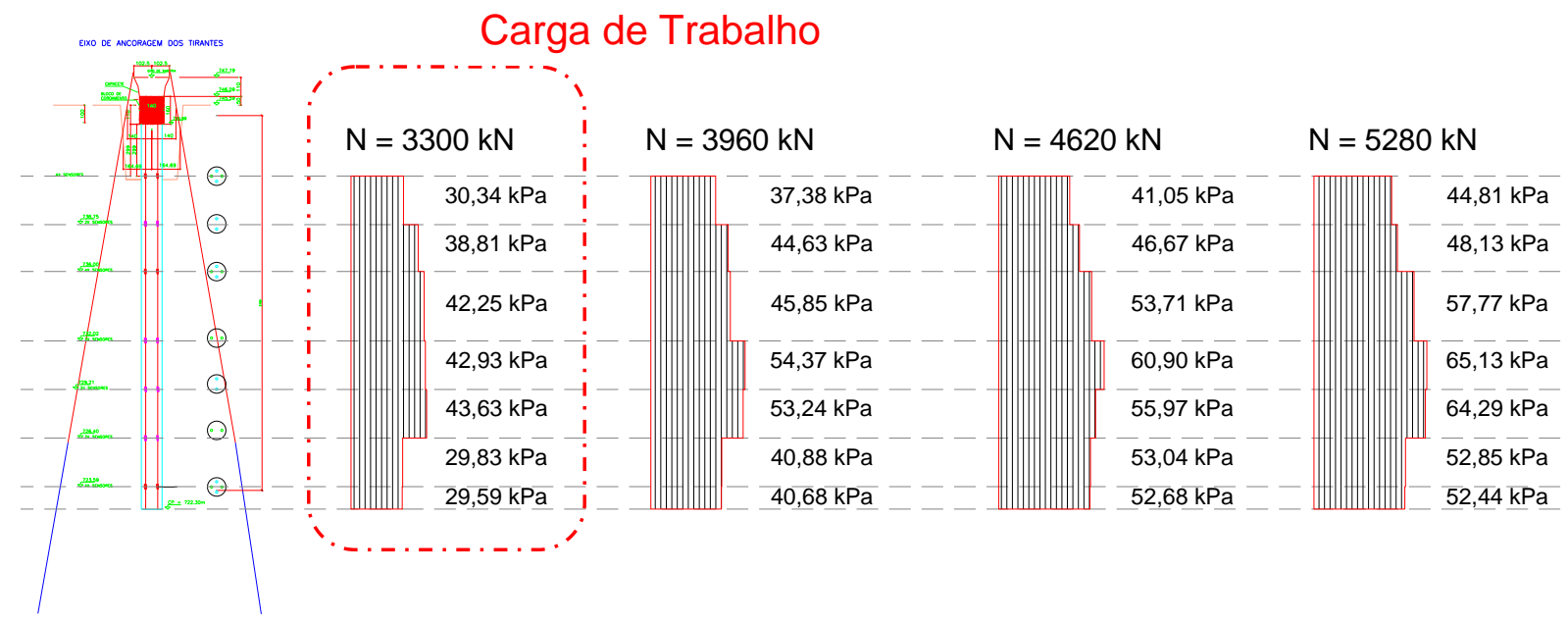

Gráfico 4.9. Diagrama Atrito Lateral Unitário_PC01 - N = 3300kN a 5280kN.

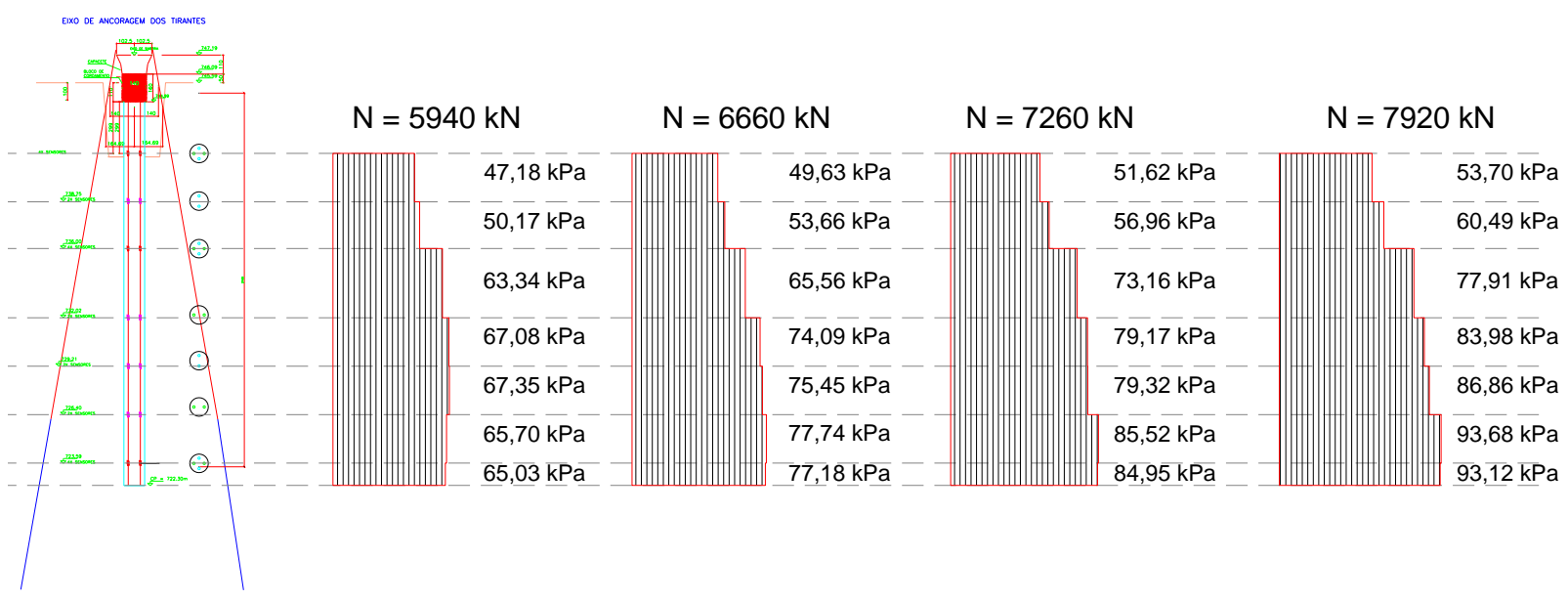

Gráfico 4.10. Diagrama Atrito Lateral Unitário_PC01 $-\mathrm{N}=5940 \mathrm{kN}$ a $7920 \mathrm{kN}$.

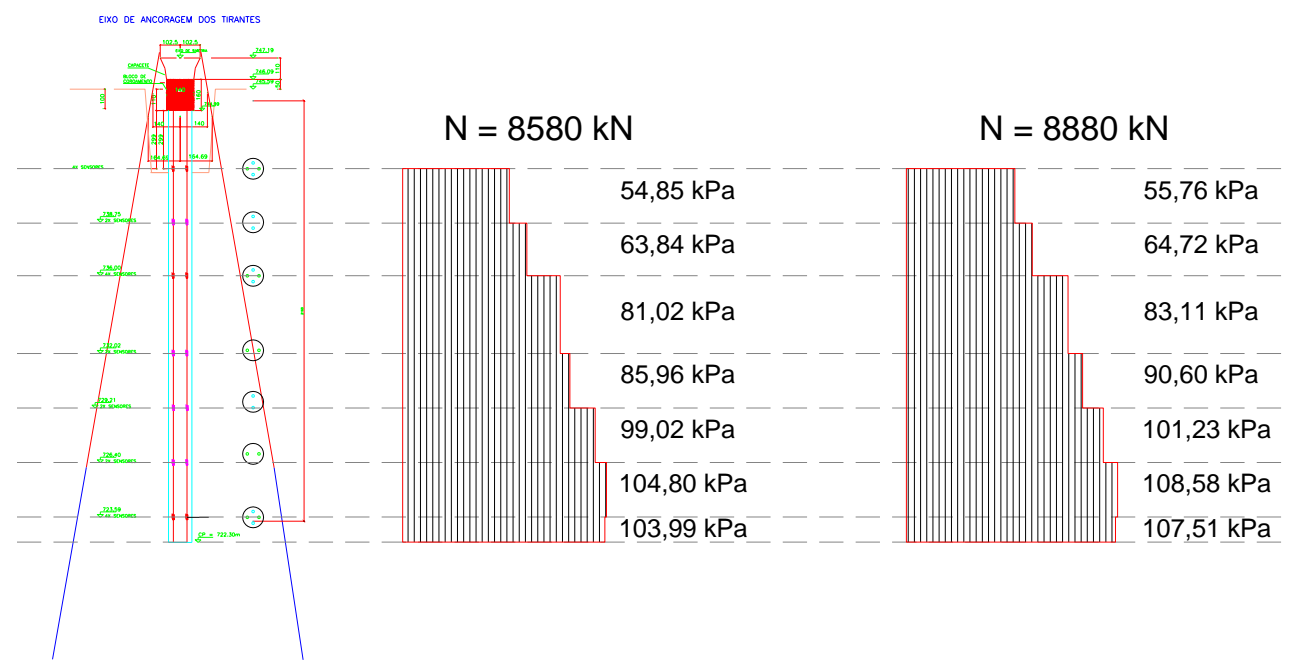

Gráfico 4.11. Diagrama Atrito Lateral Unitário_PC01 - N =8580kN e 8880kN. 


\subsubsection{Prova de Carga 02 (E.113)}

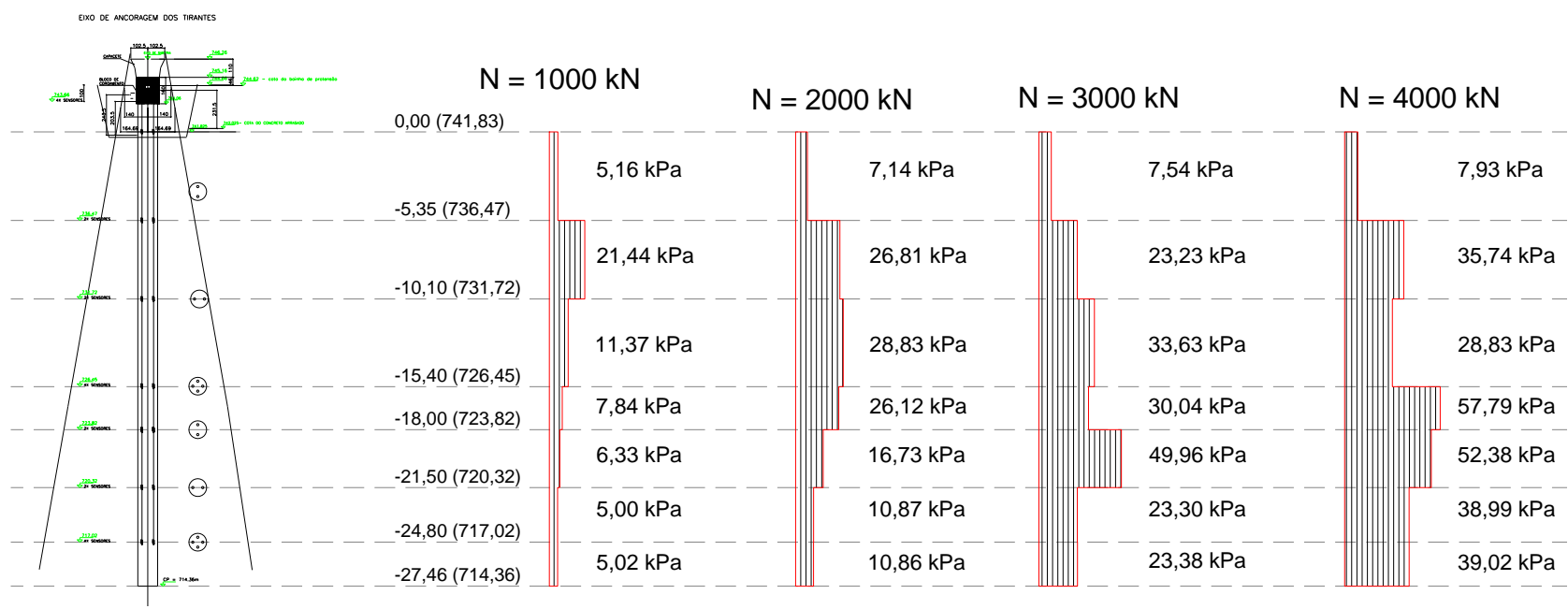

Gráfico 4.12. Diagrama Atrito Lateral Unitário_PC02 - N =1000kN a 4000kN.

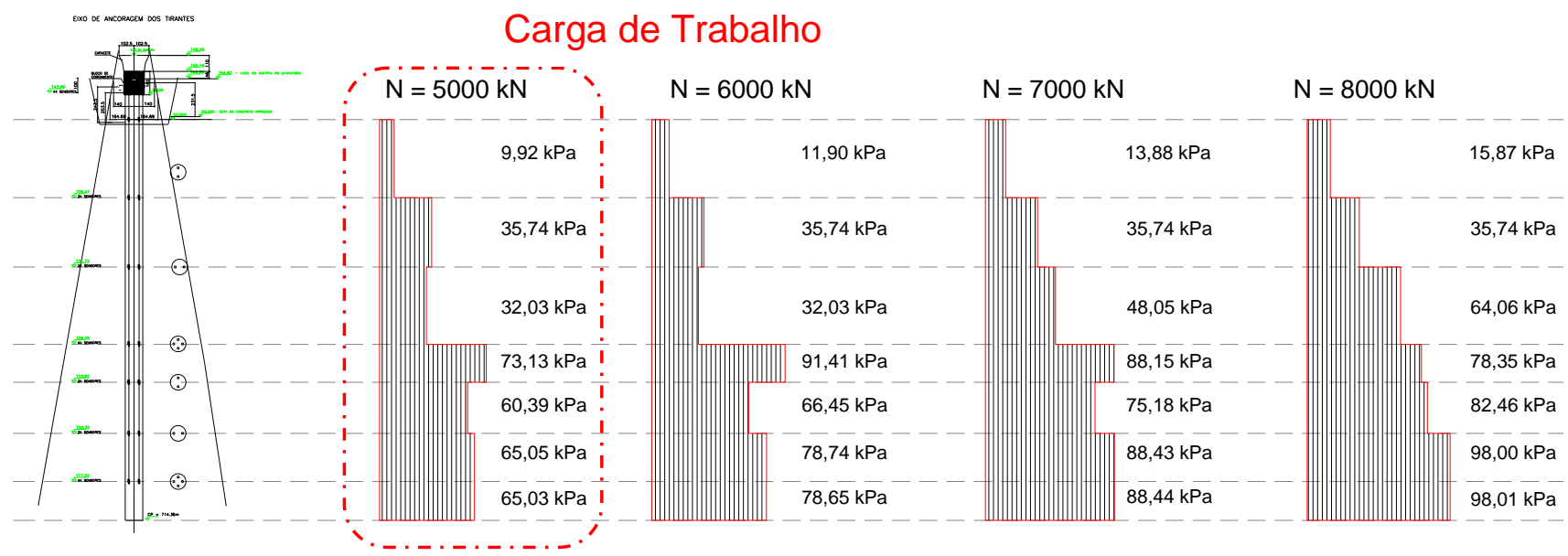

Gráfico 4.13. Diagrama Atrito Lateral Unitário_PC02 $-\mathrm{N}=5000 \mathrm{kN}$ a $8000 \mathrm{kN}$. 


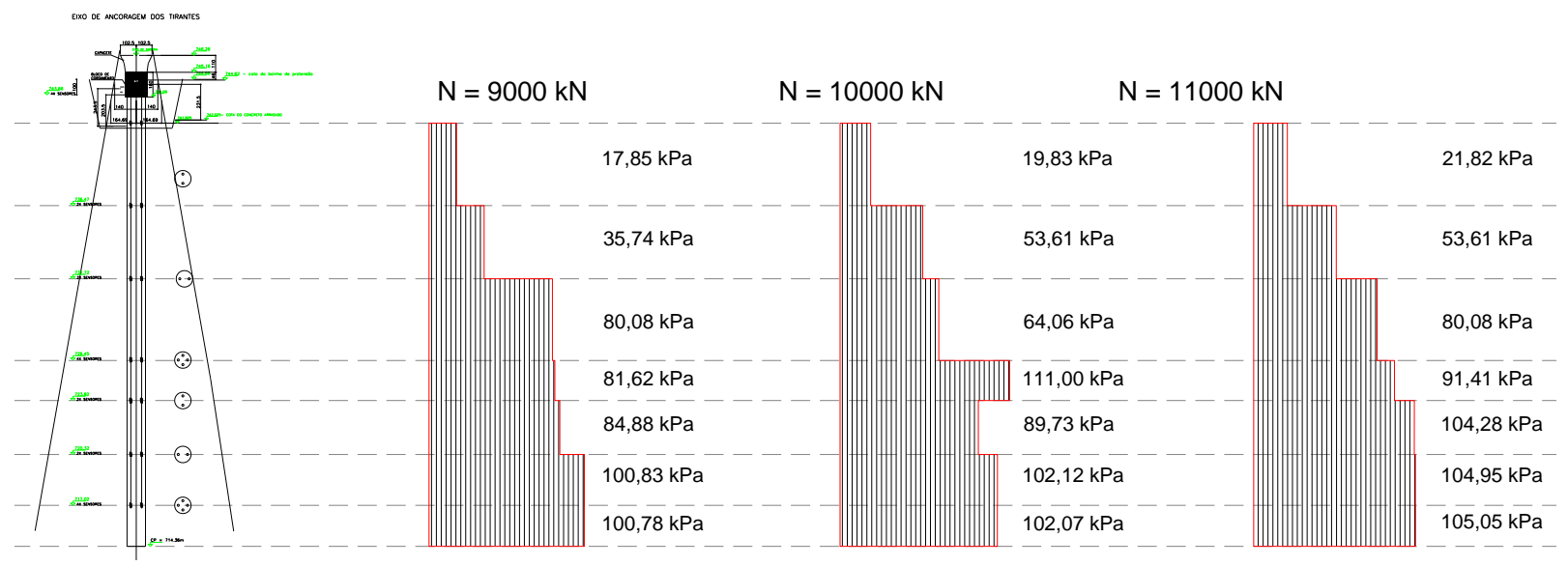

Gráfico 4.14. Diagrama Atrito Lateral Unitário_PC02 $-\mathrm{N}=9000 \mathrm{kN}$ a $11000 \mathrm{kN}$.

\subsubsection{Prova de Carga 03 (E.25)}

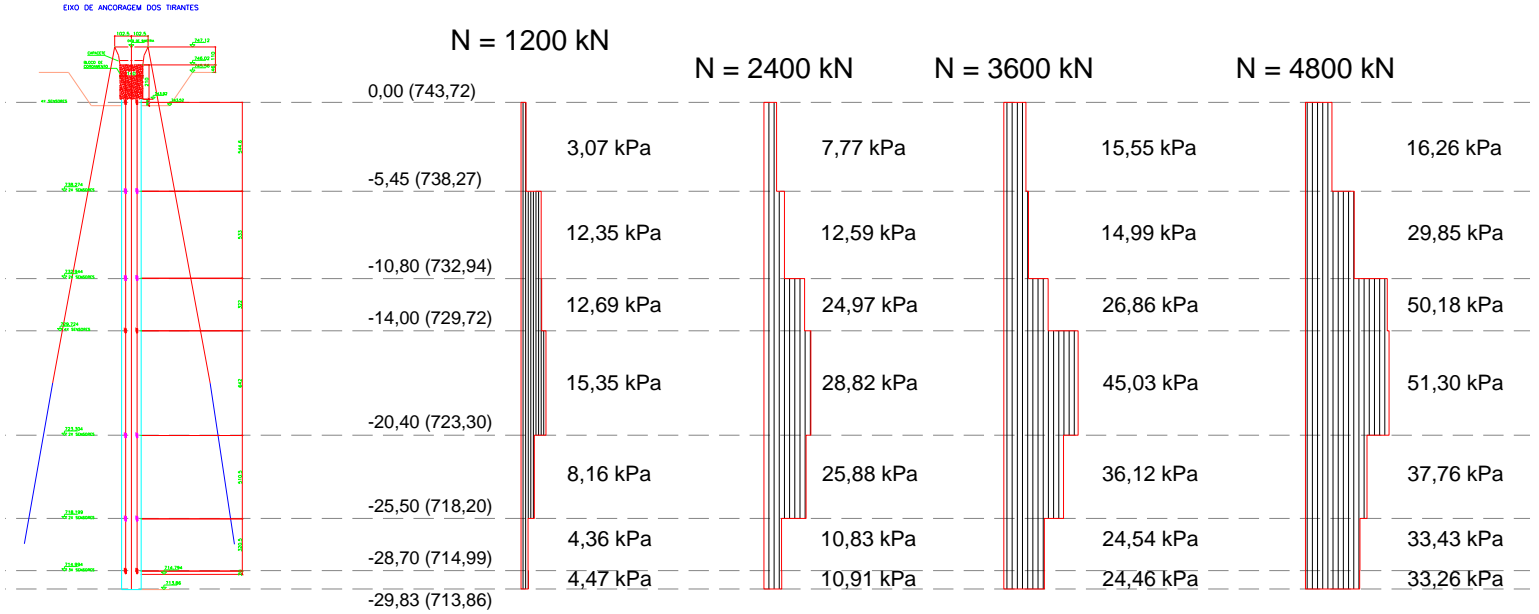

Gráfico 4.15. Diagrama Atrito Lateral Unitário_PC03 - N =1200kN a 4800kN. 


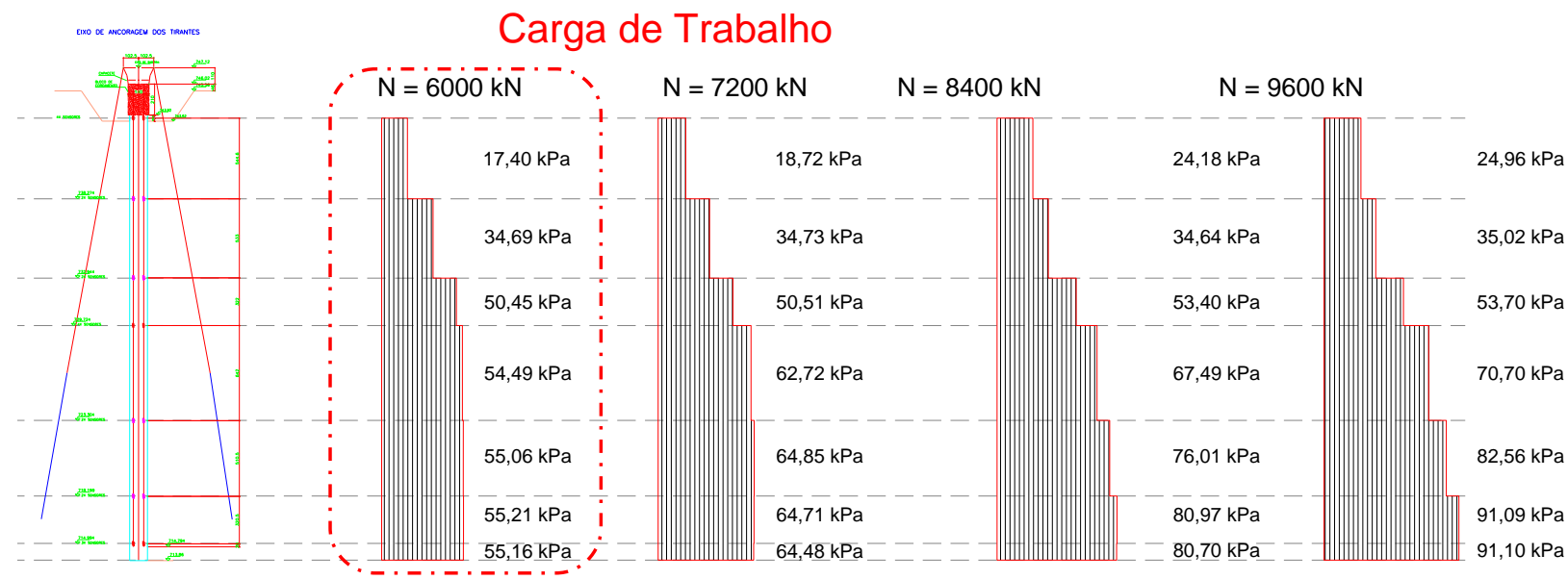

Gráfico 4.16. Diagrama Atrito Lateral Unitário_PC03 - N $=6000 \mathrm{kN}$ a 9600kN.

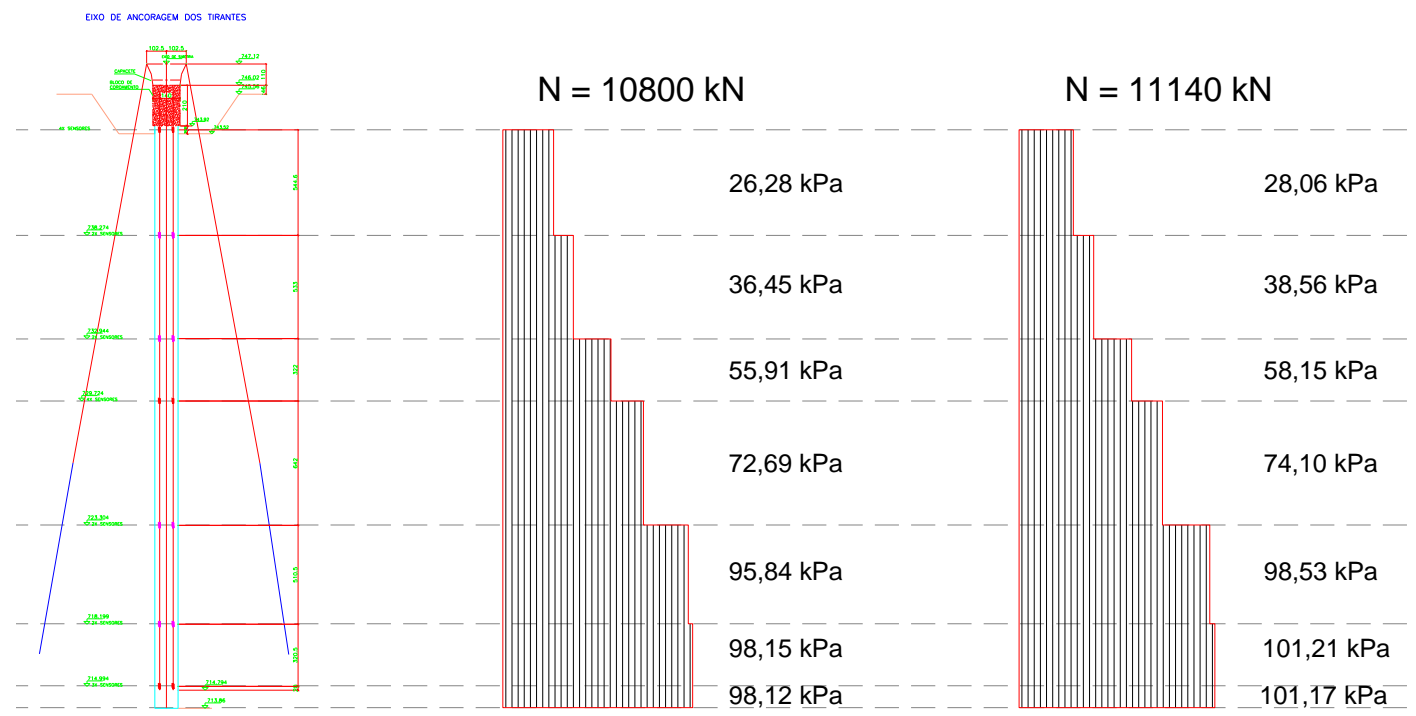

Gráfico 4.17. Diagrama Atrito Lateral Unitário_PC03 - N =10800kN e 11140kN. 


\subsection{Métodos de Interpretação da Curva $P_{0} \times y_{0}$}

\subsubsection{Funções de Transferência de Carga (Relações de Cambefort)}

Nesse item serão mostradas as funções de transferência de carga, que são os modelos baseados nas duas relações de Cambefort, conforme item 2.5.4. As relações expressam o atrito lateral unitário em função dos deslocamentos ao longo do fuste das estacas e a reação da ponta em função do deslocamento da ponta.

Porém, para o cálculo dos deslocamentos ao longo do fuste e da ponta, é necessário que sejam calculados os encurtamentos nos trechos instrumentados. Portanto, genericamente, considere os elementos mostrados na Figura 4.1:
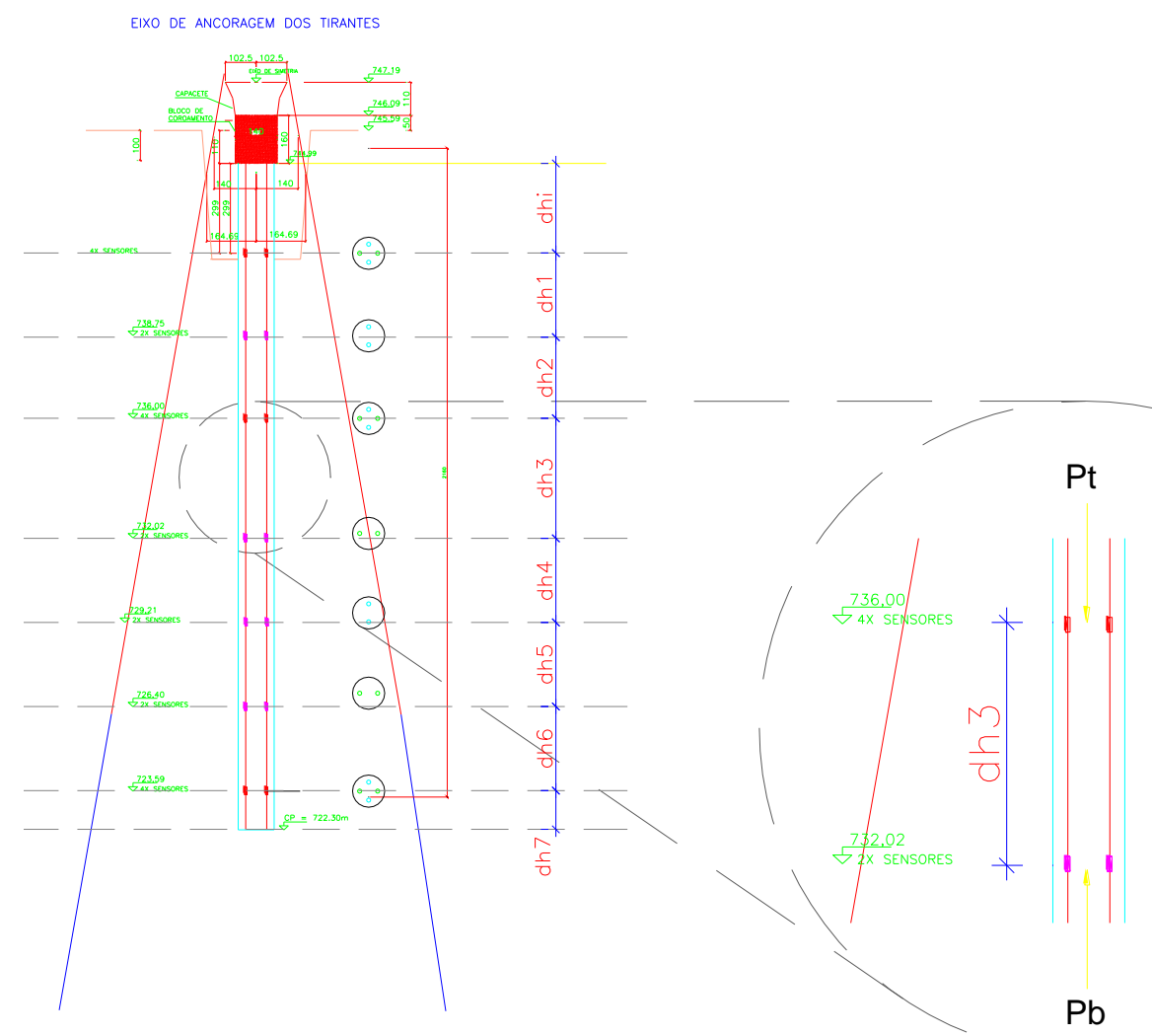

Figura 4.1 - Ampliação do Trecho Instrumentado para o Cálculo do Encurtamento.

onde:

$$
\mathrm{dh}_{\mathrm{i}}=\text { Comprimento do Trecho Inicial [L]; }
$$




$$
\begin{aligned}
& d h_{n}=\text { Comprimentos dos trechos instrumentados }[L] \\
& P_{t}=\text { Carga no nível superior da instrumentação }[F] ; \\
& P_{b}=\text { Carga no nível inferior da instrumentação }[F]
\end{aligned}
$$

Considerando-se o encurtamento na meia altura do trecho instrumentado, tem-se, para cada trecho instrumentado, o encurtamento dado pela equação (4.1):

$$
\Delta e_{n}=\frac{P_{t}+P_{b}}{2 \cdot E \cdot S} \cdot d h_{n}
$$

Sendo assim, o cálculo dos deslocamentos ao longo do fuste será dado pela equação (4.2).

$$
\delta_{f_{n}}=y_{0}-\Delta e_{i}-\frac{\Delta e_{n}}{2}
$$

onde:

$$
\begin{aligned}
& \delta_{\mathrm{fn}}=\text { Deslocamento ao longo do fuste para o enésimo trecho }[\mathrm{L}] \\
& \mathrm{y}_{\mathrm{o}}=\text { Deslocamento no topo }[\mathrm{L}] ; \\
& \Delta \mathrm{e}_{\mathrm{i}}=\text { Encurtamento do trecho inicial }[\mathrm{L}] ; \\
& \Delta \mathrm{e}_{\mathrm{n}}=\text { Encurtamento do enésimo trecho }[\mathrm{L}]
\end{aligned}
$$

\subsubsection{Prova de Carga 01 (E.263b)}

Com a teoria mostrada anteriormente, foi possível calcular, para cada patamar de carga do ensaio e em cada nível de instrumentação, os encurtamentos e os deslocamentos ao longo do fuste. Em seguida, construiu-se um gráfico que expressa a primeira relação de Cambefort, mostrando a dependência entre as variáveis já mencionadas. Os encurtamentos constam na Tabela 4.13, enquanto que os deslocamentos ao longo do fuste, na Tabela 4.14. 
Tabela 4.13 - Encurtamentos ao longo do fuste da estaca E.263b.

\begin{tabular}{|c|c|c|c|c|c|c|c|c|}
\hline \multirow{2}{*}{$\begin{array}{c}\text { Carga no Topo [kN] } \\
746,09 \mathrm{~m} \\
4,59 \mathrm{~m} \\
\end{array}$} & \multicolumn{8}{|c|}{ ENCURTAMENTOS $\left(\Delta_{\mathrm{e}}\right)[\mathrm{mm}]$ NOS NIVEIS ABSOLUTO E RELATIVO } \\
\hline & $\begin{array}{c}741,50 \mathrm{~m} \\
0,00 \mathrm{~m} \\
\end{array}$ & $\begin{array}{c}738,75 \mathrm{~m} \\
-2,80 \mathrm{~m} \\
\end{array}$ & $\begin{array}{c}736,00 \mathrm{~m} \\
-5,50 \mathrm{~m} \\
\end{array}$ & $\begin{array}{c}732,02 \mathrm{~m} \\
-9,50 \mathrm{~m} \\
\end{array}$ & $\begin{array}{l}729,21 \mathrm{~m} \\
-12,30 \mathrm{~m} \\
\end{array}$ & $\begin{array}{l}726,40 \mathrm{~m} \\
-15,10 \mathrm{~m} \\
\end{array}$ & $\begin{array}{l}723,59 \mathrm{~m} \\
-17,90 \mathrm{~m}\end{array}$ & $\begin{array}{l}722,30 \mathrm{~m} \\
-19,20 \mathrm{~m}\end{array}$ \\
\hline 0 & 0 & 0 & 0 & 0 & 0 & 0 & 0 & 0 \\
\hline 660 & 7,7677E-02 & 4,497E-02 & 3,863E-02 & 4,614E-02 & 2,287E-02 & $1,425 E-02$ & $6,843 \mathrm{E}-03$ & 170 \\
\hline 1320 & $1,5535 \mathrm{E}-01$ & 8,993E-02 & 7,569E-02 & 8,757E-02 & $4,372 \mathrm{E}-02$ & $3,017 \mathrm{E}-02$ & $1,762 \mathrm{E}-02$ &, $116 \mathrm{E}-03$ \\
\hline 1980 & 2,3303E-01 & $1,344 \mathrm{E}-01$ & $36 \mathrm{E}-01$ & 1,381E-01 & 7,457E-02 & $5,645 \mathrm{E}-02$ & 4,006 & 316E-02 \\
\hline 2640 & $3,1071 \mathrm{E}-01$ & 1,793E-01 & 1,519E-01 & 1,836E-01 & $9,885 \mathrm{E}-02$ & $7,413 \mathrm{E}-02$ & 5,215 & $=-02$ \\
\hline 3300 & 3,8838E-01 & 2,254E-01 & 1,926E-01 & 2,324E-01 & $1,236 \mathrm{E}-01$ & $9,076 \mathrm{E}-02$ & $6,292 \mathrm{E}-02$ & $2,155 \mathrm{E}-02$ \\
\hline 3960 & 4,6606E-01 & 2,701E-01 & 2,311E-01 & 2,836E-01 & 1,531E-01 & $1,124 \mathrm{E}-01$ & $7,669 \mathrm{E}-02$ & $2,509 \mathrm{E}-02$ \\
\hline 4620 & 5,4374E-01 & $3,161 \mathrm{E}-01$ & 2,734E-01 & 3,391E-01 & 1,853E-01 & $1,410 \mathrm{E}-01$ & $9,966 \mathrm{E}-02$ & $3,264 \mathrm{E}-02$ \\
\hline 5280 & $6,2142 \mathrm{E}-01$ & 3,621E-01 & $3,158 \mathrm{E}-01$ & 3,981E-01 & 2,227E-01 & 1,737E-01 & 1,293E-01 i & $4,645 \mathrm{E}-02$ \\
\hline 5940 & 6,9909E-01 & $4,086 \mathrm{E}-01$ & 3,591E-01 & $4,568 \mathrm{E}-01$ & 2,601E-01 & $2,091 \mathrm{E}-01$ & $1,587 \mathrm{E}-01$ & $5,681 \mathrm{E}-02$ \\
\hline 6600 & 7,7677E-01 & $4,550 \mathrm{E}-01$ & $4,017 \mathrm{E}-01$ & $5,165 \mathrm{E}-01$ & $80 \mathrm{E}-01$ & $2,413 \mathrm{E}-01$ & 1,833E-01 & $6,510 \mathrm{E}-02$ \\
\hline 7260 & $8,5445 \mathrm{E}-01$ & 5,017 & $4,448 \mathrm{E}-01$ & 5,727E-01 & 3,313E-01 & $2,712 \mathrm{E}-01$ & 2,088 & $7,494 \mathrm{E}-02$ \\
\hline 7920 & $9,3212 \mathrm{E}-01$ & 5,483E-01 & 4,878E-01 & 6,308E-01 & $3,675 \mathrm{E}-01$ & $3,028 \mathrm{E}-01$ & 2,344E-01 & $8,474 \mathrm{E}-02$ \\
\hline 8580 & $1,0098 \mathrm{E}+00$ & 5,952E-01 & 5,314E-01 & 6,913E-01 & $4,075 \mathrm{E}-01$ & $3,374 \mathrm{E}-01$ & $2,602 \mathrm{E}-01$ & $9,386 \mathrm{E}-02$ \\
\hline 8800 & $1,0357 \mathrm{E}+00$ & 6,107E-01 & 5,457E-01 & $7,104 \mathrm{E}-01$ & 4,179E-01 & $3,452 E-01$ & $2,658 \mathrm{E}-01$ & $9,552 \mathrm{E}-02$ \\
\hline
\end{tabular}

Valores Extrapolados

Tabela 4.14 - Deslocamentos ao longo do fuste da estaca E.263b.

\begin{tabular}{|c|c|c|c|c|c|c|c|c|}
\hline \multirow{2}{*}{$\begin{array}{c}\text { Carga no Topo }[\mathrm{kN}] \\
746,09 \mathrm{~m} \\
4,59 \mathrm{~m} \\
\end{array}$} & \multicolumn{8}{|c|}{ DESLOCAMENTOS $\left(\delta_{\mathrm{f}}\right)[\mathrm{mm}]$ NOS NIVEIS ABSOLUTO E RELATIVO (Entre extensômetros) } \\
\hline & $\begin{array}{c}741,50 \mathrm{~m} \\
0,00 \mathrm{~m} \\
\end{array}$ & $\begin{array}{c}738,75 \mathrm{~m} \\
-2,80 \mathrm{~m} \\
\end{array}$ & $\begin{array}{c}736,00 \mathrm{~m} \\
-5,50 \mathrm{~m} \\
\end{array}$ & $\begin{array}{c}732,02 \mathrm{~m} \\
-9,50 \mathrm{~m} \\
\end{array}$ & $\begin{array}{l}729,21 \mathrm{~m} \\
-12,30 \mathrm{~m} \\
\end{array}$ & $\begin{array}{l}726,40 \mathrm{~m} \\
-15,10 \mathrm{~m} \\
\end{array}$ & $\begin{array}{l}723,59 \mathrm{mi}^{-} \\
-17,90 \mathrm{~m}_{\mathrm{i}} \\
\end{array}$ & $\begin{array}{l}-722,30 \mathrm{~m} \\
-19,20 \mathrm{~m}\end{array}$ \\
\hline 0 & 0 & 0 & 0 & 0 & 0 & 0 & 0 & 0 \\
\hline 660 & 0,312 & 0,290 & 0,248 & 0,206 & 0,171 & 0,153 & 0,142 & 0,138 \\
\hline 1320 & 0,825 & 0,780 & 0,697 & 0,615 & 0,550 & 0,513 & 0,489 & 0,478 \\
\hline 1980 & 1,247 & 1,180 & 1,056 & 0,930 & 0,824 & 0,758 & 0,710 & 0,683 \\
\hline 2640 & 1,999 & 1,910 & 1,744 & 1,576 & 1,435 & 1,349 & 1,285 & 1,250 \\
\hline 3300 & 2,752 & 2,639 & 2,430 & 2,217 & 2,039 & 1,932 & 1,855 & 1,813 \\
\hline 3960 & 3,554 & 3,419 & 3,168 & 2,911 & 2,692 & 2,560 & 2,465 & 2,414 \\
\hline 4620 & 4,726 & 4,568 & 4,273 & 3,967 & 3,705 & 3,542 & 3,422 & 3,355 \\
\hline 5280 & 5,729 & 5,548 & 5,209 & 4,852 & 4,541 & 4,343 & 4,191 & 4,104 \\
\hline 5940 & 7,281 & 7,077 & 6,693 & 6,285 & 5,926 & 5,692 & 5,508 & 5,400 \\
\hline 6600 & 8,823 & 8,596 & 8,167 & 7,708 & 7,301 & 7,031 & 6,819 & 6,695 \\
\hline 7260 & 11,186 & 10,935 & 10,461 & 9,953 & 9,501 & 9,199 & ا & 8,818 \\
\hline 7920 & 13,448 & 13,174 & 12,656 & 12,096 & 11,597 & 11,262 & 10,994 & 10,834 \\
\hline 8580 & 28,440 & 28,143 & 27,579 & 26,968 & 26,419 & 26,046 & 25,747 & 25,570 \\
\hline 8800 & 51,734 & 51,429 & 50,851 & 50,223 & 49,659 & 49,277 & 48,972 & 48,791 \\
\hline
\end{tabular}




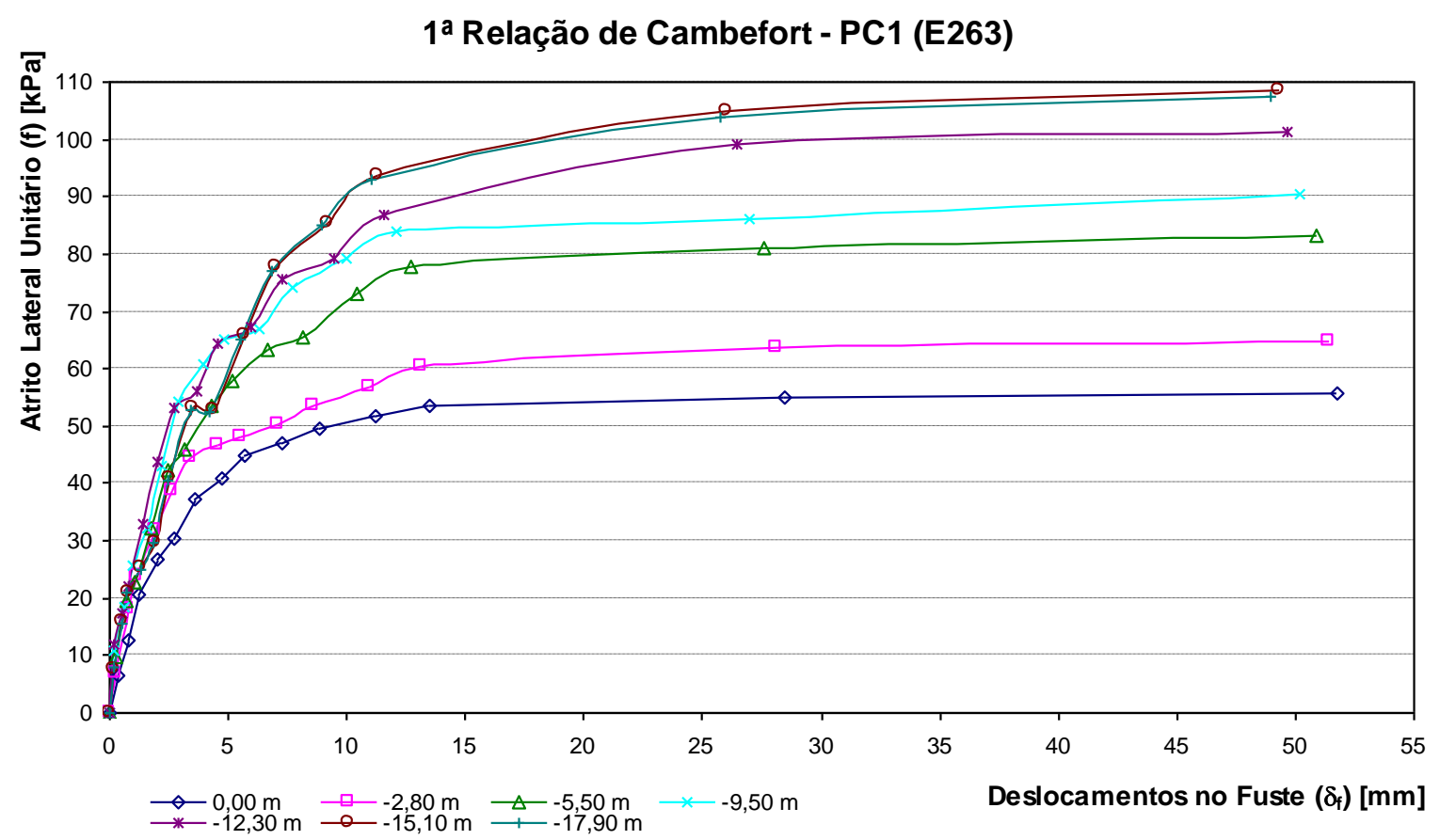

Gráfico 4.18. 1a Relação de Cambefort_PC01 (E.263b).

Por sua vez, o Gráfico 4.19 mostra a $2^{\mathfrak{a}}$ relação de Cambefort.

2를 Relação de Cambefort - PC1 (E263)

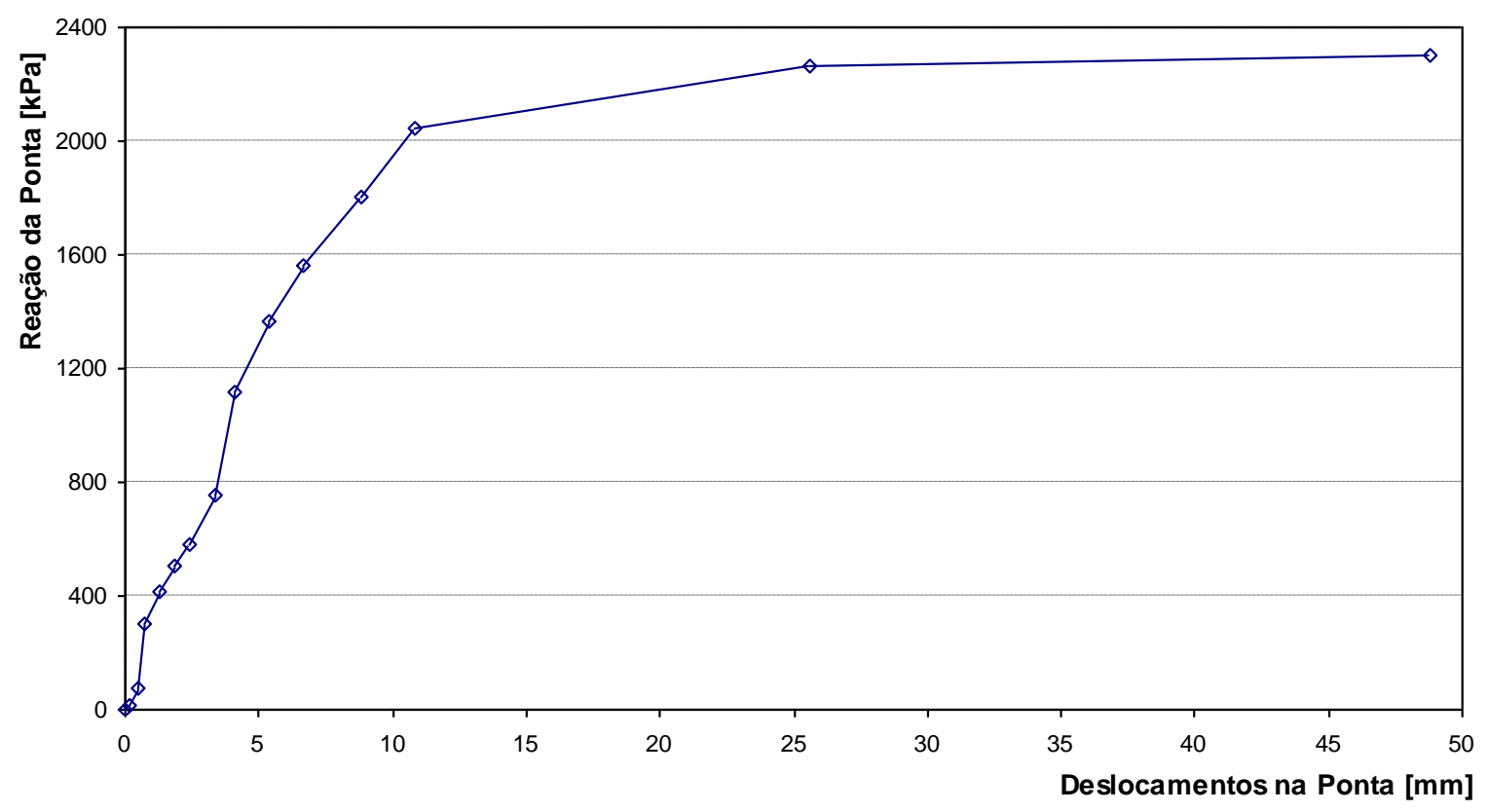

Gráfico 4.19. 2ª Relação de Cambefort_PC01 (E.263b). 
Observe pelo Gráfico 4.18 que foram necessários deslocamentos do fuste da ordem de $25 \mathrm{~mm}$ para o esgotamento do atrito, o que contradiz ao que o modelo ensina, ou seja, que 0 atrito lateral esvai-se com deslocamentos inferiores a dezena de milímetros.

O gráfico da ponta, Gráfico 4.19, já mostra resultados mais coerentes com os preceitos do método. Nele, é possível visualizar que houve a mobilização da ponta com $25 \mathrm{~mm}$ de deslocamento, o que é totalmente compatível com a prática da metodologia.

\subsubsection{Prova de Carga 02 (E.113)}

De maneira análoga à descrita no item 4.5.1.1, calcularam-se os encurtamentos e os deslocamentos ao longo do fuste. Em seguida, construiu-se um gráfico que expressa a primeira relação de Cambefort, mostrando a dependência entre as variáveis já mencionadas. Os encurtamentos constam na Tabela 4.15, enquanto que os deslocamentos ao longo do fuste, na Tabela 4.16.

Tabela 4.15 - Encurtamentos ao longo do fuste da estaca E.113.

\begin{tabular}{|c|c|c|c|c|c|c|c|c|}
\hline \multirow{2}{*}{$\begin{array}{c}\text { Carga no Topo [kN] } \\
745,16 \mathrm{~m} \\
3,33 \mathrm{~m} \\
\end{array}$} & \multicolumn{8}{|c|}{ ENCURTAMENTOS $\left(\Delta_{\mathrm{e}}\right)[\mathrm{mm}$ ] NOS NIVEIS ABSOLUTO E RELATIVO } \\
\hline & $\begin{array}{c}741,83 \mathrm{~m} \\
0,00 \mathrm{~m} \\
\end{array}$ & $\begin{array}{c}736,47 \mathrm{~m} \\
-5,35 \mathrm{~m} \\
\end{array}$ & $\begin{array}{l}731,72 \mathrm{~m} \\
-10,10 \mathrm{~m} \\
\end{array}$ & $\begin{array}{l}726,45 \mathrm{~m} \\
-15,40 \mathrm{~m}\end{array}$ & $\begin{array}{l}723,82 \mathrm{~m} \\
-18,00 \mathrm{~m} \\
\end{array}$ & $\begin{array}{l}720,32 \mathrm{~m} \\
-21,50 \mathrm{~m} \\
\end{array}$ & $\begin{array}{l}717,02 \mathrm{~m} \\
-24,80 \mathrm{~m}\end{array}$ & $\begin{array}{l}714,36 \mathrm{~m} \\
-27,46 \mathrm{~m}\end{array}$ \\
\hline 0 & 0 & 0 & 0 & 0 & 0 & 0 & 0 & 0 \\
\hline 1000 & $1,0406 \mathrm{E}-01$ & $1,585 \mathrm{E}-01$ & $1,045 \mathrm{E}-01$ & 6,599E-02 & $2,002 E-02$ & $1,818 \mathrm{E}-02$ & $9,631 \mathrm{E}-03$ & 3,088E-03! \\
\hline 2000 & 2,0812E-01 & 3,223E-01 & $2,399 \mathrm{E}-01$ & $1,802 \mathrm{E}-01$ & $5,460 \mathrm{E}-02$ & $4,743 \mathrm{E}-02$ & 2,636E-02। & $1,109 \mathrm{E}-02$ \\
\hline 3000 & $3,1219 \mathrm{E}-01$ & 4,889E-01 & $3,919 \mathrm{E}-01$ & 3,472E-01 & $1,310 \mathrm{E}-01$ & $1,243 \mathrm{E}-01$ & 6,821E-02! & $19 \mathrm{E}-02$ \\
\hline 4000 & $4,1625 \mathrm{E}-01$ & $6,554 \mathrm{E}-01$ & $5,225 \mathrm{E}-01$ & $4,823 \mathrm{E}-01$ & $1,902 \mathrm{E}-01$ & $1,873 \mathrm{E}-01$ & $1,159 \mathrm{E}-01$ & $5,699 \mathrm{E}-02$ \\
\hline 5000 & $5,2031 \mathrm{E}-01$ & 8,192E-01 & $6,650 \mathrm{E}-01$ & $6,360 \mathrm{E}-01$ & 2,569E-01 & $2,630 \mathrm{E}-01$ & $1,652 \mathrm{E}-01$ & $7,241 \mathrm{E}-02$ \\
\hline 6000 & $6,2437 \mathrm{E}-01$ & 9,831E-01 & 8,075E-01 & $7,950 \mathrm{E}-01$ & $3,276 \mathrm{E}-01$ & $3,441 \mathrm{E}-01$ & 2,287E-01' & $1,108 \mathrm{E}-01$ \\
\hline 7000 & 7,2844E-01 & $1,147 \mathrm{E}+00$ & $9,500 \mathrm{E}-01$ & $9,275 \mathrm{E}-01$ & 3,809E-01 & $4,113 \mathrm{E}-01$ & 2,799E-01 & 1,430E-01 \\
\hline 8000 & $8,3250 \mathrm{E}-01$ & $1,311 \mathrm{E}+00$ & $1,093 \mathrm{E}+00$ & $1,060 \mathrm{E}+00$ & $4,368 \mathrm{E}-01$ & $4,865 \mathrm{E}-01$ & 3,397E-01 & $1,823 \mathrm{E}-01$ \\
\hline 9000 & $9,3656 \mathrm{E}-01$ & $1,475 E+00$ & $1,235 \mathrm{E}+00$ & $1,193 \mathrm{E}+00$ & $4,875 \mathrm{E}-01$ & 5,513E-01 & 3,973E-01' & $2,261 \mathrm{E}-01$ \\
\hline 10000 & $1,0406 \mathrm{E}+00$ & $1,638 \mathrm{E}+00$ & $1,354 \mathrm{E}+00$ & $1,325 \mathrm{E}+00$ & $5,538 \mathrm{E}-01$ & $6,213 \mathrm{E}-01$ & $4,592 E-01 i$ & $2,748 \mathrm{E}-01$ \\
\hline 11000 & $1,1447 \mathrm{E}+00$ & $1,802 \mathrm{E}+00$ & $1,496 \mathrm{E}+00$ & $1,458 \mathrm{E}+00$ & $6,136 \mathrm{E}-01$ & $7,018 \mathrm{E}-01$ & $5,234 \mathrm{E}-01$ & $3,238 \mathrm{E}-01$ \\
\hline
\end{tabular}


Tabela 4.16 - Deslocamentos ao longo do fuste da estaca E.113.

\begin{tabular}{ccccccccc}
\hline Carga no Topo $[\mathbf{k N}]$ & \multicolumn{7}{c}{ DESLOCAMENTOS $\left(\boldsymbol{\delta}_{\mathrm{f}}\right)$} & $\mathbf{m m}]$ NOS NIVEIS ABSOLUTO E RELATIVO (Entre extensômetros) \\
\cline { 2 - 9 } $\mathbf{7 4 5 , 1 6 ~} \mathbf{m}$ & $741,83 \mathrm{~m}$ & $736,47 \mathrm{~m}$ & $731,72 \mathrm{~m}$ & $726,45 \mathrm{~m}$ & $723,82 \mathrm{~m}$ & $720,32 \mathrm{~m}$ & $717,02 \mathrm{~m}$ & $714,36 \mathrm{~m}$ \\
$\mathbf{3 , 3 3} \mathbf{~ m}$ & $0,00 \mathrm{~m}$ & $-5,35 \mathrm{~m}$ & $-10,10 \mathrm{~m}$ & $-15,40 \mathrm{~m}$ & $-18,00 \mathrm{~m}$ & $-21,50 \mathrm{~m}$ & $-24,80 \mathrm{~m}$ & $-27,46 \mathrm{~m}$ \\
\hline 0 & 0 & 0 & 0 & 0 & 0 & 0 & 0 & 0 \\
1000 & $-0,064$ & $-0,143$ & $-0,275$ & $-0,360$ & $-0,403$ & $-0,422$ & $-0,436$ & $-0,442$ \\
2000 & 0,552 & 0,391 & 0,110 & $-0,100$ & $-0,218$ & $-0,269$ & $-0,306$ & $-0,324$ \\
3000 & 1,288 & 1,043 & 0,603 & 0,234 & $-0,006$ & $-0,133$ & $-0,229$ & $-0,280$ \\
4000 & 2,394 & 2,066 & 1,477 & 0,975 & 0,638 & 0,450 & 0,298 & 0,212 \\
5000 & 3,680 & 3,270 & 2,528 & 1,877 & 1,431 & 1,171 & 0,957 & 0,838 \\
6000 & 5,376 & 4,884 & 3,989 & 3,188 & 2,626 & 2,290 & 2,004 & 1,834 \\
7000 & 7,382 & 6,808 & 5,760 & 4,821 & 4,167 & 3,771 & 3,425 & 3,214 \\
8000 & 12,308 & 11,652 & 10,451 & 9,374 & 8,626 & 8,164 & 7,751 & 7,490 \\
9000 & 18,483 & 17,746 & 16,391 & 15,178 & 14,338 & 13,818 & 13,344 & 13,032 \\
10000 & 31,799 & 30,980 & 29,484 & 28,145 & 27,205 & 26,618 & 26,078 & 25,711 \\
11000 & 41,975 & 41,074 & 39,425 & 37,948 & 36,912 & 36,255 & 35,642 & 35,219 \\
\hline
\end{tabular}

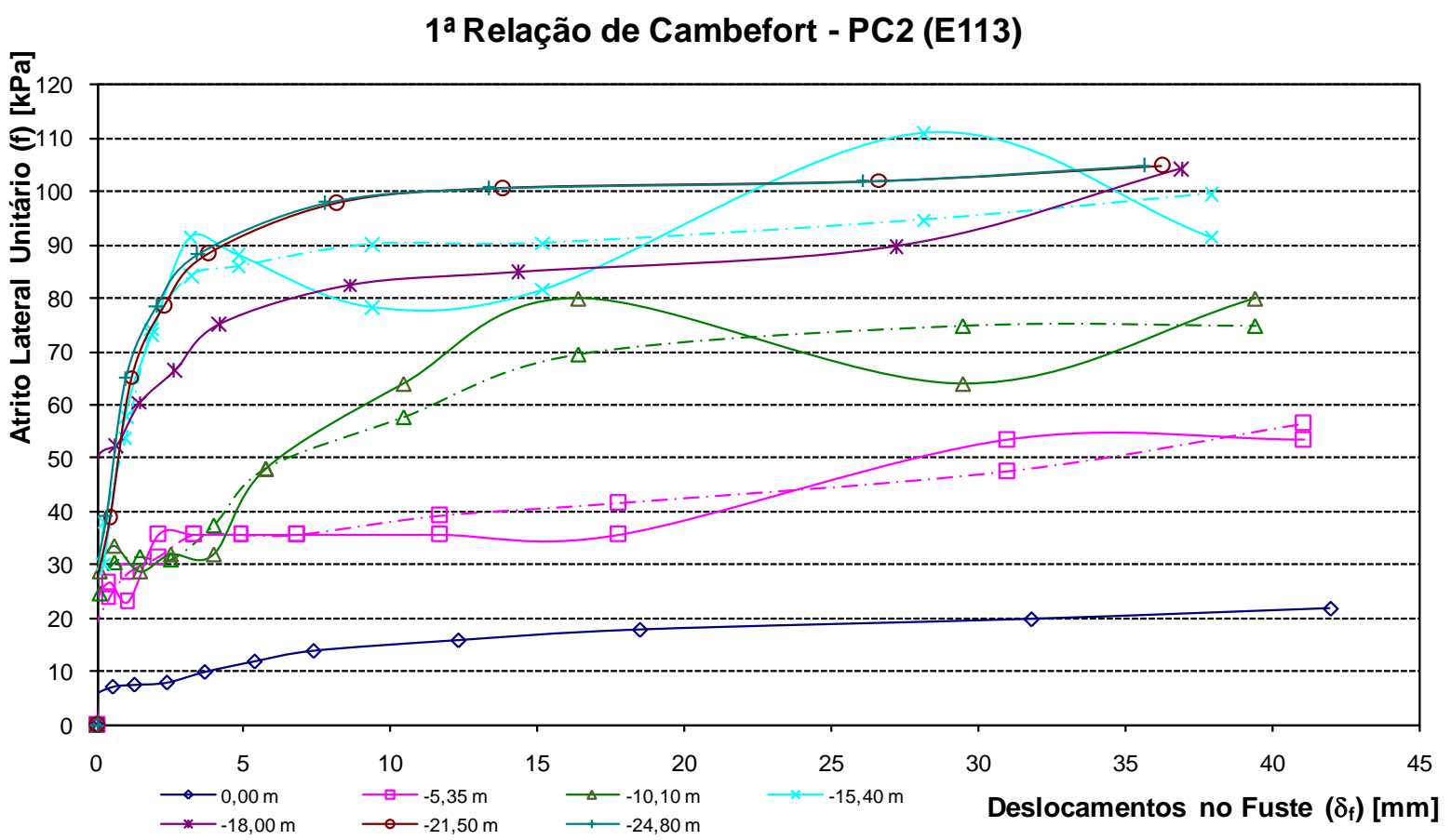

Gráfico 4.20. 1롤 Relação de Cambefort_PC02 (E.113).

Para a PC.02 pode-se perceber um comportamento anômalo nos $2^{\circ}$, $3^{\circ}$ e $4^{\circ}$ níveis de instrumentação, o qual foi ocasionado por uma provável imprecisão na leitura dos instrumentos ou na própria instrumentação. Prova disso, são as linhas tracejadas que foram obtidas usando-se média móvel para a obtenção do atrito lateral unitário.

Com relação às demais curvas que expressam a 1a relação de Cambefort, no Gráfico 4.20, é possível ver que o atrito lateral está na iminência de esgotamento, pois ainda é visível um ligeiro crescimento da curva. No mesmo gráfico, é notável que o atrito lateral teve o início com deslocamentos do fuste próximos de $8 \mathrm{~mm}$. 
Por sua vez, o Gráfico 4.21 mostra a $2^{\mathfrak{a}}$ relação de Cambefort.

2ª Relação de Cambefort - PC2 (E113)

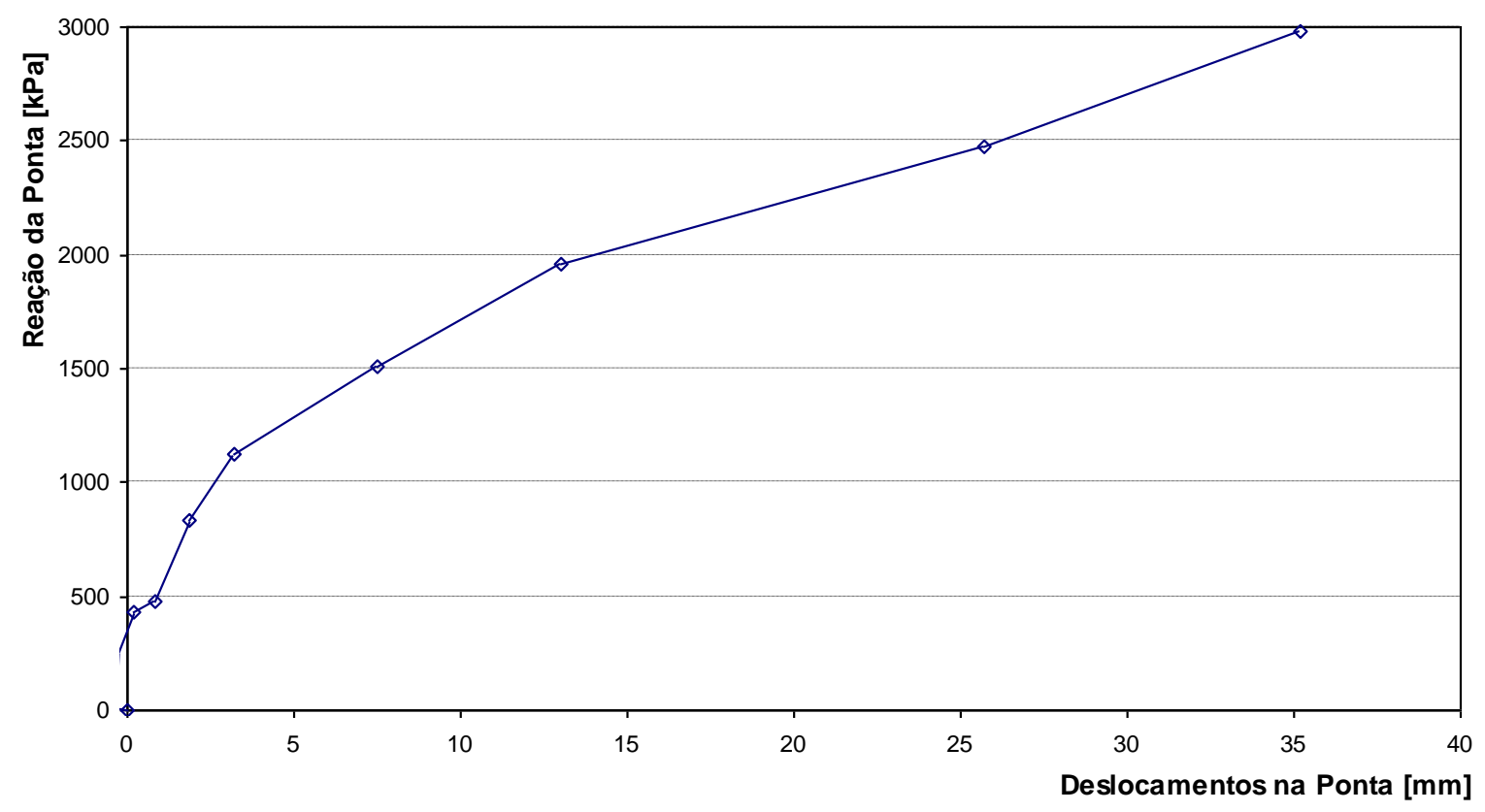

Gráfico 4.21. 2ª Relação de Cambefort_PC02 (E.113).

E no Gráfico 4.21 também se vê que ainda há uma boa reserva de carga na ponta, pois, para o nível de carregamento ao qual a estaca foi submetida, não se percebe que a curva esteja próxima de um ponto de inflexão, o qual começa a representar a mobilização total da ponta. 


\subsubsection{Prova de Carga 03 (E.25)}

De maneira análoga à descrita no item 4.5.1.1, calcularam-se os encurtamentos e os deslocamentos ao longo do fuste. Em seguida, construiu-se um gráfico que expressa a primeira relação de Cambefort, mostrando a dependência entre as variáveis já mencionadas. Os encurtamentos constam na Tabela 4.17, enquanto que os deslocamentos ao longo do fuste, na Tabela 4.18.

Tabela 4.17 - Encurtamentos ao longo do fuste da estaca E.25.

\begin{tabular}{|c|c|c|c|c|c|c|c|}
\hline \multirow{2}{*}{$\begin{array}{c}\text { Carga no Topo [kN] } \\
746,02 \mathrm{~m} \\
2,30 \mathrm{~m} \\
\end{array}$} & \multicolumn{7}{|c|}{ ENCURTAMENTOS $\left(\Delta_{\mathrm{e}}\right)[\mathrm{mm}]$ NOS NIVEIS ABSOLUTO E RELATIVO } \\
\hline & $\begin{array}{c}743,72 \mathrm{~m} \\
0,00 \mathrm{~m}\end{array}$ & $\begin{array}{l}738,27 m \\
-5,45 m\end{array}$ & $\begin{array}{l}732,94 m \\
-10,80 m\end{array}$ & $\begin{array}{l}729,72 \mathrm{~m} \\
-14,00 \mathrm{~m} \\
\end{array}$ & $\begin{array}{l}723,30 m \\
-20,40 m \\
\end{array}$ & $\begin{array}{l}718,20 m \\
-25,50 m\end{array}$ & \begin{tabular}{l|l|}
$714,99 m$ & $713,86 m$ \\
$-28,70 m$ & $-29,83 m$ \\
\end{tabular} \\
\hline 0 & 0 & 0 & 0 & 0 & 0 & 0 & 0 \\
\hline 1200 & 7,4595E-02 & $1,721 \mathrm{E}-01$ & $1,464 \mathrm{E}-01$ & 7,018E-02 & $9,508 \mathrm{E}-02$ & 3,943E-02 & $1,568 \mathrm{E}-02,4,444 \mathrm{E}-03$ \\
\hline & 4919E-01 & $3,418 \mathrm{E}-01$ & $3,056 \mathrm{E}-01$ & $1,588 \mathrm{E}-01$ & $313 \mathrm{E}-01$ & $1,021 \mathrm{E}-01$ & $3,691 \mathrm{E}-02,1,033$ \\
\hline & ,2378E-01 & 5,067E-01 & 25E-01 & 2,436E-01 & 3,651E-01 & $E-01$ & $02: 1,604$ \\
\hline 4800 & $2,9838 \mathrm{E}-01$ & 6,824E-01 & $6,022 \mathrm{E}-01$ & $3,080 \mathrm{E}-01$ & $4,566 \mathrm{E}-01$ & 2,285 & -02 , 2,507E-02! \\
\hline 6000 & 3,7297E-01 & $8,575 \mathrm{E}-01$ & $7,653 \mathrm{E}-01$ & $4,012 \mathrm{E}-01$ & $6,360 \mathrm{E}-01$ & $3,433 \mathrm{E}-01$ & $1,408 \mathrm{E}-01,3,596 \mathrm{E}-02$ \\
\hline 7200 & 4,4757E-01 & $1,032 \mathrm{E}+00$ & $9,348 \mathrm{E}-01$ & $5,025 \mathrm{E}-01$ & $8,214 \mathrm{E}-01$ & 4,644E-01 & $2,037 \mathrm{E}-01 \mathrm{i}, 581 \mathrm{E}-02$ \\
\hline 8400 & $5,2216 \mathrm{E}-01$ & $1,201 \mathrm{E}+00$ & $1,092 \mathrm{E}+00$ & $5,952 \mathrm{E}-01$ & $9,940 \mathrm{E}-01$ & $5,791 \mathrm{E}-01$ & $2,579 \mathrm{E}-01,7,091 \mathrm{E}-02 ;$ \\
\hline 9600 & $5,9676 \mathrm{E}-01$ & $1,376 \mathrm{E}+00$ & $1,263 E+00$ & $6,968 \mathrm{E}-01$ & $1,190 \mathrm{E}+00$ & 7,214E-01 & $3,365 \mathrm{E}-01,9,611 \mathrm{E}-02$ \\
\hline 10800 & $6,7135 \mathrm{E}-01$ & $1,551 \mathrm{E}+00$ & $1,430 \mathrm{E}+00$ & 7,946E-01 & $1,379 \mathrm{E}+00$ & $8,512 \mathrm{E}-01$ & 4,032E-01 i $1,179 \mathrm{E}-01$ \\
\hline 11140 & $6,9249 \mathrm{E}-01$ & $1,598 \mathrm{E}+00$ & $1,471 \mathrm{E}+00$ & $8,160 \mathrm{E}-01$ & $1,417 \mathrm{E}+00$ & $8,752 \mathrm{E}-01$ & $4,144 \mathrm{E}-01,1,211 \mathrm{E}-01$ \\
\hline
\end{tabular}

Valores Extrapolados

Tabela 4.18 - Deslocamentos ao longo do fuste da estaca E.25.

\begin{tabular}{ccccccccc}
\hline Carga no Topo [kN] & \multicolumn{1}{c}{ DESLOCAMENTOS $\left(\boldsymbol{\delta}_{\mathrm{f}}\right)[\mathbf{m m}$ ] NOS NIVEIS ABSOLUTO E RELATIVO (Entre extensômetros) } \\
\cline { 2 - 9 } $\mathbf{7 4 6 , 0 2} \mathbf{~ m}$ & $743,72 \mathrm{~m}$ & $738,27 \mathrm{~m}$ & $732,94 \mathrm{~m}$ & $729,72 \mathrm{~m}$ & $723,30 \mathrm{~m}$ & $718,20 \mathrm{~m}$ & $714,99 \mathrm{~m}$ & $713,86 \mathrm{~m}$ \\
$\mathbf{2 , 3 0} \mathbf{~ m}$ & $0,00 \mathrm{~m}$ & $-5,45 \mathrm{~m}$ & $-10,80 \mathrm{~m}$ & $-14,00 \mathrm{~m}$ & $-20,40 \mathrm{~m}$ & $-25,50 \mathrm{~m}$ & $-28,70 \mathrm{~m}$ & $-29,83 \mathrm{~m}$ \\
\hline 0 & 0 & 0 & 0 & 0 & 0 & 0 & 0 & 0 \\
1200 & 0,205 & 0,119 & $-0,040$ & $-0,148$ & $-0,231$ & $-0,298$ & $-0,326$ & $-0,336$ \\
2400 & 0,931 & 0,760 & 0,436 & 0,204 & 0,009 & $-0,158$ & $-0,227$ & $-0,251$ \\
3600 & 1,906 & 1,653 & 1,173 & 0,825 & 0,521 & 0,254 & 0,139 & 0,099 \\
4800 & 2,922 & 2,580 & 1,938 & 1,483 & 1,101 & 0,758 & 0,597 & 0,537 \\
6000 & 4,447 & 4,018 & 3,207 & 2,624 & 2,105 & 1,615 & 1,373 & 1,285 \\
7200 & 6,522 & 6,006 & 5,023 & 4,304 & 3,642 & 2,999 & 2,665 & 2,535 \\
8400 & 9,468 & 8,867 & 7,721 & 6,877 & 6,083 & 5,296 & 4,878 & 4,713 \\
9600 & 13,953 & 13,265 & 11,946 & 10,966 & 10,022 & 9,066 & 8,538 & 8,321 \\
10800 & 28,539 & 27,763 & 26,272 & 25,160 & 24,073 & 22,958 & 22,331 & 22,070 \\
11140 & 33,378 & 32,578 & 31,043 & 29,900 & 28,784 & 27,638 & 26,993 & 26,725 \\
\hline
\end{tabular}




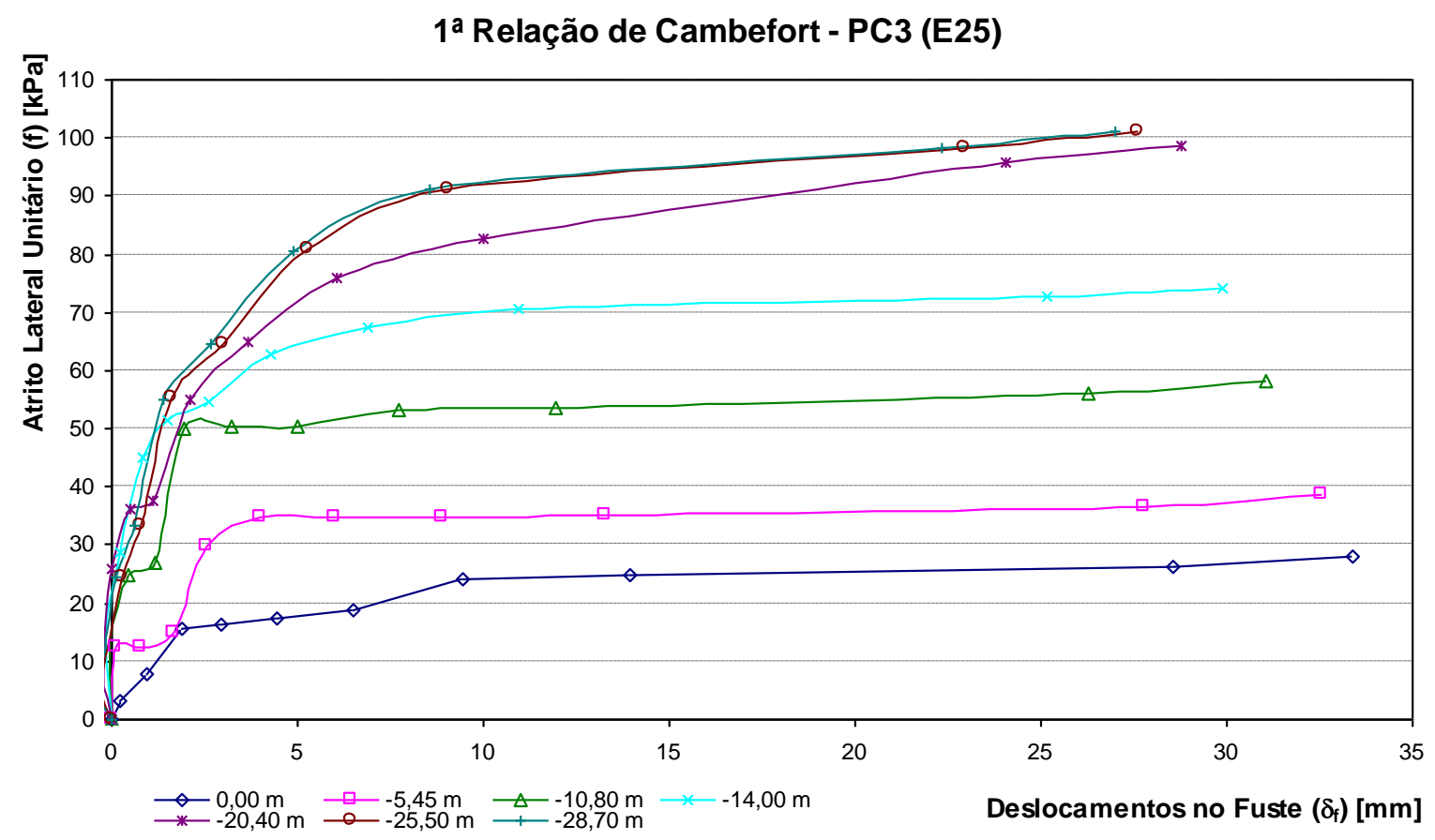

Gráfico 4.22. 1ª Relação de Cambefort_PC03 (E.25).

Por sua vez, o Gráfico 4.23 mostra a $2^{\mathfrak{a}}$ relação de Cambefort.

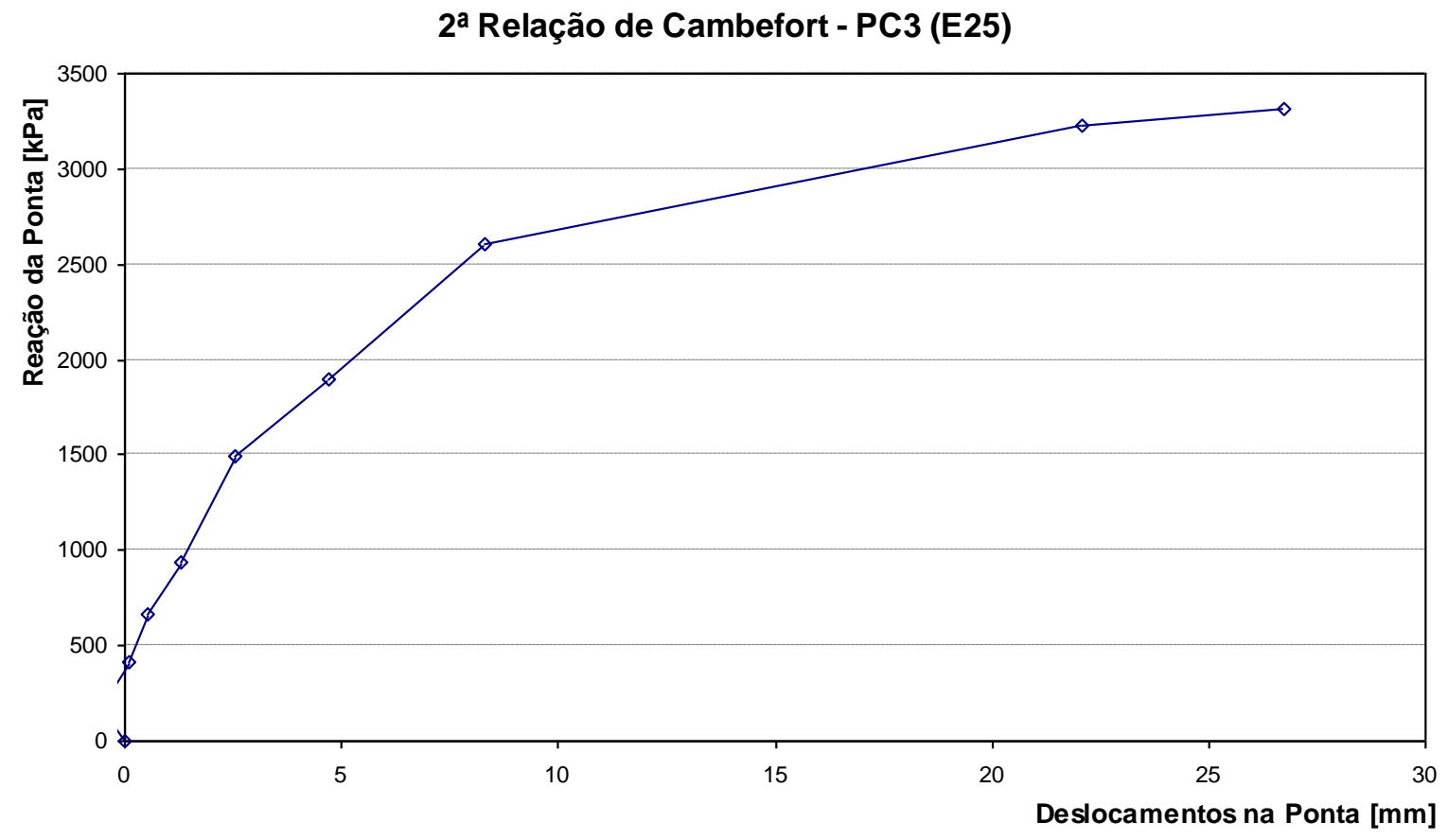

Gráfico 4.23. $2^{\text {a }}$ Relação de Cambefort_PC03 (E.25). 
Analisando a PC.03, a situação é praticamente a mesma da PC.02, com exceção da reação de ponta, que no Gráfico 4.23 fica aparente o possível início da mobilização da ponta, com $28 \mathrm{~mm}$, aproximadamente.

Já o Gráfico 4.22 mostra que a estaca ainda tem reserva de atrito lateral, pois as curvas não atingiram um patamar horizontal, mostrando um total esgotamento do mesmo. 


\subsubsection{Metódo da Rigidez (Décourt, 1996)}

De acordo com a teoria exposta no item 2.5.1, foram elaborados os gráficos de rigidez para as três provas de cargas estáticas, plotando-se a rigidez em função da carga aplicada. Também serão mostradas as divisões das parcelas de atrito lateral e ponta presentes em cada ensaio.

\subsubsection{Prova de Carga 01 (E.263b)}

O método da rigidez não se aplicou bem à primeira prova de carga estática. Devido à ocorrência do segundo carregamento, houve o aparecimento de uma carga residual advinda do carregamento anterior. Por conta dessa carga residual, o método proposto por Décourt não se adéqua à situação, conforme exposto pelo autor, em palestra técnica no IE, e apresentado por Massad (2008).

\subsubsection{Prova de Carga 02 (E.113)}

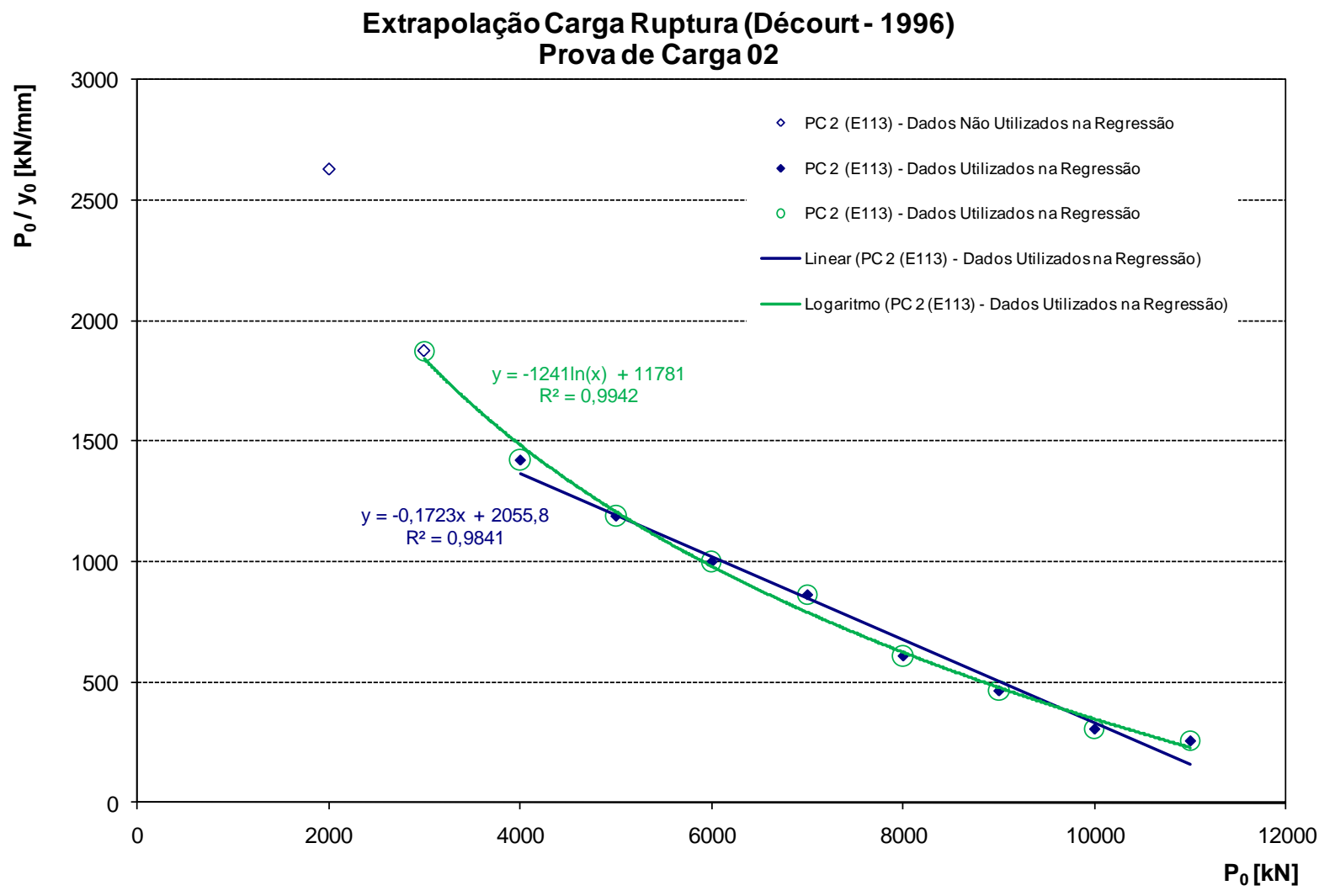

Gráfico 4.24. Método da Rigidez para a PC02 (E.113) 
Analisando o Gráfico 4.24, percebe-se que a correlação logarítmica apresentou valor de $\mathrm{R}^{2}$ mais próximo da unidade, indicando o que o autor já tem demonstrado: que as estacas moldadas in loco não apresentam ruptura física, pois a curva tende para uma assíntota horizontal. Com base na equação de regressão, representada pela equação (4.3),

$$
\frac{P_{0}}{y_{0}}=-1241 \cdot \ln \left(P_{0}\right)+11781
$$

chega-se ao valor de $\mathrm{P}_{0}=13268,5 \mathrm{kN}$.

\subsubsection{Prova de Carga 03 (E.25)}

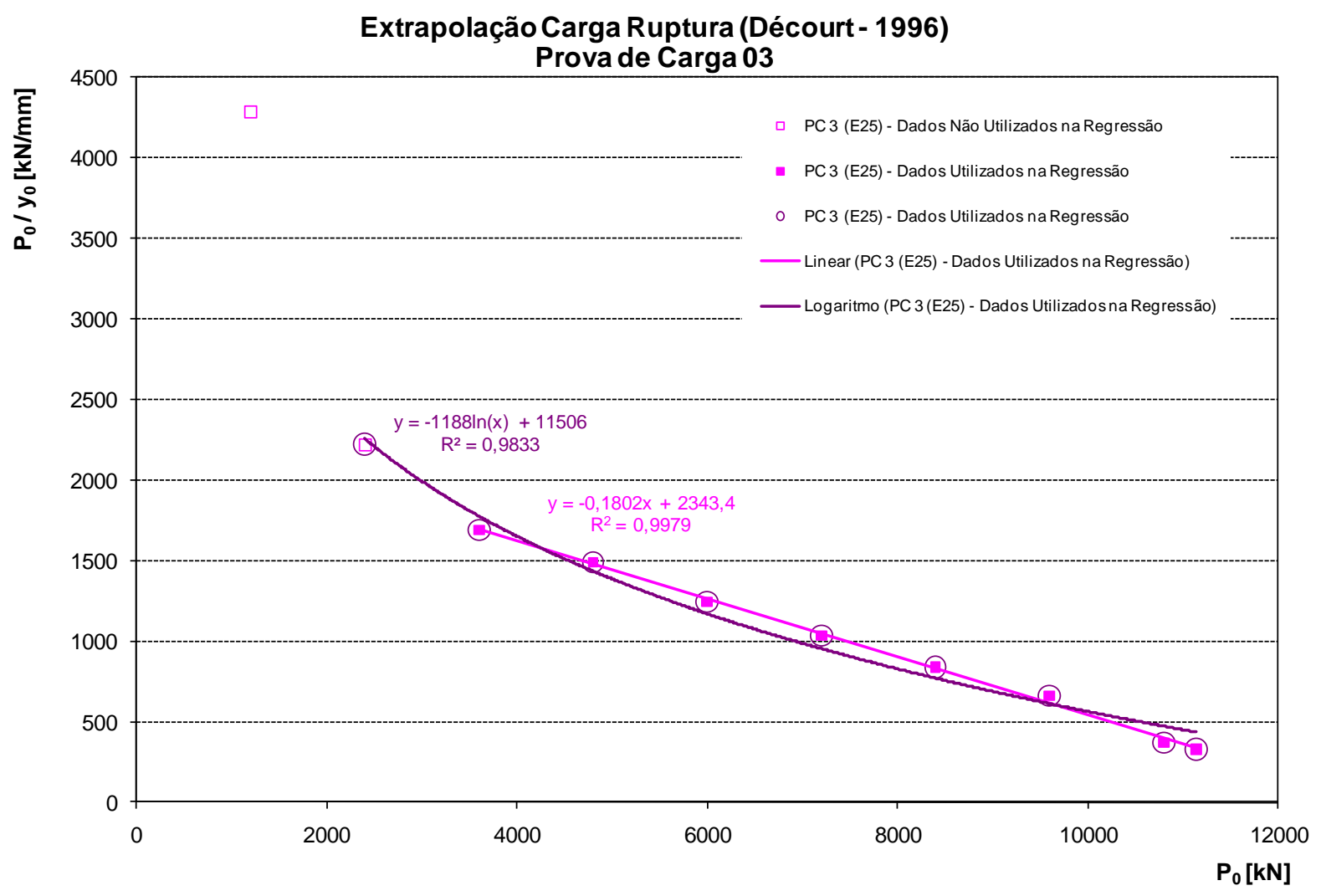

Gráfico 4.25. Método da Rigidez para a PC03 (E.25)

Considerando o Gráfico 4.25, nota-se que a correlação linear apresentou coeficiente de correlação igual a 0,9979. Desse modo, os resultados mostram exatamente que 
essa estaca apresenta o mesmo comportamento das estacas pré-moldadas, no qual existe a possibilidade de ocorrência de ruptura física.

Sendo assim, com base na equação de regressão, representada pela equação (4.4),

$$
\frac{P_{0}}{y_{0}}=-0,1802 \cdot P_{0}+2343,4
$$

chega-se ao valor de $\mathrm{PO}=13004,45 \mathrm{kN}$.

\subsubsection{Método de Chin-Kondner (1963; 1970; 1971)}

Conforme o tópico 2.5.2 elaborou-se os gráficos para as provas de cargas em questão, plotando-se a relação entre o recalque e a respectiva carga em função do próprio recalque. Isto posto pode ser visto no Gráfico 4.26.

Extrapolação Carga Ruptura (Chin-Kondner-1963,1970 e 1971)

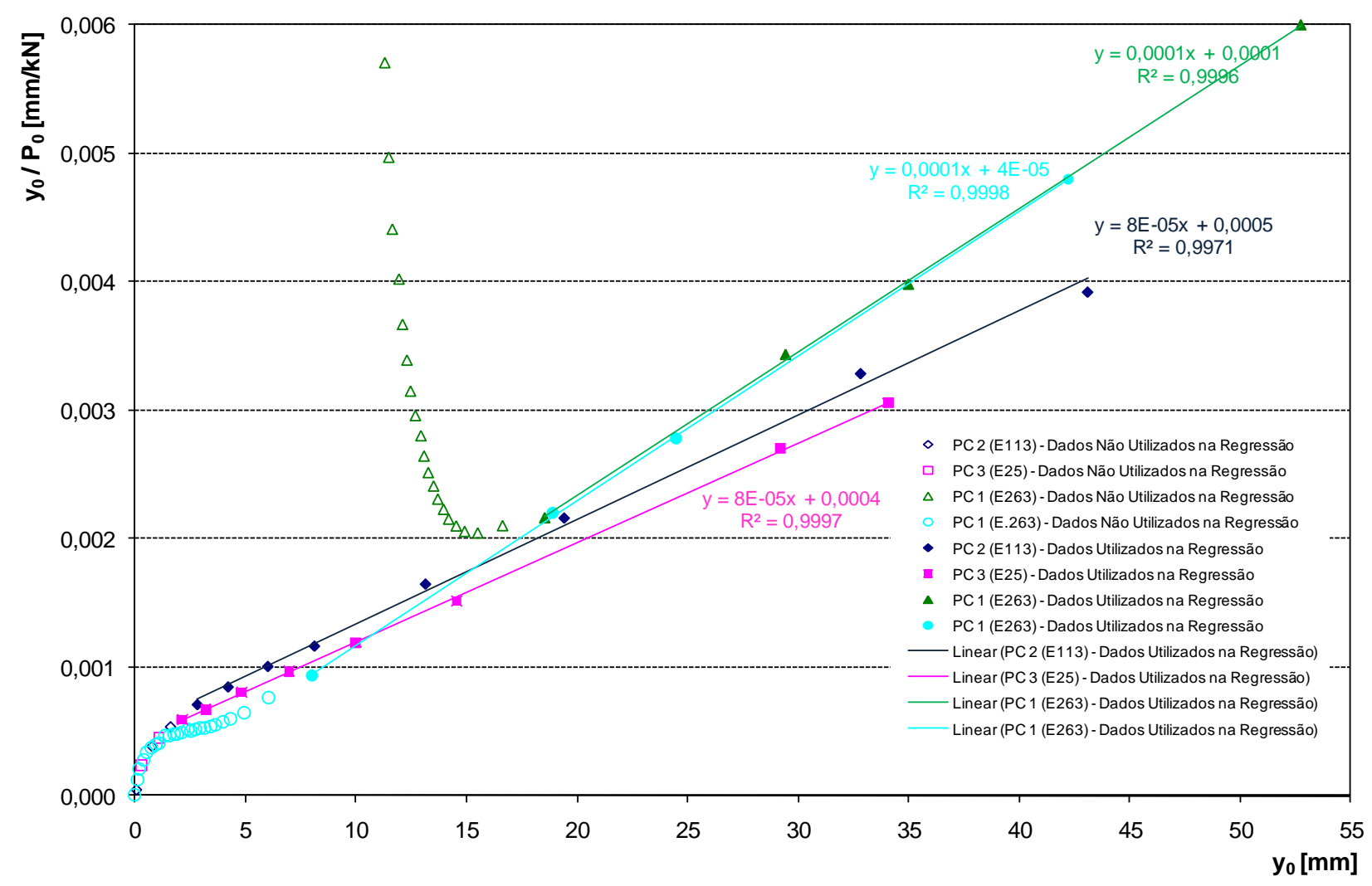

Gráfico 4.26. Método de Chin-Kondner para os 3 ensaios. 
Analisando os resultados apresentados no Gráfico 4.26 podem-se fazer as seguintes afirmações:

a.) Os resultados originais da PC.01 (marcadores verdes) não apresentaram, em sua parte inicial, o formato esperado da curva; no entanto, os últimos valores se adequaram ao método, fornecendo um coeficiente de correlação de 0,9996, proporcionando um valor de carga de ruptura igual a $8956 \mathrm{kN}$;

b.) Ainda analisando a PC.01 e desconsiderando os deslocamentos causados no primeiro carregamento (devido ao problema já relatado no item 3.3.1.1, alínea a.), observa-se (marcadores ciano) que houve um comportamento semelhante aos demais e o valor de $\mathrm{R}^{2}$ de 0,9998 mostrou-se praticamente o mesmo dos dados originais. Sendo assim, a carga de ruptura alcançada foi de $8877 \mathrm{kN}$;

c.) Os resultados da PC.02 (marcadores azuis) comportaram-se de maneira esperada e a melhor relação obtida refletiu um valor de $\mathrm{R}^{2}$ de 0,9971 . Com isso, a carga de ruptura estimada chegou a $12313 \mathrm{kN}$;

d.) Os resultados da PC.03 (marcadores rosa) também apresentaram o aspecto esperado da curva proposta pelo método. A carga de ruptura foi de $12895 \mathrm{kN}$, com $\mathrm{R}^{2}$ de 0,9997 .

A Tabela 4.19 mostra um resumo dos valores das cargas de ruptura pelo método de Chin-Kondner.

Tabela 4.19. Valores da Carga de Ruptura pelo Método de Chin-Kondner.

\begin{tabular}{cccc}
\hline & $\mathbf{R}^{\mathbf{2}}$ & $\mathbf{C 1}\left[\mathbf{k N}^{-1}\right]$ & $\mathbf{Q}_{\mathbf{u}}[\mathbf{k N}]$ \\
\cline { 2 - 4 } PC1 & 0,9996 & $1,116 \mathrm{E}-04$ & 8956,66 \\
PC1 (Zerando os & & & \\
Deslocamentos & 0,9998 & $1,126 \mathrm{E}-04$ & 8877,31 \\
Iniciais) & & & \\
PC2 & 0,9971 & $8,121 \mathrm{E}-05$ & 12313,53 \\
PC3 & 0,9997 & $7,755 \mathrm{E}-05$ & 12895,68 \\
\hline
\end{tabular}

\subsubsection{Método de Davisson (1972)}

De acordo com a formulação teórica explícita no tópico 2.5.3, foi possível a elaboração do Gráfico 4.27. 
O método de Davisson pôde ser aplicado às três provas de carga, porém apresentou valores menores quando comparado com os dois métodos citados anteriormente. Como as três estacas possuem o mesmo diâmetro, o offset registrado foi de $14 \mathrm{~mm}$. Os valores da carga de ruptura seguem listados abaixo, na Tabela 4.20.

Tabela 4.20. Valores das Cargas de Ruptura pelo Método de Davisson.

\begin{tabular}{ccc}
\hline & OFFSET $(\mathbf{m m})$ & $\mathbf{Q}_{\mathbf{u}}[\mathbf{k N}]$ \\
\cline { 2 - 3 } PC1 & 14,00 & 8600,00 \\
PC2 & 14,00 & 9200,00 \\
PC3 & 14,00 & 10200,00 \\
\hline
\end{tabular}

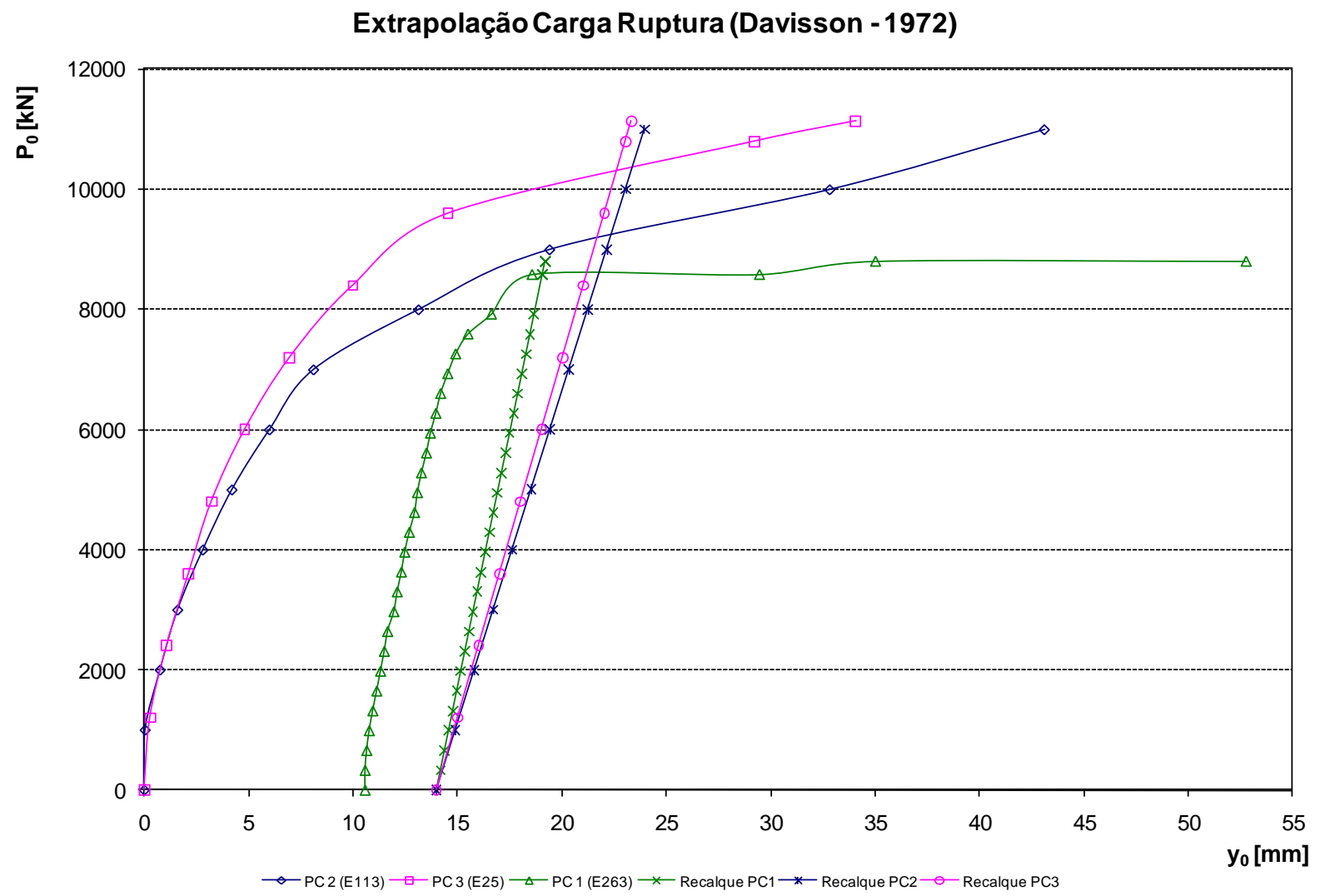

Gráfico 4.27. Método de Davisson para os 3 ensaios.

\subsubsection{Método das Duas Retas}

Seguindo as explicações teóricas do método proposto por Massad e Lazo (1998), de acordo com o item 2.5.5, foi possível aplicá-lo graficamente aos casos estudados. 
Nos próximos itens, 4.5.5.1 a 4.5.5.3, é possível visualizar esses gráficos e os resultados obtidos pelos mesmos.

\subsubsection{Prova de Carga 01 (E.263)}

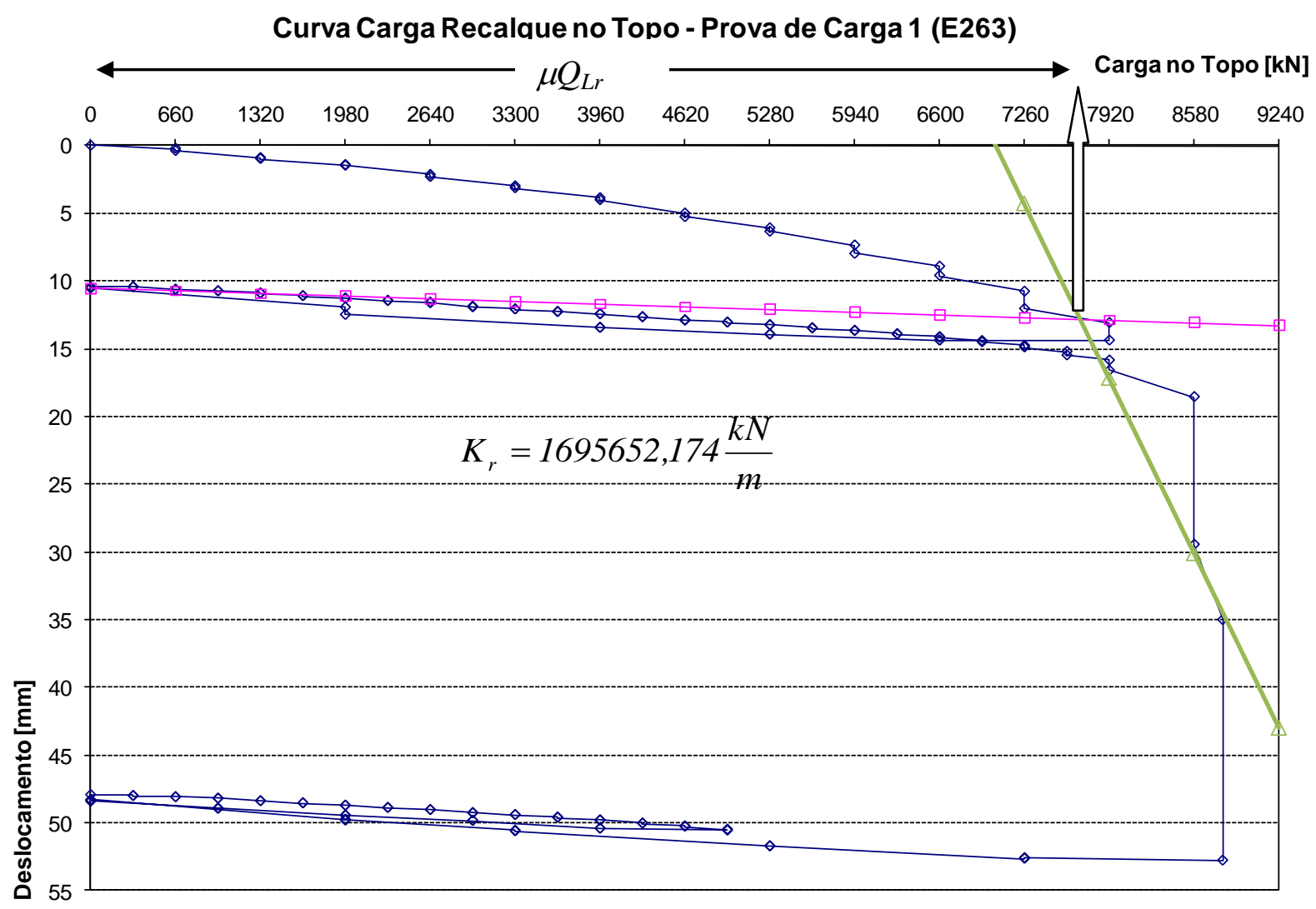

Gráfico 4.28. Método das 2 Retas aplicado à PC.01.

No Gráfico 4.28 é possível observarmos que a intersecção entre as duas retas proporciona a equação (4.5):

$$
\mu \cdot Q_{L_{R}} \cong 7800 k N
$$

onde:

$$
\begin{aligned}
& \mu=\text { Fator de Majoração da Carga Residual }\left[\mathrm{F}^{0} \mathrm{~L}^{0} \mathrm{~T}^{0}\right] \\
& \mathrm{QLr}=\text { Atrito Lateral na Ruptura }[\mathrm{F}] \text {, obtido da Tabela 4.10; }
\end{aligned}
$$

Com as variáveis já definidas, tem-se: $\mu .(8800-2602) \cong 7800 k N \therefore \mu=1,258$. Sendo assim, a carga aprisionada na ponta, denominada como Carga Residual, está expressa na equação (4.6): 


$$
\mu=1+\frac{P_{h}}{Q_{L_{R}}} \therefore P_{h}=1602 k N
$$

\subsubsection{Prova de Carga 02 (E.113)}

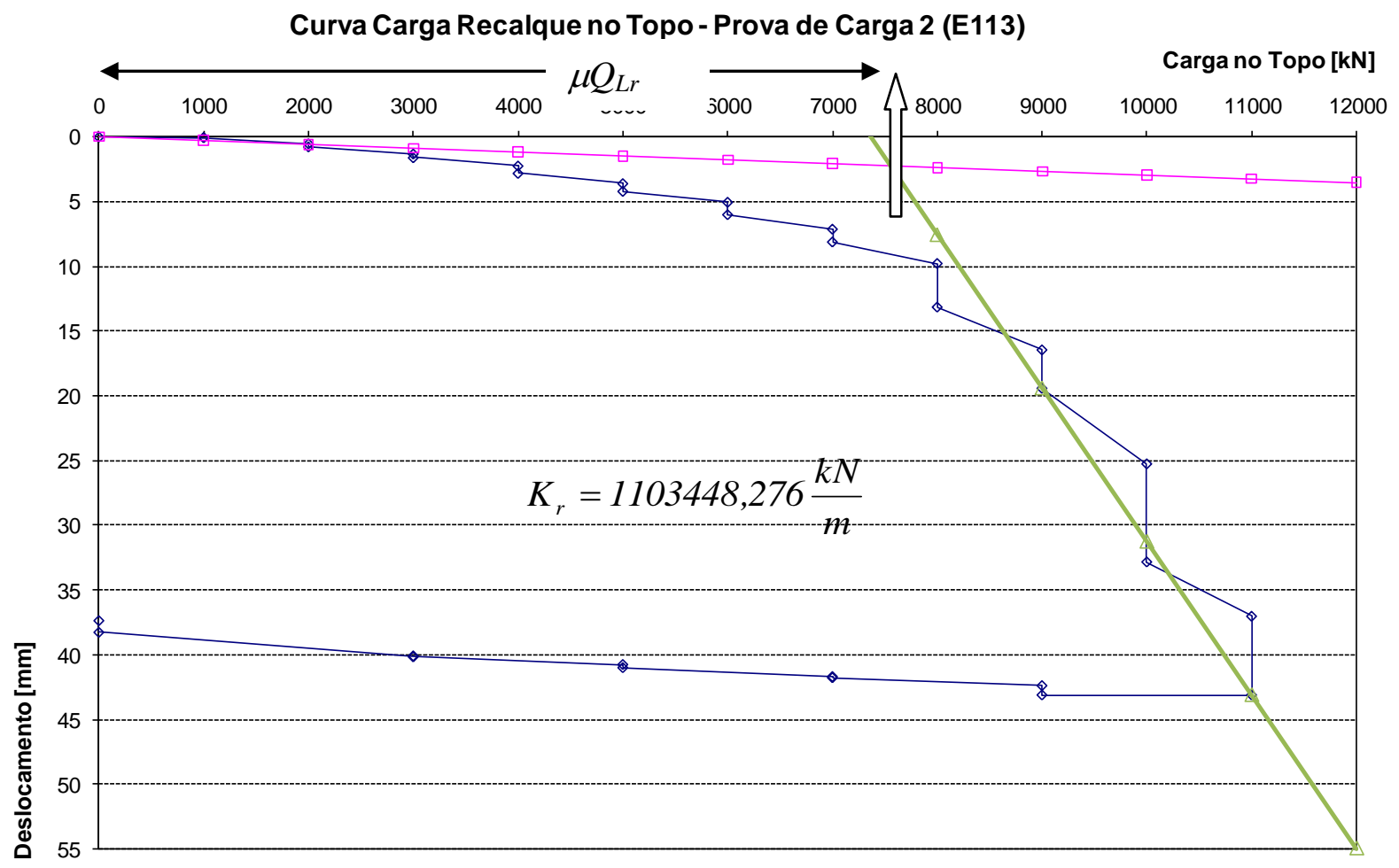

Gráfico 4.29. Método das 2 Retas aplicado à PC.02.

Já no Gráfico 4.29, a intersecção entre as duas retas proporciona a equação (4.7):

$$
\mu \cdot Q_{L_{R}} \cong 7600 k N
$$

Como nessa prova de carga não houve o segundo carregamento e o fato da estaca ser escavada, não existe carga residual e o fator majorador é unitário. Sendo assim:

$$
Q_{L_{R}} \cong 7600 k N
$$




\subsubsection{Prova de Carga 03 (E.25)}

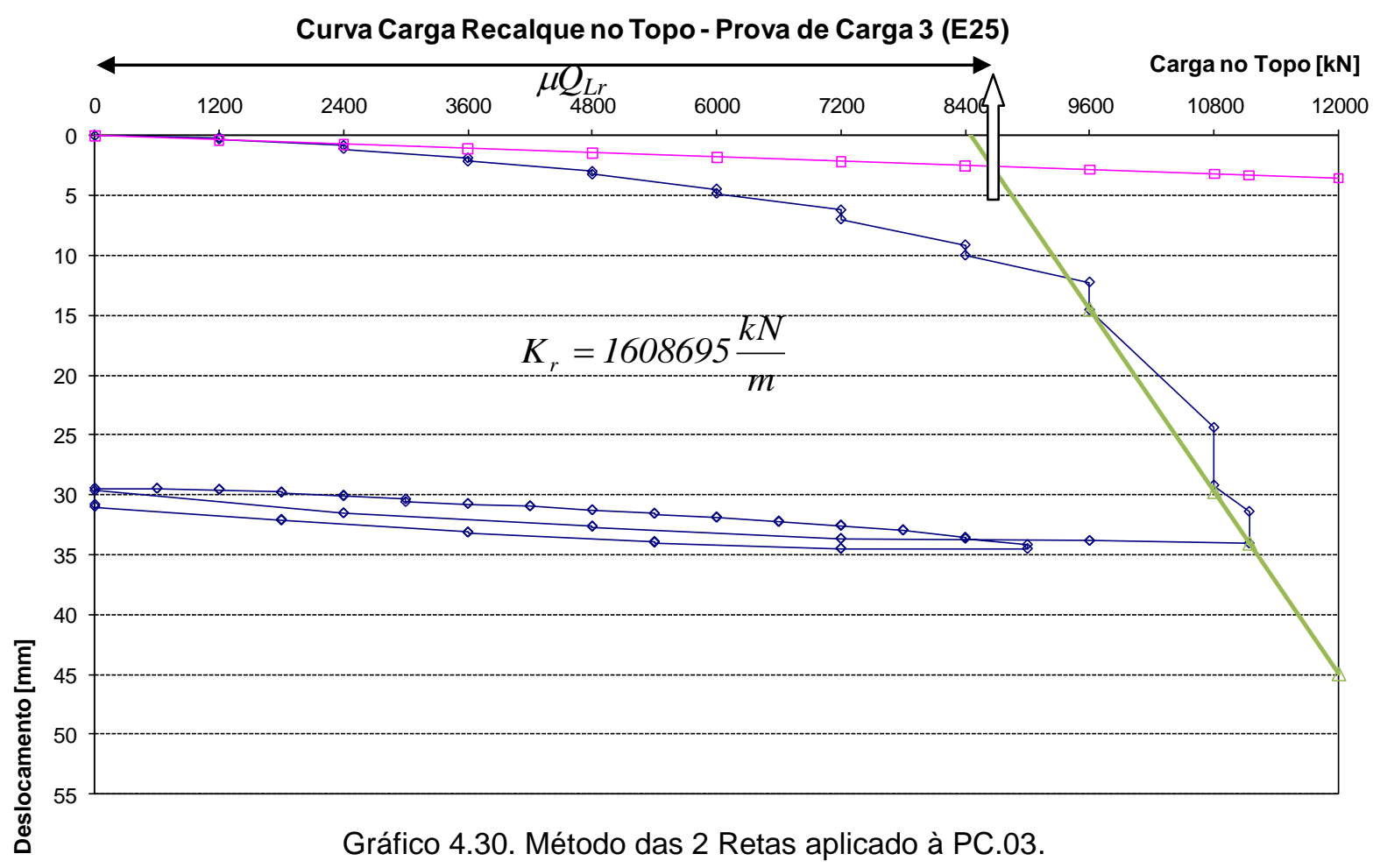

Analogamente ao item anterior, tem-se:

$$
\mu \cdot Q_{L_{R}} \cong 8500 k N
$$

E, por fim:

$$
Q_{L_{R}} \cong 8500 k N
$$

\subsubsection{Método da Norma Brasileira (NBR 6122/1996)}

Analogamente ao Método de Davisson, pode-se construir os gráficos baseados nas prescrições da norma brasileira de fundações. Mais uma vez ressalta-se que não houve alteração da metodologia proposta na nova edição da norma, publicada e válida desde 2010.

O método proposto pela norma brasileira é muito semelhante ao método elaborado por Davisson, exceto pelo deslocamento inicial. No entanto, em virtude do diâmetro 
da estaca, o offset em relação à origem foi excessivo, superando, exceto para a PC01, os recalques máximos obtidos dos ensaios estáticos. Sendo assim, o método não foi aplicável aos casos de estudo. Tal confirmação pode ser vista no Gráfico 4.31 .

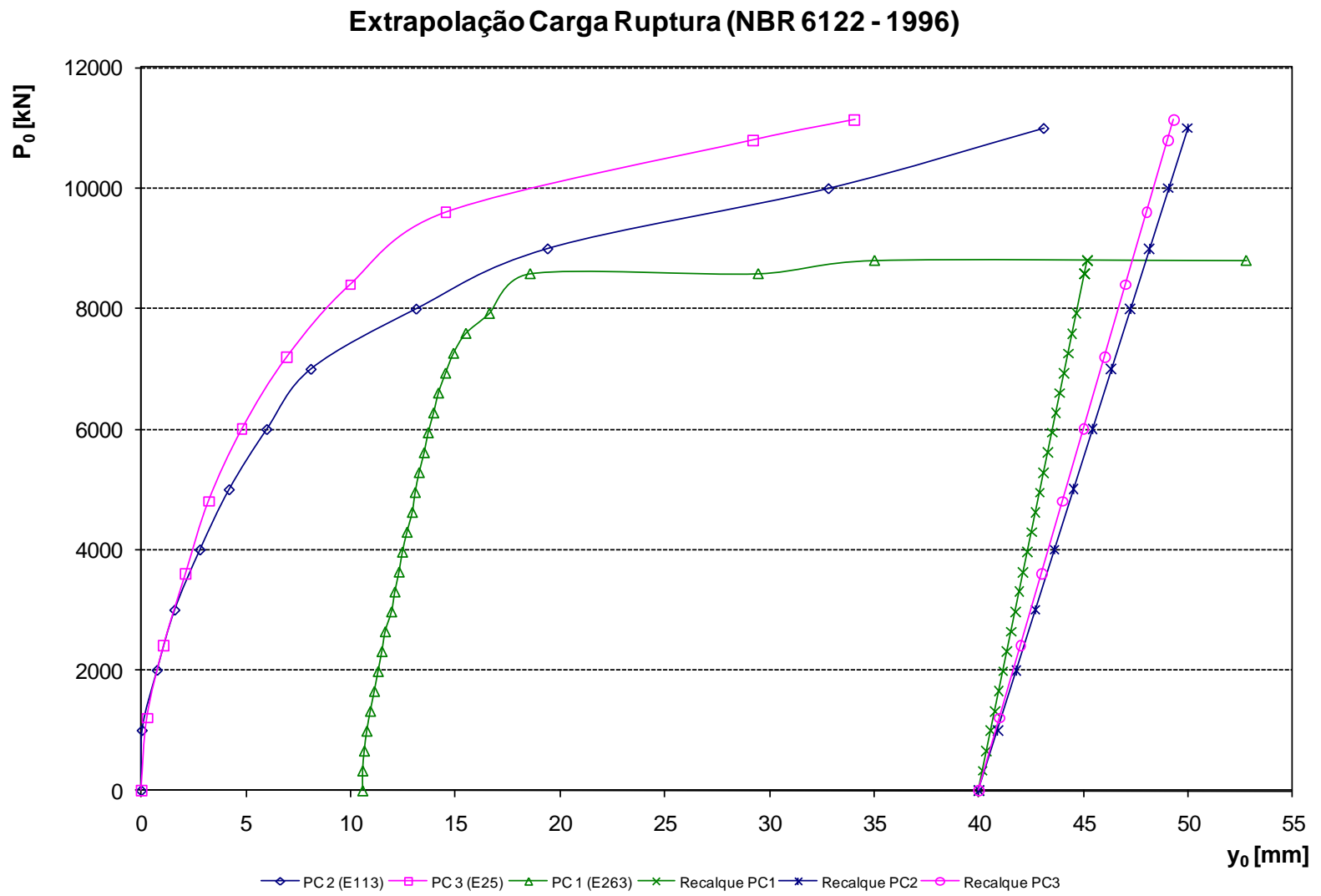

Gráfico 4.31. Método de Extrapolação da NBR 6122.

\subsubsection{Método de Brinch-Hansen $80 \%$ (1963)}

Conforme o item 2.5.7 foram calculadas as raízes quadradas dos recalques e feita a divisão pelas respectivas cargas, colocando essa relação no eixo das ordenadas. Por sua vez, no eixo das abscissas foram colocados os recalques obtidos durante a prova de carga estática.

Olhando-se o Gráfico 4.32, as seguintes observações podem ser feitas: 
a.) Os resultados originais da PC.01 (marcadores verdes) não apresentaram, em sua parte inicial, o formato esperado da curva; no entanto, os últimos valores se adequaram o método, fornecendo um coeficiente de correlação de 0,9989, proporcionando um valor de carga de ruptura igual a $8646 \mathrm{kN}$;

b.) Ainda analisando a PC.01 e desconsiderando os deslocamentos causados no primeiro carregamento (devido ao problema já relatado no item 3.3.1.1, alínea a.), observa-se (marcadores ciano) que houve um comportamento semelhante aos demais e o valor de $R^{2}$ de 1,00 proporcionou carga de ruptura de $9159 \mathrm{kN}$;

c.) Os resultados da PC.02 (marcadores azuis) comportaram-se de maneira esperada e a melhor relação obtida refletiu um valor de $R^{2}$ de 0,9762, embora esse valor esteja muito distante da unidade. Com isso, a carga de ruptura estimada chegou a $11209 \mathrm{kN}$;

d.) Os resultados da PC.03 (marcadores rosa) também apresentaram o aspecto esperado da curva proposta pelo método. A carga de ruptura foi de $13173 \mathrm{kN}$, com $\mathrm{R}^{2}$ de 0,9961 .

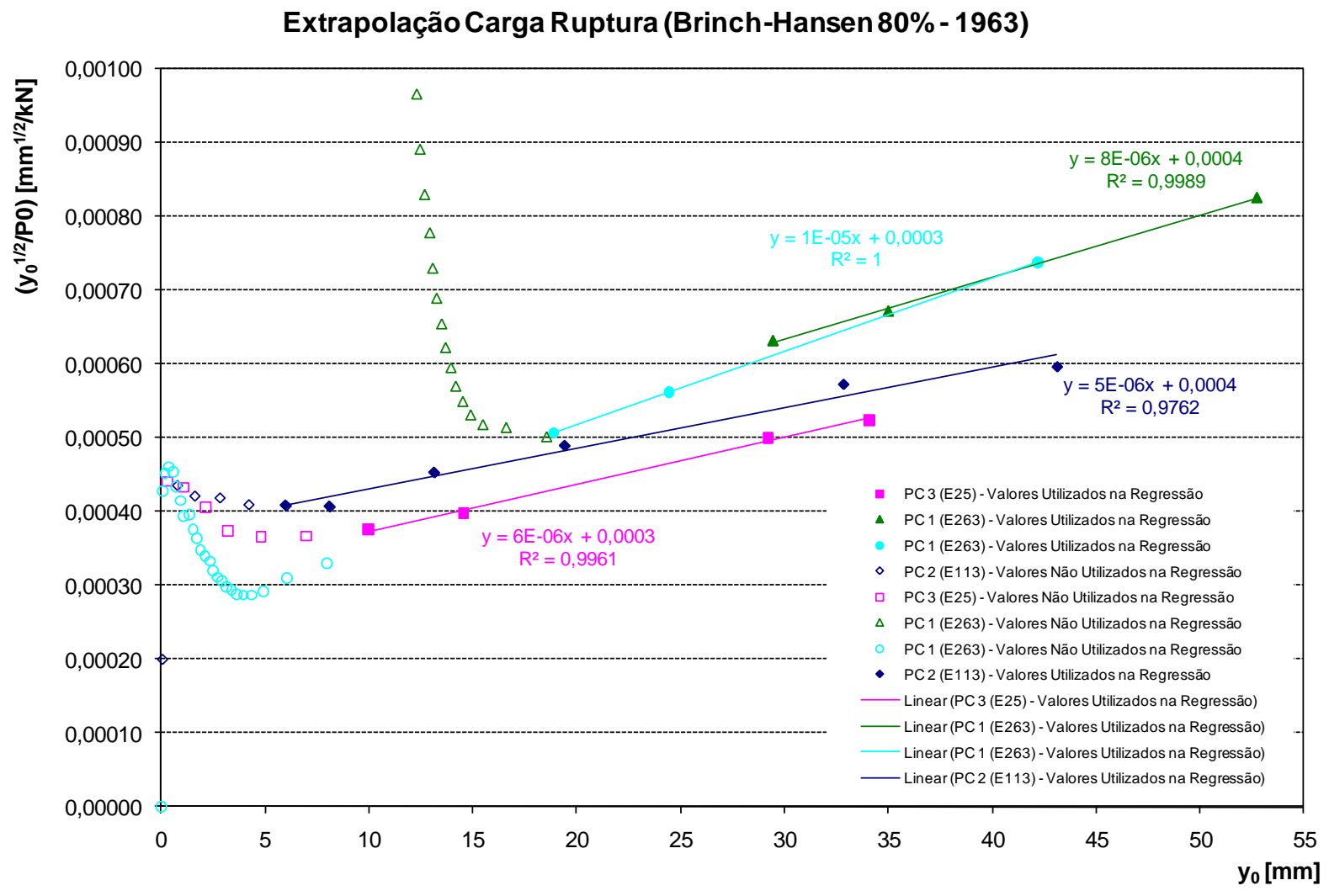

Gráfico 4.32. Método de Brinch-Hansen $80 \%$ para os 3 ensaios. 


\subsubsection{Método de De Beer (1968)}

Conforme proposto pelo autor, foram calculados os logaritmos das cargas, o qual foi plotado no eixo das ordenadas, e dos recalques, no eixo das abscissas. O Gráfico 4.33 mostra os resultados para as três provas de cargas estáticas realizadas.

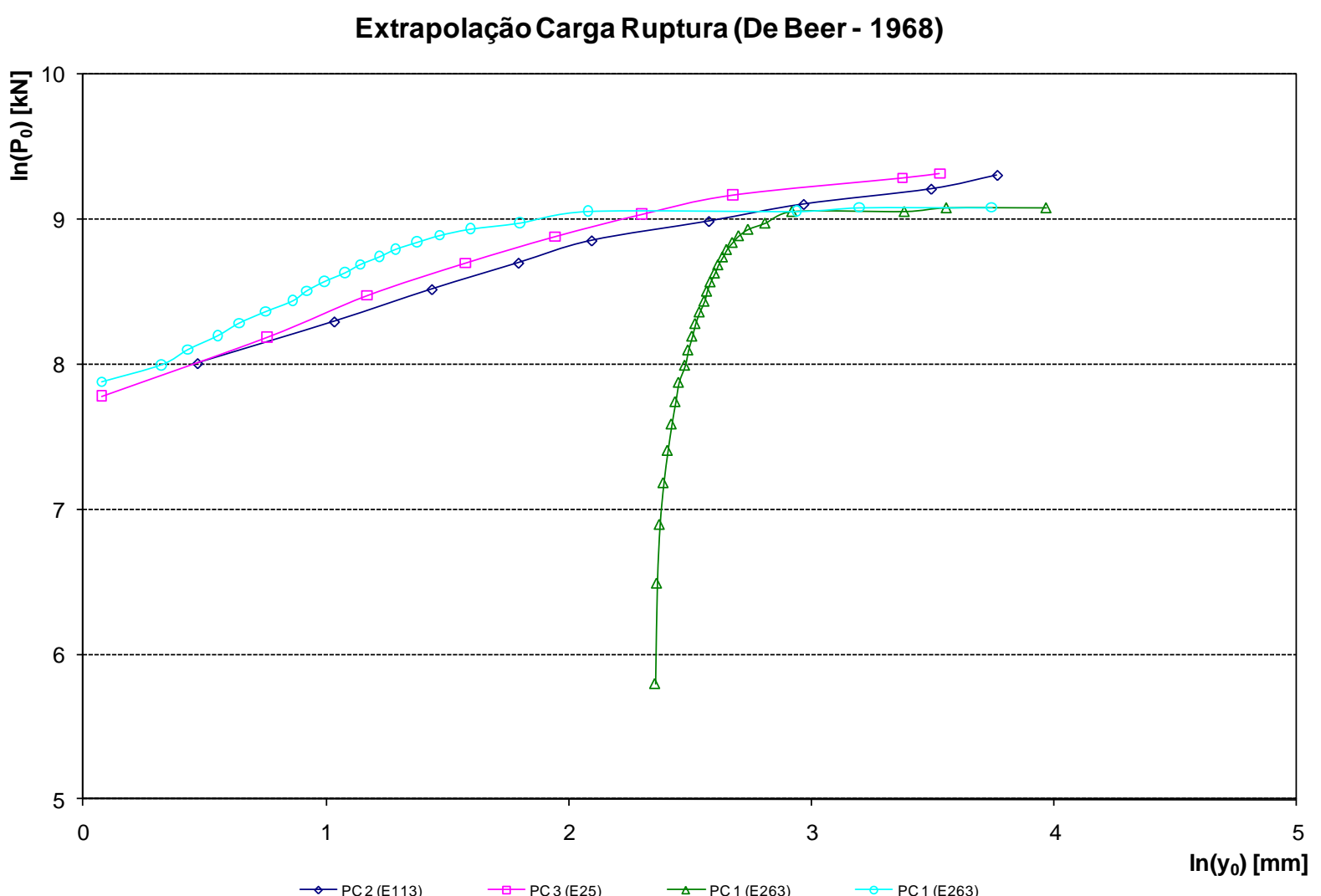

Gráfico 4.33. Método de De Beer para os 3 ensaios.

Os valores das cargas de ruptura constam na Tabela 4.21.

Tabela 4.21. Valores da Carga de Ruptura pelo Método de De Beer.

\begin{tabular}{ccc}
\hline & \multicolumn{1}{l}{$\mathbf{( \mathbf { P } _ { \mathbf { 0 } } )}$} & $\mathbf{Q}_{\mathbf{u}}[\mathbf{k N}]$ \\
\cline { 2 - 3 } PC1 & \multicolumn{2}{c}{ Não aplicável } \\
PC1 (Zerando os & 9,05 & 8518,54 \\
Deslocamentos & & \\
Iniciais) & 8,80 & 6634,24 \\
PC2 & 9,10 & 8955,29 \\
PC3 &
\end{tabular}




\subsubsection{Método de Van der Veen (1953)}

Aplicou-se o método de Vand der Veen, conforme item 2.5.9, às três estacas submetidas aos carregamentos de compressão e foram obtidos os seguintes resultados, vistos no Gráfico 4.34 a Gráfico 4.36 .

Extrapolação Carga Ruptura (Van der Veen - 1953)_PC.01

$$
\ln \left(1-\mathbf{P}_{0} / \mathbf{P}_{\mathrm{u}}\right)
$$

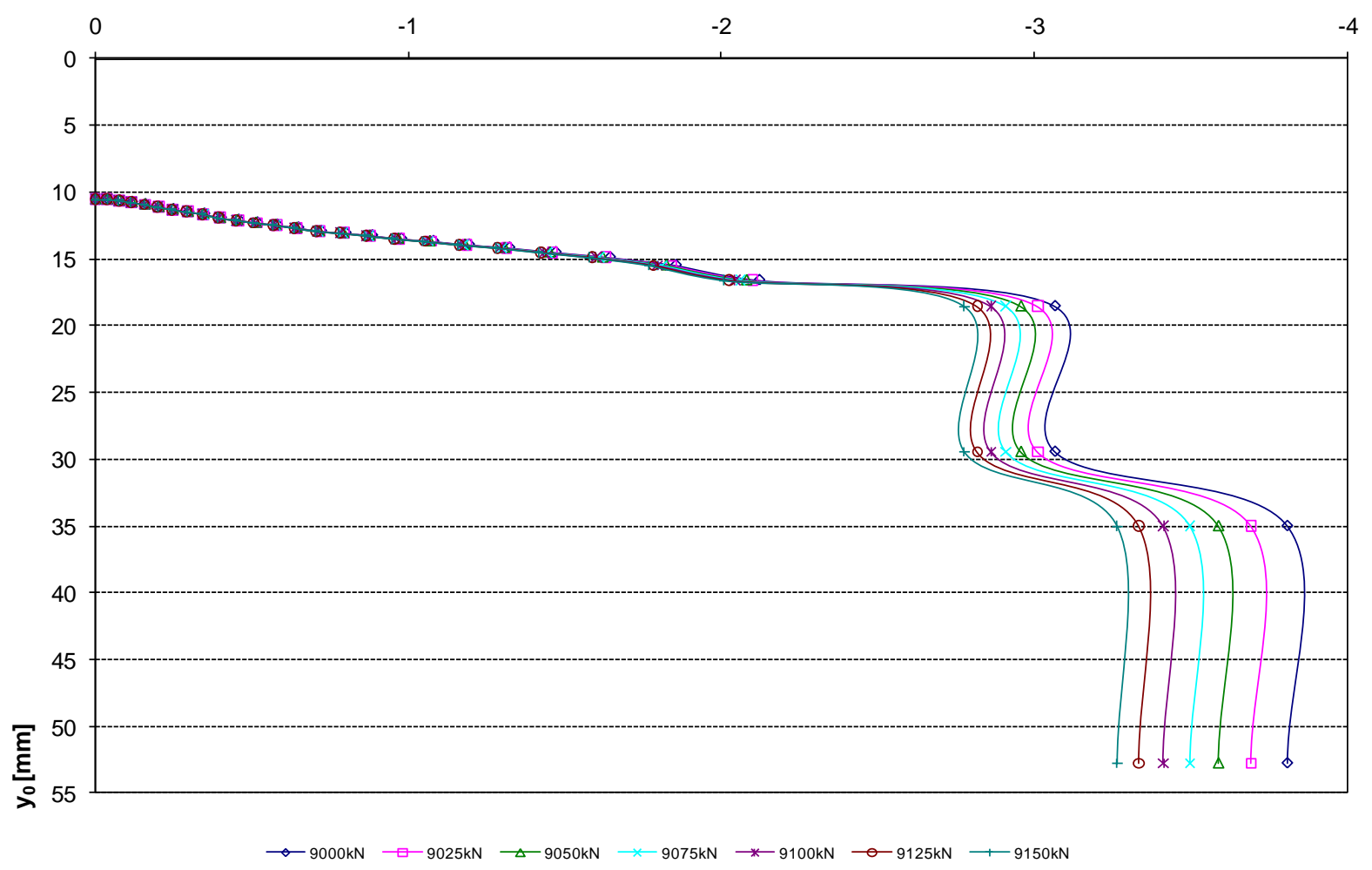

Gráfico 4.34. Método de Van der Veen para a PC.01 (E263) 
Extrapolação Carga Ruptura (Van der Veen - 1953)_PC.02

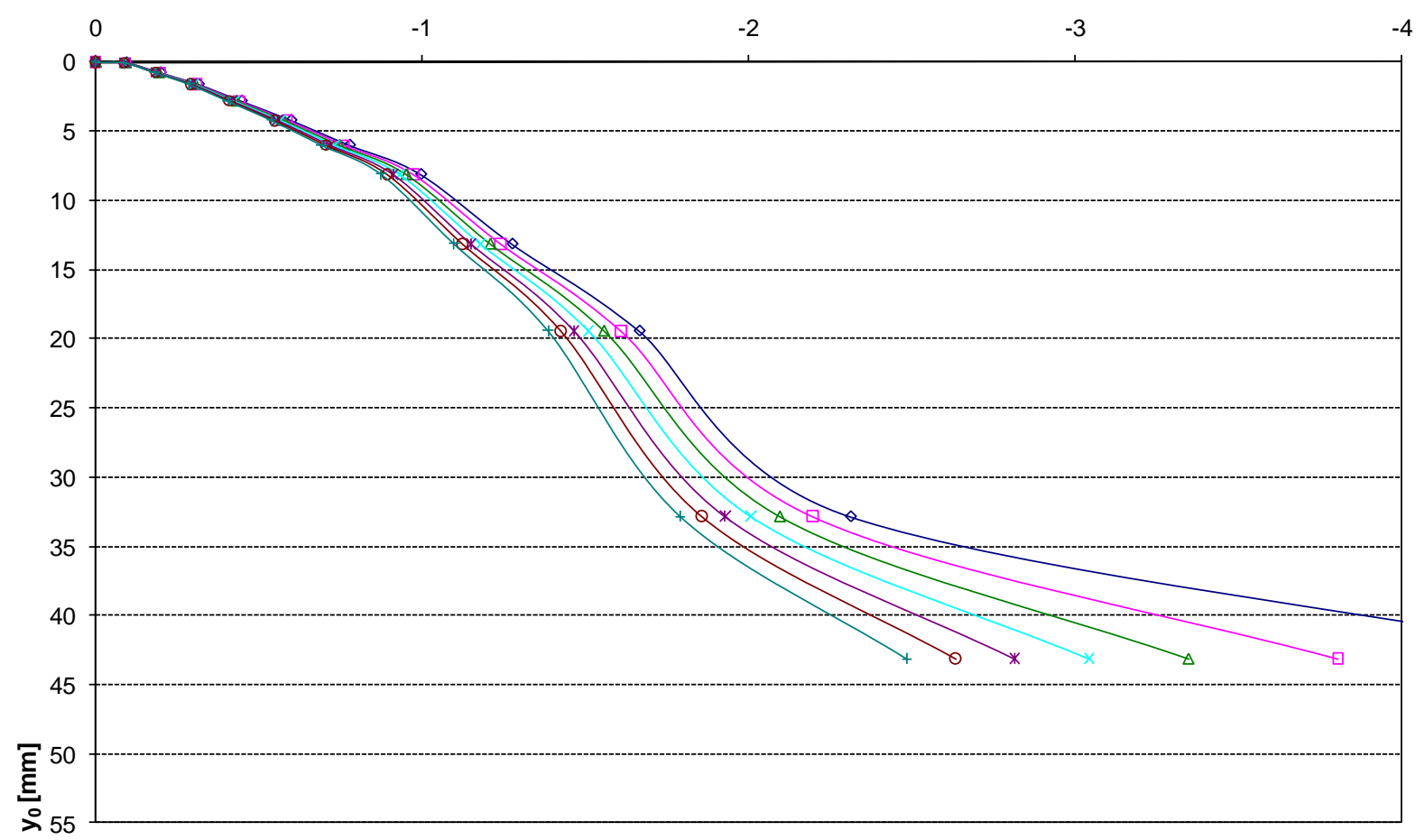

$\multimap 11100 \mathrm{kN} \square-11250 \mathrm{kN} \longrightarrow 11400 \mathrm{kN} \rightleftharpoons 11550 \mathrm{kN} \longrightarrow 11700 \mathrm{kN} \longrightarrow 11850 \mathrm{kN} \longrightarrow 12000 \mathrm{kN}$

Gráfico 4.35. Método de Van der Veen para a PC.02 (E113)

Extrapolação Carga Ruptura (Van der Veen - 1953)_PC.03

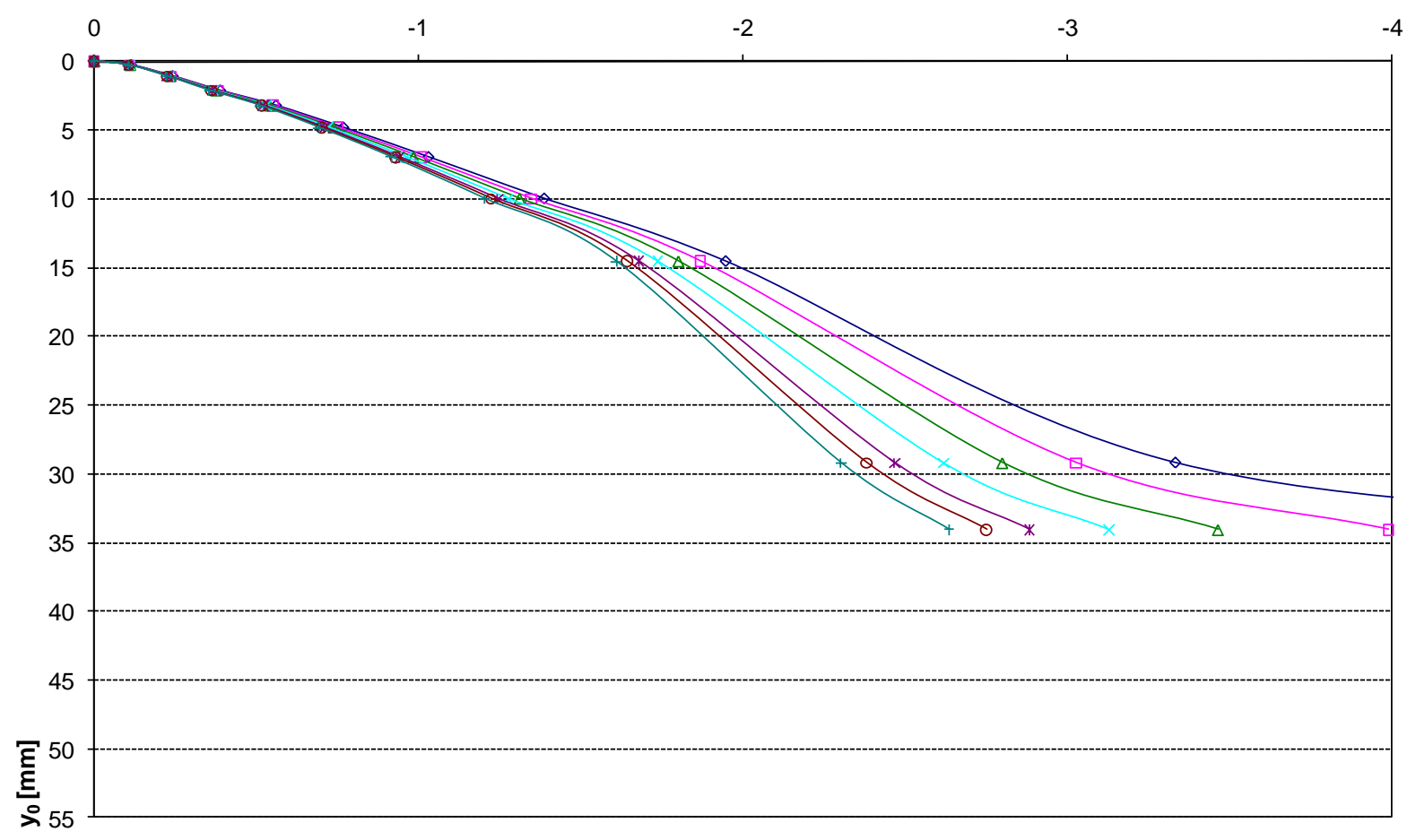

$\multimap 11200 \mathrm{kN} \square-11350 \mathrm{kN} \longrightarrow 11500 \mathrm{kN} \rightarrow 11650 \mathrm{kN} \rightarrow 11800 \mathrm{kN} \longrightarrow 11900 \mathrm{kN} \longrightarrow 12000 \mathrm{kN}$

Gráfico 4.36. Método de Van der Veen para a PC.03 (E25) 
Os gráficos expostos com base no método proposto por Van de Veen, em geral, não se aplicaram bem ao tipo de estaca em questão. Em nenhuma das provas de carga apresentadas foi possível encontrar uma relação linear que representasse a carga de ruptura estimada. No entanto, isso não foi surpresa, haja vista que o método não é adequado para estacas escavadas, como já é sabido no meio técnico e mostrado em Décourt e Niyama (1994).

\subsubsection{Método de Mazurkiewicz (1972)}

O método proposto por Mazurkiewicz, de acordo com o tópico 2.5.10, apresentou resultados mais conservadores quando comparados aos métodos anteriores, com exceção ao método de De Beer, o qual apresentou os valores mais baixos entre todos os métodos apresentados.

No Gráfico 4.37 é possível ver a aplicação do método e na Tabela 4.22, os valores das cargas de ruptura atingidas.

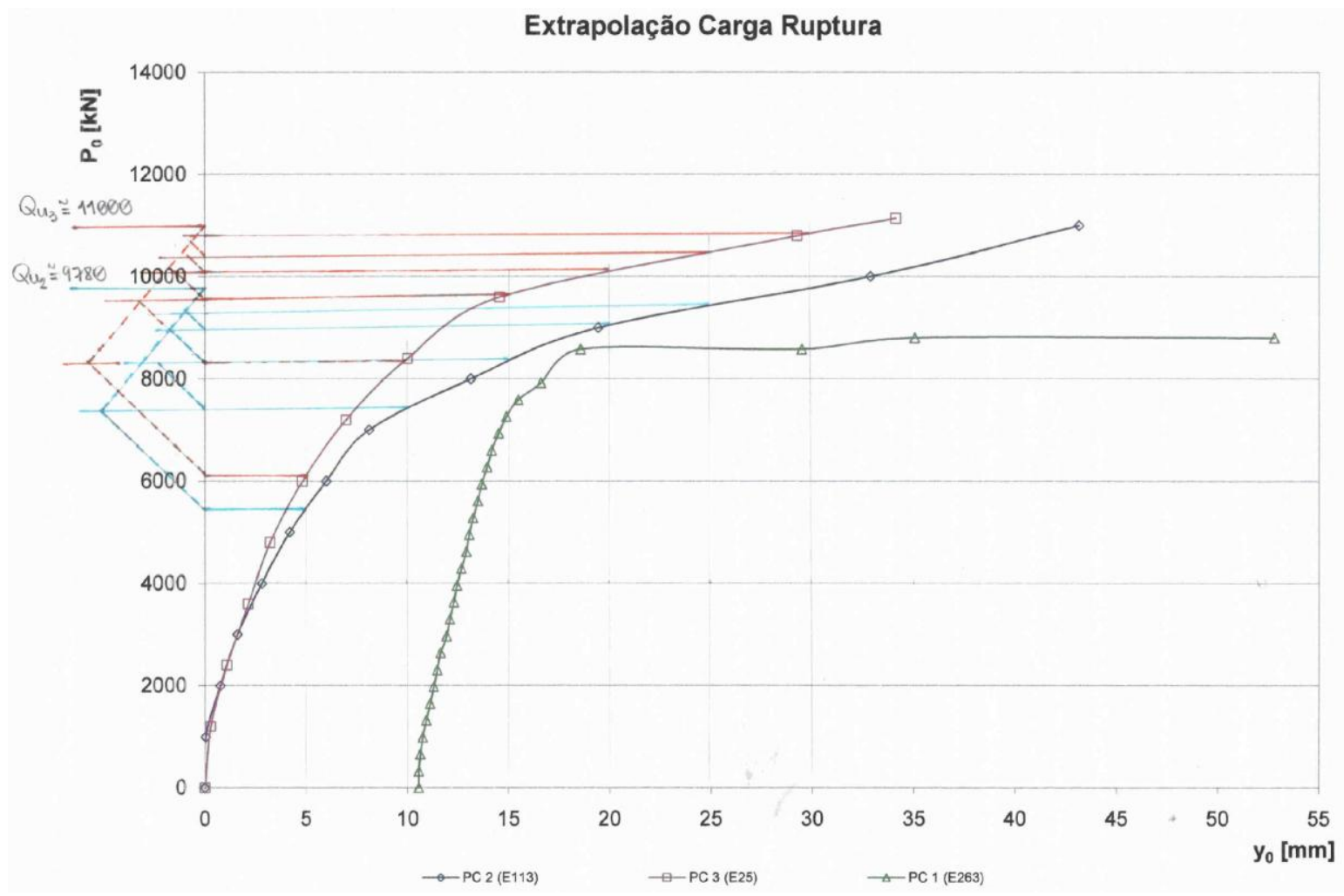

Gráfico 4.37. Método de Mazurkiewicz para os 3 ensaios. 
Tabela 4.22. Valores das Cargas de Ruptura pelo Método de Mazurkiewicz.

\begin{tabular}{cc}
\hline & $\left.\mathbf{Q}_{\mathbf{u}} \mathbf{[ k N}\right]$ \\
\cline { 2 - 2 } PC1 & Não se Aplica \\
PC2 & 9780,00 \\
PC3 & 11000,00 \\
\hline
\end{tabular}

\subsubsection{Método de Butler \& Roy (1977)}

Com base na descrição do método, no item 2.5.11, foi possível a construção do Gráfico 4.38 e a estimativa das cargas de ruptura, indicadas na Tabela 4.23.

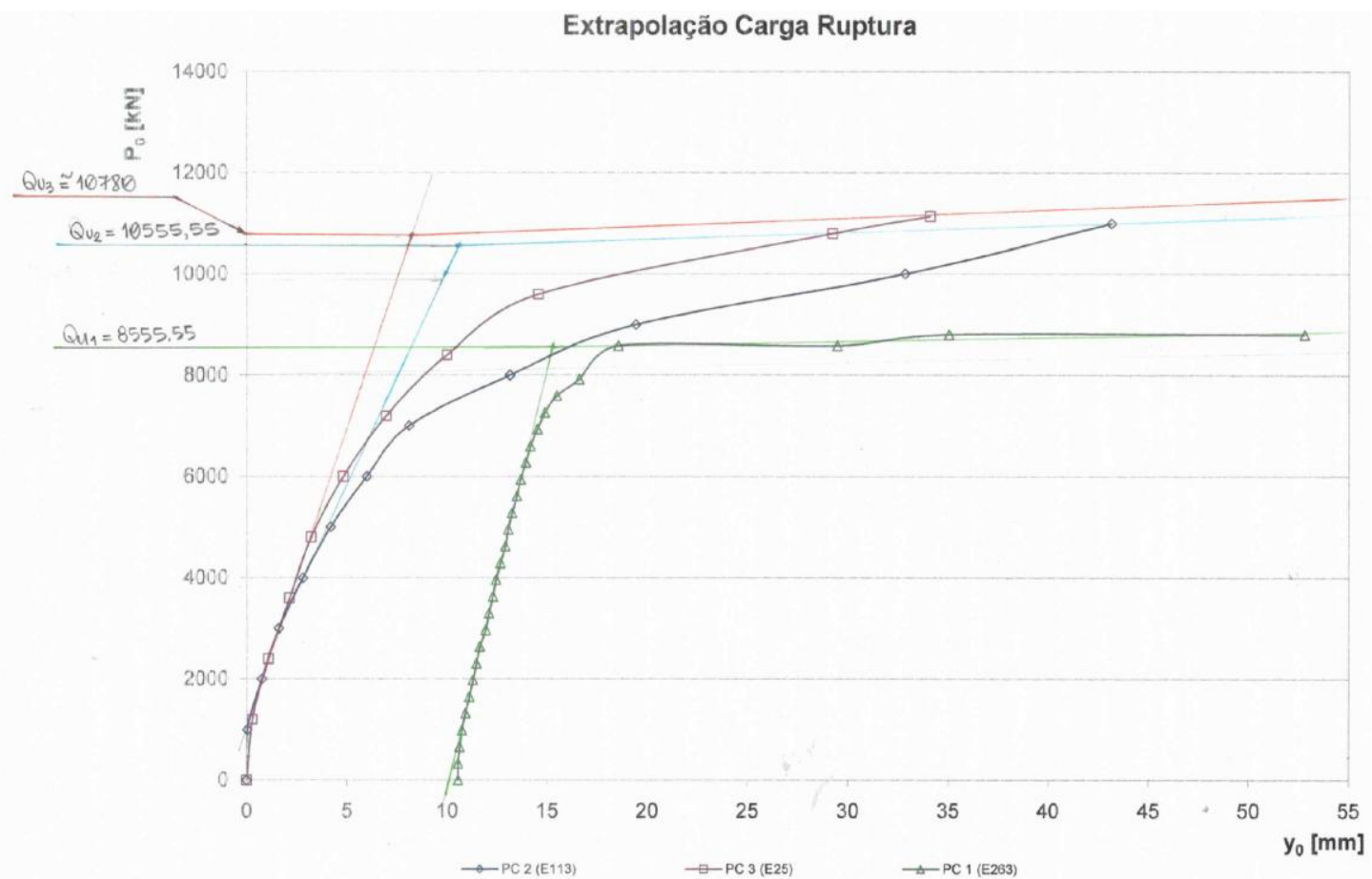

Gráfico 4.38. Método de Butler\&Roy para os 3 ensaios.

Tabela 4.23. Valores das Cargas de Ruptura para o Método de Butler \& Roy.

\begin{tabular}{cc}
\hline & $\mathbf{Q}_{\mathbf{u}}[\mathbf{k} \mathbf{N}]$ \\
\cline { 2 - 2 } PC1 & 8555,55 \\
PC2 & 10555,55 \\
PC3 & 10780,00 \\
\hline
\end{tabular}


Esse método também não apresentou resultados satisfatórios, pois as cargas últimas ficaram muito abaixo do esperado. O método representou bem, como efeito de comparação, a carga de ruptura para a PC01, que já havia atingido a ruptura.

\subsubsection{Método de Randolph - Wroth}

Para a utilização desse método, um dos parâmetros necessário é o módulo de elasticidade do solo. Como não se tem ensaios laboratoriais para essa finalidade, a correlação expressa pela equação (4.9), conforme Negro, Ferreira e Sozio (1982), será utilizada.

$$
E_{0}=5 . N_{S P T}
$$

onde:

$$
\begin{aligned}
& N_{\mathrm{SPT}}=\mathrm{SPT} \text { médio ao longo do fuste; } \\
& \mathrm{E}_{0}=\text { Módulo de Elasticidade Tangente Inicial do Solo [MPa]; }
\end{aligned}
$$




\subsubsection{Prova de Carga PC.01}

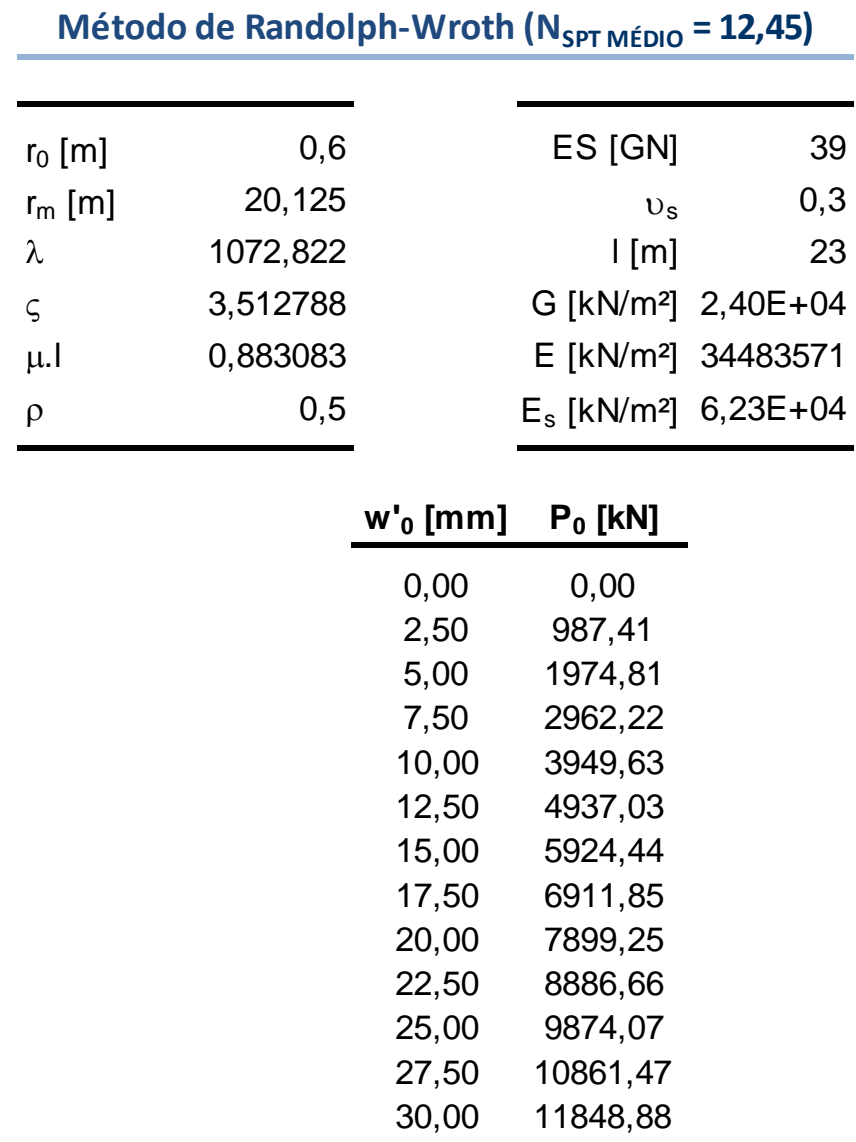

Figura 4.2. Resultados do Método de Randolph-Wroth para a PC.01 ( $\mathrm{N}_{\mathrm{SPT}}$ médio)

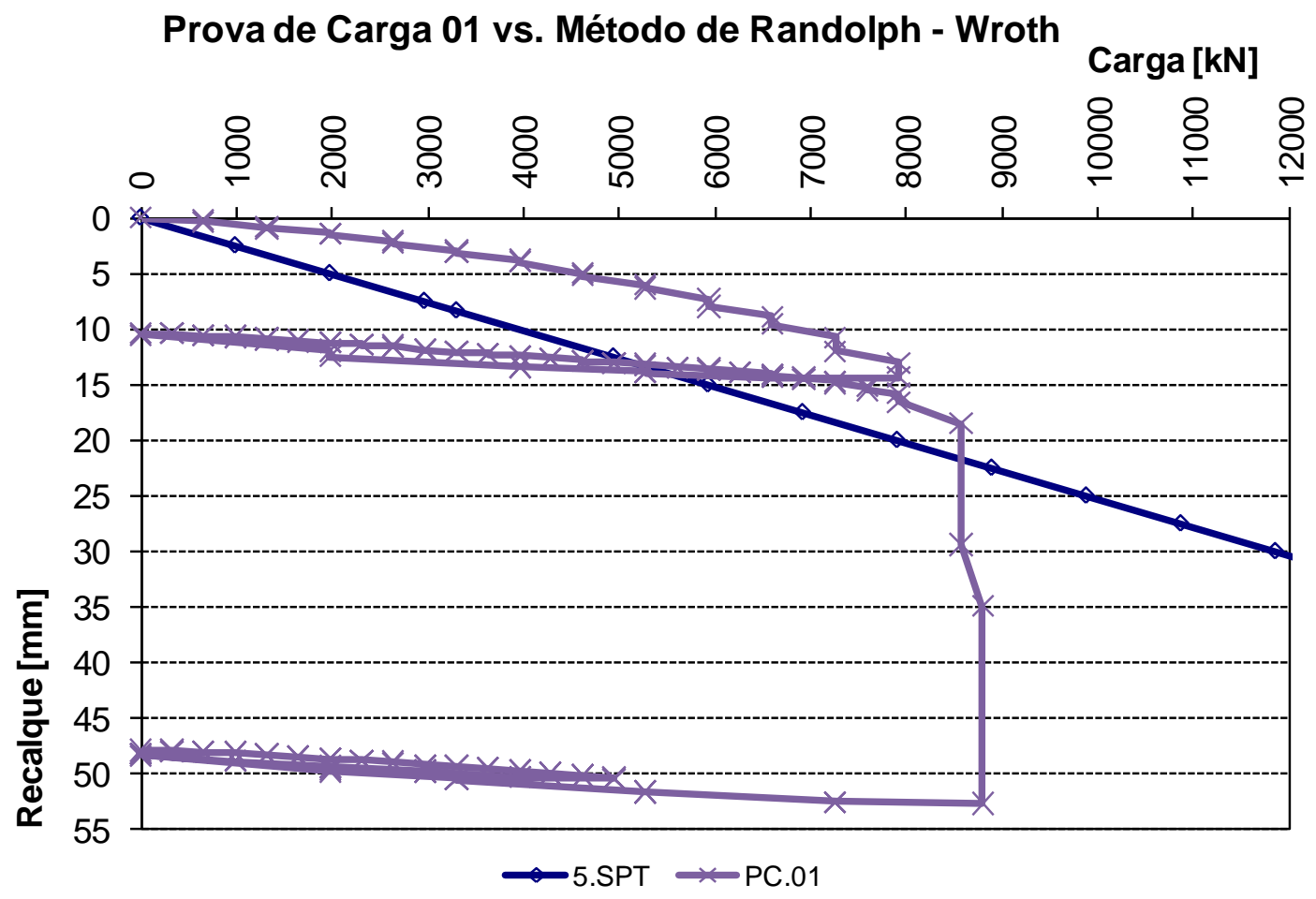

Gráfico 4.39. Método de Randolph-Wroth para a PC.01 (E.263b) 
Para a carga de trabalho de $3300 \mathrm{kN}$, o recalque estimado chegou a $8,35 \mathrm{~mm}$, resultando em $265 \%$ de diferença com relação ao recalque obtido pela prova de carga estática, que foi de $3,14 \mathrm{~mm}$, conforme Tabela 4.1. No entanto, Randolph (1994) sugere a utilização do módulo de cisalhamento próximo ao módulo tangente inicial, pois a situação trata de pequenas deformações. Sendo assim, procurou-se encontrar o melhor valor desse módulo que se adaptasse à curva carga vs recalque; e a conclusão foi a seguinte: o módulo de Young necessário para o cálculo do módulo de cisalhamento tangente inicial é o dobro do valor proposto por Negro, Ferreira e Sozio (1982). A equação (4.10) mostra a correlação sugerida.

$$
E_{0}=2 .\left(5 . N_{S P T}\right)
$$

O Gráfico 4.40 mostra o método de Randolph-Wroth utilizando-se três variações da equação (4.9). Nele fica clara que a correlação dada pela equação (4.10) apresentou ótimos resultados para os fins de engenharia.

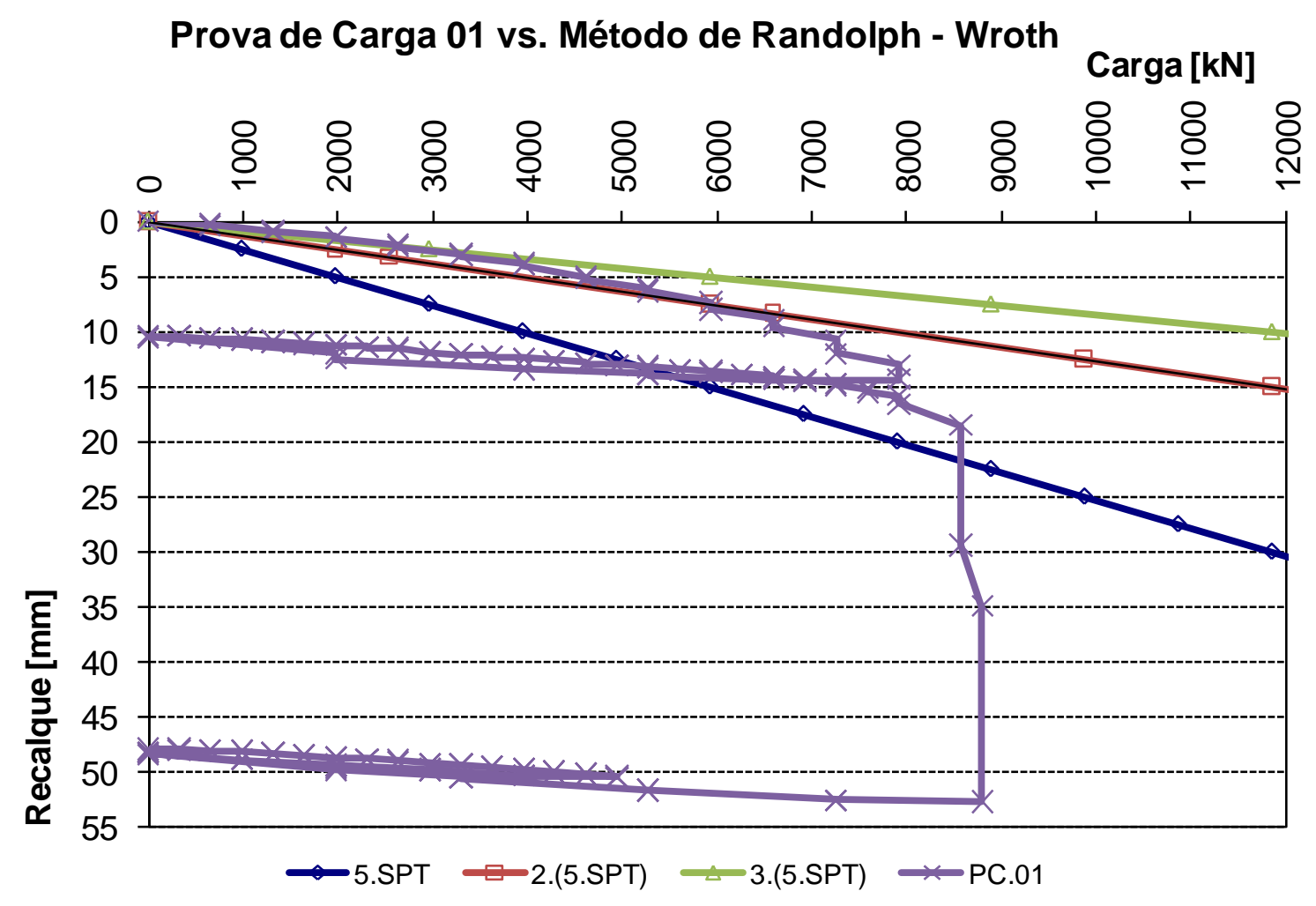

Gráfico 4.40. Método de Randolph-Wroth Ajustado para a PC.01. 


\subsubsection{Prova de Carga PC.02}

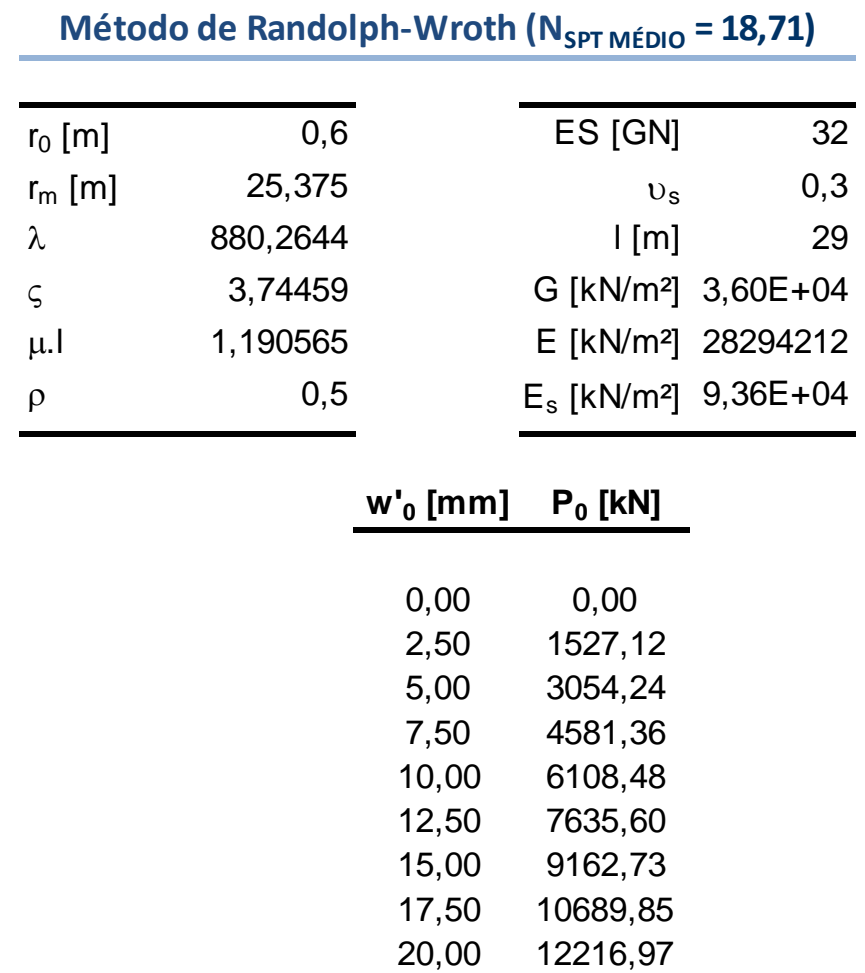

Figura 4.3. Resultados do Método de Randolph-Wroth para a PC.02 ( $\mathrm{N}_{\mathrm{SPT}}$ médio)

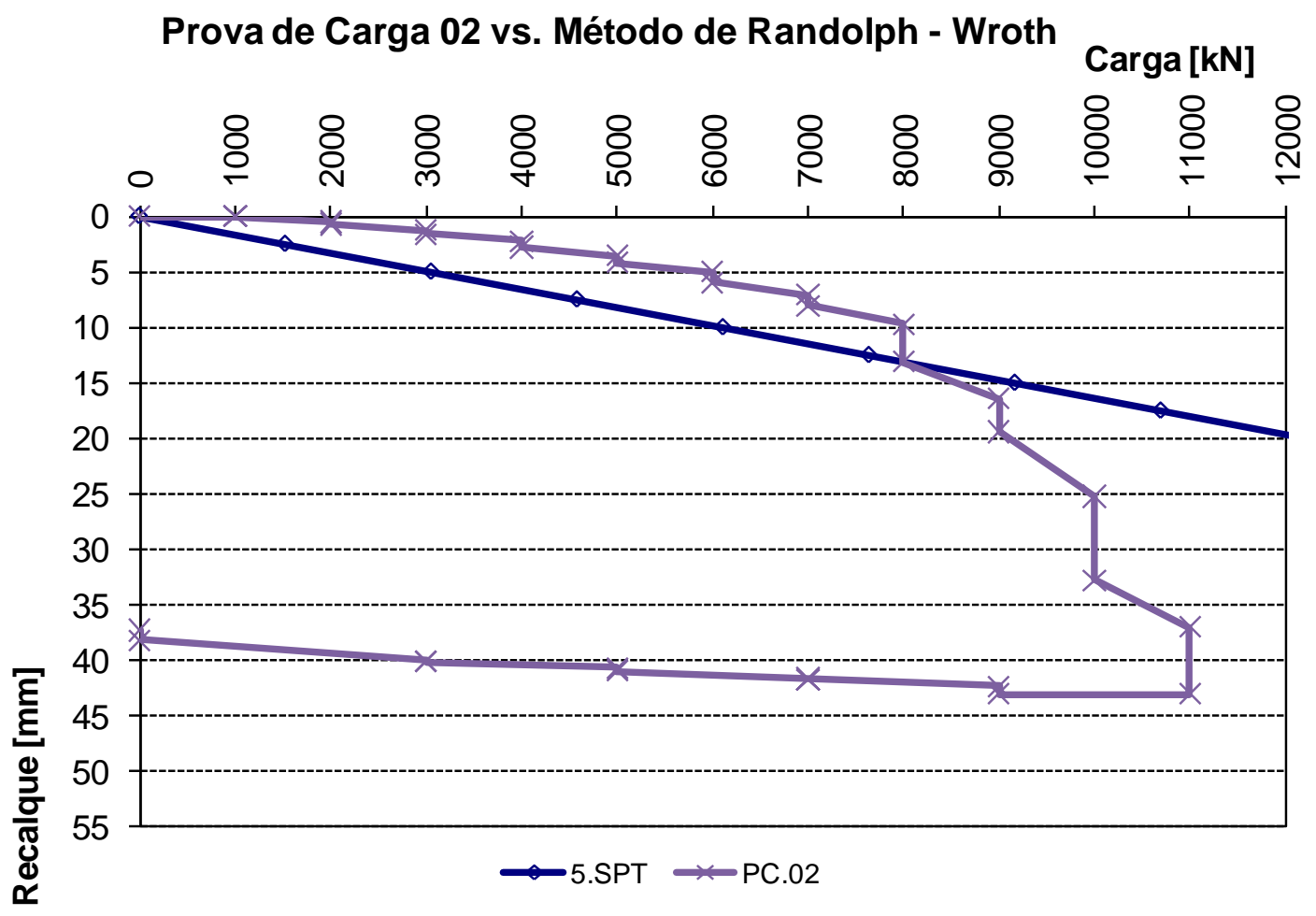

Gráfico 4.41. Método de Randolph-Wroth para a PC.02 (E.113) 
Para a carga de trabalho de $5000 \mathrm{kN}$, o recalque estimado chegou a $8,20 \mathrm{~mm}$, resultando em 195\% de diferença com relação ao recalque obtido pela prova de carga estática, que foi de 4,20mm, conforme Tabela 4.2. Seguindo a premissa explicada no item anterior, 4.5.12.1, e utilizando-se a equação (4.10), chega-se ao Gráfico 4.42.

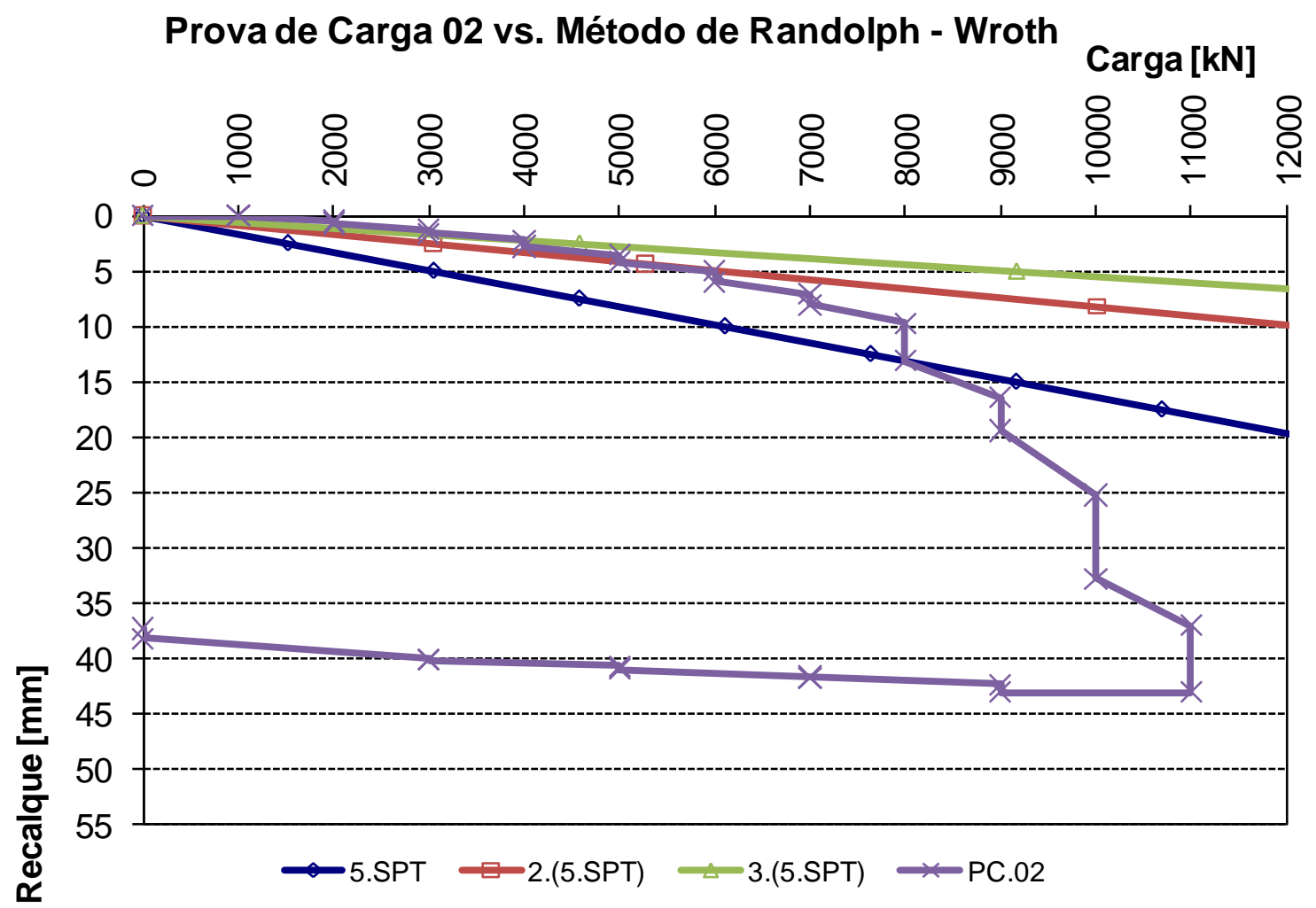

Gráfico 4.42. Método de Randolph-Wroth Ajustado para a PC.02. 


\subsubsection{Prova de Carga PC.03}

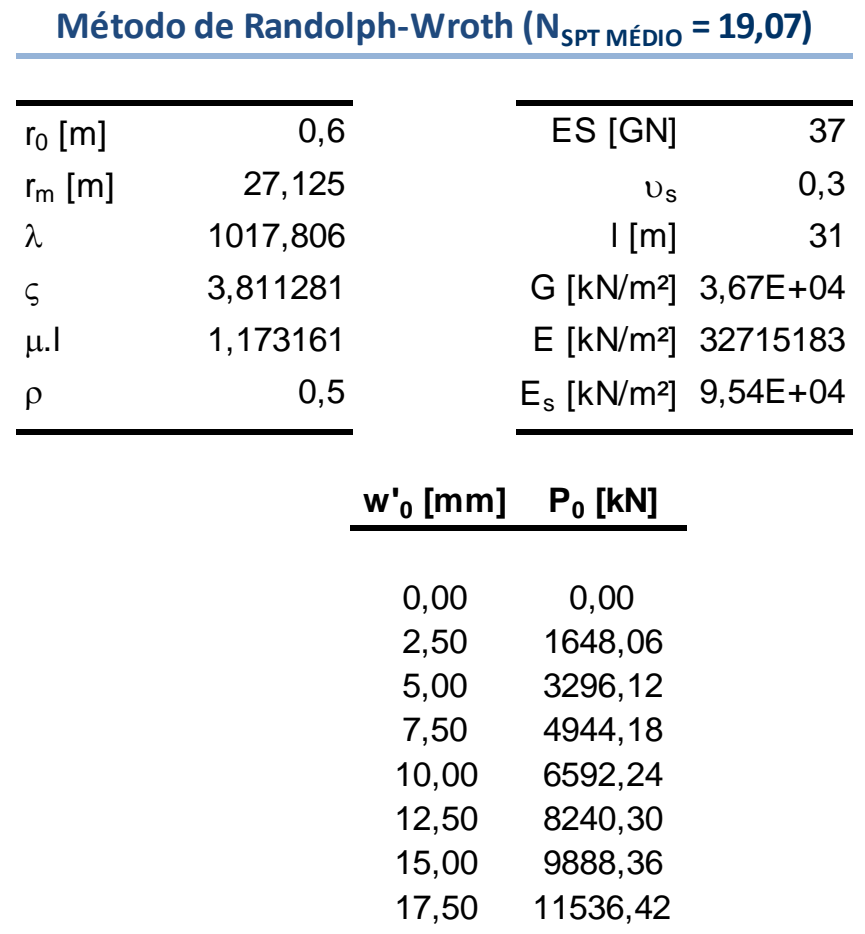

Figura 4.4. Resultados do Método de Randolph-Wroth para a PC.03 ( $\mathrm{N}_{\mathrm{SPT}}$ médio)



Gráfico 4.43. Método de Randolph-Wroth para a PC.03 (E.25) 
Para a carga de trabalho de $6000 \mathrm{kN}$, o recalque estimado chegou a $9,15 \mathrm{~mm}$, resultando em $190 \%$ de diferença com relação ao recalque obtido pela prova de carga estática, que foi de 4,82mm, conforme Tabela 4.3. Novamente, com a utilização da equação (4.10) conseguiu-se a melhor correlação com a prova de carga estática e, com isso, construiu-se o Gráfico 4.44.

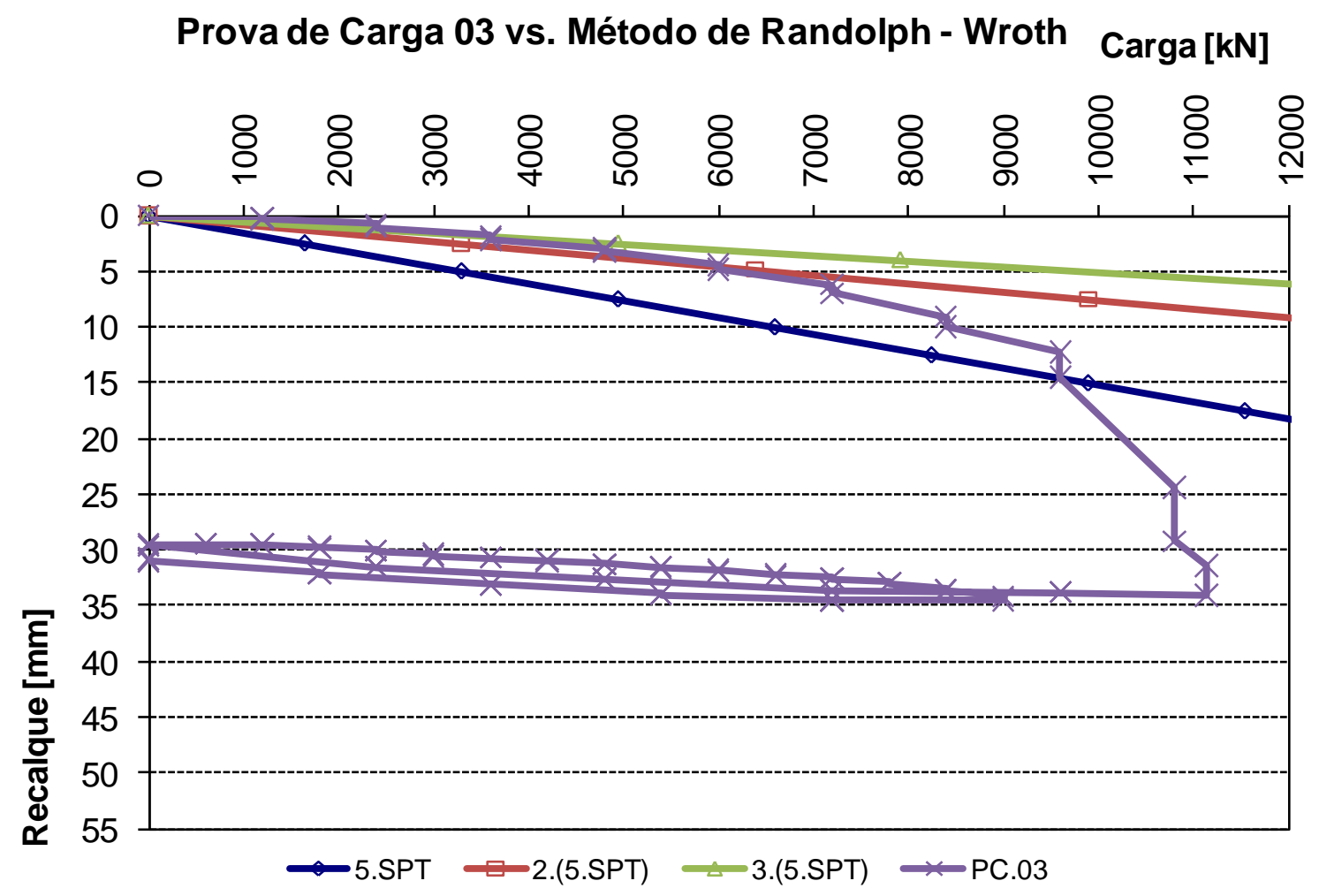

Gráfico 4.44. Método de Randolph-Wroth Ajustado para a PC.03. 


\subsection{Capacidade de Carga}

Para o cálculo das capacidades de carga foram utilizadas as teorias de Décourt \& Quaresma (1978, 1998) e Aoki-Velloso (1975), conforme itens 2.4.1 e 2.4.2. A seguir, são apresentados os cálculos ${ }^{2}$ referentes aos dois métodos citados.

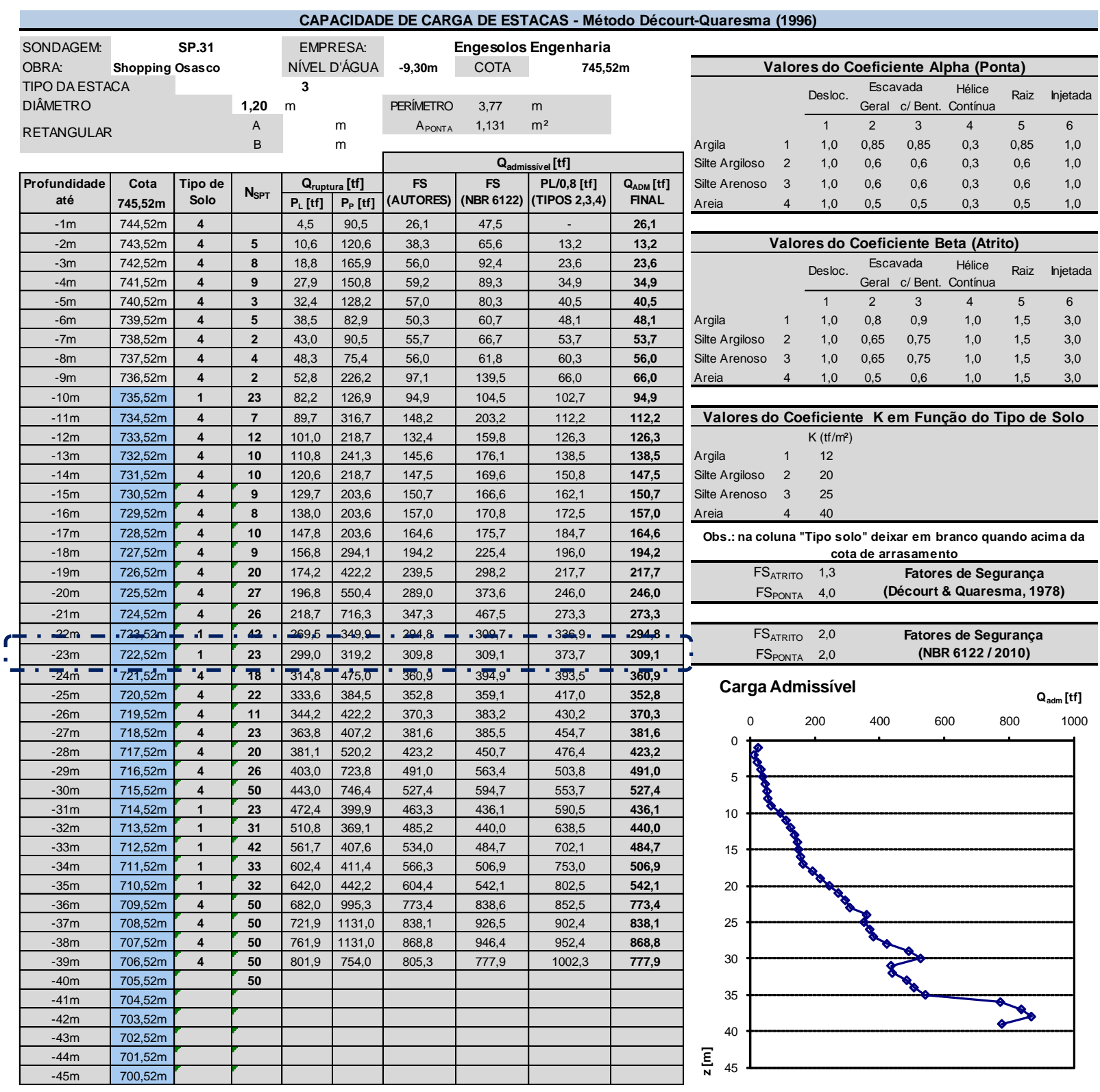

Figura 4.5. Capacidade de Carga utilizando a SP.31 pelo Método de Décourt-Quaresma (PC.01)

2 As planilhas eletrônicas indicadas pela Figura 4.5 à Figura 4.10 são de propriedade da INTERACT Assessoria Técnica em Engenharia Ltda. e foram gentilmente cedidas pela mesma. Por isso, seus resultados não estão de acordo com o Sistema Internacional de Unidades. 


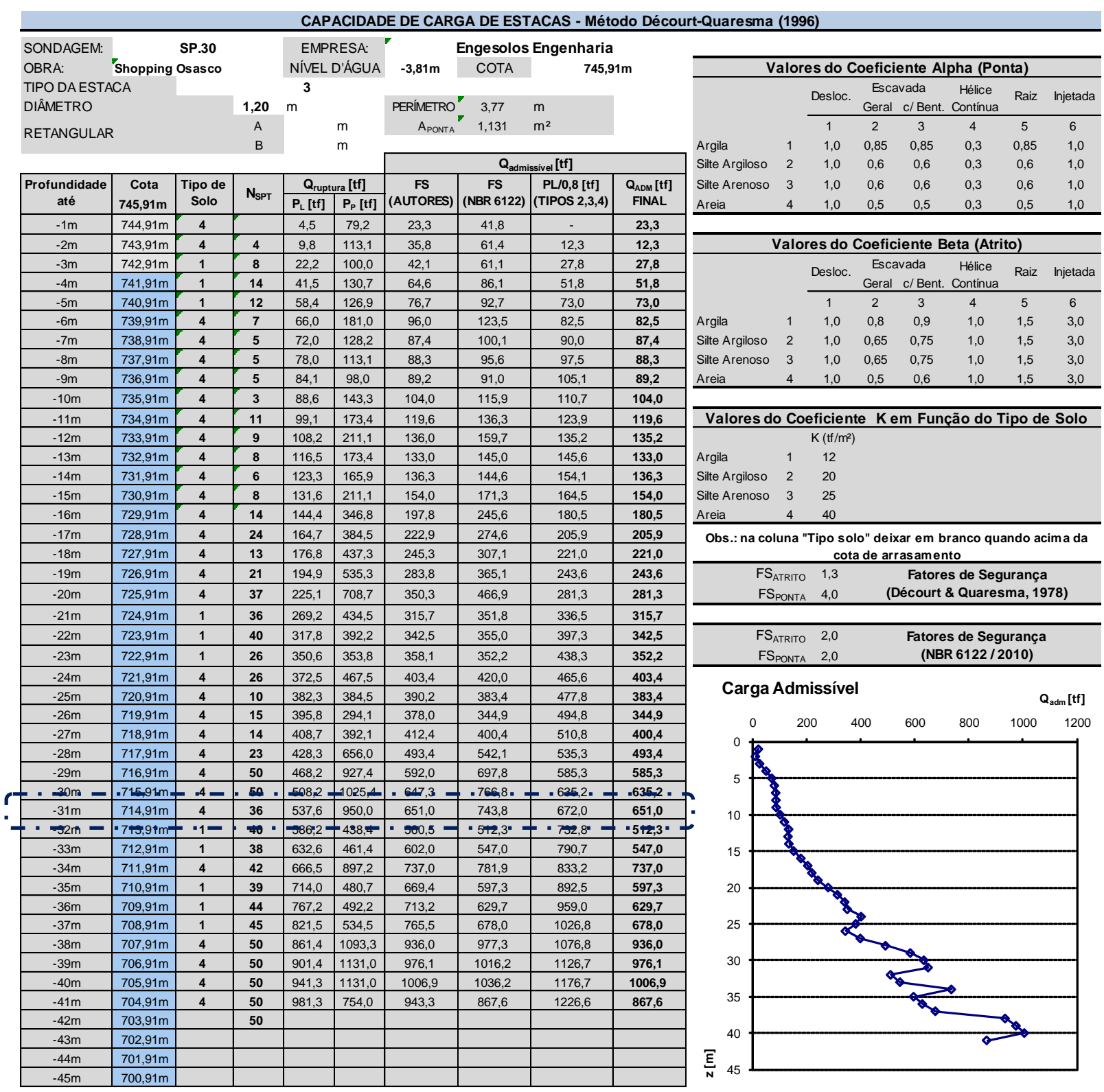

Figura 4.6. Capacidade de Carga utilizando a SP.30 pelo Método de Décourt-Quaresma (PC.02) 


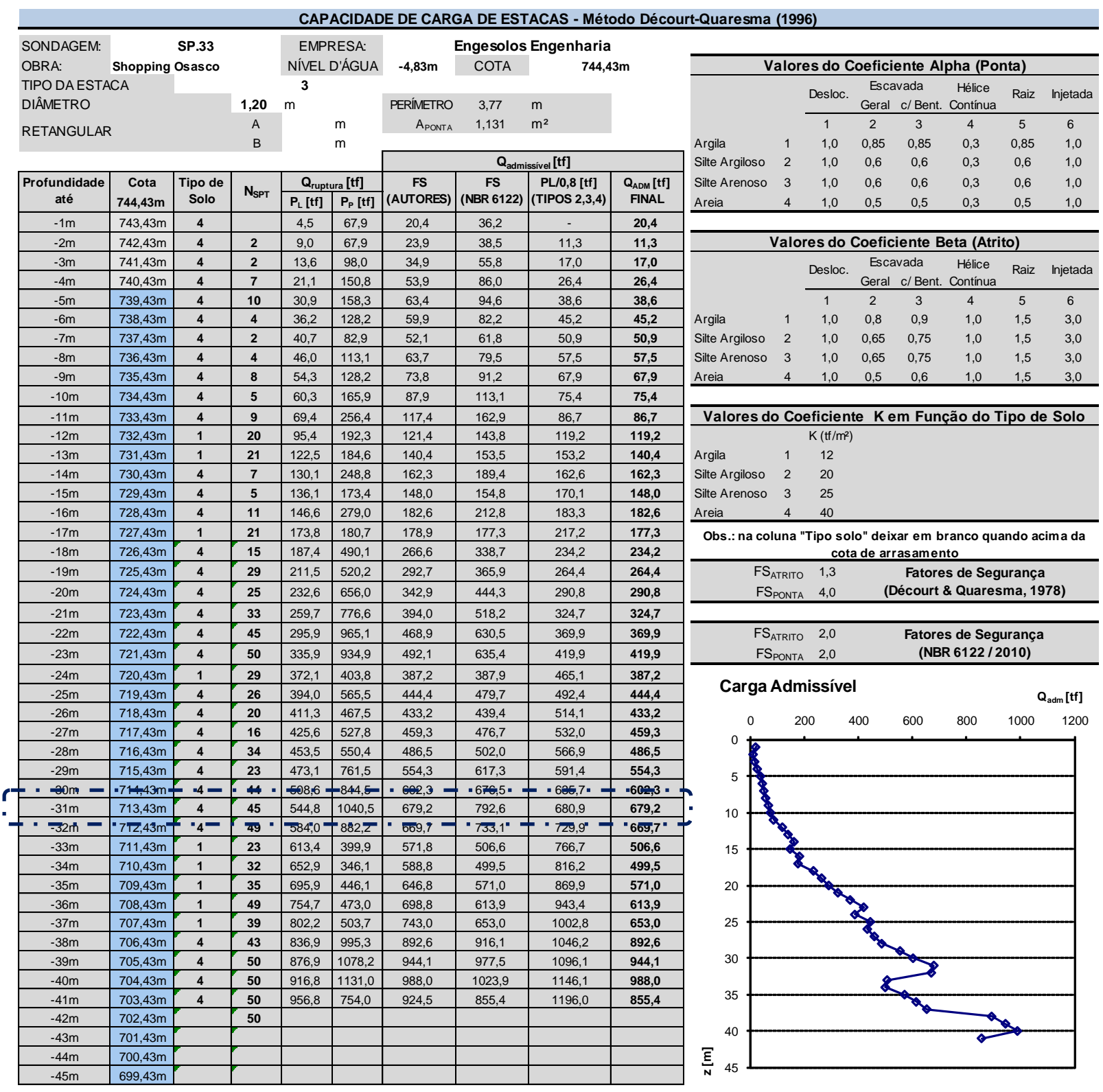

Figura 4.7. Capacidade de Carga utilizando a SP.33 pelo Método de Décourt-Quaresma (PC.03) 
CAPACIDADE DE CARGA DE ESTACAS - Método Aoki-Velloso (1975)

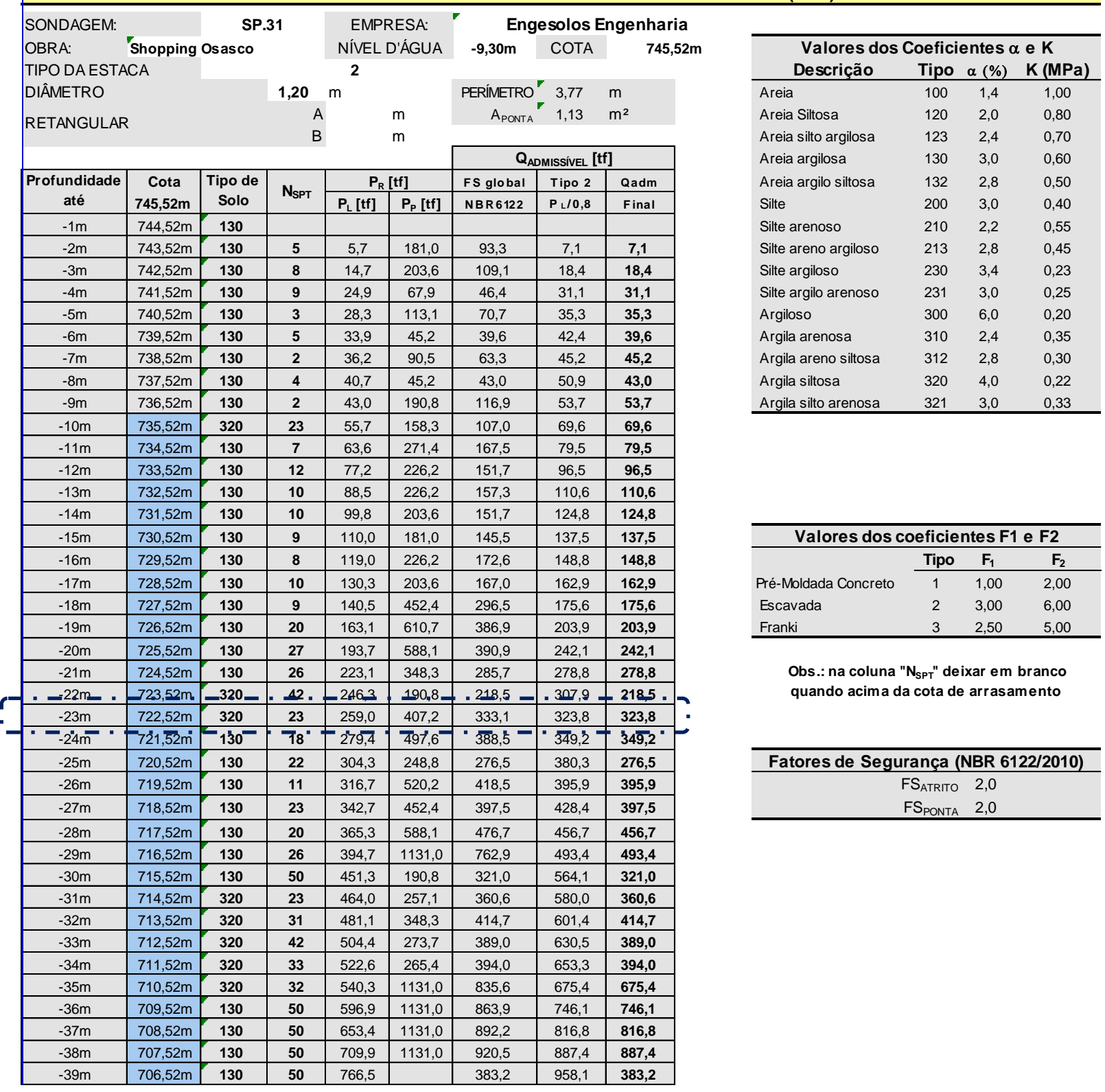

Figura 4.8. Capacidade de Carga utilizando a SP.31 pelo Método de Aoki-Velloso (PC.01) 
CAPACIDADE DE CARGA DE ESTACAS - Método Aoki-Velloso (1975)

\begin{tabular}{|c|c|c|c|c|c|c|c|c|}
\hline \multicolumn{2}{|l|}{ SONDAGEM: } & \multirow{2}{*}{\multicolumn{2}{|c|}{$\begin{array}{l}\text { SP.30 } \\
\text { Osasco }\end{array}$}} & \multirow{2}{*}{\multicolumn{2}{|c|}{$\begin{array}{l}\text { EMPRESA: } \\
\text { NÍVEL D'ÁGUA }\end{array}$}} & \multicolumn{3}{|c|}{ Engesolos Engenharia } \\
\hline OBRA: & Shopping Osasco & & & & & $-3,81 \mathrm{~m}$ & COTA & \multirow[t]{2}{*}{745,9} \\
\hline \multicolumn{3}{|c|}{ TIPO DA ESTACA } & \multirow{2}{*}{\multicolumn{3}{|c|}{$m^{2}$}} & & & \\
\hline \multicolumn{3}{|c|}{ DIÂMETRO } & & & & PERÍMETRO & 3,77 & $\mathrm{~m}$ \\
\hline \multirow{2}{*}{\multicolumn{2}{|c|}{ RETANGULAR }} & & \multicolumn{2}{|c|}{ A } & & A PONTA $^{\prime}$ & 1,13 & $\mathrm{~m}^{2}$ \\
\hline & & & \multirow{2}{*}{\multicolumn{2}{|c|}{ B }} & $\mathrm{m}$ & & & \\
\hline & & & & & & \multicolumn{3}{|c|}{$\mathbf{Q}_{\text {ADMIssivel [tf] }}$} \\
\hline \multirow{2}{*}{\begin{tabular}{|c|}
$\begin{array}{c}\text { Profundidade } \\
\text { até }\end{array}$ \\
\end{tabular}} & \multirow{2}{*}{\begin{tabular}{|c|} 
Cota \\
$745,91 \mathrm{~m}$ \\
\end{tabular}} & Tipo de & $\mathrm{N}_{\mathrm{PTT}}$ & & [tf] & FS global & \begin{tabular}{|l|} 
Tipo 2 \\
\end{tabular} & Qadm \\
\hline & & Solo & INSPT & $P_{L}[t f]$ & $P_{P}[t f]$ & NBR6122 & $P_{L} / 0,8$ & Final \\
\hline$-1 \mathrm{~m}$ & $744,91 \mathrm{~m}$ & 130 & & & & & & \\
\hline$-2 m$ & $743,91 \mathrm{~m}$ & 130 & 4 & 4,5 & 66,4 & 35,4 & 5,7 & 5,7 \\
\hline$-3 m$ & $742,91 \mathrm{~m}$ & 320 & 8 & 8,9 & 116,1 & 62,5 & 11,2 & 11,2 \\
\hline$-4 m$ & $741,91 \mathrm{~m}$ & 320 & 14 & 16,7 & 99,5 & 58,1 & 20,9 & 20,9 \\
\hline$-5 m$ & $740,91 \mathrm{~m}$ & 320 & 12 & 23,3 & 158,3 & 90,8 & 29,2 & 29,2 \\
\hline$-6 m$ & $739,91 \mathrm{~m}$ & 130 & 7 & 31,2 & 113,1 & 72,2 & 39,0 & 39,0 \\
\hline$-7 m$ & $738,91 \mathrm{~m}$ & 130 & 5 & 36,9 & 113,1 & 75,0 & 46,1 & 46,1 \\
\hline$-8 m$ & $737,91 \mathrm{~m}$ & 130 & 5 & 42,5 & 113,1 & 77,8 & 53,2 & 53,2 \\
\hline$-9 m$ & $736,91 \mathrm{~m}$ & 130 & 5 & 48,2 & 67,9 & 58,0 & 60,3 & 58,0 \\
\hline$-10 m$ & $735,91 \mathrm{~m}$ & 130 & 3 & 51,6 & 248,8 & 150,2 & 64,5 & 64,5 \\
\hline$-11 m$ & $734,91 \mathrm{~m}$ & 130 & 11 & 64,0 & 203,6 & 133,8 & 80,0 & 80,0 \\
\hline$-12 m$ & $733,91 \mathrm{~m}$ & 130 & 9 & 74,2 & 181,0 & 127,6 & 92,8 & 92,8 \\
\hline$-13 m$ & $732,91 \mathrm{~m}$ & 130 & 8 & 83,3 & 135,7 & 109,5 & 104,1 & 104,1 \\
\hline$-14 m$ & $731,91 \mathrm{~m}$ & 130 & 6 & 90,1 & 99,5 & 94,8 & 112,6 & 94,8 \\
\hline$-15 m$ & $730,91 \mathrm{~m}$ & 321 & 8 & 95,0 & 316,7 & 205,8 & 118,8 & 118,8 \\
\hline$-16 m$ & $729,91 \mathrm{~m}$ & 130 & 14 & 110,9 & 542,9 & 326,9 & 138,6 & 138,6 \\
\hline$-17 m$ & $728,91 \mathrm{~m}$ & 130 & 24 & 138,0 & 294,1 & 216,0 & 172,5 & 172,5 \\
\hline$-18 m$ & $727,91 \mathrm{~m}$ & 130 & 13 & 152,7 & 261,3 & 207,0 & 190,9 & 190,9 \\
\hline$-19 m$ & $726,91 \mathrm{~m}$ & 321 & 21 & 165,8 & 460,3 & 313,0 & 207,2 & 207,2 \\
\hline$-20 m$ & $725,91 \mathrm{~m}$ & 321 & 37 & 188,8 & 298,6 & 243,7 & 236,0 & 236,0 \\
\hline$-21 m$ & $724,91 \mathrm{~m}$ & 320 & 36 & 208,7 & 331,8 & 270,2 & 260,9 & 260,9 \\
\hline$-22 m$ & $723,91 \mathrm{~m}$ & 320 & 40 & 230,8 & 215,6 & 223,2 & 288,5 & 223,2 \\
\hline$-23 m$ & $722,91 \mathrm{~m}$ & 320 & 26 & 245,2 & 588,1 & 416,6 & 306,5 & 306,5 \\
\hline$-24 m$ & $721,91 \mathrm{~m}$ & 130 & 26 & 274,6 & 226,2 & 250,4 & 343,2 & 250,4 \\
\hline$-25 m$ & $720,91 m$ & 130 & 10 & 285,9 & 339,3 & 312,6 & 357,4 & 312,6 \\
\hline$-26 m$ & $719,91 \mathrm{~m}$ & 130 & 15 & 302,9 & 316,7 & 309,8 & 378,6 & 309,8 \\
\hline$-27 m$ & $718,91 \mathrm{~m}$ & 130 & 14 & 318,7 & 520,2 & 419,5 & 398,4 & 398,4 \\
\hline$-28 m$ & $717,91 \mathrm{~m}$ & 130 & 23 & 344,7 & 1131,0 & 737,8 & 430,9 & 430,9 \\
\hline$-29 m$ & $716,91 \mathrm{~m}$ & 130 & 50 & 401,3 & 1131,0 & 766,1 & 501,6 & 501,6 \\
\hline . $-30 \mathrm{~m}$ & $715,91 \mathrm{~m}$ & -130 & 50. & -4578 & 814,3 & $.636,1-$ & $.572,3=$ & 5723. \\
\hline$-31 \mathrm{~m}$ & $714,91 \mathrm{~m}$ & 130 & 36 & 498,5 & 331,8 & 415,1 & 623,2 & 415,1 \\
\hline$=-3^{3} 2 \mathrm{~m}$ & $-713,91 \mathrm{~m}^{\circ}$ & $=320^{-}$ & $70^{\circ}$ & 520,6 & 315,2 & $=47,9-$ & $=650,8$ & $417,9^{\circ}$ \\
\hline$-33 m$ & $712,91 \mathrm{~m}$ & 320 & 38 & 541,6 & 950,0 & \begin{tabular}{l|l}
745,8 \\
\end{tabular} & 677,1 & 677,1 \\
\hline$-34 m$ & $711,91 \mathrm{~m}$ & 130 & 42 & 589,1 & 323,5 & 456,3 & 736,4 & 456,3 \\
\hline$-35 m$ & $710,91 \mathrm{~m}$ & 320 & 39 & 610,7 & 364,9 & 487,8 & 763,4 & 487,8 \\
\hline$-36 m$ & $709,91 \mathrm{~m}$ & 320 & 44 & 635,0 & 373,2 & 504,1 & 793,8 & 504,1 \\
\hline$-37 m$ & $708,91 \mathrm{~m}$ & 320 & 45 & 659,9 & 1131,0 & 895,4 & 824,9 & 824,9 \\
\hline$-38 m$ & $707,91 \mathrm{~m}$ & 130 & 50 & 716,5 & 1131,0 & 923,7 & 895,6 & 895,6 \\
\hline$-39 m$ & $706,91 \mathrm{~m}$ & 130 & 50 & 773,0 & 1131,0 & 952,0 & 966,3 & 952,0 \\
\hline$-40 m$ & $705,91 \mathrm{~m}$ & 130 & 50 & 829,6 & 1131,0 & 980,3 & 1037,0 & 980,3 \\
\hline$-41 m$ & $704,91 \mathrm{~m}$ & 130 & 50 & 886,1 & & 443,1 & 1107,6 & 443,1 \\
\hline
\end{tabular}

\begin{tabular}{lccc}
\hline \multicolumn{5}{c}{ Valores dos Coeficientes $\alpha$ e K } \\
Descrição & Tipo & $\boldsymbol{\alpha}(\%)$ & K (MPa) \\
\hline Areia & 100 & 1,4 & 1,00 \\
Areia Siltosa & 120 & 2,0 & 0,80 \\
Areia silto argilosa & 123 & 2,4 & 0,70 \\
Areia argilosa & 130 & 3,0 & 0,60 \\
Areia argilo siltosa & 132 & 2,8 & 0,50 \\
Silte & 200 & 3,0 & 0,40 \\
Silte arenoso & 210 & 2,2 & 0,55 \\
Silte areno argiloso & 213 & 2,8 & 0,45 \\
Silte argiloso & 230 & 3,4 & 0,23 \\
Silte argilo arenoso & 231 & 3,0 & 0,25 \\
Argiloso & 300 & 6,0 & 0,20 \\
Argila arenosa & 310 & 2,4 & 0,35 \\
Argila areno siltosa & 312 & 2,8 & 0,30 \\
Argila siltosa & 320 & 4,0 & 0,22 \\
Argila silto arenosa & 321 & 3,0 & 0,33 \\
\hline
\end{tabular}

\begin{tabular}{lccc}
\hline \multicolumn{4}{c}{ Valores dos coeficientes F1 e F2 } \\
\hline & Tipo & $\mathbf{F}_{\mathbf{1}}$ & $\mathbf{F}_{\mathbf{2}}$ \\
\cline { 2 - 4 } Pré-Moldada Concreto & 1 & 1,00 & 2,00 \\
Escavada & 2 & 3,00 & 6,00 \\
Franki & 3 & 2,50 & 5,00 \\
\hline
\end{tabular}

Obs.: na coluna " $\mathrm{N}_{\mathrm{SPT}}$ " deixar em branco quando acima da cota de arrasamento

$\begin{array}{r}\hline \text { Fatores de Segurança (NBR 6122/2010) } \\ \hline \text { FS }_{\text {ATRITO }} 2,0 \\ \text { FS }_{\text {PONTA }} \quad 2,0 \\ \hline\end{array}$

Figura 4.9. Capacidade de Carga utilizando a SP.30 pelo Método de Aoki-Velloso (PC.02) 
CAPACIDADE DE CARGA DE ESTACAS - Método Aoki-Velloso (1975)

\begin{tabular}{|c|c|c|c|c|c|c|c|c|c|c|c|c|}
\hline & \multirow{2}{*}{\multicolumn{2}{|c|}{$\begin{array}{l}\text { SP.33 } \\
\text { Osasco }\end{array}$}} & \multirow{2}{*}{\multicolumn{2}{|c|}{$\begin{array}{l}\text { EMPRESA: } \\
\text { NÍVEL D'ÁGUA }\end{array}$}} & \multicolumn{3}{|c|}{ Engesolos Engenharia } & & & & \\
\hline OBRA: & \multirow{2}{*}{\multicolumn{2}{|c|}{$\begin{array}{l}\text { Shopping Osasco } \\
A C A\end{array}$}} & & & & $-4,83 m$ & COTA & \multirow[t]{2}{*}{$744,43 m$} & \multicolumn{4}{|c|}{ Valores dos Coeficientes $\alpha$ e K } \\
\hline \multirow{2}{*}{\multicolumn{3}{|c|}{$\begin{array}{l}\text { TIPO DA ESTACA } \\
\text { DIÂMETRO }\end{array}$}} & \multirow{2}{*}{\multicolumn{3}{|c|}{$1,20 \mathrm{~m}$}} & & & & Descrição & Tipo & \multirow{2}{*}{$\frac{\alpha(\%)}{1,4}$} & $\mathrm{~K}(\mathrm{MPa}$ \\
\hline & & & & & & PERÍMETRO & 3,77 & $\mathrm{~m}$ & Areia & 100 & & 1,00 \\
\hline \multirow{2}{*}{\multicolumn{2}{|c|}{ RETANGULAR }} & & \multicolumn{2}{|c|}{ A } & $\mathrm{m}$ & A PONTA & 1,13 & $m^{2}$ & Areia Siltosa & 120 & 2,0 & 0,80 \\
\hline & & & \multirow{2}{*}{\multicolumn{2}{|c|}{$B$}} & \multirow[t]{2}{*}{$\mathrm{m}$} & & & & Areia silto argilosa & 123 & 2,4 & 0,70 \\
\hline & & & & & & \multicolumn{3}{|c|}{$\mathbf{Q}_{\text {ADMIssivel }}[\mathrm{tf}]$} & Areia argilosa & 130 & 3,0 & 0,60 \\
\hline \multirow{2}{*}{$\begin{array}{c}\text { Profundidade } \\
\text { até }\end{array}$} & \multirow{2}{*}{\begin{tabular}{|c|} 
Cota \\
$744,43 \mathrm{~m}$
\end{tabular}} & \multirow{2}{*}{\begin{tabular}{|c|} 
Tipo de \\
Solo
\end{tabular}} & \multirow{2}{*}{$\mathrm{N}_{\mathrm{SPT}}$} & \multicolumn{2}{|c|}{$P_{R}[t f]$} & FS global & Tipo 2 & Qadm & Areia argilo siltosa & 132 & 2,8 & 0,50 \\
\hline & & & & $P_{L}[t f]$ & $P_{P}[t f]$ & NBR6122 & $P_{\llcorner} / 0,8$ & Final & Silte & 200 & 3,0 & 0,40 \\
\hline$-1 \mathrm{~m}$ & $743,43 \mathrm{~m}$ & 130 & & & & & & & Silte arenoso & 210 & 2,2 & 0,55 \\
\hline$-2 m$ & $742,43 m$ & 130 & 2 & 2,3 & 45,2 & 23,8 & 2,8 & 2,8 & Silte areno argiloso & 213 & 2,8 & 0,45 \\
\hline$-3 m$ & $741,43 m$ & 130 & 2 & 4,5 & 158,3 & 81,4 & 5,7 & 5,7 & Silte argiloso & 230 & 3,4 & 0,23 \\
\hline$-4 m$ & $740,43 m$ & 130 & 7 & 12,4 & 226,2 & 119,3 & 15,6 & 15,6 & Silte argilo arenoso & 231 & 3,0 & 0,25 \\
\hline$-5 m$ & $739,43 m$ & 130 & 10 & 23,8 & 90,5 & 57,1 & 29,7 & 29,7 & Argiloso & 300 & 6,0 & 0,20 \\
\hline$-6 m$ & $738,43 m$ & 130 & 4 & 28,3 & 45,2 & 36,8 & 35,3 & 35,3 & Argila arenosa & 310 & 2,4 & 0,35 \\
\hline$-7 m$ & $737,43 m$ & 130 & 2 & 30,5 & 90,5 & 60,5 & 38,2 & 38,2 & Argila areno siltosa & 312 & 2,8 & 0,30 \\
\hline$-8 m$ & $736,43 m$ & 130 & 4 & 35,1 & 181,0 & 108,0 & 43,8 & 43,8 & Argila siltosa & 320 & 4,0 & 0,22 \\
\hline$-9 m$ & $735,43 \mathrm{~m}$ & 130 & 8 & 44,1 & 113,1 & 78,6 & 55,1 & 55,1 & Argila silto arenosa & 321 & 3,0 & 0,33 \\
\hline
\end{tabular}

Figura 4.10. Capacidade de Carga utilizando a SP.33 pelo Método de Aoki-Velloso (PC.03)

De posse de todos os cálculos de capacidade de carga pelos métodos acima empregados, foi possível a construção do Gráfico 4.45, mostrando, de uma forma muito clara, as profundidades dos estacões. 


\section{Cota de Ponta das Estacas}

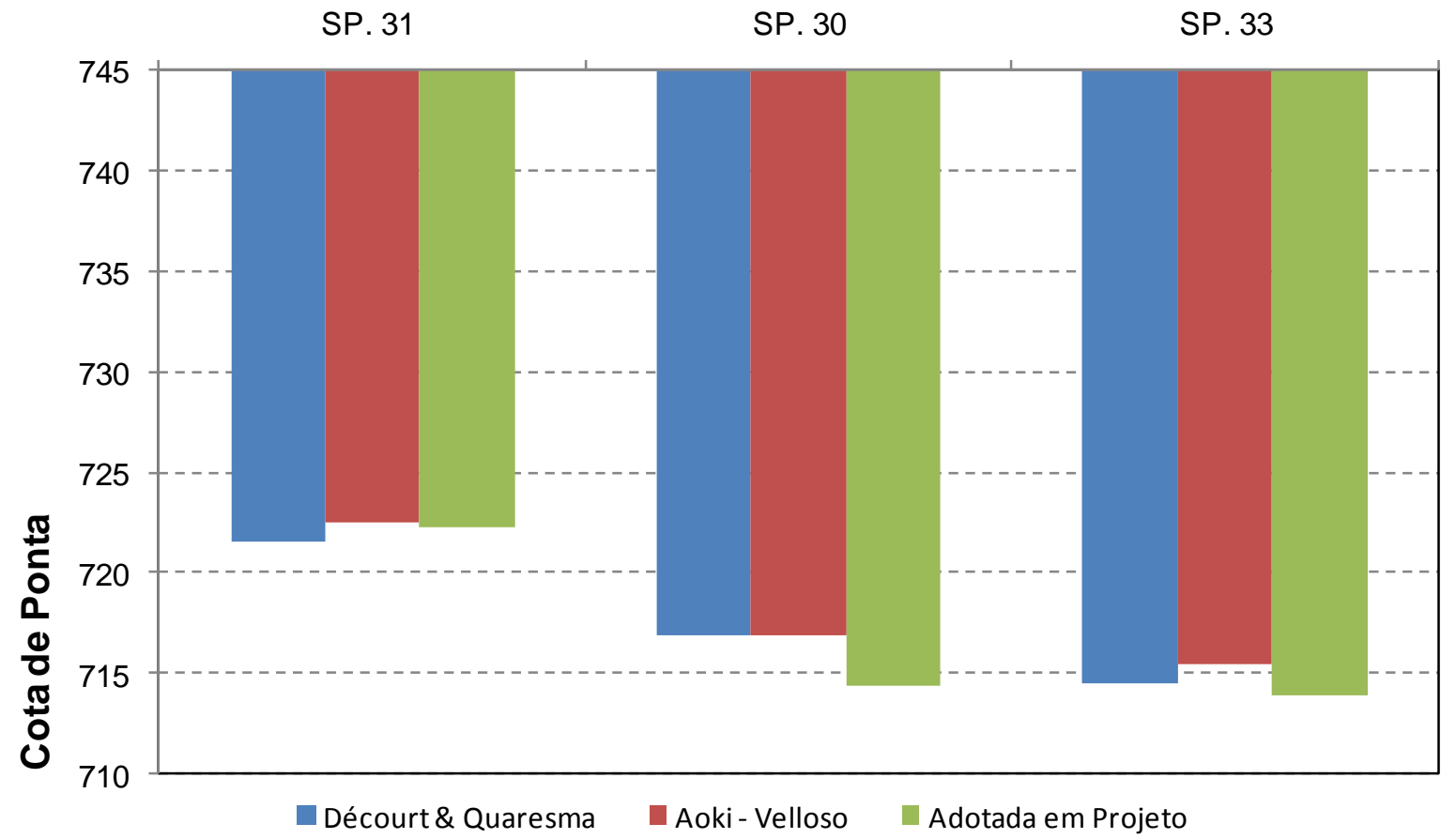

Gráfico 4.45. Cota de Ponta das Estacas Pertencentes às Provas de Cargas

Na Tabela 4.24 é possível visualizar os valores que deram origem ao Gráfico 4.45.

Tabela 4.24. Cotas de Ponta para os Estacões das Provas de Cargas Estáticas.

\begin{tabular}{cccccc}
\hline \multicolumn{6}{c}{ Cotas de Ponta dos Estacões } \\
\hline Sondagem & Prova de Carga Carga de Trabalho [kN] Décourt\&Quaresma & Aoki-Velloso & Adotada \\
SP. 31 & PC. 1 & 3300 & 721,52 & 722,52 & 722,30 \\
SP. 30 & PC. 2 & 5000 & 716,91 & 716,91 & 714,36 \\
SP. 33 & PC. 3 & 6000 & 714,43 & 715,43 & 713,86 \\
\hline
\end{tabular}

\subsection{Comparações entre as Provas de Cargas Estáticas e os Métodos Semi-Empíricos}

O objetivo aqui é mostrar algumas comparações, em termos de atrito lateral e ponta, entre os resultados obtidos pelos métodos semi-empíricos utilizados anteriormente, e os valores obtidos pelas três provas de cargas estáticas. 
Na Tabela 4.10 a Tabela 4.12 podem ser vistas as cargas no topo e na base de cada estaca, em cada prova de carga. A diferença entre as mesmas é o atrito lateral mobilizado ao longo do fuste. A Tabela 4.25 mostra essas cargas.

Tabela 4.25. Cargas no Topo, Ponta e Atrito Lateral Obtidos das Provas de Cargas Estáticas.

\begin{tabular}{ccccc}
\hline Prova de Carga & Estaca & Carga no Topo [kN] & Carga na Ponta [kN] & Atrito Lateral [kN] \\
\hline PC. 01 & E.263 & 8800 & 2602 & 6198 \\
PC. 02 & E.113 & 11000 & 3369 & 7631 \\
PC. 03 & E.25 & 11140 & 3750 & 7390 \\
\hline
\end{tabular}

Pelo Gráfico 4.46, que expressa o atrito lateral em função do deslocamento do centro do fuste, fica claro o atrito lateral na ruptura, para o caso da estaca E.263; bem como para as cargas últimas, em se tratando das estacas E.113 e E.25.

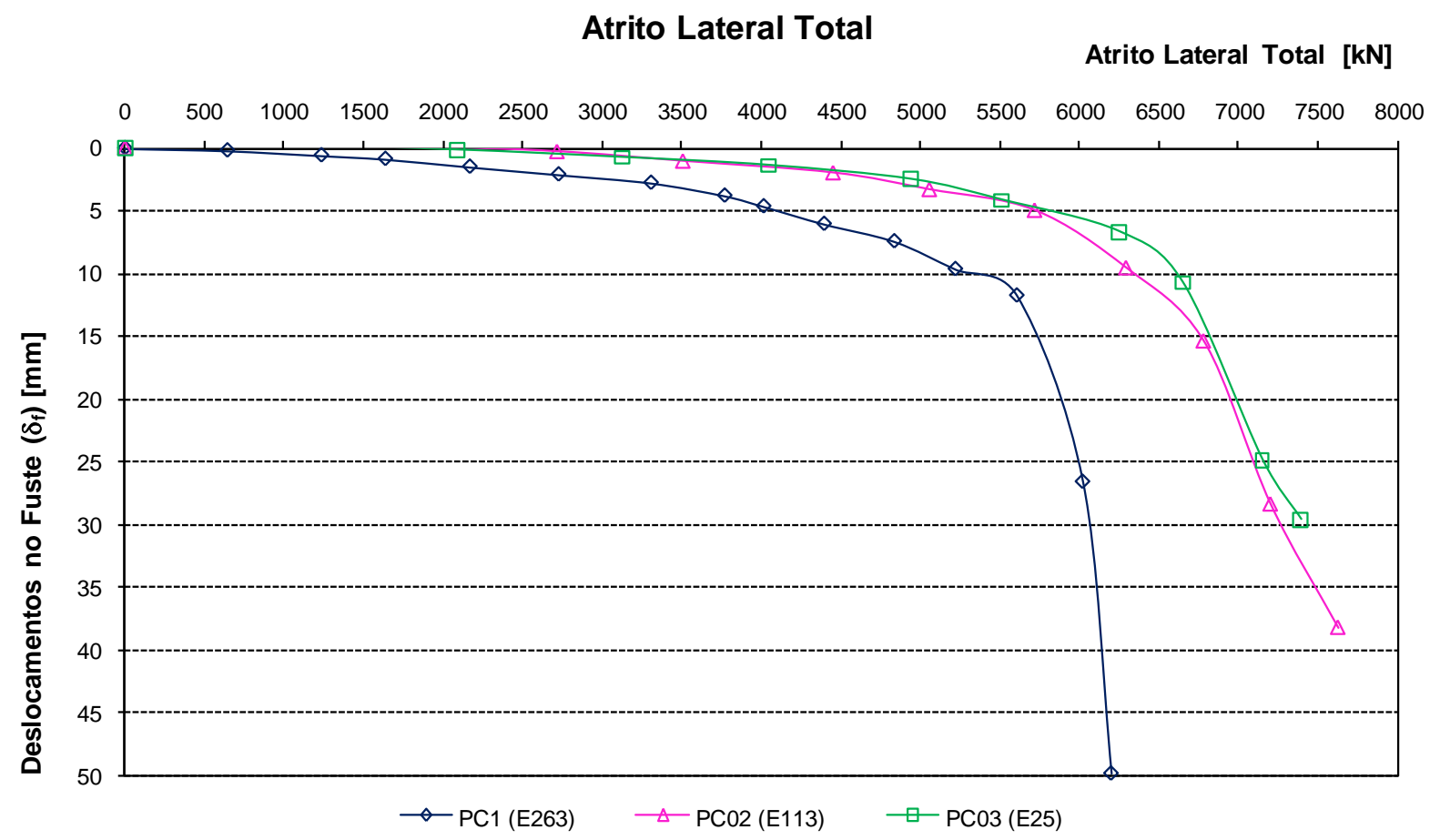

Gráfico 4.46. Atrito Lateral Total para as 3 Provas de Cargas Estáticas.

Por meio dos diagramas de atrito lateral unitário também é possível calcular o atrito lateral total para cada estaca, os quais são obtidos pela integração dos valores indicados no Gráfico 4.9, Gráfico 4.11, Gráfico 4.13, Gráfico 4.14, Gráfico 4.16 e 
Gráfico 4.17, e a posterior multiplicação pelo comprimento da circunferência da estaca. A explicação pode ser mostrada por meio da equação (4.11).

$$
Q_{L}=. \pi \cdot D \cdot \int_{0}^{l} f . d l
$$

onde:

$$
\begin{aligned}
& Q_{L}=\text { Atrito Lateral Total }[F] ; \\
& f=\text { Atrito Lateral Unitário }\left[\mathrm{FL}^{-2}\right] \\
& D=\text { Diâmetro da Estaca }[\mathrm{L}]
\end{aligned}
$$

A seguir, da Tabela 4.26 à Tabela 4.28, são mostrados os valores do atrito lateral

\begin{tabular}{|c|c|c|c|c|c|}
\hline \multicolumn{6}{|c|}{ Atrito Lateral Prova de Carga vs Métodos Semi-Empíricos } \\
\hline \multirow{2}{*}{ Cota } & \multicolumn{5}{|c|}{ Prova de Carga PC.01 (SP. $31-$ Cota de topo = 745,52) } \\
\hline & Décourt\&Quaresma & Aoki-Velloso & Ensaio $(8800 \mathrm{kN})$ & Ensaio $(6660 \mathrm{kN})$ & Ensaio $(3300 \mathrm{kN})$ \\
\hline 744,52 & 45,24 & 0,00 & 588,59 & 523,88 & 320,26 \\
\hline 743,52 & 105,56 & 56,55 & 588,59 & 523,88 & 320,26 \\
\hline 742,52 & 188,50 & 147,03 & 588,59 & 523,88 & 320,26 \\
\hline 741,52 & 278,97 & 248,81 & 588,59 & 523,88 & 320,26 \\
\hline 740,52 & 324,21 & 282,74 & 588,59 & 523,88 & 320,26 \\
\hline 739,52 & 384,53 & 339,29 & 588,59 & 523,88 & 320,26 \\
\hline 738,52 & 429,77 & 361,91 & 1003,37 & 1070,07 & 715,30 \\
\hline 737,52 & 482,55 & 407,15 & 1003,37 & 1070,07 & 715,30 \\
\hline 736,52 & 527,79 & 429,77 & 2256,64 & 2058,70 & 1352,41 \\
\hline 735,52 & 821,84 & 556,94 & 2256,64 & 2058,70 & 1352,41 \\
\hline 734,52 & 897,24 & 636,11 & 2256,64 & 2058,70 & 1352,41 \\
\hline 733,52 & 1010,34 & 771,83 & 2256,64 & 2058,70 & 1352,41 \\
\hline 732,52 & 1108,35 & 884,92 & 2256,64 & 2058,70 & 1352,41 \\
\hline 731,52 & 1206,37 & 998,02 & 3554,54 & 2840,77 & 1805,57 \\
\hline 730,52 & 1296,85 & 1099,81 & 3554,54 & 2840,77 & 1805,57 \\
\hline 729,52 & 1379,79 & 1190,29 & 4623,10 & 3637,20 & 2266,12 \\
\hline 728,52 & 1477,81 & 1303,38 & 4623,10 & 3637,20 & 2266,12 \\
\hline 727,52 & 1568,28 & 1405,17 & 4623,10 & 3637,20 & 2266,12 \\
\hline 726,52 & 1741,70 & 1631,37 & 5769,25 & 4457,81 & 2581,00 \\
\hline 725,52 & 1967,89 & 1936,73 & 5769,25 & 4457,81 & 2581,00 \\
\hline 724,52 & 2186,55 & 2230,78 & 5769,25 & 4457,81 & 2581,00 \\
\hline 723,52 & 2695,49 & 2463,01 & 6296,14 & 4836,06 & 2726,02 \\
\hline 722,52 & 2989,54 & 2590,18 & 6296,14 & 4836,06 & 2726,02 \\
\hline
\end{tabular}
total para cada prova de carga, ao mesmo tempo em que são mostrados os valores de atrito obtidos pelos métodos semi-empíricos.

Tabela 4.26. Atrito Lateral Total para a PC.01 (E.263) 
Tabela 4.27. Atrito Lateral Total para a PC.02 (E.113)

\begin{tabular}{|c|c|c|c|c|c|}
\hline \multicolumn{6}{|c|}{ Atrito Lateral Prova de Carga vs Métodos Semi-Empíricos } \\
\hline \multirow{2}{*}{ Cota } & \multicolumn{5}{|c|}{ Prova de Carga PC.02 (SP. 30 - Cota de topo $=745,91$ ) } \\
\hline & Décourt\&Quaresma & Aoki-Velloso & Ensaio $(11000 \mathrm{kN})$ & Ensaio $(10000 \mathrm{kN})$ & Ensaio $(5000 \mathrm{kN})$ \\
\hline 744,91 & 45,24 & 0,00 & 436,05 & 399,95 & 200,08 \\
\hline 743,91 & 98,02 & 45,24 & 436,05 & 399,95 & 200,08 \\
\hline 742,91 & 222,42 & 89,47 & 436,05 & 399,95 & 200,08 \\
\hline 741,91 & 414,69 & 166,88 & 436,05 & 399,95 & 200,08 \\
\hline 740,91 & 584,34 & 233,23 & 436,05 & 399,95 & 200,08 \\
\hline 739,91 & 659,73 & 312,40 & 436,05 & 399,95 & 200,08 \\
\hline 738,91 & 720,05 & 368,95 & 436,05 & 399,95 & 200,08 \\
\hline 737,91 & 780,37 & 425,50 & 436,05 & 399,95 & 200,08 \\
\hline 736,91 & 840,69 & 482,05 & 436,05 & 399,95 & 200,08 \\
\hline 735,91 & 885,93 & 515,98 & 1396,05 & 1359,95 & 840,08 \\
\hline 734,91 & 991,49 & 640,38 & 1396,05 & 1359,95 & 840,08 \\
\hline 733,91 & 1081,96 & 742,17 & 1396,05 & 1359,95 & 840,08 \\
\hline 732,91 & 1164,90 & 832,65 & 1396,05 & 1359,95 & 840,08 \\
\hline 731,91 & 1232,76 & 900,51 & 2996,09 & 2639,90 & 1480,05 \\
\hline 730,91 & 1315,70 & 950,27 & 2996,09 & 2639,90 & 1480,05 \\
\hline 729,91 & 1443,88 & 1108,61 & 2996,09 & 2639,90 & 1480,05 \\
\hline 728,91 & 1647,45 & 1380,04 & 2996,09 & 2639,90 & 1480,05 \\
\hline 727,91 & 1768,09 & 1527,07 & 2996,09 & 2639,90 & 1480,05 \\
\hline 726,91 & 1949,04 & 1657,69 & 2996,09 & 2639,90 & 1480,05 \\
\hline 725,91 & 2250,64 & 1887,85 & 3892,07 & 3727,90 & 2196,86 \\
\hline 724,91 & 2691,72 & 2086,90 & 3892,07 & 3727,90 & 2196,86 \\
\hline 723,91 & 3178,04 & 2308,07 & 5268,02 & 4911,86 & 2993,68 \\
\hline 722,91 & 3506,02 & 2451,82 & 5268,02 & 4911,86 & 2993,68 \\
\hline 721,91 & 3724,67 & 2745,88 & 5268,02 & 4911,86 & 2993,68 \\
\hline 720,91 & 3822,69 & 2858,97 & 5268,02 & 4911,86 & 2993,68 \\
\hline 719,91 & 3958,41 & 3028,62 & 6573,67 & 6182,30 & 3802,95 \\
\hline 718,91 & 4086,58 & 3186,96 & 6573,67 & 6182,30 & 3802,95 \\
\hline 717,91 & 4282,62 & 3447,08 & 6573,67 & 6182,30 & 3802,95 \\
\hline 716,91 & 4682,23 & 4012,57 & 7636,13 & 7205,86 & 4455,07 \\
\hline 715,91 & 5081,84 & 4578,05 & 7636,13 & 7205,86 & 4455,07 \\
\hline 714,91 & 5375,89 & 4985,20 & 7636,13 & 7205,86 & 4455,07 \\
\hline 713,91 & 5862,21 & 5206,37 & 7636,13 & 7205,86 & 4455,07 \\
\hline 712,91 & 6325,91 & 5416,48 & & & \\
\hline 711,91 & 6665,20 & 5891,49 & & & \\
\hline 710,91 & 7140,21 & 6107,13 & & & \\
\hline 709,91 & 7671,77 & 6350,42 & & & \\
\hline 708,91 & 8214,64 & 6599,23 & & & \\
\hline 707,91 & 8614,25 & 7164,72 & & & \\
\hline 706,91 & 9013,86 & 7730,20 & & & \\
\hline 705,91 & 9413,47 & 8295,69 & & & \\
\hline 704,91 & 9813,08 & 8861,18 & & & \\
\hline
\end{tabular}


Tabela 4.28. Atrito Lateral Total para a PC.03 (E.25)

\begin{tabular}{|c|c|c|c|c|}
\hline \multicolumn{5}{|c|}{ Atrito Lateral Prova de Carga vs Métodos Semi-Empíricos } \\
\hline \multirow{2}{*}{ Cota } & \multicolumn{4}{|c|}{ Prova de Carga PC.03 (SP. 33 - Cota de topo $=744,43$ ) } \\
\hline & Décourt\&Quaresma & Aoki-Velloso & Ensaio $(6000 \mathrm{kN})$ & Ensaio $(11140 \mathrm{kN})$ \\
\hline 743,43 & 45,24 & 0,00 & 357,50 & 576,52 \\
\hline 742,43 & 90,48 & 22,62 & 357,50 & 576,52 \\
\hline 741,43 & 135,72 & 45,24 & 357,50 & 576,52 \\
\hline 740,43 & 211,12 & 124,41 & 357,50 & 576,52 \\
\hline 739,43 & 309,13 & 237,50 & 357,50 & 576,52 \\
\hline 738,43 & 361,91 & 282,74 & 1057,16 & 1354,24 \\
\hline 737,43 & 407,15 & 305,36 & 1057,16 & 1354,24 \\
\hline 736,43 & 459,93 & 350,60 & 1057,16 & 1354,24 \\
\hline 735,43 & 542,87 & 441,08 & 1057,16 & 1354,24 \\
\hline 734,43 & 603,19 & 497,63 & 1057,16 & 1354,24 \\
\hline 733,43 & 693,66 & 599,42 & 1057,16 & 1354,24 \\
\hline 732,43 & 953,79 & 825,61 & 1665,78 & 2055,74 \\
\hline 731,43 & 1225,22 & 941,72 & 1665,78 & 2055,74 \\
\hline 730,43 & 1300,62 & 1020,89 & 1665,78 & 2055,74 \\
\hline 729,43 & 1360,94 & 1077,44 & 2980,48 & 3843,59 \\
\hline 728,43 & 1466,50 & 1201,85 & 2980,48 & 3843,59 \\
\hline 727,43 & 1737,93 & 1439,35 & 2980,48 & 3843,59 \\
\hline 726,43 & 1873,65 & 1522,29 & 2980,48 & 3843,59 \\
\hline 725,43 & 2114,92 & 1850,27 & 2980,48 & 3843,59 \\
\hline 724,43 & 2326,04 & 2133,02 & 2980,48 & 3843,59 \\
\hline 723,43 & 2597,47 & 2506,24 & 4039,10 & 5737,98 \\
\hline 722,43 & 2959,38 & 3015,17 & 4039,10 & 5737,98 \\
\hline 721,43 & 3358,99 & 3580,66 & 4039,10 & 5737,98 \\
\hline 720,43 & 3720,90 & 3741,01 & 4039,10 & 5737,98 \\
\hline 719,43 & 3939,56 & 4035,06 & 4039,10 & 5737,98 \\
\hline 718,43 & 4112,97 & 4261,26 & 4705,13 & 6958,95 \\
\hline 717,43 & 4256,23 & 4442,21 & 4705,13 & 6958,95 \\
\hline 716,43 & 4535,20 & 4826,74 & 4705,13 & 6958,95 \\
\hline 715,43 & 4731,24 & 5086,87 & 4940,12 & 7389,93 \\
\hline 714,43 & 5085,61 & 5584,50 & 4940,12 & 7389,93 \\
\hline 713,43 & 5447,52 & 6093,43 & 4940,12 & 7389,93 \\
\hline 712,43 & 5839,59 & 6647,61 & & \\
\hline 711,43 & 6133,65 & 6774,78 & & \\
\hline 710,43 & 6529,49 & 6951,72 & & \\
\hline 709,43 & 6959,26 & 7145,24 & & \\
\hline 708,43 & 7547,36 & 7416,17 & & \\
\hline 707,43 & 8022,37 & 7631,81 & & \\
\hline 706,43 & 8369,20 & 8118,13 & & \\
\hline 705,43 & 8768,81 & 8683,61 & & \\
\hline 704,43 & 9168,42 & 9249,10 & & \\
\hline 703,43 & 9568,03 & 9814,59 & & \\
\hline
\end{tabular}


Para uma melhor visualização, construiu-se o Gráfico 4.47 mostrando as relações de atrito lateral dos métodos semi-empíricos e das provas de cargas estáticas.
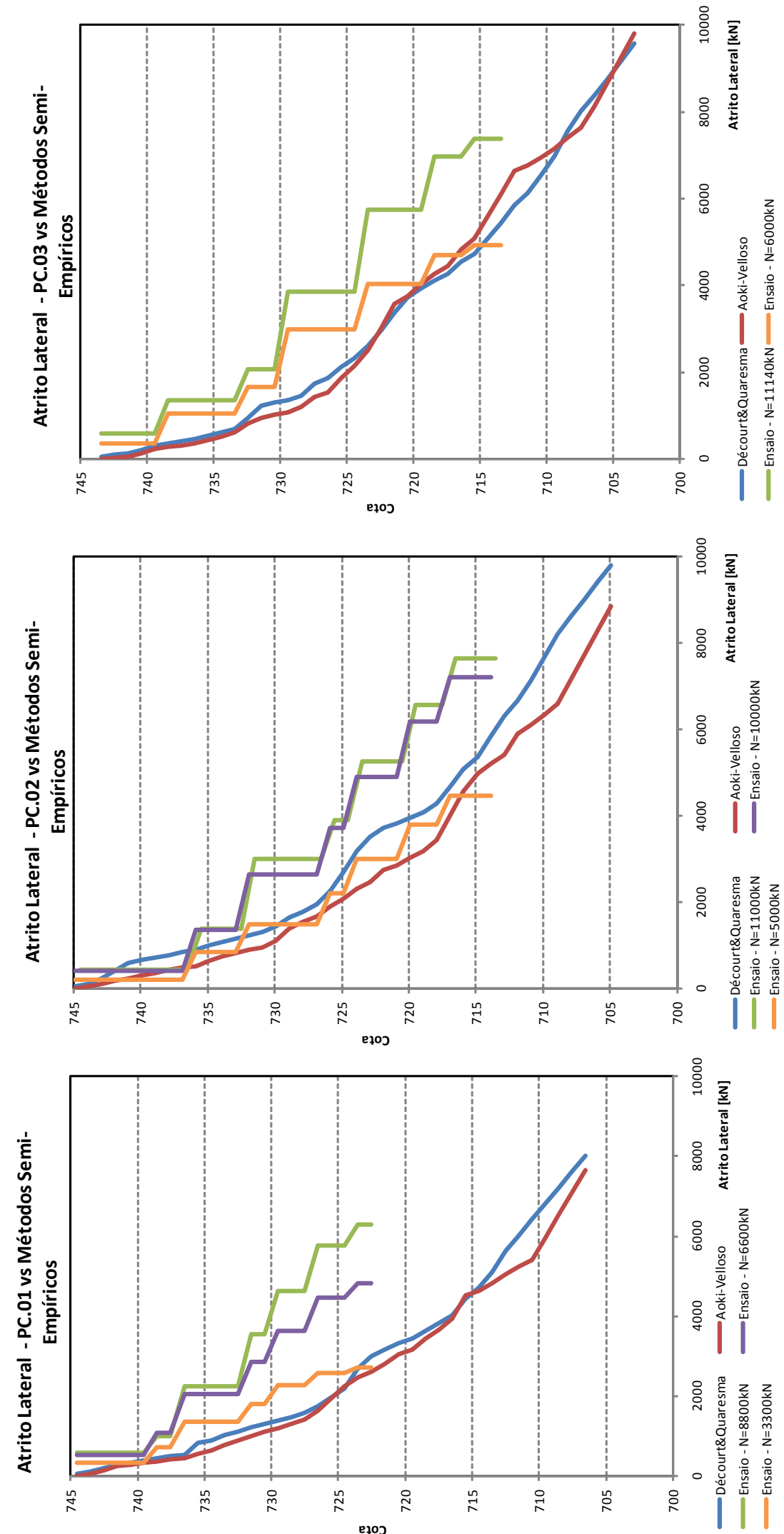

Gráfico 4.47. Comparativo entre os Valores de Atrito Lateral dos Métodos Semi-Empíricos e das Provas de Carga. 
Também foi construído o Gráfico 4.48, que expressa o atrito lateral unitário máximo em função do NSPT médio ao longo do fuste da estaca obtido pelas provas de cargas estáticas e pelos métodos Décourt\&Quaresma e Aoki-Velloso.

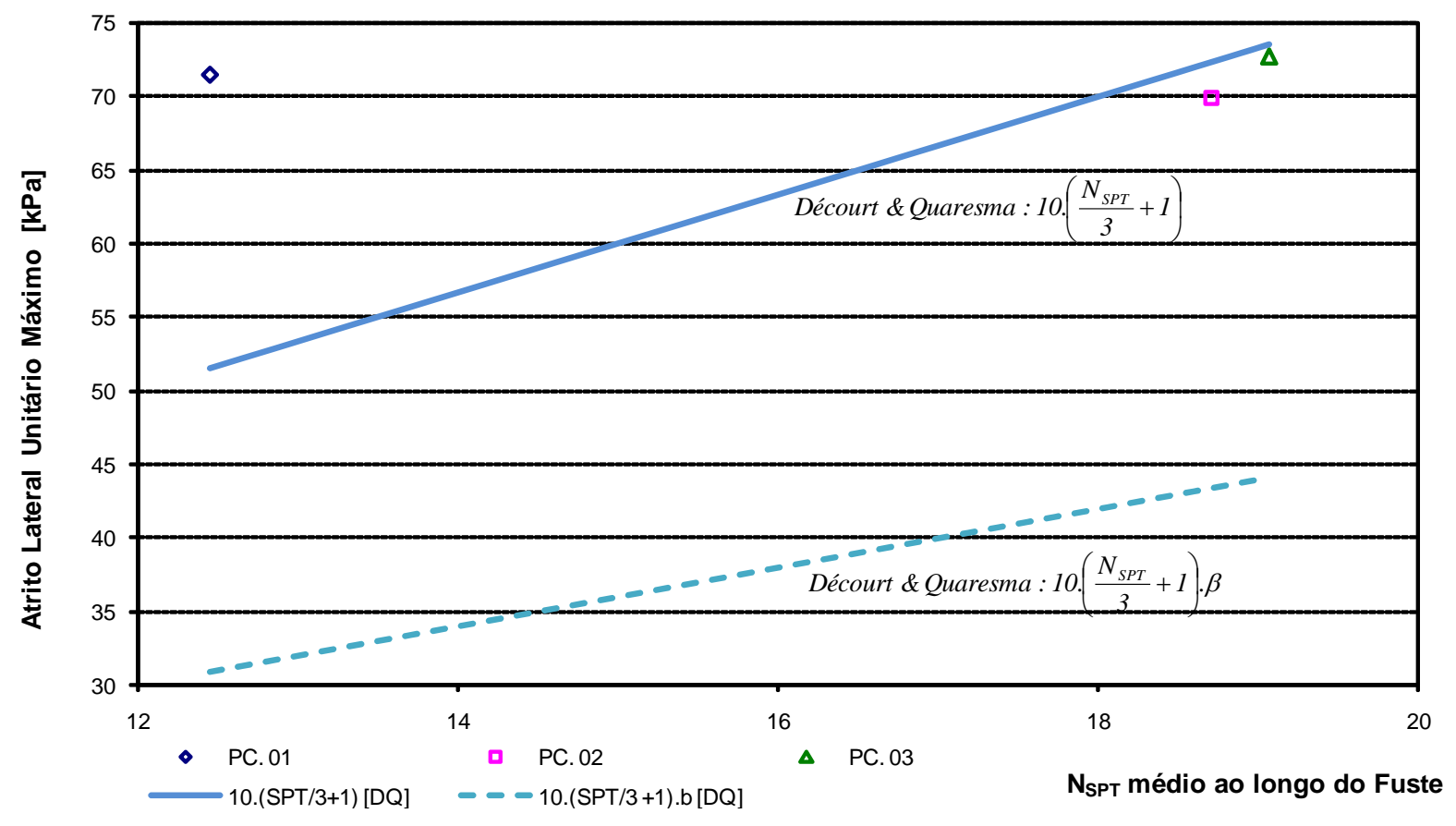

Gráfico 4.48. Comparação do Atrito Lateral Unitário Máximo obtido pelas Provas de Cargas Estáticas e o Método Décourt-Quaresma.

Analisando o Gráfico 4.47 e o Gráfico 4.48 nota-se que o método subestima a parcela referente ao atrito lateral, haja vista que os resultados foram substancialmente inferiores aos registrados pelas provas de cargas estáticas. No entanto, uma peculiaridade observada no Gráfico 4.48 reflete que a utilização da expressão do atrito lateral proposta por Décourt\&Quaresma, com a utilização do parâmetro $\beta$ unitário, proporcionou resultados muito bons para a PC.02 e PC.03. Já para a PC.01, o valor de atrito lateral unitário ter sido da mesma ordem de grandeza das outras duas foi surpreendente e, por isso, a relação não se adaptou satisfatoriamente.

Com relação às cargas de ponta, o Gráfico 4.49 mostra os valores obtidos das provas de cargas estáticas e pelos métodos semi-empíricos. 
Carga de Ponta - Provas de Cargas Estáticas vs Métodos Semi-Empíricos

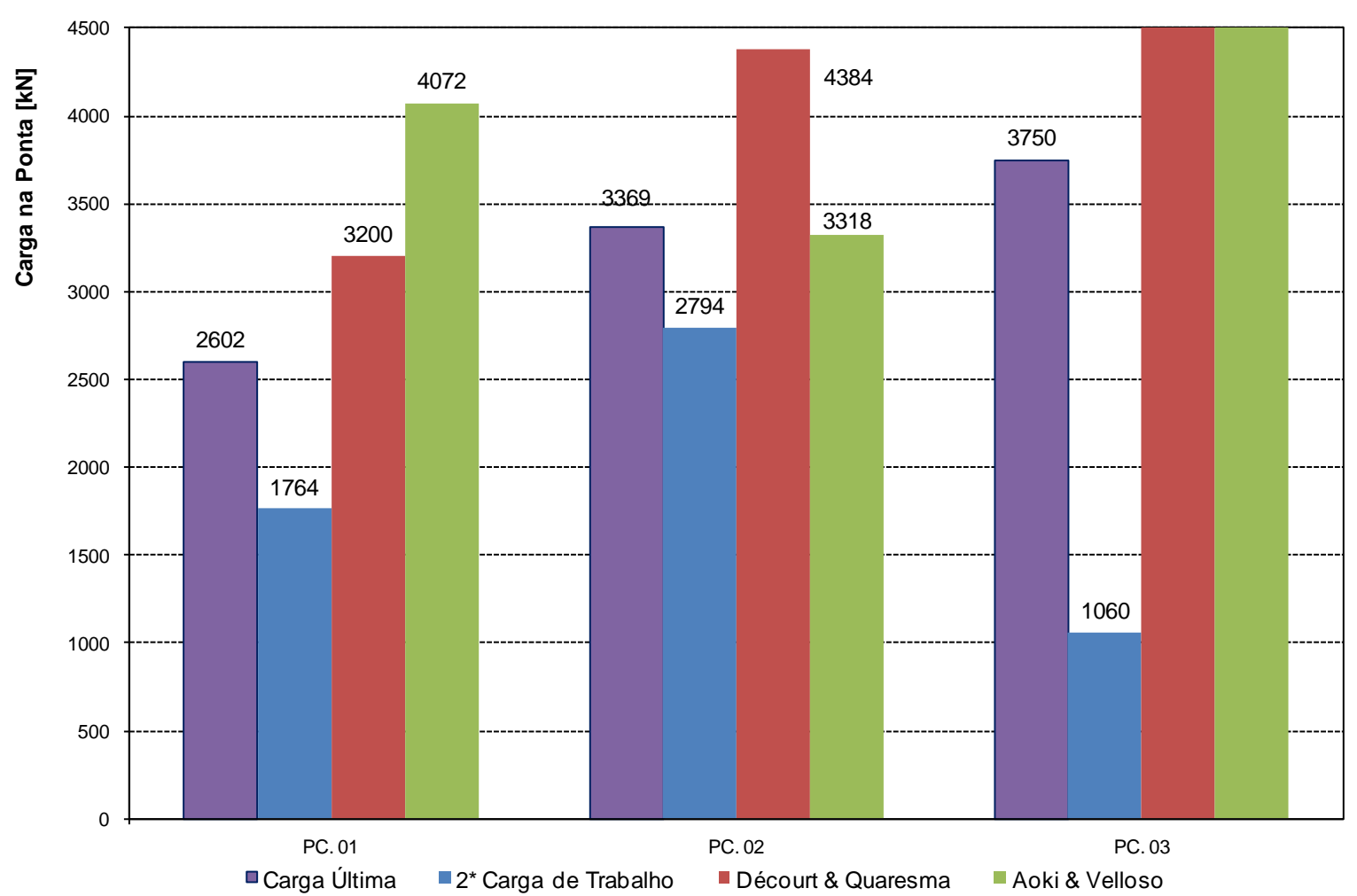

Gráfico 4.49. Comparativo entre os Valores de Ponta dos Métodos Semi-Empíricos e das Provas de Carga.

Com o auxílio do Gráfico 4.50 também é possível perceber que o método de Décourt-Quaresma previu a carga de ponta de maneira espetacular, haja vista que a mesma atingiu a ruptura. Quando as estacas estão apoiadas em camada argilosa, os resultados não são tão díspares, no entanto, quando a ponta encontra-se em areia, a diferença nos resultados é muito significativa, o que também pode ser visualizado no Gráfico 4.49. 


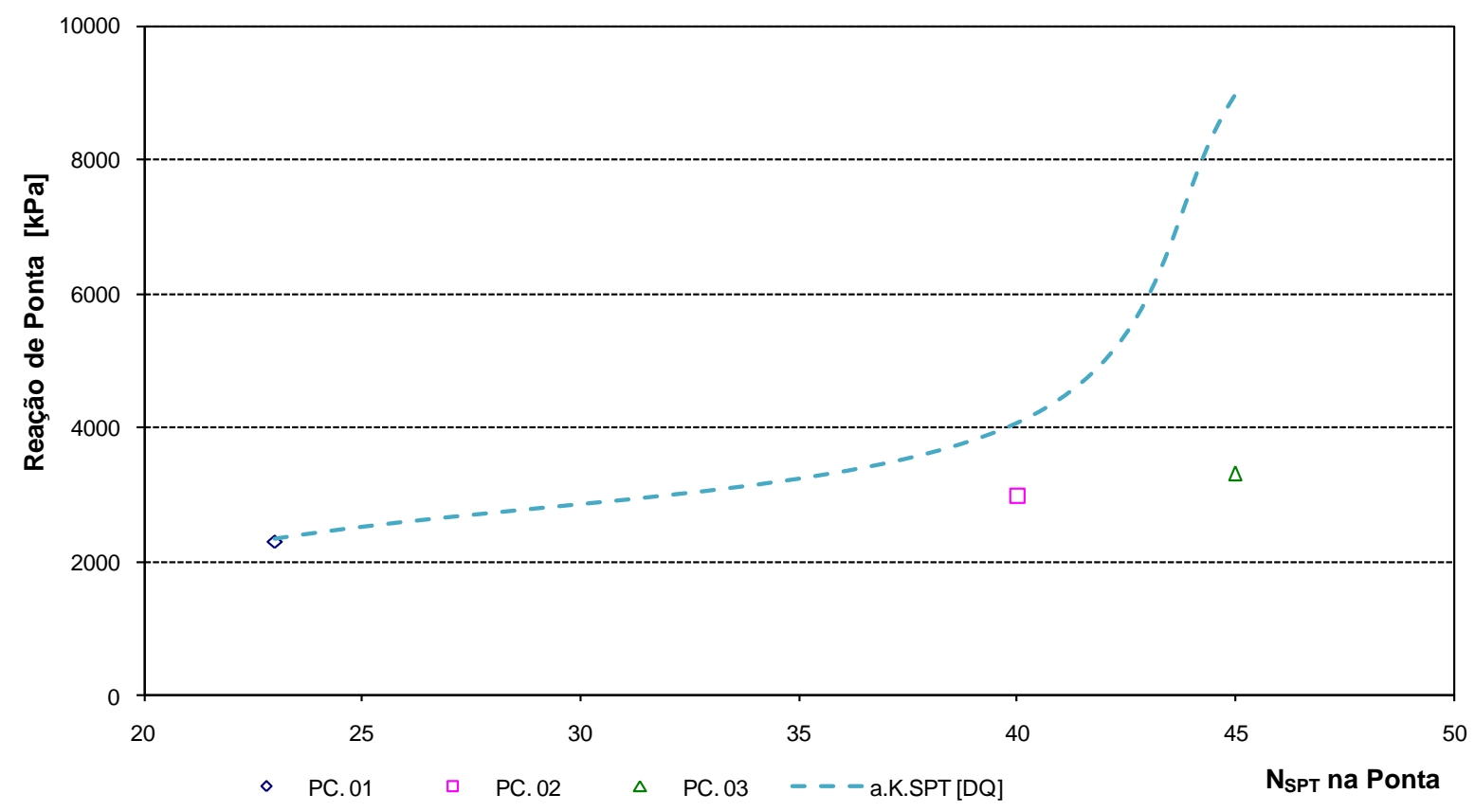

Gráfico 4.50. Comparação da Reação de Ponta obtida pelas Provas de Cargas Estáticas e os Métodos Semi-Empíricos

\subsubsection{Estudo para a Tentativa de Redução do Comprimento das Estacas}

No último item desse capítulo, procura-se mostrar o procedimento elaborado para a tentativa de redução, caso seja possível, dos estacões com base nos resultados obtidos das provas de cargas estáticas, no tocante ao atrito lateral e à ponta. Analisando-se o lado do cliente, como o custo dos ensaios é alto, seria muito benéfica a redução dos comprimentos como um retorno ao investimento feito, já que isso proporcionaria uma sensível economia no desenvolvimento da obra.

A metodologia utilizou-se das conclusões referentes ao atrito, no Gráfico 4.48, e à ponta, no Gráfico 4.50, acerca do método de Décourt\&Quaresma, ou seja, utilizouse o método tomando-se o parâmetro $\beta$ igual a 1. Para a ponta, nada foi alterado, haja vista que o método proporcionou resultados compatíveis com as medições das provas de cargas estáticas. Os cálculos seguem listados na Figura 4.11, Figura 4.12 e Figura 4.13. 
CAPACIDADE DE CARGA DE ESTACAS - Método Décourt-Quaresma (1996)_MODIFICADO

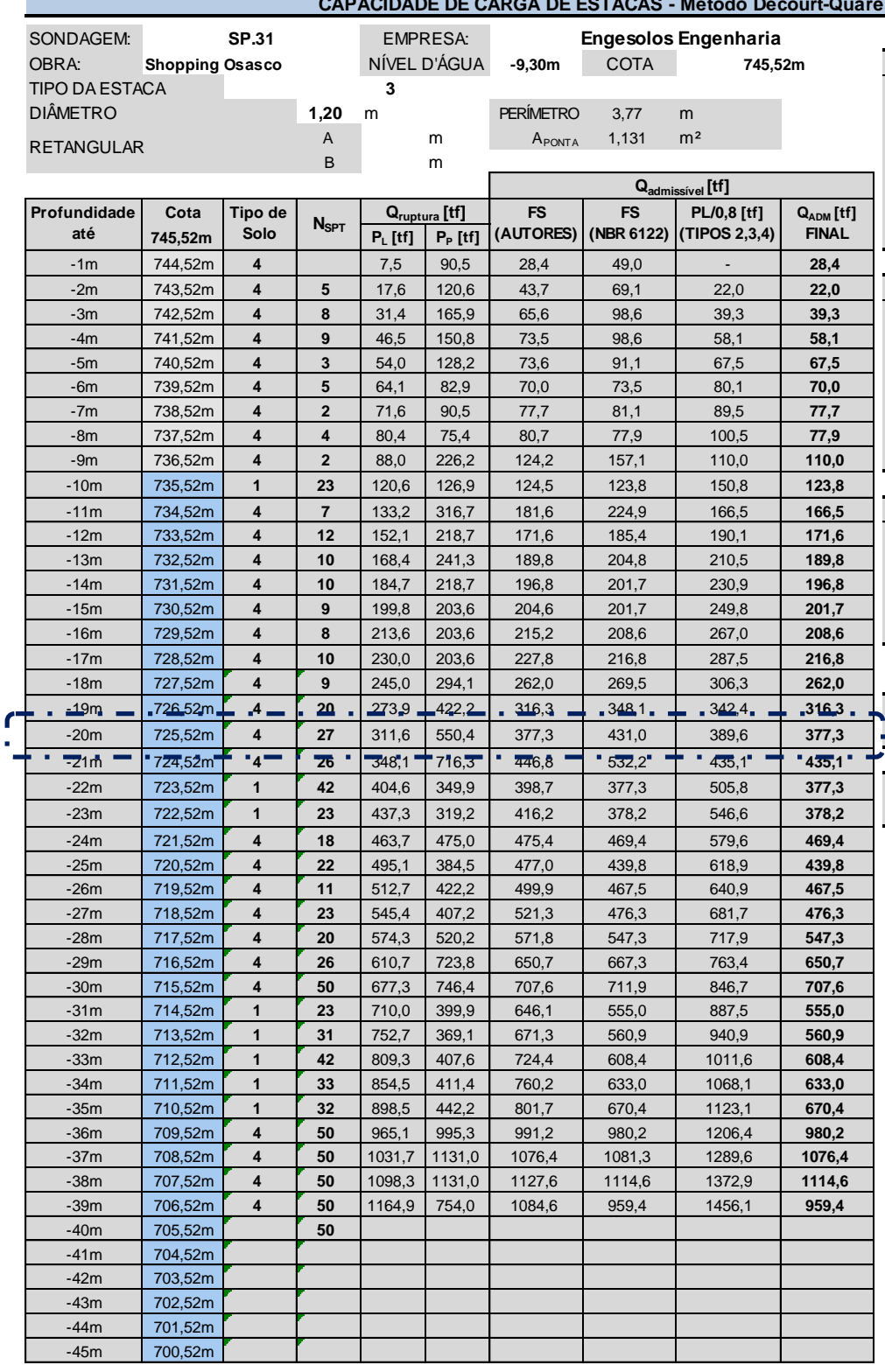

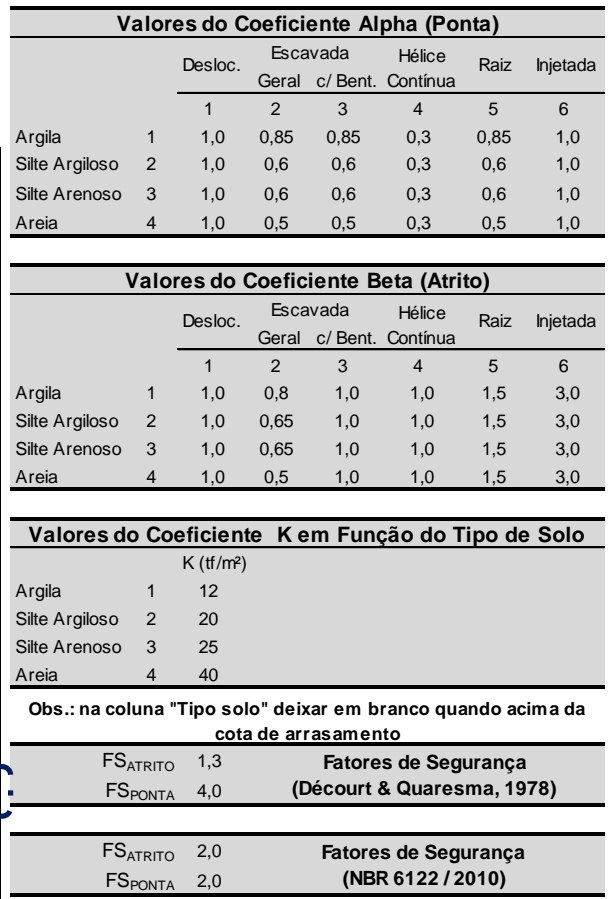

Carga Admissível

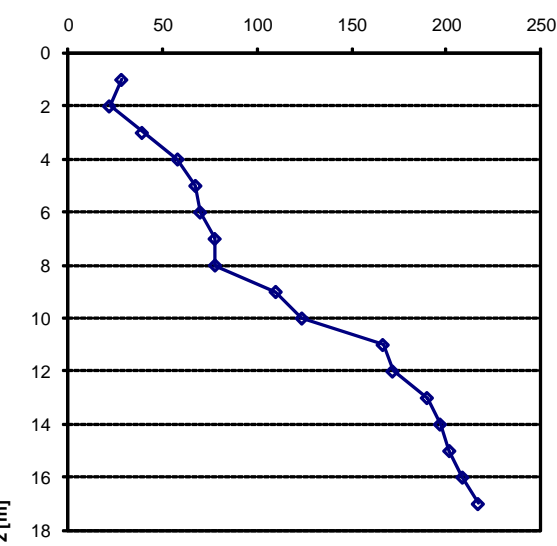

Figura 4.11. Capacidade de Carga para a SP. 31, Após os Resultados das Provas de Cargas Estáticas. 
CAPACIDADE DE CARGA DE ESTACAS - Método Décourt-Quaresma (1996)_MODIFICADO

\begin{tabular}{|c|c|c|c|c|c|c|c|c|c|}
\hline \multirow{2}{*}{$\begin{array}{l}\text { SONDAGEM: } \\
\text { OBRA: }\end{array}$} & \multirow{2}{*}{ Shopping } & \multirow{2}{*}{\multicolumn{2}{|c|}{$\begin{array}{l}\text { SP.30 } \\
\text { Osasco }\end{array}$}} & \multirow{2}{*}{\multicolumn{2}{|c|}{$\begin{array}{l}\text { EMPRESA: } \\
\text { NÍVEL D'ÁGUA }\end{array}$}} & \multicolumn{4}{|c|}{ Engesolos Engenharia } \\
\hline & & & & & & \multirow[t]{2}{*}{$-3,81 \mathrm{~m}$} & \multirow[t]{2}{*}{ COTA } & \multicolumn{2}{|c|}{$745,91 \mathrm{~m}$} \\
\hline \multirow{2}{*}{\multicolumn{2}{|c|}{$\begin{array}{l}\text { TIPO DA ESTACA } \\
\text { DIÂMETRO }\end{array}$}} & & & \multicolumn{2}{|l|}{3} & & & & \\
\hline & & & 1,20 & $\mathrm{~m}$ & & PERÍMETRO" & 3,77 & & \\
\hline \multirow{2}{*}{\multicolumn{2}{|c|}{ RETANGULAR }} & & A & \multirow{3}{*}{\multicolumn{2}{|c|}{$\begin{array}{l}\mathrm{m} \\
\mathrm{m}\end{array}$}} & A PONTA & 1,131 & \multirow{2}{*}{$\mathrm{m}^{2}$} & \\
\hline & & & B & & & \multirow{2}{*}{\multicolumn{4}{|c|}{$Q_{\text {admissivel }}[\mathrm{tt}]$}} \\
\hline & & & & & & & & & \\
\hline \multirow{2}{*}{$\begin{array}{c}\text { Profundidade } \\
\text { até }\end{array}$} & & Tipo de & $N_{\text {CPT }}$ & $\mathbf{Q}_{\text {rupt }}$ & ura $[t \mathrm{t}]$ & FS & FS & PL/0,8 [tf] & $Q_{A D M}[t f]$ \\
\hline & $745,91 \mathrm{~m}$ & Solo & N & $P_{L}[t t]$ & $P_{p}[t f]$ & (AUTORES) & (NBR 6122) & $($ TIPOS 2,3,4) & FINAL \\
\hline$-1 \mathrm{~m}$ & $744,91 \mathrm{~m}$ & 4 & & 7,5 & 79,2 & 25,6 & 43,4 & - & 25,6 \\
\hline$-2 \mathrm{~m}$ & $743,91 \mathrm{~m}$ & 4 & 4 & 16,3 & 113,1 & 40,8 & 64,7 & 20,4 & 20,4 \\
\hline$-3 \mathrm{~m}$ & $742,91 \mathrm{~m}$ & 1 & 8 & 30,2 & 100,0 & 48,2 & 65,1 & 37,7 & 37,7 \\
\hline$-4 \mathrm{~m}$ & $741,91 \mathrm{~m}$ & 1 & 14 & 51,5 & 130,7 & 72,3 & 91,1 & 64,4 & 64,4 \\
\hline$-5 \mathrm{~m}$ & $740,91 \mathrm{~m}$ & 1 & 12 & 70,4 & 126,9 & 85,9 & 98,6 & 88,0 & 85,9 \\
\hline$-6 \mathrm{~m}$ & $739,91 \mathrm{~m}$ & 4 & 7 & 82,9 & 181,0 & 109,0 & 131,9 & 103,7 & 103,7 \\
\hline$-7 \mathrm{~m}$ & $738,91 \mathrm{~m}$ & 4 & 5 & 93,0 & 128,2 & 103,6 & 110,6 & 116,2 & 103,6 \\
\hline$-8 \mathrm{~m}$ & $737,91 \mathrm{~m}$ & 4 & 5 & 103,0 & 113,1 & 107,5 & 108,1 & 128,8 & 107,5 \\
\hline$-9 \mathrm{~m}$ & $736,91 \mathrm{~m}$ & 4 & 5 & 113,1 & 98,0 & 111,5 & 105,6 & 141,4 & 105,6 \\
\hline$-10 \mathrm{~m}$ & $735,91 \mathrm{~m}$ & 4 & 3 & 120,6 & 143,3 & 128,6 & 131,9 & 150,8 & 128,6 \\
\hline$-11 \mathrm{~m}$ & $734,91 \mathrm{~m}$ & 4 & 11 & 138,2 & 173,4 & 149,7 & 155,8 & 172,8 & 149,7 \\
\hline$-12 \mathrm{~m}$ & $733,91 \mathrm{~m}$ & 4 & 9 & 153,3 & 211,1 & 170,7 & 182,2 & 191,6 & 170,7 \\
\hline$-13 \mathrm{~m}$ & $732,91 \mathrm{~m}$ & 4 & 8 & 167,1 & 173,4 & 171,9 & 170,3 & 208,9 & 170,3 \\
\hline$-14 m$ & $731,91 \mathrm{~m}$ & 4 & 6 & 178,4 & 165,9 & 178,7 & 172,2 & 223,1 & 172,2 \\
\hline$-15 \mathrm{~m}$ & $730,91 \mathrm{~m}$ & 4 & 8 & 192,3 & 211,1 & 200,7 & 201,7 & 240,3 & 200,7 \\
\hline$-16 \mathrm{~m}$ & $729,91 \mathrm{~m}$ & 4 & 14 & 213,6 & 346,8 & 251,0 & 280,2 & 267,0 & 251,0 \\
\hline$-17 m$ & $728,91 \mathrm{~m}$ & 4 & 24 & 247,6 & 384,5 & 286,6 & 316,0 & 309,4 & 286,6 \\
\hline$-18 \mathrm{~m}$ & $727,91 \mathrm{~m}$ & 4 & 13 & 267,7 & 437,3 & 315,2 & 352,5 & 334,6 & 315,2 \\
\hline$-19 m$ & $726,91 \mathrm{~m}$ & 4 & 21 & 297,8 & 535,3 & 362,9 & 416,6 & 372,3 & 362,9 \\
\hline$-20 \mathrm{~m}$ & $725,91 \mathrm{~m}$ & 4 & 37 & 348,1 & 708,7 & 444,9 & 528,4 & 435,1 & 435,1 \\
\hline$-21 \mathrm{~m}$ & $724,91 \mathrm{~m}$ & 1 & 36 & 397,1 & 434,5 & 414,1 & 415,8 & 496,4 & 414,1 \\
\hline$-22 m$ & $723,91 \mathrm{~m}$ & 1 & 40 & 451,1 & 392,2 & 445,1 & 421,7 & 563,9 & 421,7 \\
\hline$-23 m$ & $722,91 \mathrm{~m}$ & 1 & 26 & 487,6 & 353,8 & 463,5 & 420,7 & 609,5 & 420,7 \\
\hline$-24 \mathrm{~m}$ & $721,91 \mathrm{~m}$ & 4 & 26 & 524,0 & 467,5 & 520,0 & 495,7 & 655,0 & 495,7 \\
\hline$-25 \mathrm{~m}$ & $720,91 \mathrm{~m}$ & 4 & 10 & 540,4 & 384,5 & 511,8 & 462,4 & 675,4 & 462,4 \\
\hline$-26 m$ & $719,91 \mathrm{~m}$ & 4 & 15 & 563,0 & 294,1 & 506,6 & 428,5 & 703,7 & 428,5 \\
\hline$\therefore=$ & $.71091 \mathrm{~m}$ & $-4-$ & .44 & 58,3 & $-392,1$ & - 547,5 - & -482. & -.7304. & $480,2=$ \\
\hline$-28 \mathrm{~m}$ & $717,91 \mathrm{~m}$ & 4 & 23 & 617,0 & 656,0 & 638,6 & 636,5 & 771,3 & 636,5 \\
\hline$=-29 \mathrm{~m}-1$ & $" 7 \overline{\pi, 9} \mathrm{~m}$ & $+4-$ & $50 \cdot$ & $\overline{\sigma 83,6}=$ & $-927,4$ & $\cdot \sqrt{57,7}=$ & $-8 \bar{\sigma}, 5^{\prime}$ & $+854,5^{\prime \prime}$ & "75T,7," \\
\hline$-30 \mathrm{~m}$ & $715,91 \mathrm{~m}$ & 4 & 50 & 750,2 & 1025,4 & 833,4 & 887,8 & $\begin{array}{r}937,8 \\
\end{array}$ & 833,4 \\
\hline$-31 \mathrm{~m}$ & $714,91 \mathrm{~m}$ & 4 & 36 & 799,2 & 950,0 & 852,3 & 874,6 & 999,0 & 852,3 \\
\hline$-32 \mathrm{~m}$ & $713,91 \mathrm{~m}$ & 1 & 40 & 853,3 & 438,4 & 765,9 & 645,8 & 1066,6 & 645,8 \\
\hline$-33 m$ & $712,91 \mathrm{~m}$ & 1 & 38 & 904,8 & 461,4 & 811,3 & 683,1 & 1131,0 & 683,1 \\
\hline$-34 m$ & $711,91 \mathrm{~m}$ & 4 & 42 & 961,3 & 897,2 & 963,8 & 929,3 & 1201,7 & 929,3 \\
\hline$-35 \mathrm{~m}$ & $710,91 \mathrm{~m}$ & 1 & 39 & 1014,1 & 480,7 & 900,2 & 747,4 & 1267,6 & 747,4 \\
\hline$-36 \mathrm{~m}$ & $709,91 \mathrm{~m}$ & 1 & 44 & 1073,2 & 492,2 & 948,6 & 782,7 & 1341,5 & 782,7 \\
\hline$-37 \mathrm{~m}$ & $708,91 \mathrm{~m}$ & 1 & 45 & 1133,5 & 534,5 & 1005,5 & 834,0 & 1416,9 & 834,0 \\
\hline$-38 m$ & $707,91 \mathrm{~m}$ & 4 & 50 & 1200,1 & 1093,3 & 1196,5 & 1146,7 & 1500,1 & 1146,7 \\
\hline$-39 m$ & $706,91 \mathrm{~m}$ & 4 & 50 & 1266,7 & 1131,0 & 1257,1 & 1198,8 & 1583,4 & 1198,8 \\
\hline$-40 \mathrm{~m}$ & $705,91 \mathrm{~m}$ & 4 & 50 & 1333,3 & 1131,0 & 1308,4 & 1232,1 & 1666,6 & 1232,1 \\
\hline$-41 \mathrm{~m}$ & $704,91 \mathrm{~m}$ & 4 & 50 & 1399,9 & 754,0 & 1265,3 & 1076,9 & 1749,9 & 1076,9 \\
\hline$-42 \mathrm{~m}$ & $703,91 \mathrm{~m}$ & & 50 & & & & & & \\
\hline$-43 m$ & $702,91 \mathrm{~m}$ & & & & & & & & \\
\hline$-44 m$ & $701,91 \mathrm{~m}$ & & & & & & & & \\
\hline$-45 m$ & $700,91 \mathrm{~m}$ & & & & & & & & \\
\hline
\end{tabular}

\begin{tabular}{|c|c|c|c|c|c|c|c|}
\hline \multicolumn{8}{|c|}{ Valores do Coeficiente Alpha (Ponta) } \\
\hline & & \multirow{2}{*}{ Desloc. } & \multicolumn{2}{|c|}{ Escavada } & \multirow{2}{*}{$\begin{array}{c}\text { Hélice } \\
\text { Contínua }\end{array}$} & \multirow{2}{*}{ Raiz } & \multirow{2}{*}{ Injetada } \\
\hline & & & Geral & c/ Bent. & & & \\
\hline & & 1 & 2 & 3 & 4 & 5 & 6 \\
\hline Argila & 1 & 1,0 & 0,85 & 0,85 & 0,3 & 0,85 & 1,0 \\
\hline Silte Argiloso & 2 & 1,0 & 0,6 & 0,6 & 0,3 & 0,6 & 1,0 \\
\hline Silte Arenoso & 3 & 1,0 & 0,6 & 0,6 & 0,3 & 0,6 & 1,0 \\
\hline Areia & & 1,0 & 0,5 & 0,5 & 0,3 & 0,5 & 1,0 \\
\hline \multicolumn{8}{|c|}{ Valores do Coeficiente Beta (Atrito) } \\
\hline & & \multirow[t]{2}{*}{ Desloc. } & \multicolumn{2}{|c|}{ Escavada } & Hélice & \multirow{2}{*}{ Raiz } & \multirow{2}{*}{ Injetada } \\
\hline & & & Geral & c/ Bent. & Contínua & & \\
\hline & & 1 & 2 & 3 & 4 & 5 & 6 \\
\hline Argila & 1 & 1,0 & 0,8 & 1,0 & 1,0 & 1,5 & 3,0 \\
\hline Silte Argiloso & 2 & 1,0 & 0,65 & 1,0 & 1,0 & 1,5 & 3,0 \\
\hline Silte Arenoso & 3 & 1,0 & 0,65 & 1,0 & 1,0 & 1,5 & 3,0 \\
\hline Areia & 4 & 1,0 & 0,5 & 1,0 & 1,0 & 1,5 & 3,0 \\
\hline
\end{tabular}

Valores do Coeficiente K em Função do Tipo de Solo $\mathrm{K}\left(\mathrm{tt} / \mathrm{m}^{2}\right)$

Argila $\quad 1 \quad 12$

Silte Argiloso 20

\begin{tabular}{lll} 
Silte Arenoso & 3 & 25 \\
Areia & 4 & 40 \\
\hline
\end{tabular}

Obs.: na coluna "Tipo solo" deixar em branco quando acima da cota de arrasamento

\begin{tabular}{ccc}
\multicolumn{3}{c}{ cota de arrasamento } \\
\hline FS $_{\text {ATRITO }}$ & 1,3 & Fatores de Segurança \\
FS $_{\text {PONTA }}$ & 4,0 & (Décourt \& Quaresma, 1978) \\
\hline & & \\
\hline FS $_{\text {ATRITO }}$ & 2,0 & Fatores de Segurança \\
FS $_{\text {PONTA }}$ & 2,0 & (NBR 6122 / 2010) \\
\hline
\end{tabular}

Carga Admissível

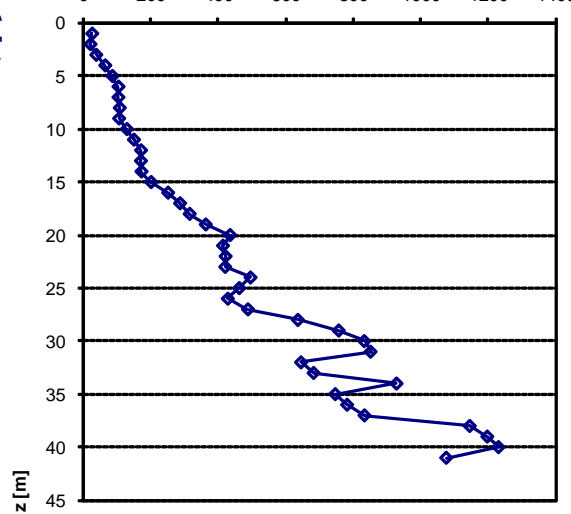

Figura 4.12. Capacidade de Carga para a SP. 30, Após os Resultados das Provas de Cargas Estáticas. 
CAPACIDADE DE CARGA DE ESTACAS - Método Décourt-Quaresma (1996)_MODIFICADO

\begin{tabular}{|c|c|c|c|c|c|c|c|c|c|}
\hline \multirow{2}{*}{$\begin{array}{l}\text { SONDAGEM: } \\
\text { OBRA: }\end{array}$} & \multirow{2}{*}{ Shopping } & \multicolumn{2}{|l|}{ SP.33 } & \multicolumn{2}{|c|}{ EMPRESA: } & \multicolumn{4}{|c|}{ Engesolos Engenharia } \\
\hline & & Osasco & & \multicolumn{2}{|c|}{ NÍVEL D'ÁGUA } & $-4,83 m$ & COTA & \multicolumn{2}{|c|}{$\mathbf{7 4 4 , 4 3 m}$} \\
\hline \multirow{2}{*}{\multicolumn{2}{|c|}{$\begin{array}{l}\text { TIPO DA ESTACA } \\
\text { DIÂMETRO }\end{array}$}} & & & \multicolumn{2}{|l|}{3} & & & & \\
\hline & & & 1,20 & $\mathrm{~m}$ & & PERÍMETRO & 3,77 & & \\
\hline \multirow{2}{*}{\multicolumn{2}{|c|}{ RETANGULAR }} & & A & \multirow{3}{*}{\multicolumn{2}{|c|}{$\begin{array}{l}\mathrm{m} \\
\mathrm{m}\end{array}$}} & A PONTA & 1,131 & $\mathrm{~m}^{2}$ & \\
\hline & & & B & & & & & & \\
\hline & & & & & & & $Q_{\text {admi }}$ & issivel [tf] & \\
\hline \multirow{2}{*}{$\begin{array}{c}\text { Profundidade } \\
\text { até }\end{array}$} & \multirow{2}{*}{\begin{tabular}{|c|} 
Cota \\
$744,43 m$
\end{tabular}} & \multirow{2}{*}{\begin{tabular}{|c|} 
Tipo de \\
Solo
\end{tabular}} & $N_{0}$ & $\mathbf{Q}_{\text {ruptu }}$ & ura $[\mathrm{tf}]$ & FS & FS & PL/0,8 [tt] & $\left.Q_{A D M}[t]\right]$ \\
\hline & & & ISPT & $P_{L}[t t]$ & $P_{P}[t f]$ & (AUTORES) & (NBR 6122) & & \\
\hline$-1 m$ & $743,43 \mathrm{~m}$ & 4 & & 7,5 & 67,9 & 22,8 & 37,7 & - & 22,8 \\
\hline$-2 m$ & $742,43 m$ & 4 & 2 & 15,1 & 67,9 & 28,6 & 41,5 & 18,8 & 18,8 \\
\hline$-3 m$ & $741,43 m$ & 4 & 2 & 22,6 & 98,0 & 41,9 & 60,3 & 28,3 & 28,3 \\
\hline$-4 m$ & $740,43 \mathrm{~m}$ & 4 & 7 & 35,2 & 150,8 & 64,8 & 93,0 & 44,0 & 44,0 \\
\hline$-5 \mathrm{~m}$ & $739,43 \mathrm{~m}$ & 4 & 10 & 51,5 & 158,3 & 79,2 & 104,9 & 64,4 & 64,4 \\
\hline$-6 m$ & $738,43 m$ & 4 & 4 & 60,3 & 128,2 & 78,4 & 94,2 & 75,4 & 75,4 \\
\hline$-7 \mathrm{~m}$ & $737,43 m$ & 4 & 2 & 67,9 & 82,9 & 72,9 & 75,4 & 84,8 & 72,9 \\
\hline$-8 m$ & $736,43 m$ & 4 & 4 & 76,7 & 113,1 & 87,2 & 94,9 & 95,8 & 87,2 \\
\hline$-9 m$ & $735,43 \mathrm{~m}$ & 4 & 8 & 90,5 & 128,2 & 101,6 & 109,3 & 113,1 & 101,6 \\
\hline$-10 m$ & $734,43 m$ & 4 & 5 & 100,5 & 165,9 & 118,8 & 133,2 & 125,7 & 118,8 \\
\hline$-11 m$ & $733,43 \mathrm{~m}$ & 4 & 9 & 115,6 & 256,4 & 153,0 & 186,0 & 144,5 & 144,5 \\
\hline$-12 m$ & $732,43 m$ & 1 & 20 & 144,5 & 192,3 & 159,2 & 168,4 & 180,6 & 159,2 \\
\hline$-13 m$ & $731,43 \mathrm{~m}$ & 1 & 21 & 174,7 & 184,6 & 180,5 & 179,6 & 218,3 & 179,6 \\
\hline$-14 m$ & $730,43 \mathrm{~m}$ & 4 & 7 & 187,2 & 248,8 & 206,2 & 218,0 & 234,0 & 206,2 \\
\hline$-15 m$ & $729,43 \mathrm{~m}$ & 4 & 5 & 197,3 & 173,4 & 195,1 & 185,4 & 246,6 & 185,4 \\
\hline$-16 m$ & $728,43 m$ & 4 & 11 & 214,9 & 279,0 & 235,0 & 246,9 & 268,6 & 235,0 \\
\hline$-17 m$ & $727,43 \mathrm{~m}$ & 1 & 21 & 245,0 & 180,7 & 233,7 & 212,9 & 306,3 & 212,9 \\
\hline$-18 m$ & $726,43 \mathrm{~m}$ & 4 & 15 & 267,7 & 490,1 & 328,4 & 378,9 & 334,6 & 328,4 \\
\hline$-19 m$ & $725,43 \mathrm{~m}$ & 4 & 29 & 307,9 & 520,2 & 366,9 & 414,1 & 384,8 & 366,9 \\
\hline$-20 m$ & $724,43 m$ & 4 & 25 & 343,1 & 656,0 & 427,9 & 499,5 & 428,8 & 427,9 \\
\hline$-21 m$ & $723,43 m$ & 4 & 33 & 388,3 & 776,6 & 492,8 & 582,5 & 485,4 & 485,4 \\
\hline$-22 m$ & $722,43 \mathrm{~m}$ & 4 & 45 & 448,6 & 965,1 & 586,4 & 706,9 & 560,8 & 560,8 \\
\hline$-23 m$ & $721,43 \mathrm{~m}$ & 4 & 50 & 515,2 & 934,9 & 630,1 & 725,1 & 644,0 & 630,1 \\
\hline$-24 m$ & $720,43 \mathrm{~m}$ & 1 & 29 & 555,4 & 403,8 & 528,2 & 479,6 & 694,3 & 479,6 \\
\hline$-25 m$ & $719,43 m$ & 4 & 26 & 591,9 & 565,5 & 596,7 & 578,7 & 739,8 & 578,7 \\
\hline$-26 \mathrm{~m}$ & $718,43 \mathrm{~m}$ & 4 & 20 & 620,8 & 467,5 & 594,4 & 544,1 & 776,0 & 544,1 \\
\hline$\because 27 m=$ & $\nabla 17,43 m$ & $-4-$ & .16 & $64,7$. & $-627,8$ & . 6으, & -5842. & $-.805,8.7$ & $68 \mathrm{G}, 2$. \\
\hline$-28 \mathrm{~m}$ & $716,43 \mathrm{~m}$ & 4 & 34 & 691,2 & 550,4 & 669,3 & 620,8 & 863,9 & 620,8 \\
\hline$\because-29 m^{\prime}-$ & $7 \sqrt{5,43 m}$ & $4-$ & $25 \cdot$ & 723,8 & $-761,5$ & " $\sqrt{47,2}=$ & ${ }^{\circ} 74 z, 7^{\circ}$ & - $904,88^{\circ}$ & $742,7^{\circ}$ \\
\hline$-30 \mathrm{~m}$ & $714,43 \mathrm{~m}$ & 4 & 44 & 782,9 & 844,5 & 813,3 & 813,7 & 978,6 & 813,3 \\
\hline$-31 m$ & $713,43 \mathrm{~m}$ & 4 & 45 & 843,2 & 1040,5 & 908,7 & 941,8 & 1054,0 & 908,7 \\
\hline$-32 m$ & $712,43 \mathrm{~m}$ & 4 & 49 & 908,5 & 882,2 & 919,4 & 895,4 & 1135,7 & 895,4 \\
\hline$-33 m$ & $711,43 \mathrm{~m}$ & 1 & 23 & 941,2 & 399,9 & 824,0 & 670,6 & 1176,5 & 670,6 \\
\hline$-34 m$ & $710,43 \mathrm{~m}$ & 1 & 32 & 985,2 & 346,1 & 844,4 & 665,6 & 1231,5 & 665,6 \\
\hline$-35 m$ & $709,43 \mathrm{~m}$ & 1 & 35 & 1033,0 & 446,1 & 906,1 & 739,5 & 1291,2 & 739,5 \\
\hline$-36 m$ & $708,43 \mathrm{~m}$ & 1 & 49 & 1098,3 & 473,0 & 963,1 & 785,6 & 1372,9 & 785,6 \\
\hline$-37 m$ & $707,43 \mathrm{~m}$ & 1 & 39 & 1151,1 & 503,7 & 1011,4 & 827,4 & 1438,8 & 827,4 \\
\hline$-38 m$ & $706,43 \mathrm{~m}$ & 4 & 43 & 1208,9 & 995,3 & 1178,7 & 1102,1 & 1511,1 & 1102,1 \\
\hline$-39 m$ & $705,43 \mathrm{~m}$ & 4 & 50 & 1275,5 & 1078,2 & 1250,7 & 1176,8 & 1594,4 & 1176,8 \\
\hline$-40 \mathrm{~m}$ & $704,43 \mathrm{~m}$ & 4 & 50 & 1342,1 & 1131,0 & 1315,1 & 1236,5 & 1677,6 & 1236,5 \\
\hline$-41 m$ & $703,43 \mathrm{~m}$ & 4 & 50 & 1408,7 & 754,0 & 1272,1 & 1081,3 & 1760,9 & 1081,3 \\
\hline$-42 m$ & $702,43 \mathrm{~m}$ & & 50 & & & & & & \\
\hline$-43 m$ & $701,43 \mathrm{~m}$ & & & & & & & & \\
\hline$-44 m$ & $700,43 \mathrm{~m}$ & & & & & & & & \\
\hline$-45 m$ & $699,43 \mathrm{~m}$ & & & & & & & & \\
\hline
\end{tabular}

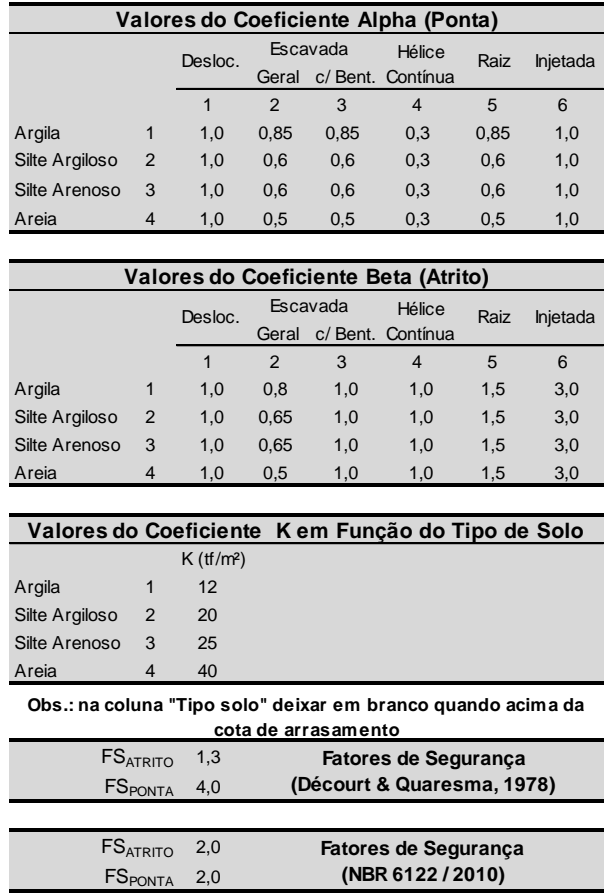

Carga Admissível

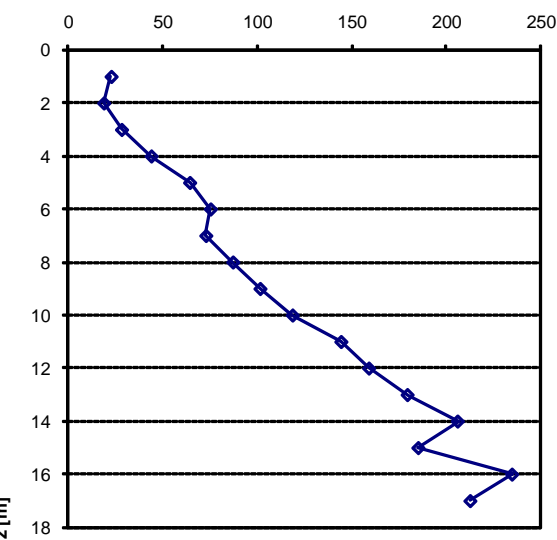

Figura 4.13. Capacidade de Carga para a SP. 33, Após os Resultados das Provas de Cargas Estáticas.

Com os resultados das capacidades de carga, pode-se observar que as profundidades poderiam ser reduzidas em 3m, conforme a Tabela 4.29. 
Tabela 4.29. Cotas de Ponta das Estacas Após os Resultados das Provas de Cargas Estáticas.

\begin{tabular}{lccccc}
\hline Prova de Carga & $\begin{array}{c}\text { Carga de Trabalho Cota de Ponta } \\
{[\mathrm{kN}]}\end{array}$ & $\begin{array}{c}\text { SP. 31 } \\
\text { de Projeto }\end{array}$ & $\begin{array}{c}\text { SP.30 } \\
\text { Após PCE }\end{array}$ & $\begin{array}{c}\text { SP. 33 } \\
\text { Após PCE }\end{array}$ & Após PCE \\
\hline PC. 01 (E.263) & 3300 & 722,30 & $\mathbf{7 2 5 , 5 2}$ & 726,91 & 725,43 \\
PC. 02 (E.113) & 5000 & 714,32 & 717,52 & $\mathbf{7 1 7 , 9 1}$ & 719,43 \\
PC. 03 (E.25) & 6000 & 713,86 & 712,52 & 717,91 & $\mathbf{7 1 6 , 4 3}$ \\
\hline
\end{tabular}

E no Gráfico 4.51, pode-se visualizar mais claramente essa redução.

\section{Comparativo das Cotas de Ponta}

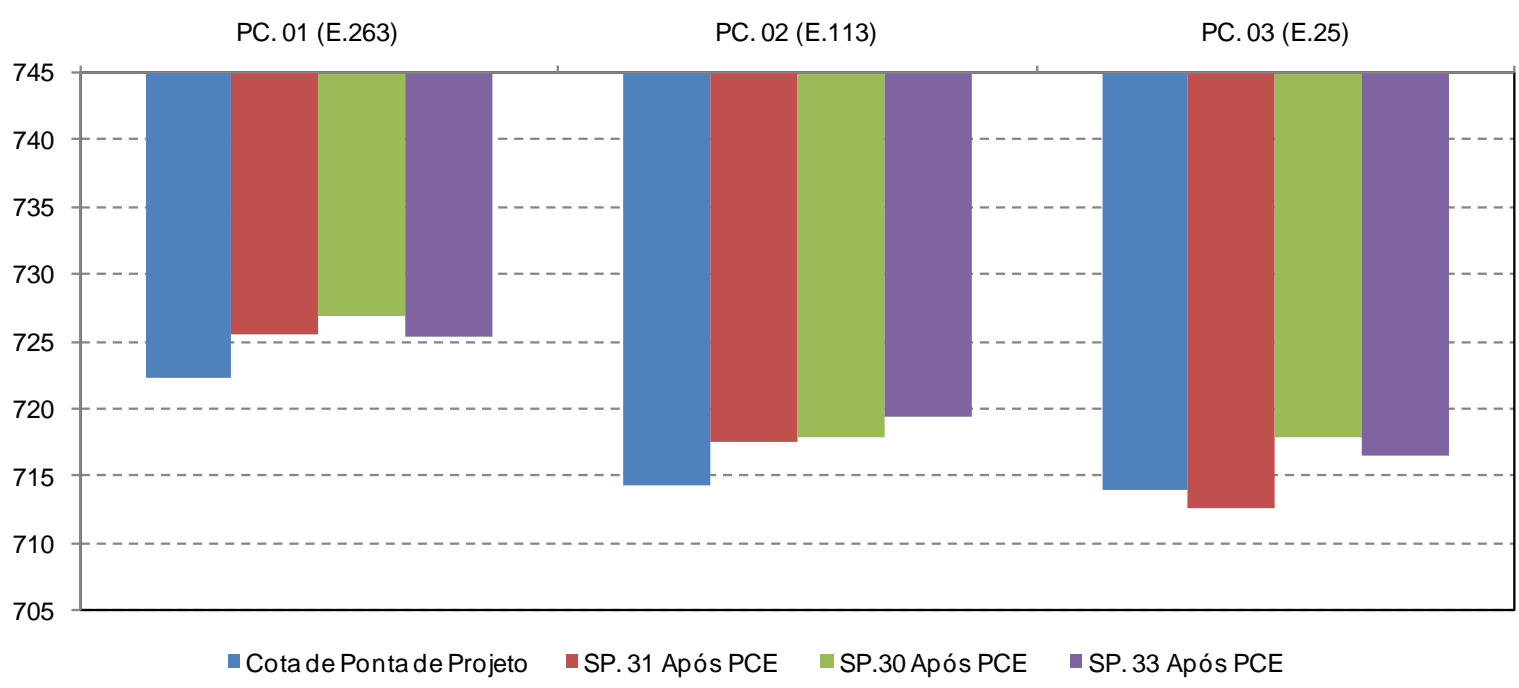

Gráfico 4.51. Cotas de Ponta das Estacas Após os Resultados das Provas de Cargas Estáticas. 


\section{Conclusões e Sugestões para Pesquisas Futuras}

Este capítulo finaliza o trabalho até aqui apresentado, mostrando as conclusões sobre os assuntos tratados em seu andamento, os quais se encontram nas análises dos resultados, conforme capítulo 4.

Esse trabalho, em seu início, tratou como objetivo a interpretação de diversos métodos de análise da curva carga vs recalque e mostrar a viabilidade da aplicação dos mesmos às estacas escavadas de grande diâmetro. Além disso, pretendia-se descobrir quais as cargas de ruptura para duas provas de cargas que não a alcançaram. No entanto, o ponto principal era a tentativa em diminuir os comprimentos das estacas, já que a obra ainda estava em andamento quando da elaboração dos ensaios.

As conclusões serão elaboradas em parágrafos independentes, de modo que as mesmas fiquem bem distintas e fundamentadas.

Ao final desse capítulo, serão também apresentadas, de modo itemizado, algumas sugestões de assuntos para futuras pesquisas que possam ser elaboradas com base nesse trabalho.

Antes de qualquer conclusão, é prudente considerar alguns aspectos que devem ser levados em consideração quando da elaboração de um programa de provas de cargas estáticas, pois eles podem afetar as leituras dos instrumentos e mascarar os resultados. 
a.) As leituras podem ser feitas por meio de manômetros calibrados instalados no sistema que alimenta o curso dos macacos. No entanto, sempre que possível, deve-se preferir a utilização de células de carga, pois permitem uma maior precisão dos resultados. Na obra em questão, a carga máxima da prova era de até $12000 \mathrm{kN}$ e os modelos normalmente encontrados no mercado possuem capacidade de até $5000 \mathrm{kN}$.

b.) As provas de carga que possuem como sistema de reação uma viga horizontal sustentada por estacas tracionadas ou tirantes, dependendo do diâmetro da mesma, utilizam-se de apenas um macaco hidráulico. Sendo assim, não é necessária a preocupação com o carregamento. Porém, quando se usa mais de um macaco, como é o caso, a preocupação existe e uma programação de carregamentos deve ser cuidadosamente elaborada para garantir o ponto de aplicação e a direção da carga.

c.) A viga de referência geralmente é metálica (perfis I) e deve manter-se imóvel no terreno. Para isso, a mesma é apoiada nas extremidades e deve ficar distante do eixo da estaca ensaiada de 5D ou 1,5m. Os deflectômeros mecânicos medem o deslocamento do bloco de coroamento da estaca baseado na viga de referência. Salienta-se que os efeitos de intempéries, como vento e temperatura, devem ser considerados se proporcionarem deslocamento na viga.

d.) A preocupação com os tirantes também deve ser considerada. O eixo da estaca ensaiada deve ficar distante 3D ou 1,5m, no mínimo, do ponto mais próximo do bulbo do tirante. A execução do tirante provoca uma melhora nas propriedades do solo adjacente e isso pode influenciar, caso esteja próximo do fuste ou ponta, os resultados de atrito lateral e resistência de ponta, falseando o ensaio estático. Nas provas de carga em questão, esse espaçamento foi de 4,80m (4D). 


\subsection{Conclusões}

Durante a execução das provas de cargas estáticas, mais especificamente na PC.01, houve um problema no sistema hidráulico que impediu a continuação do ensaio. Após o reparo do mesmo, houve a continuação e a estaca atingiu a ruptura, com o valor de $8800 \mathrm{kN}$ e um deslocamento total de $52,77 \mathrm{~mm}$, de acordo com a Tabela 4.1. No caso da PC.02, o par de valores carga e recalque foi de $11000 \mathrm{kN}$ e 43,12mm, conforme Tabela 4.2; por sua vez, a PC.03, como pode ser visto na Tabela 4.3, apresentou como carga máxima o valor de $11140 \mathrm{kN}$ e $34,07 \mathrm{~mm}$, como deslocamento vertical. Nesse último ensaio, a máxima carga não chegou ao dobro da carga de trabalho da estaca, pois algumas cordoalhas dos tirantes de reação foram rompidas pelo trânsito de equipamentos em obra, e isso impossibilitou fazer o ensaio segundo a prescrição da NBR 12131. A Tabela 5.1 mostra um resumo das informações descritas.

Tabela 5.1. Carga no Topo e Deslocamento Atingidos nas Provas de Cargas Estáticas.

\begin{tabular}{|c|c|c|c|c|c|}
\hline Prova de Carga & Estaca & Carga de Trabalho [kN] & Carga no Topo [kN] & Recalque Máximo [mm] & Observação \\
\hline PC.01 & E.263 & 3300 & 8800 & 52,77 & Rompeu \\
\hline PC.02 & E.113 & 5000 & 11000 & 43,12 & Não Rompeu \\
\hline PC.03 & E.25 & 6000 & 11140 & 34,07 & Não Rompeu \\
\hline
\end{tabular}

Com os dados das cargas no topo e as deformações específicas foi possível calcular o produto de rigidez para cada tipo de estaca pelo Método do Módulo Tangente de Fellenius (1989), visto na Tabela 4.5, Tabela 4.7 e Tabela 4.9, e que se encontram resumidos abaixo:

Tabela 5.2. Valores do Produto ES das Estacas Ensaiadas.

\begin{tabular}{ccc}
\hline Prova de Carga & Estaca & Produto ES [GN] \\
\hline PC. 01 & E.263 & 39 \\
PC. 02 & E.113 & 32 \\
PC. 03 & E. 25 & 37 \\
\hline
\end{tabular}

Por meio dos diagramas de transferência de carga, item 4.3, possibilitados pela instrumentação em profundidade, com a utilização de strain gages, e pelos 
diagramas de atrito lateral unitário, item 4.4, pode-se conhecer as cargas de atrito lateral e ponta, para cada estágio de carga. Mas, na Tabela 5.3 constam listadas apenas as cargas de atrito e ponta para as cargas de trabalho, para o dobro da carga de trabalho e cargas máximas atingidas nos ensaios.

Tabela 5.3. Cargas no Topo, Ponta e Atrito Lateral Obtidos das Provas de Cargas Estáticas.

\begin{tabular}{ccccc}
\hline Prova de Carga & Estaca & Carga no Topo [kN] & Carga na Ponta [kN] & Atrito Lateral [kN] \\
\hline \multirow{2}{*}{ PC. 01 } & \multirow{3}{*}{ E.263 } & 8800 & 2602 & 6198 \\
& & 6600 & 1764 & 4836 \\
& & 3300 & 574 & 2726 \\
PC. 02 & E.113 & 11000 & 3369 & 7631 \\
& & 50000 & 2794 & 7206 \\
PC. 03 & E.25 & 11140 & 545 & 4455 \\
& & 6000 & 3750 & 7390 \\
\hline
\end{tabular}

No que se refere às funções de transferência de carga, pode-se perceber que, para a PC.01, que atingiu a ruptura, houve o esgotamento total do atrito, vista no Gráfico 4.18 e a mobilização quase completa da ponta, no Gráfico 4.19. Para a PC.02 e PC.03, que possuem quase o mesmo comprimento, as relações de Cambefort mostram que o atrito está na iminência do esgotamento, enquanto que a ponta ainda pode contribuir para o aumento da resistência da estaca; isto posto pode ser visto no Gráfico 4.20 a Gráfico 4.23.

Sobre os métodos de extrapolação da curva carga vs recalque, nove metodologias foram utilizadas e os resultados estão resumidos na Tabela 5.4. O método de Décourt (1996) e de Chin-Kondner (1963, 1970 e 1971) apresentaram valores próximos e coerentes com o andamento das provas de cargas estáticas. No método de Décourt, infelizmente não foi possível fazer a separação dos limites superior, dada pela resistência da ponta, e inferior, dada pela resistência do atrito, pelo fato dos deslocamentos não terem atingidos valores suficientemente grandes. O máximo recalque atingido foi da ordem de $5 \%$ do diâmetro da estaca. Os métodos restantes não revelaram valores satisfatórios. 
Tabela 5.4. Resumo dos Métodos de Extrapolação da Curva Carga vs Recalque.

\begin{tabular}{|c|c|c|c|}
\hline Método & $\begin{array}{c}\text { Prova de Carga } \\
\text { Estática }\end{array}$ & $\begin{array}{l}\text { Coeficiente de } \\
\text { Correlação }\left(\mathbf{R}^{2}\right)\end{array}$ & $\begin{array}{c}\text { Valor } \\
\text { Extrapolado }[\mathrm{kN}]\end{array}$ \\
\hline Décourt (Rigidez) & $\begin{array}{l}1 \text { (E.263b) } \\
2 \text { (E.113) } \\
3(\text { (E.25) }\end{array}$ & $\begin{array}{c}- \\
0,9942 \\
0,9979\end{array}$ & $\begin{array}{c}- \\
13268,5 \\
13004,5\end{array}$ \\
\hline Chin-Kondner & $\begin{array}{c}1 \text { (E.263b) } \\
2(\text { E.113) } \\
3(\text { E.25) }\end{array}$ & $\begin{array}{l}0,9998 \\
0,9971 \\
0,9997\end{array}$ & $\begin{array}{c}8877 \\
12313 \\
12895\end{array}$ \\
\hline Davisson & $\begin{array}{c}1 \text { (E.263b) } \\
2(E .113) \\
3(E .25)\end{array}$ & $\begin{array}{l}- \\
- \\
-\end{array}$ & $\begin{array}{c}8600 \\
9200 \\
10200\end{array}$ \\
\hline NBR 6122 & $\begin{array}{c}1 \text { (E.263b) } \\
2(E .113) \\
3(E .25)\end{array}$ & $\begin{array}{l}- \\
- \\
-\end{array}$ & $\begin{array}{c}8800 \\
- \\
-\end{array}$ \\
\hline Brinch-Hansen $80 \%$ & $\begin{array}{l}1 \text { (E.263b) } \\
2 \text { (E.113) } \\
3(\text { E.25) }\end{array}$ & $\begin{array}{l}0,9989 \\
1,0000 \\
0,9961\end{array}$ & $\begin{array}{r}8646 \\
9159 \\
13173\end{array}$ \\
\hline De Beer & $\begin{array}{l}1 \text { (E.263b) } \\
2(\mathrm{E} .113) \\
3(\mathrm{E} .25)\end{array}$ & $\begin{array}{l}- \\
- \\
-\end{array}$ & $\begin{array}{l}8518 \\
6634 \\
8955\end{array}$ \\
\hline Van der Veen & $\begin{array}{l}1 \text { (E.263b) } \\
2(\mathrm{E} .113) \\
3(\mathrm{E} .25)\end{array}$ & \multicolumn{2}{|c|}{$\begin{array}{l}\text { Não Proporcionou Nenhuma Curva que } \\
\text { apresentasse um bom coeficiente de } \\
\text { correlação e Carga de Ruptura }\end{array}$} \\
\hline Mazurkiewicz & $\begin{array}{c}1 \text { (E.263b) } \\
2(\mathrm{E} .113) \\
3(\mathrm{E} .25)\end{array}$ & $\begin{array}{l}- \\
- \\
-\end{array}$ & $\begin{array}{c}- \\
9780 \\
11000\end{array}$ \\
\hline Butler \& Roy & $\begin{array}{l}1(\mathrm{E} .263 \mathrm{~b}) \\
2(\mathrm{E} .113) \\
3(\mathrm{E} .25)\end{array}$ & $\begin{array}{l}- \\
- \\
-\end{array}$ & $\begin{array}{r}8555 \\
10555 \\
10780\end{array}$ \\
\hline
\end{tabular}

Com a utilização do método das 2 retas, proposto por Massad e Lazo (1998), exposto no item 4.5.5, foi possível descobrir, para a PC.01, na qual houve um segundo carregamento, que o valor do fator majorador da carga residual foi de 1,258, o que significa que essa carga residual aprisionada na ponta foi de $1602 \mathrm{kN}$. Para a PC.03 os valores de atrito lateral não ficaram muito próximos dos valores fornecidos pela instrumentação, pois não houve a mobilização integral do atrito. Por outro lado, os resultados foram excelentes para a PC.01 e PC.02. A Tabela 5.5 mostra o comparativo. 
Tabela 5.5. Comparativo dos Valores de Atrito Lateral: Método das 2 Retas e PCE's

\begin{tabular}{cccc}
\hline Prova de Carga & Estaca & Método 2 Retas & Ensaio \\
\hline PC. 01 & E.263 & $6198 \mathrm{kN}$ & $6198 \mathrm{kN}$ \\
PC.02 & E. 113 & $7600 \mathrm{kN}$ & $\geq 7631 \mathrm{kN}$ \\
PC. 03 & E. 25 & $8500 \mathrm{kN}$ & $\geq 7390 \mathrm{kN}$ \\
\hline
\end{tabular}

A utilização do método de Randolph-Wroth (1978), juntamente com uma variante da correlação entre o módulo de elasticidade do solo com o $\mathrm{N}_{\text {SPT }}$ médio ao longo do fuste, conforme a equação (4.5), proposta por Negro, Ferreira e Sozio (1982) mostrou-se uma excelente opção para o meio técnico na previsão de recalques para a carga de trabalho da estaca. Com o uso da equação (4.10), os recalques estimados ficaram muito próximos dos recalques medidos, para as três provas de cargas estáticas. Isto posto pode ser visto no Gráfico 4.39, Gráfico 4.41 e Gráfico 4.43. Aqui a equação (4.10) é novamente mostrada:

$$
E_{0}=2 \cdot\left(5 . N_{S P T}\right)
$$

Com relação aos comparativos entre os métodos semi-empíricos, ficou comprovado, pelo Gráfico 4.47, Gráfico 4.48 e Gráfico 4.49, que as parcelas de atrito e ponta não apresentaram uma boa proximidade com os valores obtidos das provas de cargas estáticas. No entanto, os métodos apresentam resultados mais coerentes quando se compara os valores da carga admissível, o que, na prática, é o mais importante, já que o dimensionamento é feito com base na carga admissível (que é a soma das parcelas de atrito e ponta minoradas por um fator de segurança). Na Tabela 5.6 é possível visualizar o comparativo entre os parâmetros mencionados anteriormente.

Tabela 5.6. Comparativo entre os Métodos Semi-Empíricos e as Provas de Cargas Estáticas

\begin{tabular}{ccccccccc}
\hline $\begin{array}{c}\text { Prova de } \\
\text { Carga }\end{array}$ & \multirow{2}{*}{ Estaca } & \multicolumn{2}{c}{ Carga de } & \multicolumn{3}{c}{ Décourt\&Quaresma } & \multicolumn{3}{c}{ Aoki\&Velloso } \\
& & Trabalho $[\mathbf{k N}]$ & $\mathbf{Q}_{\mathbf{L}}[\mathbf{k N}]$ & $\mathbf{Q}_{\mathbf{P}}[\mathbf{k N}]$ & $\mathbf{N}_{\text {ADM }}[\mathbf{k N}]$ & $\mathbf{Q}_{\mathbf{L}}[\mathbf{k N}]$ & $\mathbf{Q}_{\mathrm{P}}[\mathbf{k N}]$ & $\mathbf{N}_{\text {ADM }}[\mathbf{k N}]$ \\
\hline PC.01 & \multirow{E}{*}{.263} & 3300 & 2990 & 3200 & 3091 & 2590 & 4072 & 3238 \\
PC.02 & E.113 & 5000 & 5376 & 9500 & 6510 & 4985 & 3318 & 4151 \\
PC.03 & E.25 & 6000 & 5448 & 10405 & 6792 & 6093 & 11084 & 7617 \\
\hline
\end{tabular}

Analisando o Gráfico 4.47 e o Gráfico 4.48 nota-se que os métodos subestimam a parcela referente ao atrito lateral, haja vista que os resultados foram 
substancialmente inferiores aos registrados pelas provas de cargas estáticas. No entanto, uma peculiaridade observada no Gráfico 4.48 reflete que a utilização da expressão do atrito lateral proposta por Décourt\&Quaresma, com a utilização do parâmetro $\beta$ unitário, proporcionou resultados muito bons para a PC.02 e PC.03. Já para a PC.01, o valor de atrito lateral unitário ter sido da mesma ordem de grandeza das outras duas foi surpreendente e, por isso, a relação não se adaptou satisfatoriamente.

Com o auxílio do Gráfico 4.50 também é possível perceber que os métodos semiempíricos superestimam a parcela referente à ponta. No caso da PC.01 e da PC.02, que estão apoiadas em camada argilosa, os resultados não são tão díspares. Para a PC.01, o método previu de maneira espetacular, haja vista que a mesma atingiu a ruptura. No entanto, quando a ponta encontra-se em areia, a diferença nos resultados é muito significativa, o que também pode ser visualizado no Gráfico 4.49.

Por fim, o objetivo principal em procurar a redução dos comprimentos das estacas foi alcançado. Com a modificação do método de Décourt\&Quaresma, utilizando-se o parâmetro $\beta$ unitário, com base nos resultados obtidos pelas provas de cargas estáticas, foi possível uma redução de $3 \mathrm{~m}$ em relação às cotas de ponta estipuladas em projeto. Esses resultados podem ser vistos na Tabela 4.29 ou no Gráfico 4.51. 


\subsection{Sugestões para Pesquisas Futuras}

a.) Comparação dos recalques obtidos pelas provas de cargas estáticas com a utilização de modelos numéricos, por meio de um software de análise tensão-deformação, baseados em elementos finitos;

b.) Aplicação de outros métodos de capacidade de carga com o objetivo de verificar a proximidade dos valores de atrito e ponta com os fornecidos pelos ensaios estáticos;

c.) Envidar esforços para utilizar instrumentos de medida do encurtamento de estacas de metro em metro, como, por exemplo, os extensômetros removíveis. 


\section{Referências Bibliográficas}

ALONSO, U.R. e DA SILVA, P.E.C.A.F. Curva de "Recalque Equivalente" do Topo de uma Estaca Hélice Contínua Ensaiada com Célula Expansiva Hidrodinâmica (Expancell). SEFE IV, São Paulo, 2000, vol. 1, pp. 416 - 425;

AOKI, N.; VELLOSO, D.A. An Approximated Method to Estimate the Bearing Capacity of Piles. V PACSMFE, Buenos Aires, 1975, pp. 367-376;

ASSOCIAÇÃO BRASILEIRA DE NORMAS TÉCNICAS. NBR 6118. Projeto de Estruturas de Concreto - Procedimento. Rio de Janeiro, 2003;

ASSOCIAÇÃO BRASILEIRA DE NORMAS TÉCNICAS. NBR 6122. Projeto e Execução de Fundações. Rio de Janeiro, 1996;

ASSOCIAÇÃO BRASILEIRA DE NORMAS TÉCNICAS. NBR 8522. Determinação do Módulo Estático de Deformação Secante. Rio de Janeiro, 2006;

ASSOCIAÇÃO BRASILEIRA DE NORMAS TÉCNICAS. NBR 12131. Estacas Prova de Carga Estática - Métodos de Ensaio. Rio de Janeiro, 1992;

AVIZ, L.B.M. Estimativa da Capacidade de Carga de Estacas por Métodos Semiempíricos e Teóricos. 2006. 133p. Dissertação de Mestrado - Pontifícia Universidade Católica, Rio de Janeiro, 2006;

BAGUELIN, F. e VENON, V.P. Influence de La Compressibilité des Pieux sur La Mobilizations des éfforts Resistant. Le Comportement des Sols Avant La Rupture. 
Bulletin des Liaison de Laboratoire des Ponts et Chaussés. Numéro Especial. Paris, Mai, 1971;

CAMBEFORT, M. Essai sur Le Comportement en terrain homogéne des Vieux isoles et des groupes de pieux. Annales de $1^{\circ}$ Institut du Batiment et des Travaux Public, nº 204, Decémbre, 1964;

CARVALHO, J.C; CUNHA, R.P; MAGALHÃES, E.P; SILVA, C.M; SALES, M.M. Análise da Capacidade de Carga de Duas Estacas Escavadas a partir de Provas de Cargas Lentas. XII COBRAMSEG, São Paulo, 2002, vol. 3, pp. 13051311;

CAPUTO, A. Instrumented Large Diameter Bored Pile. Proceedings of the $5^{\text {th }}$ International Symposium on Deep Foundations on Bored and Auger Piles (BAP V), Ghent-Belgium, 2008, pp. 213-227;

CHIN, F.K. Estimation of the Ultimate Load of Piles not carried to Failure. Proceedings of the $2^{\text {nd }}$ Southeast Asian Conference on Soil Engineering, 1970, pp. 81-90;

CHIN, F.K. Discussion of Pile Test. Arkansas River Project. Journal for Soil Mechanics and Foundation Engineering, ASCE, 1971, vol. 97, SM 6, pp. 930-932;

COYLE, H.M.; REESE, L.C. Load Transfer for Axially Loaded Piles in Clay. JSMFD. Proc.of the ASCE, 1996, v. 92, SM2;

DA SILVA, P.E.C.A.F. Célula Expansiva Hidrodinâmica - Uma Nova Maneira de Executar Prova de Carga. VIII COBRAMSEF, Porto Alegre, 1986, vol. VI, pp. 223241 ;

DAVISSON, M.T. High Capacity Piles. Proceedings of Lecture Series on Innovations in Foundation Construction, ASCE, 1972, Illinois Section, Chicago, March 22, pp. 81-112; 
DÉCOURT, L. A Ruptura de Fundações Avaliada com Base no Conceito de Rigidez. SEFE III, São Paulo, 1996, vol. 1, pp. 215 -224;

DÉCOURT, L.; QUARESMA, A.R. Capacidade de Carga de Estacas a Partir de Valores de SPT. Proc. of VI COBRAMSEF, Rio de Janeiro, 1978, pp. 45-53;

DÉCOURT, L.; NIYAMA, S. Predicted an Measured Behaviour of Displacement Piles in Residual Soils. XIII ICSMFE, New Delhi, 1994, vol. 02, pp. 477-486;

DÉCOURT, L. On the Load-Settlement Behaviour of Piles. Revista Solos e Rochas, ABMS, São Paulo, 1995, vol. 18 no 2, pp. 93-112;

DÉCOURT, L. O Conceito de $\mathrm{N}$-Equivalente $\left(\mathrm{N}_{\mathrm{eq}}\right)$ na Prática da Engenharia. Ainda um Postulado ou já uma Realidade Comprovada? XII COBRAMSEG, São Paulo, 2002, vol. 1, pp. 119-134;

DÉCOURT, L. Loading Tests: Interpretation and Prediction of their Results. Geotechnical Special Publication (GSP): From Research to Practice in Geotechnical Engineering, 2008, № 180, 21 páginas;

DÉCOURT, L. Análise e Projeto de Fundações Profundas. Fundações: Teoria e Prática, editado por Hachich et al., PINI, São Paulo, 1998, cap. 8, pp. 265-301;

DÉCOURT, L. Ruptura de Fundações e Coeficientes de Segurança à Luz do Conceito de Rigidez. XI COBRAMSEG, Brasília, 1998, vol. 3, pp. 1599-1606;

DÉCOURT, L. Provas de Carga em Estacas Podem Dizer Muito Mais do Que Têm Dito. SEFE VI, São Paulo, 2008, vol. 1, pp. 221 - 245;

FAG (Faculdade Assis Gurgacz). Comportamento de Estacas Isoladas. Departamento de Fundações, Cascavel, 2008, 16p. Disponível em: < http://www.fag.edu.br/professores/deboraf/Funda\%E7\%F5es/2\%20Bimestre/capitul 05Comportamento\%20estacas\%20isoladas >. Acesso em: 30 de novembro de 2010. 
FELLENIUS, B.H. Basic of Foundation Design. Eletronic Edition. Calgary, 2006, Capítulo 8, pp. 1-40. Disponível em <www.fellenius.net> ;

FELLENIUS, B.H. From Strain Measurements to Load in an Instrumented Pile. Geotechnical News Magazine, 2001, vol. 19 nº 1, pp. 35-38;

FELLENIUS, B.H. Tangent Modulus of Piles determined from Strain Data. American Society of Civil Engineers, ASCE, Geotechnical Engineering Division, 1989 Foundation Congress, F.H. Kulhawy, vol. 1, pp. 500-510;

FELLENIUS, B.H.; SANTOS, J.A.; FONSECA, A.V. Analysis of piles in a residual soil. The ISC'2 prediction. "canadian geotechnical journal”, 2007, Accepted for publication in vol.1 (January);

KONDNER, R.L. Hyperbolic Stress-strain response. Cohesive Soils. Journal for Soil Mechanics and Foundation Engineering, ASCE, 1963, vol. 89, SM 1, pp. 115143;

JAMALUDIN, A., HUSSEIN, A.N. The Performance of Large Diameter Bored Pile used for a Road Project in Malaysia. Proceedings of the $3^{\text {rd }}$ International Geotechnical Seminar on Deep Foundations on Bored and Auger Piles (BAP III), Ghent-Belgium, 1998, pp. 335-340;

LIMA, A.P. Comportamento de uma Escavação Grampeada em Solo Residual de Gnaisse. 2007. 431p. Tese de Doutorado - Pontifícia Universidade Católica, Rio de Janeiro, 2007;

MAERTENS, J., THEYS, F. e MAEKELBERG, W. A Full-Scale Test on Large Diameter Bored Piles for the Construction of the HST Tunnel in Antwerp (Belgium). Proceedings of the $4^{\text {th }}$ International Geotechnical Seminar on Deep Foundations on Bored and Auger Piles (BAP IV), Ghent-Belgium, 2003, pp. 323-329; 
MASSAD, F. Análise de Transferência de Carga em Duas Estacas Instrumentadas, quando submetidas à Compressão Axial. SEFE II, São Paulo, 1991, vol. 1, pp. 235-244;

MASSAD, F. Comportamento de Estacas Escavadas de Elevadas Compressibilidades. SEFE II, São Paulo, 1991, vol. 1, pp. 245-254;

MASSAD, F. Sobre a Interpretação de Provas de Carga em Estacas considerando as Cargas Residuais na Ponta e a Reversão do Atrito Lateral. Parte I: Solos Relativamente Homogêneos. Revista Solos e Rochas, ABMS, São Paulo, 1992, vol. 15 no 2, pp. 103-115;

MASSAD, F. Sobre a Interpretação de Provas de Carga em Estacas considerando as Cargas Residuais na Ponta e a Reversão do Atrito Lateral. Parte II: Estaca Embutida em Camada mais Resistente. Revista Solos e Rochas, ABMS, São Paulo, 1993, vol. 16 ํo 2, pp. 93-112;

MASSAD, F. Notes on the Interpretation of Failure Load from Routine Pile Load Tests. Revista Solos e Rochas, ABMS, São Paulo, 1992, vol. 9 no 1, pp. 103-115;

MASSAD, F., LAZO, G. Método Gráfico para Interpretar a Curva Carga-Recalque de Provas de Carga Verticais em Estacas Rígidas ou Curtas. XI Congresso Brasileiro de Mecânica dos Solos e Engenharia Geotécnica, Brasília, 1998, vol. 3, pp.1407-1414;

MASSAD, F.; Winz, H.C. Capacidade de Carga em Estacas Verticais: Influência da Velocidade de Carregamento em Provas de Carga. SEFE IV, São Paulo, 2000, vol. 1, pp. 177-190;

MASSAD, F. Fundamentação Matemática do Método da Rigidez de Décourt e Definição de Seu Campo de Aplicação. SEFE VI, São Paulo, 2008, vol. 1, pp. 117131 ; 
MELLO, L. G., ROBBE, G. e BILFINGER, W. Comparison between Osterberg and Statnamic Load Test on Large Diameter Drilled Piles. Proceedings of the $5^{\text {th }}$ International Symposium on Deep Foundations on Bored and Auger Piles (BAP V), Ghent-Belgium, 2008, pp. 229-234;

MEYERHOFF, G.G. Bearing Capacity and Settlements of Pile Foundations. Journal Geotechnical Engineering Div., ASCE, 1976, vol. 102 nํ GT3, pp. 195-228; MILITITSKY, J. Provas de Carga Estáticas. SEFE II, São Paulo, 1991, vol. 2, pp. 203-221;

NACANO, M. Capacidade de Carga de Estacas Apiloadas Confeccionadas com Solo-Cimento Plástico. 2001. 175p. Dissertação de Mestrado - Universidade Estadual Paulista de Ilha Solteira, São Paulo, 2001. Disponível em <http://www.ppgec.feis.unesp.br/teses/2001/nacano 2001.pdf>. Acesso em 22 de fevereiro de 2010;

NEGRO, A.; FerReIRA, A. A. e SOZIO, L. E. Solos da Cidade de São Paulo Mesa Redonda, editado por Negro, A., Ferreira, A. A., Alonso, U. R. e Luz, P. A. C., ABMS/ABEF, São Paulo, 1992, cap. 13, pp. 297-328;

PENTEADO, M.L. e BRITO, J. Técnicas Actuais e Inovadoras na Monitorização e Controlo de Qualidade das Estacas de Betão. Revista da Universidade do Minho, 2009, ํㅡ 34, 51-71. D. Disponível em $<$ http://www.civil.uminho.pt/revista/n34/Pag 51-71.pdf $>$. Acesso em 22 de fevereiro de 2010;

PEREZ, E.N.P. O uso da Teoria da Elasticidade na Determinação do Módulo de Young do Solo Adjacente a Estacas Carregadas Verticalmente na Argila Porosa de Brasília. 1997. 146p. Dissertação de Mestrado - Departamento de Engenharia Civil, Universidade de Brasília, Brasília, 1997. Disponível em <http://www.geotecnia.unb.br/dissertacao/GDM049A97.pdf>. Acesso em 21 de fevereiro de 2010; 
PORTElA, A. e SILVA, A. Mecânica dos Materiais. Ed. Plátano, Lisboa, 1996. Disponível

$<$ http://www.dec.fct.unl.pt/seccoes/S Estruturas/Mecanica Meios Continuos/upgrad e/l extensometria.pdf>. Acesso em: 21 de fevereiro de 2010.

RANDOLPH, M.F.; WROTH, C.P. Analysis of Deformation of Vertically Loaded Piles. Journal of the Geotechnical Engineering. Div., ASCE, 1978, vol.104 no GT12, pp. 1465-1487;

RANDOLPH, M.F. Design Methods for Pile Groups and Piles Rafts. XIII ICSMFE, New Delhi, 1994, vol. 05, pp. 61-82;

RIN, P.D; BARROS, L.A. e Mello, L.G.F.S. Provas de Carga Especiais nas Estacas de Grande Diâmetro do Porto do Rio Grande. Revista Solos e Rochas, ABMS, São Paulo, 1983, vol. 6 nº 3, pp. 79-88;

ROTTMANN, E. Previsões Teóricas e Resultados de Instrumentação como Elementos de Projetos de Estacas: Um caso Real. 1985. vol. 1 e 2. Dissertação de Mestrado - Escola Politécnica, Universidade de São Paulo, São Paulo, 1985.

SOUZA, R.N; MASSAD, F. Previsão do Comportamento de Estacas Escavadas de Grandes Dimensões com base em resultados de ensaios SPT. Revista Solos e Rochas, ABMS, São Paulo, 1998, vol. 21 nำ 2, pp. 79-88;

SOUZA, R.N. Estudo do Comportamento de Estacas Escavadas de Grandes Dimensões: Estacões e Barretes. 1996. 262p. Dissertação de Mestrado - Escola Politécnica, Universidade de São Paulo, São Paulo, 1996;

UFSC (Universidade Federal de Santa Catarina). Apostila de Extensometria. Departamento de Engenharia Mecânica, Florianópolis, 2004, 48p. Disponível em: $<$ http://www.grante.ufsc.br/download/SG-Apostila.pdf>. Acesso em: 21 de fevereiro de 2010. 
VAN DER VEEN, C. The Bearing Capacity of a Pile. Proc. Third International Conference Soil Mechanics Foundation Engineering, Zurich, 1953, vol. II, pp. 84-90;

VELLOSO, D.A. Capacidade de Carga por meio do SPT. SEFE II, São Paulo, 1991, vol. 2, pp. 293-312;

VESIC, A.S.Investigations of Bearing Capacity of Piles in Sand. Proc. North American Conference on Deep Foundation, México City, 1964;

VESIC, A.S A Study of Bearing Capacity of Deep Foundations. Final Report, Project B-189, Georgia Institute of Technology, Atlanta, Georgia, 1967,

VIANA DA FONSECA, A.; SANTOS, J.A; ESTEVES, E.C.; MASSAD, F. Analysis of Piles in Residual Soil from Granite considering Residual Loads. Revista Solos e Rochas, ABMS, São Paulo, 2007, vol. 30 nº 1, pp. 63-80;

VIANA DA FONSECA, A. Relato da Experiência Portuguesa em Ensaios de Carga em Estacas. Parte I: Acções Verticais. Revista Luso-Brasileira de Geotecnia, 2007, ํㅜ 111, pp. 5-58;

VIANA DA FONSECA, A.; COSTA ESTEVES, E. e SANTOS, J.A. Ensaios de Carga Verticais em Estacas executadas em Solos de Residual do Granito. SEFE V, São Paulo, 2004, vol. 2, pp. 57-68; 